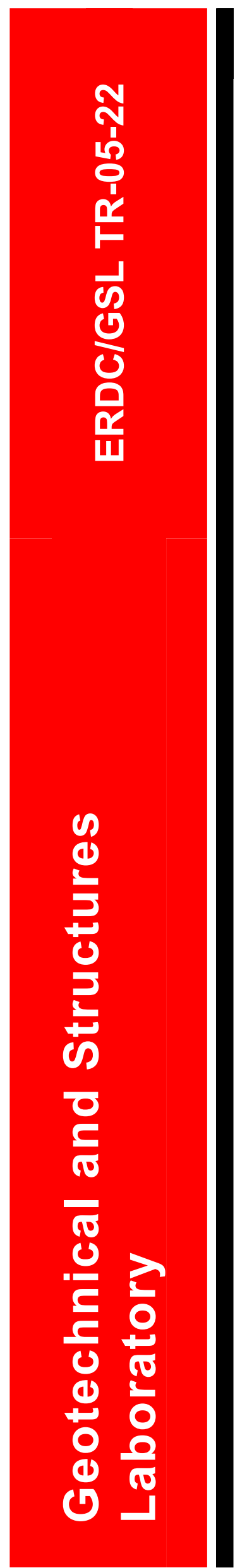

\title{
Dynamic Testing and Numerical Correlation Studies for Folsom Dam
}

Ziyad Duron, Enrique E. Matheu, Vincent P. Chiarito,

John F. Hall, and Michael K. Sharp

US Army Corps of Engineers ${ }_{\circledast}$

Engineer Research and Development Center 


\title{
Dynamic Testing and Numerical Correlation Studies for Folsom Dam
}

\author{
Ziyad Duron \\ Harvey Mudd College \\ Engineering Department \\ 301 E. 12th Street \\ Claremont, CA 91711 \\ Enrique E. Matheu, Vincent P. Chiarito, Michael K. Sharp \\ Geotechnical and Structures Laboratory \\ U.S. Army Engineer Research and Development Center \\ 3909 Halls Ferry Road \\ Vicksburg, MS 39180-6199 \\ John F. Hall \\ California Institute of Technology \\ Department of Civil Engineering and Applied Mechanics \\ 1200 East California Boulevard \\ Pasadena, CA 91125
}

Final report

Approved for public release; distribution is unlimited 


\begin{abstract}
It is widely recognized that full-scale dynamic testing produces a wealth of useful information in the context of seismic performance evaluation studies of concrete dams. These types of tests can be used not only to determine the main characteristics of the dynamic response of the structure, but can also provide information to assess the relative importance of interaction mechanisms involving the dam, the impounded reservoir, and the underlying foundation region. The information gathered by dynamic full-scale tests can also be used to assess the limitations of the different numerical models that could be employed to quantify the response of the system under severe seismic excitations. This report describes a research study conducted by the U.S. Army Engineer Research and Development Center consisting of a series of field tests and numerical analyses performed on Folsom Dam, California, at the request of the U.S. Army Engineer District, Sacramento. Ambient tests and forced vibration were conducted to determine the main dynamic characteristics of the dam-foundation-reservoir system. Numerical studies of the observed response behavior were performed using 2D and 3D models of the system. This report describes these experimental and modeling efforts and discusses the comparison between the critical response features derived from observed and computed results. The results from this study complement and validate the results from other previous and current technical studies conducted on Folsom Dam, and they will effectively contribute toward a more accurate assessment of the seismic performance of this critical structure.
\end{abstract}

DISCLAIMER: The contents of this report are not to be used for advertising, publication, or promotional purposes. Citation of trade names does not constitute an official endorsement or approval of the use of such commercial products. All product names and trademarks cited are the property of their respective owners. The findings of this report are not to be construed as an official Department of the Army position unless so designated by other authorized documents. 


\section{Contents}

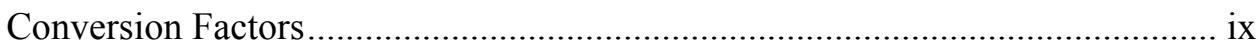

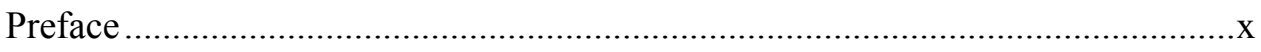

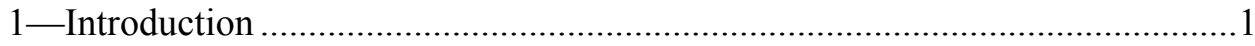

Importance of Field Testing of Concrete Dams ............................................. 1

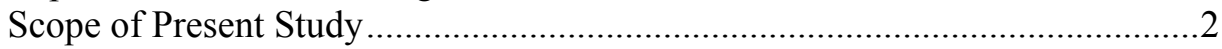

Description of Folsom Dam ..................................................................2

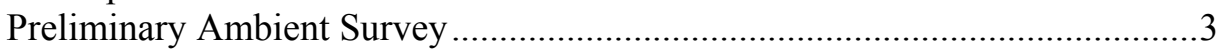

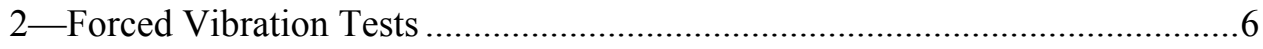

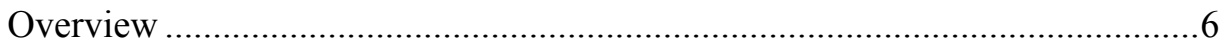

Measurement Layout and Test Schedule ....................................................... 7

Description of Instrumentation and Test Procedures .......................................

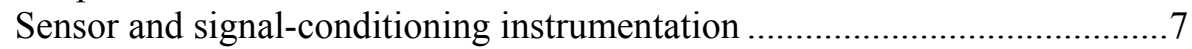

Eccentric mass vibrator system (shaker) ....................................................12

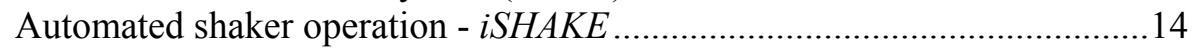

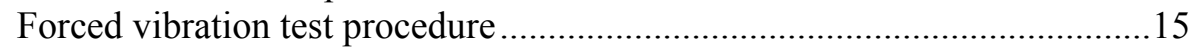

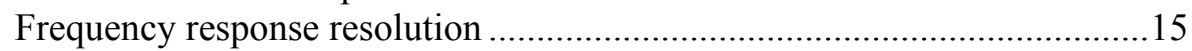

Example steady-state responses and curve fits .........................................16

3-Description of Dam Response Characteristics ............................................ 18

Measured Acceleration Frequency Response Characteristics .........................18

Shaker mounted on crest at Monolith 11..................................................18

Shaker mounted on crest at Monolith 21 ...................................................20

Shaker mounted in the pipeline gallery at Monolith $14 \ldots \ldots \ldots \ldots \ldots \ldots \ldots \ldots \ldots . . .22$

Identification of Dam Resonance Characteristics........................................22

Trends in resonant frequencies ..........................................................22

Right gravity response behavior - Monoliths 1-11 ..................................25

Spillway response behavior - Monoliths 12-20 .....................................26

Left gravity response behavior - Monoliths 21-28 .................................26

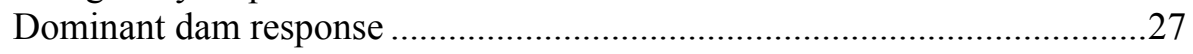

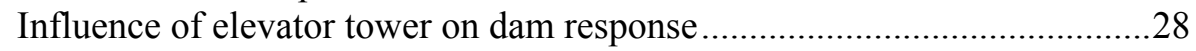

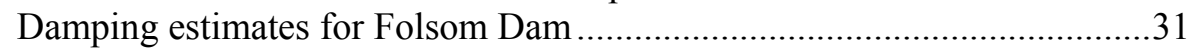

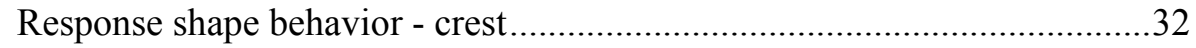

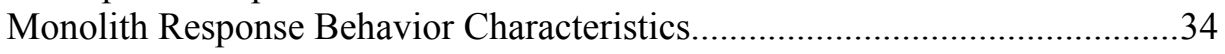

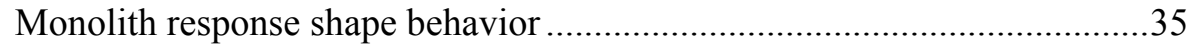

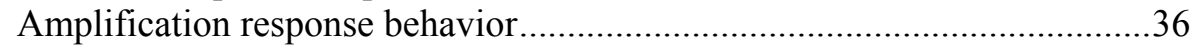

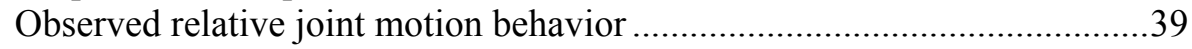

Influence of Foundation Flexibility on Monolith Response.............................41 


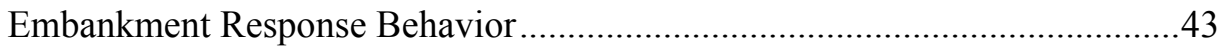

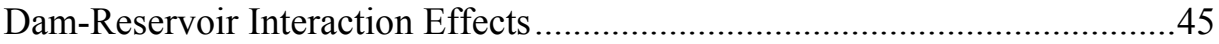

Determination of reservoir frequency response characteristics...................45

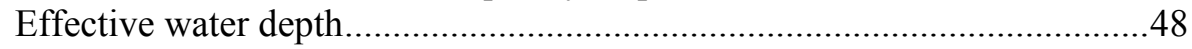

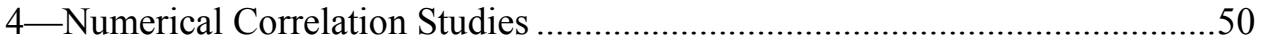

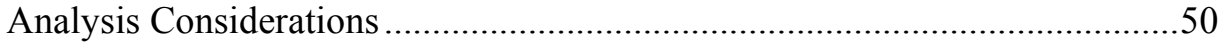

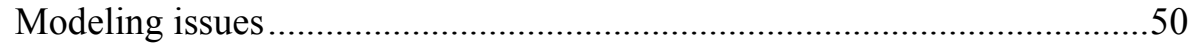

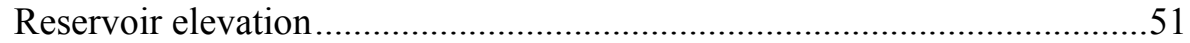

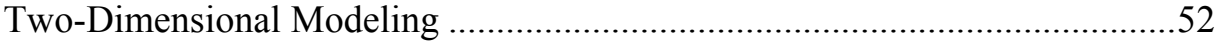

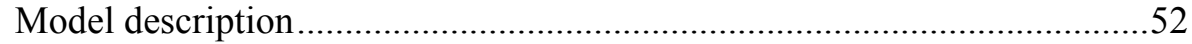

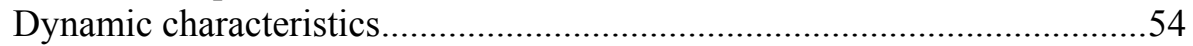

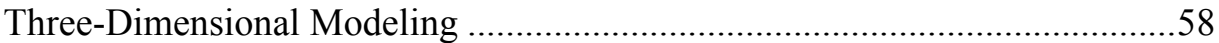

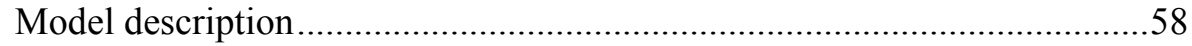

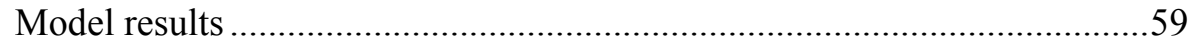

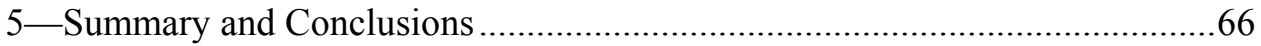

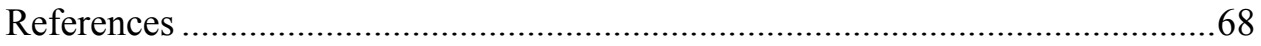

Appendix A: Crest Response Curves …………...............................................

Appendix B: Individual Monolith Response Curves........................................... B1

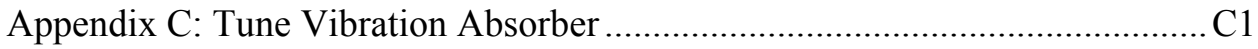

Appendix D: Curve-Fitting Approach to Measured Responses ..........................D1

SF 298

\section{List of Figures}

Figure 1. Plan view of Folsom Dam ..........................................................

Figure 2. Fundamental response behavior indicated from preliminary ambient survey .....................................................................

Figure 3. Measurement layout at Folsom Dam........................................ 8

Figure 4. Measurement layout for monolith response behavior at

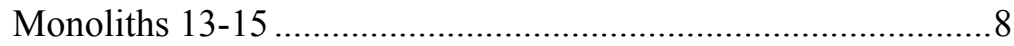

Figure 5. Measurement layout for hydrodynamics pressure response

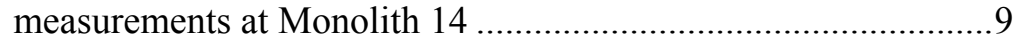

Figure 6. Spillway and toe measurement locations at Monolith 14............9

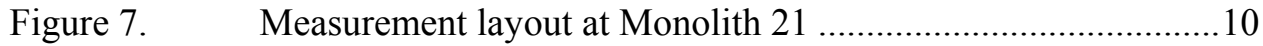

Figure 8. Measurement layout along elevator tower in Monolith 11 ........10

Figure 9. Eccentric mass vibrator installed at Folsom Dam ....................12

Figure 10. Shaker force levels achieved at Folsom Dam............................13 


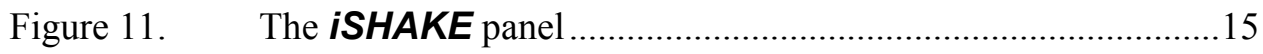

Figure 12. Response measurement and curve fit comparison.....................17

Figure 13. Crest response at Monolith 8 with shaker at Monolith 11 .........19

Figure 14. Crest response at Monolith 14 with shaker at Monolith 11 .......19

Figure 15. Crest response at Monolith 21 with shaker at Monolith 11 .......20

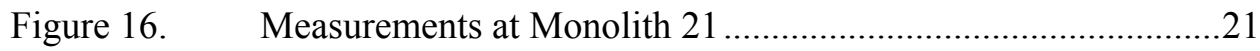

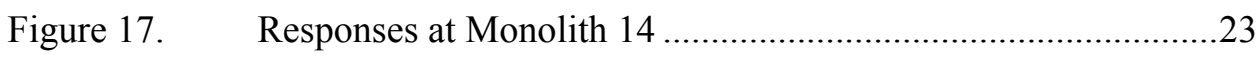

Figure 18. Resonant frequency distributions at Folsom Dam.....................24

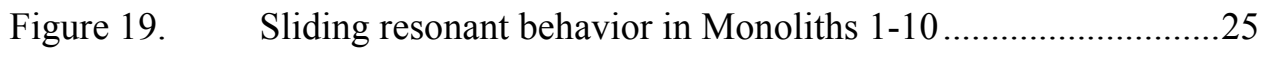

Figure 20. Surface plot of crest acceleration responses with the shaker

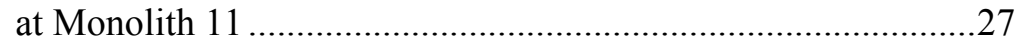

Figure 21. Measured tower response behavior .......................................28

Figure 22. Response behavior on crest at Monolith 21 ...........................29

Figure 23 Evidence of absorption characteristics at Folsom Dam...............30

Figure 24. Response shapes corresponding to resonances below $10 \mathrm{~Hz}$.....33

Figure 25. Response shapes indicating influence of tower and spillway characteristics on dam response ................................................ 34

Figure 26. Resonant response behavior observed at Monoliths 14 and

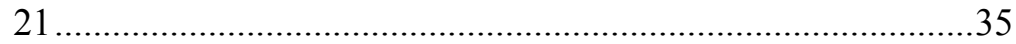

Figure 27. Observed amplification response behavior ...............................36

Figure 28. Measured crest and grouting gallery acceleration responses used to determine amplification behavior in Monolith 15 .........38

Figure 29. Relative joint motion measurement layout................................39

Figure 30. Relative joint movement ……................................................

Figure 31. Vertical motion at base of Monolith 14...................................42

Figure 32. Relative phase of vertical motion in Monolith 14 .....................42

Figure 33. Contribution to measured radial crest response at Monolith 14 due to foundation flexibility effects ......................43

Figure 34. Embankment response measurement layout ............................43

Figure 35. Left embankment responses ................................................4

Figure 36. Measured hydrodynamic pressure behind Monolith 14 at $244 \mathrm{ft}$ below the water surface .46 
Figure 37. Hydrodynamic pressure profiles behind Monolith 14................47

Figure 38. Reservoir frequency response at Folsom Dam..........................48

Figure 39. Simplified reservoir geometry ...............................................49

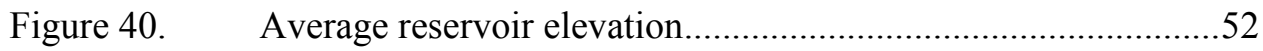

Figure 41. Geometry of overflow Monolith 14 .........................................53

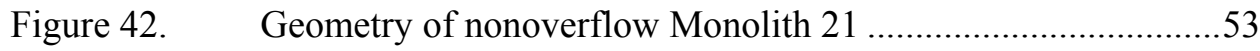

Figure 43. Finite-element model of Monolith 14 ........................................55

Figure 44. Finite-element model of Monolith 21 ......................................55

Figure 45. First and second mode shapes computed for Monolith 21 .........56

Figure 46. First and second mode shapes computed for Monolith 14 .........57

Figure 47. Three-dimensional finite-element model of Folsom Dam..........59

Figure 48. Comparisons of measured and predicted frequency responses for Monoliths 8, 14, and 21 ....................................61

Figure 49. Resonant behavior for Monoliths 1-10 computed by 3-D numerical model....................................................................62

Figure 50. Comparison of measured and predicted tower response

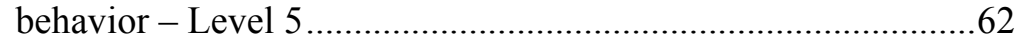

Figure 51. Comparison of measured and predicted tower response behavior - Level 9 ..............................................................63

Figure 52. Surface plot comparison of crest acceleration responses ...........64

Figure 53. Predicted contribution to crest response due to foundation

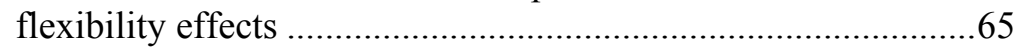

Figure A1. Crest response - Monolith 1 ................................................A2

Figure A2. Crest response - Monolith 2 ..............................................A2

Figure A3. Crest response - Monolith 3 .................................................A3

Figure A4. Crest response - Monolith 4 ................................................A3

Figure A5. Crest response - Monolith 5 ................................................A4

Figure A6. Crest response - Monolith 6...............................................A4

Figure A7. Crest response - Monolith 7 ..................................................A5

Figure A8. Crest response - Monolith 8 ...............................................A5

Figure A9. Crest response - Monolith 9.................................................A6

Figure A10. Crest response - Monolith 10..............................................A6 
Figure A11. Crest response - Monolith 11 .............................................A7

Figure A12. Crest response - Monolith 12 .............................................A7

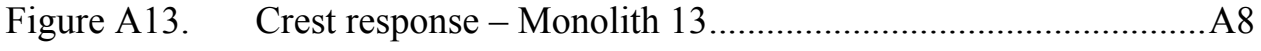

Figure A14. Crest response - Monolith 14_............................................A8

Figure A15. Crest response - Monolith 15 ................................................A9

Figure A16. Crest response - Monolith 16...............................................A9

Figure A17. Crest response - Monolith 17 ..............................................A10

Figure A18. Crest response - Monolith 18...............................................A10

Figure A19. Crest response - Monolith 19..............................................A11

Figure A20. Crest response - Monolith 20............................................A11

Figure A21. Crest response - Monolith 21 ............................................A12

Figure A22. Crest response - Monolith 22 .............................................A12

Figure A23. Crest response - Monolith 23 ...........................................A13

Figure A24. Crest response - Monolith 24_.............................................A13

Figure A25. Crest response - Monolith 25 ..........................................A14

Figure A26. Crest response - Monolith 26.............................................A14

Figure A27. Crest response - Monolith 27 ............................................A15

Figure A28. Crest response - Monolith 28 …........................................A15

Figure B1. Monolith 13 response - Elevation $193 \mathrm{ft}$............................... B2

Figure B2. Monolith 13 response - Elevation $224 \mathrm{ft}$............................... B2

Figure B3. Monolith 13 response - Elevation $294 \mathrm{ft}$................................B3

Figure B4. Monolith 13 response - Elevation $432 \mathrm{ft}$................................B3

Figure B5. Monolith 13 response - Elevation $476 \mathrm{ft}$...............................B4

Figure B6. Monolith 14 response - Elevation $168 \mathrm{ft}$................................B4

Figure B7. Monolith 14 response - Elevation $224 \mathrm{ft}$..............................B5

Figure B8. Monolith 14 response - Elevation $294 \mathrm{ft}$................................ B5

Figure B9. Monolith 14 response - Elevation $432 \mathrm{ft}$..............................B6

Figure B10. Monolith 14 response - Elevation $476 \mathrm{ft}$............................... B6

Figure B11. Monolith 15 response - Elevation $170 \mathrm{ft}$..............................B7

Figure B12. Monolith 15 response - Elevation $224 \mathrm{ft}$.............................. B7 
Figure B13. Monolith 15 response - Elevation $294 \mathrm{ft}$............................... B8

Figure B14. Monolith 15 response - Elevation $432 \mathrm{ft}$................................B8

Figure B15. Monolith 15 response - Elevation $476 \mathrm{ft}$...............................B

Figure B16. Monolith 21 response - Elevation $243 \mathrm{ft}$............................... B9

Figure B17. Monolith 21 response - Elevation $308 \mathrm{ft}$............................. B10

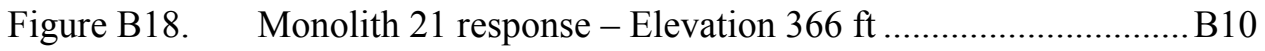

Figure B19. Monolith 21 response - Elevation $424 \mathrm{ft}$.............................. B11

Figure B20. Monolith 21 response - Crest............................................... B11

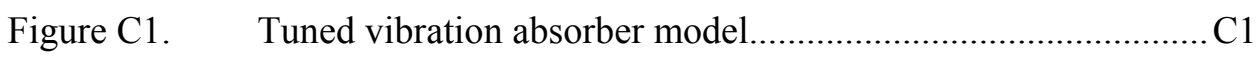

Figure C2. Main system frequency response functions.............................. 3

Figure C3. Vibration absorber frequency response function........................ 4

Figure D1. Curve fit results for Monolith 6..............................................D2

Figure D2. Curve fit results for Monolith 14...........................................D3

Figure D3. Curve fit results for Monolith 21 .............................................D4

\section{List of Tables}

Table 1. Description of Tests Completed at Folsom Dam, June 2004 .....11

Table 2. Resonant Frequencies and Damping Estimates Identified

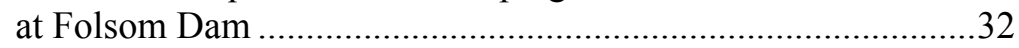

Table 3. Comparison of Measured Ambient and Forced Resonances

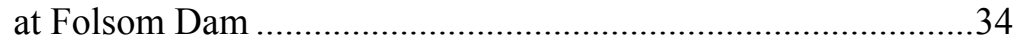

Table 4. Material Parameters Used in Finite-Element Models..................54

Table 5. Dynamic Characteristics of Monolith 21 .................................56

Table 6. Vibration Characteristics of Monolith 14_.................................56

Table 7. Foundation Flexibility Effects on the Vibration Characteristics of Monoliths 14 and 21....................................57

Table 8. Comparison of Measured Resonant and Modal Frequencies .....60 


\section{Conversion Factors, Non-SI to SI Units of Measurement}

Non-SI units of measurement used in this report can be converted to SI units as follows:

\begin{tabular}{||l|l|l||}
\hline \hline Multiply & By & To Obtain \\
\hline \hline cubic feet & 0.02831685 & cubic meters \\
\hline feet & 0.3048 & meters \\
\hline inches & 25.4 & millimeters \\
\hline miles (U.S. statute) & 1.609347 & kilometers \\
\hline pounds (force) & 4.448222 & newtons \\
\hline pounds (force) per square inch & 6.894757 & kilopascals \\
\hline pounds (mass) & 0.4535924 & kilograms \\
\hline
\end{tabular}




\section{Preface}

This report describes research conducted by the U.S. Army Engineer Research and Development Center (ERDC) consisting of a series of ambient tests, forced vibration tests, and numerical analyses performed on Folsom Dam, California. This work was commissioned by the U.S. Army Engineer District, Sacramento (SPK). Results from this study complement the information provided by other previous and current technical studies. It is expected that these results will contribute toward a more accurate assessment of the seismic performance of this critical structure.

The study was the result of a joint effort by personnel from Harvey Mudd College (HMC), Claremont, CA; the ERDC Geotechnical and Structures Laboratory (GSL), Vicksburg, MS; and the ERDC Information Technology Laboratory (ITL), Vicksburg, MS. The research described herein was performed by Professor Ziyad H. Duron, Mr. Nate Yoder, Mr. Eric Flynn, Mr. Nicolas Von Gersorff, Ms. Angela Cho, and Mr. Robert Panish of HMC; Dr. Enrique E. Matheu and Mr. Vincent P. Chiarito of GSL; and Mr. Bruce Barker of ITL. Dr. Michael K. Sharp, GSL, was the program manager for the study. Professor John F. Hall, California Institute of Technology, Pasadena, CA, provided technical review. Mr. Rick L. Poeppelman, SPK, was the technical monitor.

Professor Duron, Dr. Matheu, Mr. Chiarito, and Professor Hall prepared this publication under the overall project supervision of Dr. Sharp. The research was conducted under the general supervision of Dr. Joseph P. Koester, Chief, Geotechnical and Earthquake Engineering Branch; Mr. James S. Shore, Chief, Structural Engineering Branch; Dr. Robert L. Hall, Chief, Geosciences and Structures Division; and Dr. David W. Pittman, Director, GSL.

At the time of publication of this report, COL James R. Rowan, EN, was Commander and Executive Director of ERDC, and Dr. James R. Houston was Director. 


\section{Introduction}

\section{Importance of Field Testing of Concrete Dams}

In 1990, a comprehensive report prepared with support from the National Research Council of the United States reviewed the state of practice on seismic design and evaluation of concrete dams and identified the corresponding research needs (NRC 1990). This document also provided recommendations and improved criteria for evaluating the seismic performance of concrete dams. It was noted that, as early as the $1950 \mathrm{~s}$, concrete dams were assumed essentially rigid systems even though the importance of their dynamic behavior was partially recognized. About a decade later, it was understood that amplifications large enough to produce damage could occur in concrete dams, but the analytical tools were not yet widely available for a proper consideration of these effects. With the introduction of analytical tools to evaluate effects of dam-foundation-reservoir interactions in the 1970s, improvements in the criteria to evaluate results from analytical studies were needed. For example, it was recognized that the numerical prediction of tensile stresses large enough to indicate initiation of cracking and/or compressive stresses larger than allowable working levels did not necessarily indicate instability.

With the advent of advanced analytical techniques and computer technology, nonlinear analysis techniques and nonlinear material behavior of dams occupied much of the research focus over the last 20 years. Still, it is probably the case today that many analysts would prefer to avoid a full nonlinear analysis in lieu of a linear elastic study supported by postearthquake stability evaluation. Although inherently restricted by the linearity assumption, undoubtedly these types of studies still provide a great deal of information about the earthquake response that can be expected under realistic conditions (Duron et al. 2003).

An exhaustive review of experimental behavior and field-test data of concrete dams was presented by Hall (1988). This study examined available knowledge of the seismic behavior of concrete dams from observations made during actual earthquakes and from experiments conducted on prototype and model dams. Near the end of his review, Hall addressed the usefulness of testing techniques in the context of model validation. For example, a model's ability to reproduce field data acquired at varying water depths tests the model's distributed qualities in that comparisons are made not only at resonant peaks, but at frequencies between resonances as well. In addition, resonances predicted by 
models using material properties obtained from sample core testing can be compared with field-test findings. Furthermore, dynamic tests on dam models can be used to determine resonant frequencies and response shapes, thus providing a verifiable starting point for investigation of nonlinear dam response behavior. It is clear that the availability of measured or observational evidence of how a dam system behaves can provide the analyst with a wealth of knowledge with which to critically evaluate analytical findings (Duron et al. 2003).

\section{Scope of Present Study}

The Geotechnical and Structures Laboratory of the U.S. Army Engineer Research and Development Center in Vicksburg, MS, was commissioned by the U.S. Army Engineer District, Sacramento, to conduct a series of field tests and numerical studies designed to provide improved understanding of the dynamic behavior of Folsom Dam. These efforts included a comprehensive series of geophysical tests, ambient vibration tests, forced vibration tests, and numerical studies.

This report begins with a summary of the ambient tests conducted during March 2004. The ambient survey results were used to plan the forced vibration tests and provide an appropriate context for interpreting measured forced response behavior. The findings from the forced vibration tests conducted in June 2004 are presented in a subsequent section. It is important to note that not every measurement acquired during the tests is presented here; rather, an attempt is made to provide the reader with sufficient information to highlight the dominant response characteristics of Folsom Dam. Sample response data acquired in the dam, adjacent foundation, and reservoir are presented. Evidence of damfoundation and dam-reservoir interaction effects is also provided. Finally, this report describes preliminary two-dimensional (2-D) and three-dimensional (3-D) numerical modeling efforts carried out after completion of the field tests. Conclusions and recommendations for further analyses are also presented.

\section{Description of Folsom Dam}

Folsom Dam, located approximately 23 miles $^{1}$ northeast of Sacramento, CA, was constructed in 1956 by the U.S. Army Corps of Engineers and is now operated by the U.S. Bureau of Reclamation. The dam crest is $1,400 \mathrm{ft}$ long and $36 \mathrm{ft}$ wide, and the maximum height and base width are $340 \mathrm{ft}$ and $270 \mathrm{ft}$, respectively. The dam consists of 28 monoliths, $50 \mathrm{ft}$ wide each, constructed in 5-ft lifts and founded in hard granodiorite rock (Hall et al. 1989). Monoliths 1 through 11 are referred to as the right gravity section, Monoliths 12 through 20 as the spillway section, and Monoliths 21 through 28 as the left gravity section ( Figure 1). Except where noted, measurement locations along the crest and inside the dam were placed at the center of each monolith.

1 A table of factors for converting non-SI units of measurement to SI units is presented on page ix. 


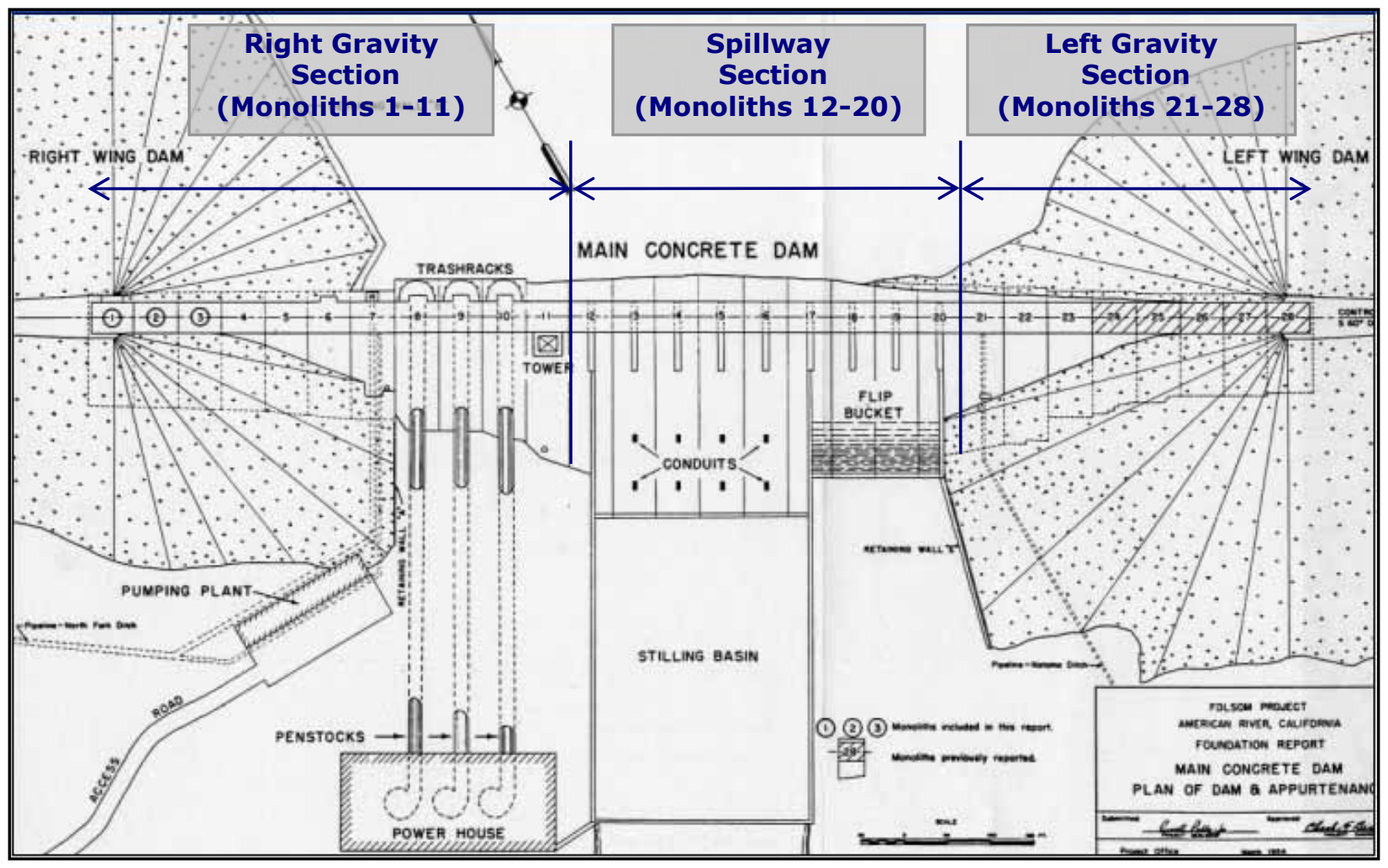

Figure 1. Plan view of Folsom Dam

The Folsom Dam Modification Project consists primarily of outlet works modifications in the concrete portion of the dam aimed at reducing the risk of flooding to the city of Sacramento from the American River. After its completion, this project will increase the river outlet release capacity from $26,000 \mathrm{cu} \mathrm{ft} / \mathrm{sec}$ to $115,000 \mathrm{cu} \mathrm{ft} / \mathrm{sec}$ at the reservoir water-surface elevation corresponding to the spillway crest. This increased release capacity will allow the dam to pass the downstream channel capacity earlier in the flood event, thus making more efficient use of the flood reservation space and increasing the overall level of flood protection downstream. The project basically consists of enlarging the four existing upper tier river outlets from $5 \mathrm{ft}$ wide by $9 \mathrm{ft}$ high to $9.33 \mathrm{ft}$ wide by $14 \mathrm{ft}$ high, constructing two new upper tier river outlets of the same size, and enlarging the four existing lower tier river outlets from $5 \mathrm{ft}$ wide by $9 \mathrm{ft}$ high to $9.33 \mathrm{ft}$ wide by $12 \mathrm{ft} \mathrm{high}$. Other analysis and design efforts directly involved with the project include stability analyses of all the affected spillway monoliths; design of a concrete excavation plan and new reinforced concrete conduit liner; and design of new outlet gates, enlarged air intake shafts and tunnels, and temporary and permanent bulkheads (Wong et al. 2002).

\section{Preliminary Ambient Survey}

A preliminary ambient survey was conducted at Folsom Dam in March 2004. It consisted of 16 tests at 73 monitored locations in the dam, on the adjacent 
foundation, and on the left embankment. Ambient hydrodynamic pressure responses were also acquired behind Monoliths 14 and 21 (Duron et al. 2004).

Analyses of measured responses indicated near-monolithic behavior in the dam below $10 \mathrm{~Hz}$ in which fundamental response shapes along the crest of the dam were identified as shown in Figure 2. It is noted that these resonances differ slightly from those initially reported in the preliminary report from the ambient survey. The near-monolithic response character observed in the dam suggested that a single vibrator (shaker) attached to the crest on Monolith 11 could yield similar behavior. Furthermore, since ambient responses indicated that individual monolith response behavior appeared above $10 \mathrm{~Hz}$, an attempt could be made to capture relative joint motion during the forced vibration tests.

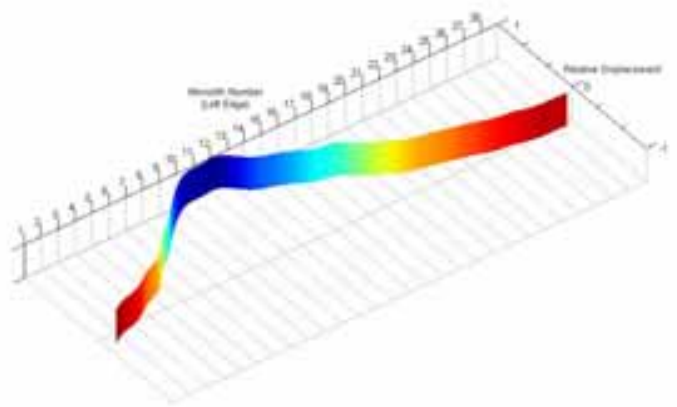

a. $4.64 \mathrm{~Hz}$

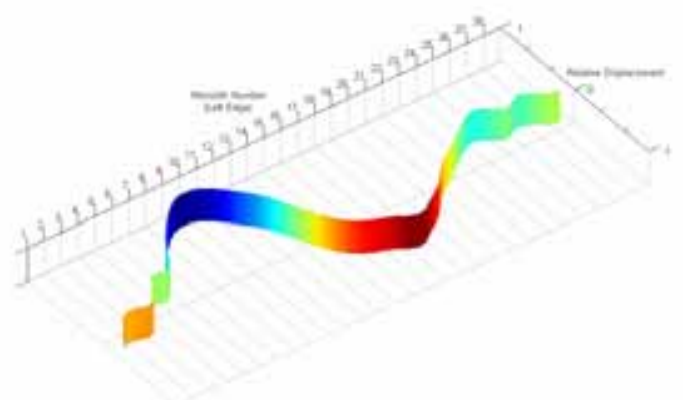

c. $6.47 \mathrm{~Hz}$

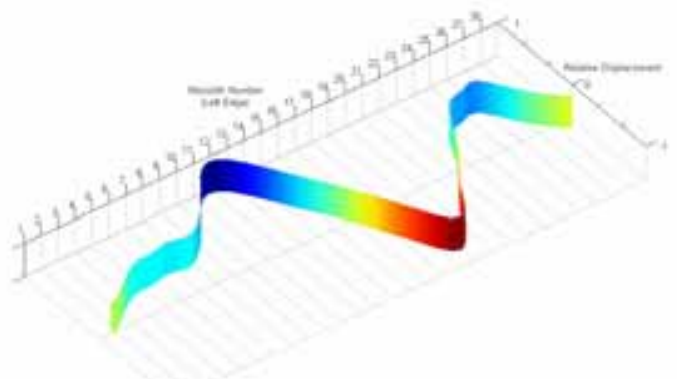

e. $8.18 \mathrm{~Hz}$

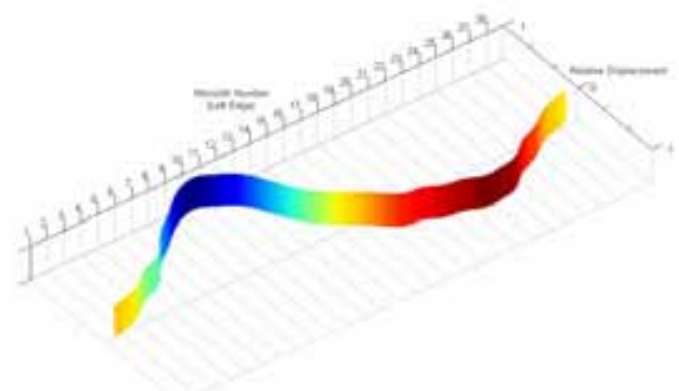

b. $5.49 \mathrm{~Hz}$

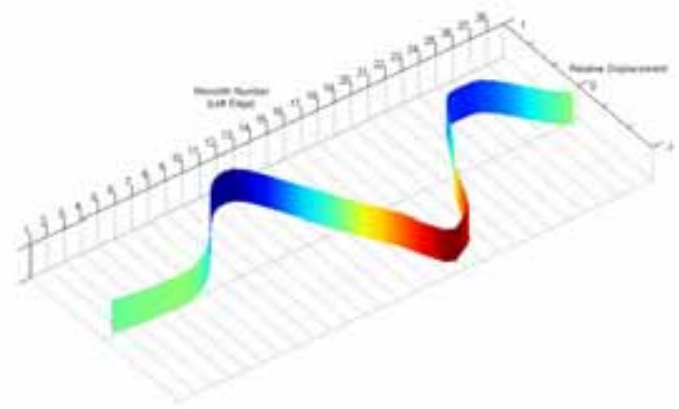

d. $7.32 \mathrm{~Hz}$

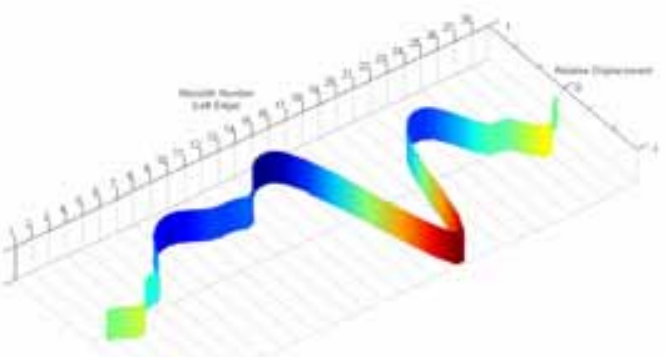

f. $8.91 \mathrm{~Hz}$

Figure 2. Fundamental response behavior indicated from preliminary ambient survey 
Evidence of foundation flexibility effects was also observed at the base of Monolith 12 from ambient responses acquired in the vertical direction at the heel and toe of the monolith. Based on this, an attempt could be made to further characterize foundation flexibility effects by placing the shaker inside a monolith in order to excite vertical responses at the heel and toe. Ambient measurements of hydrodynamic pressure responses in the reservoir indicated strong resonant behavior. This offered confidence to attempt extraction of reservoir frequency response behavior from forced response measurements of pressure. 


\section{Forced Vibration Tests}

Response behavior characteristics at Folsom Dam derived from ambient response measurements provided confidence that a single eccentric mass vibrator, hereafter referred to as a shaker, capable of producing 20,000 lbf would excite steady-state responses in the dam, reservoir, and adjacent foundation. The forced vibration test objectives were as follows:

a. To obtain steady-state responses in the dam along the crest and in Monoliths 13, 14, 15, and 21.

b. To obtain steady-state responses in the reservoir and left embankment at crest and stilling basin elevations.

c. To characterize crest forced response shape behavior and to compare against previously reported ambient findings.

d. To characterize monolith response behavior including relative motion between monoliths and at the base.

e. To characterize dam-reservoir interaction effects using steady-state hydrodynamic pressure and dam acceleration responses to determine fundamental reservoir response characteristics.

f. To provide adequate response information suitable for numerical model validation.

\section{Overview}

A forced vibration survey of Folsom Dam was conducted between 14 and 25 June 2004, during which steady-state responses were monitored in the dam, on the adjacent foundation, and on the left embankment. Hydrodynamic pressure responses in the reservoir were monitored behind Monoliths 14 and 21. Ambient response measurements were also taken prior to acquisition of steady-state responses for comparison against previously reported ambient behavior and to aid in the conduct of the forced vibration tests.

A total of 23 forced tests and 16 ambient tests were performed in which a total of 73 locations were monitored in the dam, on the adjacent foundation, and on the left embankment. Steady-state responses were induced in the 
dam-foundation-reservoir system by attaching a single shaker to the dam at three locations. Crest and Monolith 11 responses were acquired with the shaker attached to the crest on Monolith 11; responses in Monolith 21 were acquired with the shaker attached to the crest at Monolith 21; and responses in Monoliths 13, 14, and 15 were acquired with the shaker located in the pipeline gallery in Monolith 14. Left embankment responses were acquired with the shaker at Monolith 21, and hydrodynamic responses were acquired with the shaker at Monolith 21 and again at Monolith 14.

\section{Measurement Layout and Test Schedule}

Schematics are shown in Figure 3-8 of the measurement layouts used during the forced vibration tests at Folsom Dam. Three shaker attachment locations are indicated on the crest at Monoliths 11 and 21 and in the pipeline gallery of Monolith 14. The measurement layouts were designed to focus on

a. Crest response behavior.

b. Influence of dam-foundation interaction effects by monitoring amplification and cantilever response behavior in Monoliths 13, 14, 15, and 21 and on the left embankment.

c. Influence of dam-reservoir interaction effects by monitoring hydrodynamic pressure response in the reservoir.

Responses were acquired using uniaxial, biaxial, and triaxial accelerometer configurations as indicated in the layout schematics, and the hydrophone instrument array was used to acquire the reservoir pressure response measurements. A listing of the tests completed during the forced vibration survey is provided as Table 1.

\section{Description of Instrumentation and Test Procedures}

\section{Sensor and signal-conditioning instrumentation}

The instrumentation used to conduct the ambient survey of Folsom Dam was also used during the forced vibration tests. Although excitation levels associated with the shaker were larger than the ambient levels previously recorded, accelerometer sensitivities remained suitable for response monitoring and sufficient signal-conditioning capabilities were available to ensure satisfactory data quality. Detailed descriptions of the instrumentation used can be found in Duron et al. (2004), and a brief summary is provided below. 


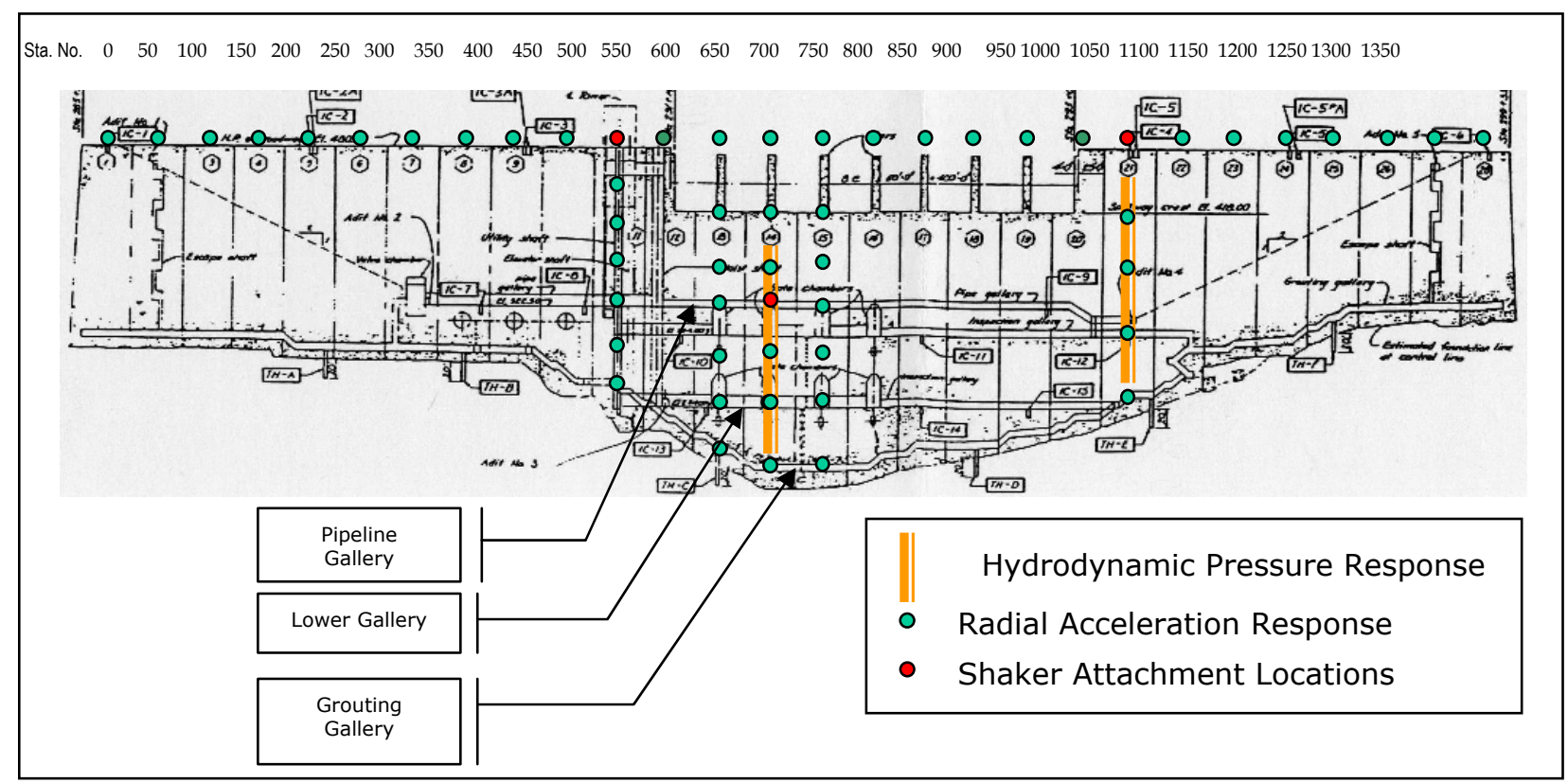

Figure 3. Measurement layout at Folsom Dam

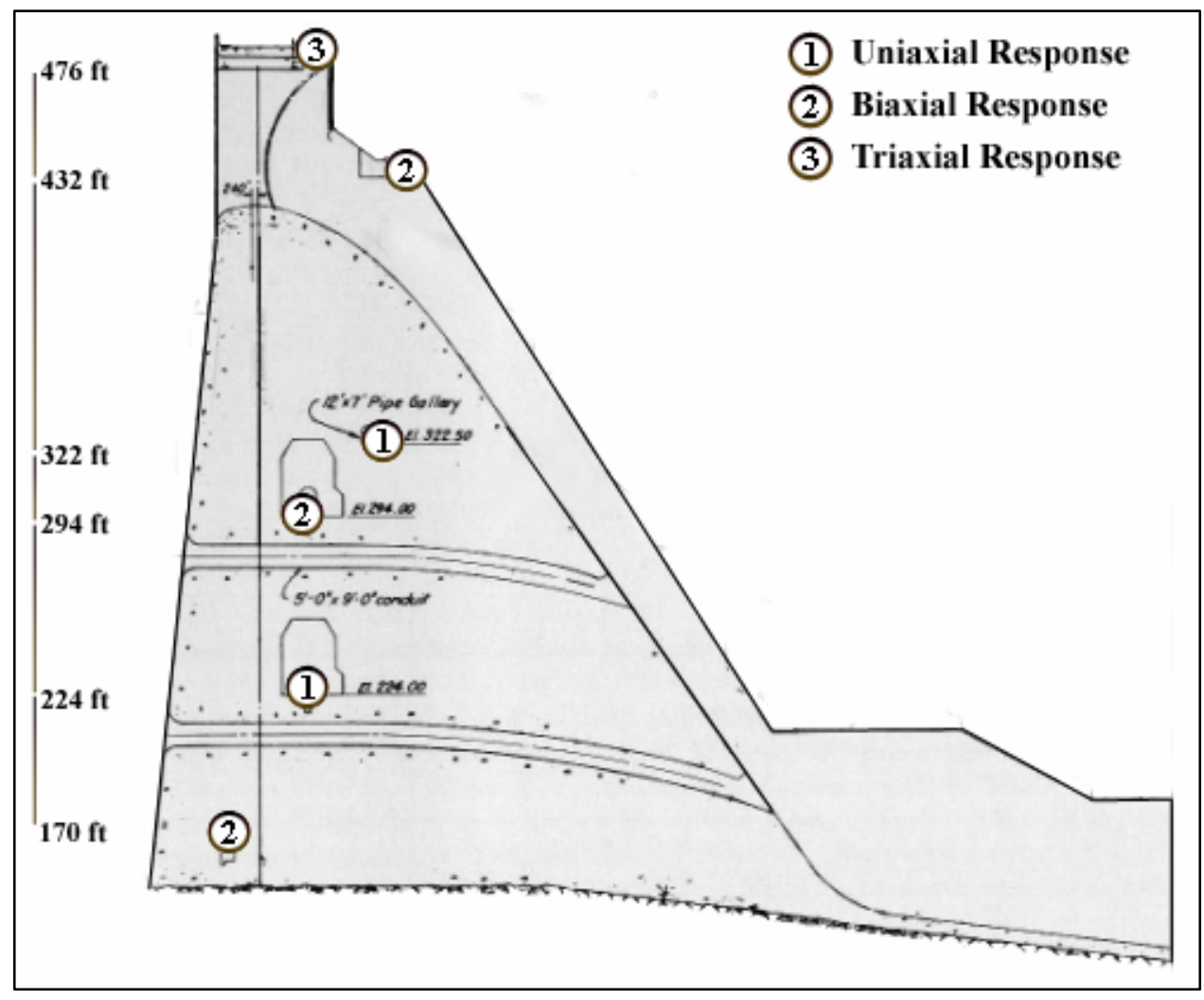

Figure 4. Measurement layout for monolith response behavior at Monoliths 13-15 


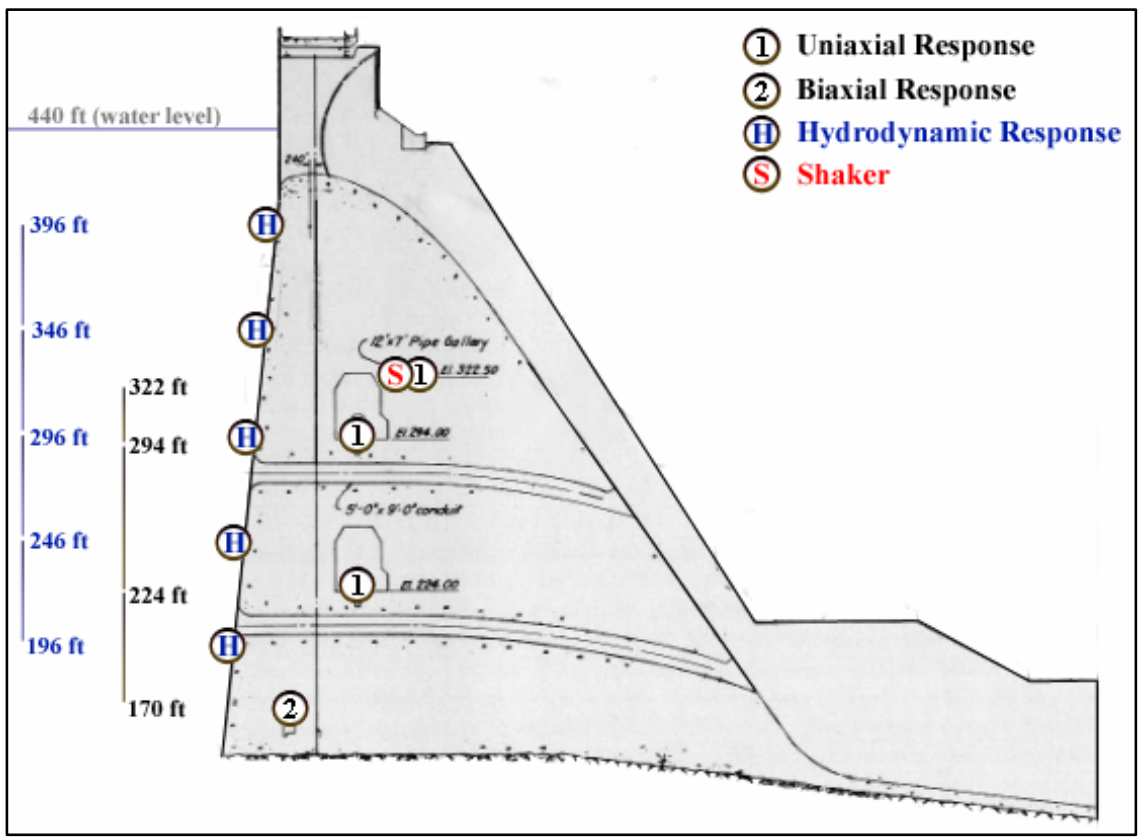

Figure 5. Measurement layout for hydrodynamics pressure response measurements at Monolith 14

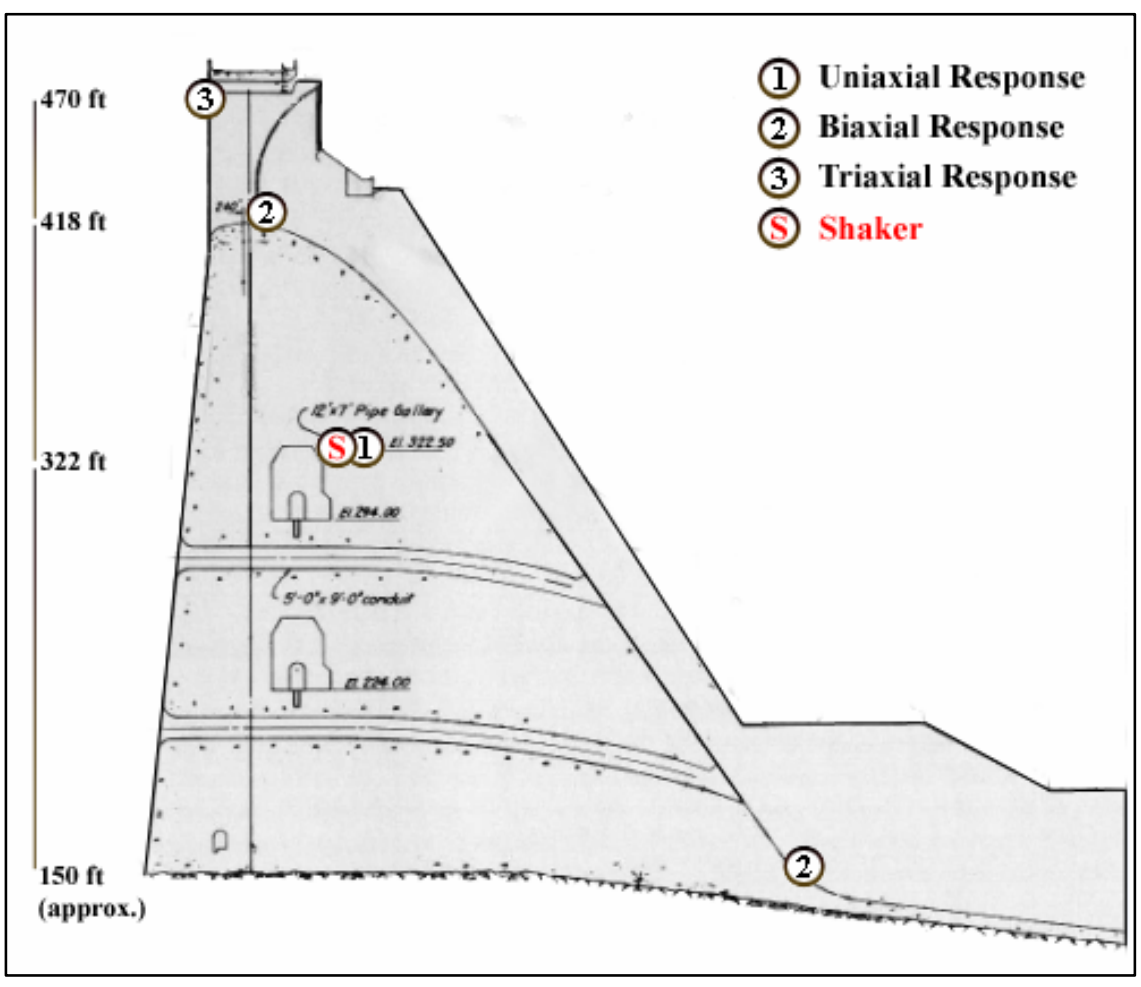

Figure 6. Spillway and toe measurement locations at Monolith 14 


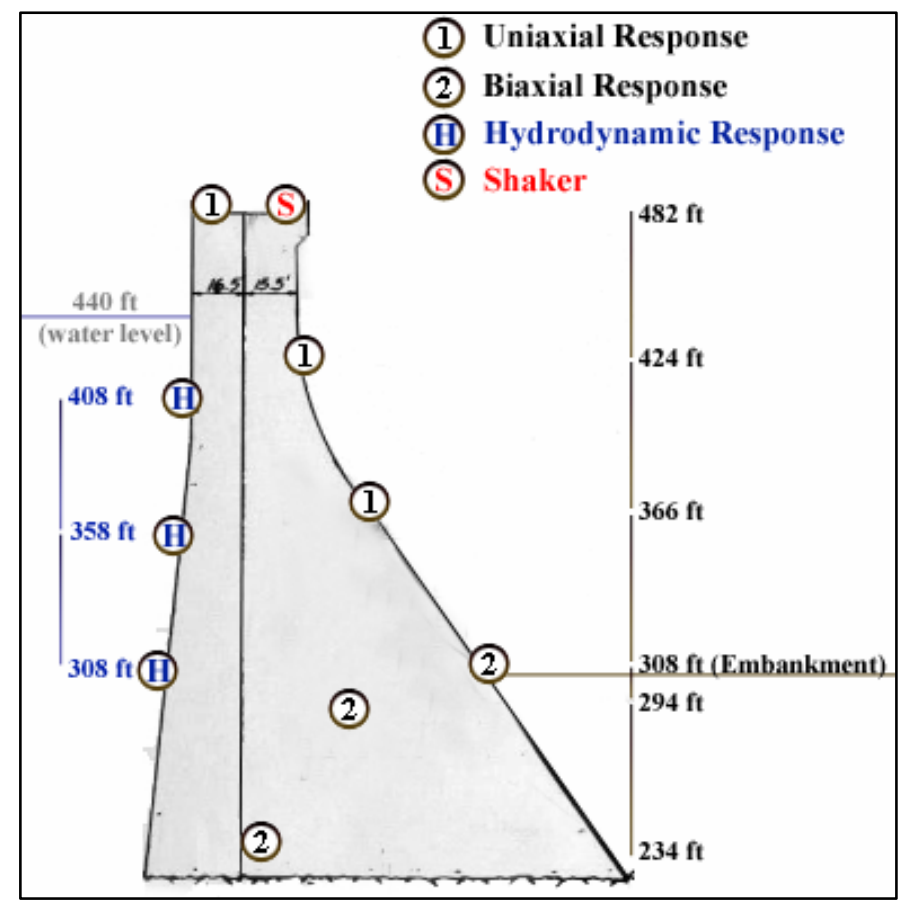

Figure 7. Measurement layout at Monolith 21

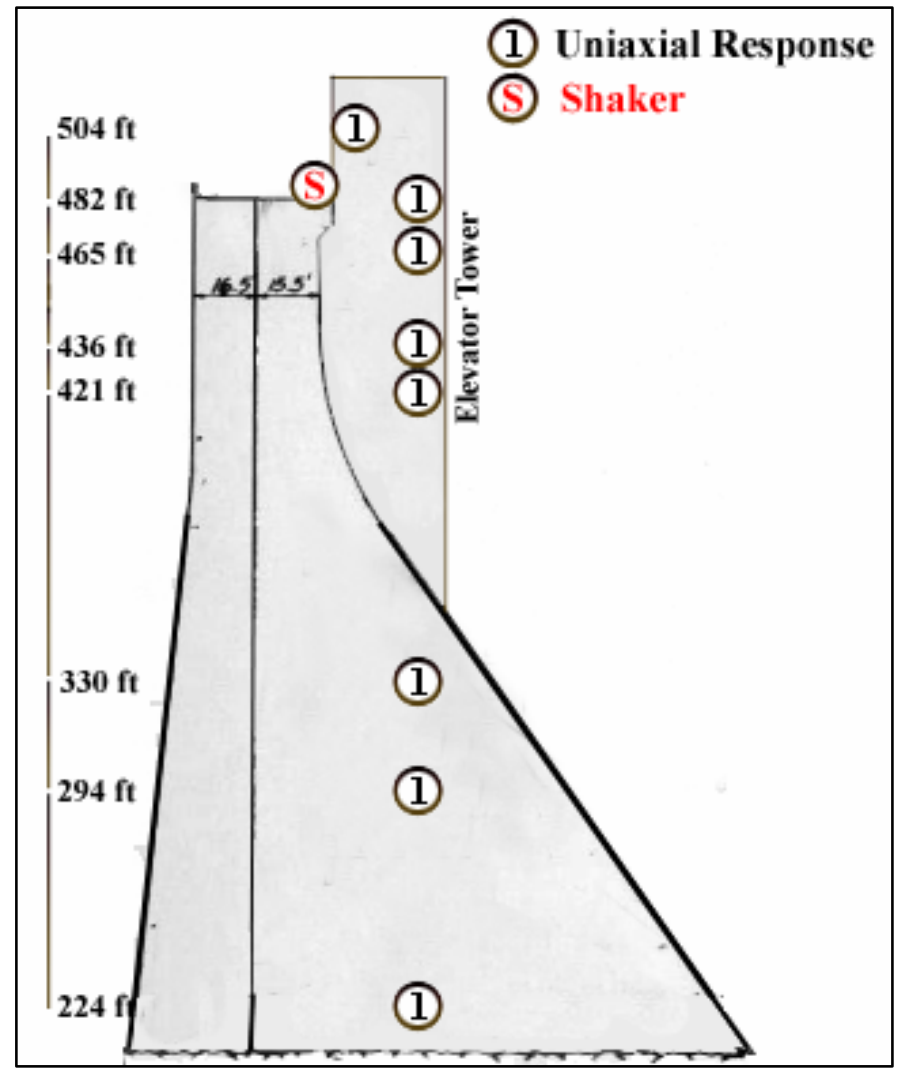

Figure 8. Measurement layout along elevator tower in Monolith 11 


\begin{tabular}{|c|c|c|}
\hline \multicolumn{3}{|c|}{$\begin{array}{l}\text { Table } 1 \\
\text { Description of Tests Completed at Folsom Dam, June } 2004\end{array}$} \\
\hline Test Name & Day & Description \\
\hline & 1 & Setup \\
\hline & 2 & Setup \\
\hline $\begin{array}{l}\text { Amb_1, Amb_2, Amb_3, FV_1, } \\
\text { FV_2, FV_3 }\end{array}$ & 3 & $\begin{array}{l}\text { Measurements: Crest } \\
\text { Excitation: Shaker at crest of Monolith } 11\end{array}$ \\
\hline Amb_4, FV_4, FV_5, FV_6 & 4 & $\begin{array}{l}\text { Measurements: Crest, elevator tower } \\
\text { Excitation: Shaker at crest of Monolith } 11\end{array}$ \\
\hline & 5 & Setup \\
\hline & 6 & Setup \\
\hline $\begin{array}{l}\text { Amb_5, Amb_6, FV_7, FV_8, } \\
\text { FV_9 }\end{array}$ & 7 & $\begin{array}{l}\text { Measurements: Monolith } 21 \text { including downstream face, } \\
\text { hydrodynamic pressure at Monolith } 21 \\
\text { Excitation: Shaker at crest of Monolith } 11\end{array}$ \\
\hline & 8 & Setup \\
\hline $\begin{array}{l}\text { Amb_7, FV_10, FV_11, } \\
\text { FV_12, FV_13 }\end{array}$ & 9 & $\begin{array}{l}\text { Measurements: Monolith 14, hydrodynamic pressure at } \\
\text { Monolith } 14 \\
\text { Excitation: Shaker in Monolith } 14 \text { (pipeline gallery) }\end{array}$ \\
\hline Amb_8, FV_14, FV_15 & 10 & $\begin{array}{l}\text { Measurements: Monolith } 14 \text { including toe and spillway } \\
\text { Excitation: Shaker in Monolith } 14 \text { (pipeline gallery) }\end{array}$ \\
\hline $\begin{array}{l}\text { Amb_9, Amb_10, Amb_11, } \\
\text { Amb_12, Amb_13, Amb_14, } \\
\text { Amb_15, Amb_16, FV_16, } \\
\text { FV_17, FV_18, FV_19, FV_20, } \\
\text { FV_21, FV_22, FV_23 }\end{array}$ & 11 & $\begin{array}{l}\text { Measurements: Monoliths } 13-15 \\
\text { Excitation: Shaker in Monolith } 14 \text { (pipeline gallery) }\end{array}$ \\
\hline
\end{tabular}

Forced vibration responses on the dam and on the adjacent foundation were acquired using Q-Flex accelerometers (models QA-700, QA-750, and QA-900) manufactured by Honeywell. The Q-Flex technology incorporates a servo-forcebalance design that produces an output current proportional to the surface acceleration, allowing the use of extended cable lengths (approaching 1,000 ft if necessary) without significant signal loss. Current output from each sensor is converted into voltage across a load resistor at the signal-conditioning unit to produce a V/g sensitivity that averaged $11 \mathrm{~V} / \mathrm{g}$ for the forced vibration tests at Folsom Dam. The unit is particularly effective because of its high signal-to-noise ratio, which helps ensure data quality during shaking in which the force and response levels are relatively low.

Hydrodynamic pressure responses in the reservoir were acquired using the same hydrophone instrument array used during the ambient survey. The array consists of eight solid-state hydrophones spaced $50 \mathrm{ft}$ apart along an 800-ft-long Kevlar reinforced cable. Hydrophone sensitivity averaged $0.7 \mathrm{~V} / \mathrm{psi}$.

Responses were acquired digitally using a National Instruments Model 6036E data acquisition card installed in a laptop computer. A MATLAB-based software package, iSHAKE, developed for the tests at Folsom Dam, provided capability for data acquisition, writing and storing data files, and shaker control. Responses were digitized at 1,000 samples per second, and filter and gain settings were adjusted to ensure satisfactory signal quality. Filtering was performed using two-pole high-pass filters with cutoffs at $1 \mathrm{~Hz}$, and four-pole low-pass filters with cutoffs below $30 \mathrm{~Hz}$. Amplification gains ranged from 10 to 1,000. Gains of 1,000 were used for all responses acquired on the left embankment and for all measurements taken with the shaker located in the pipeline gallery of Monolith 14. 


\section{Eccentric mass vibrator system (shaker)}

The forced vibration tests employed a single shaker (Figure 9) that provided sinusoidal excitation to the dam at the point of attachment. The shaker, Model MK-12.8A and manufactured by ANCO, Inc., is capable of continuous operation at force levels of $10,000 \mathrm{lbf}$ and intermittent operation at levels up to $20,000 \mathrm{lbf}$ over a frequency range of 0.5 to $20 \mathrm{~Hz}$. The force is generated by the rotation of eccentric masses about two parallel shafts. A 7.6-metric hp controller powers a 5 -metric hp induction motor capable of providing frequency control to $\pm 0.01 \mathrm{~Hz}$. Two sets of masses are available (large at 4,600 lbm-in. and small at $980 \mathrm{lbm}$-in.) whose eccentricity can be adjusted to achieve desired force levels over the operating frequency range.

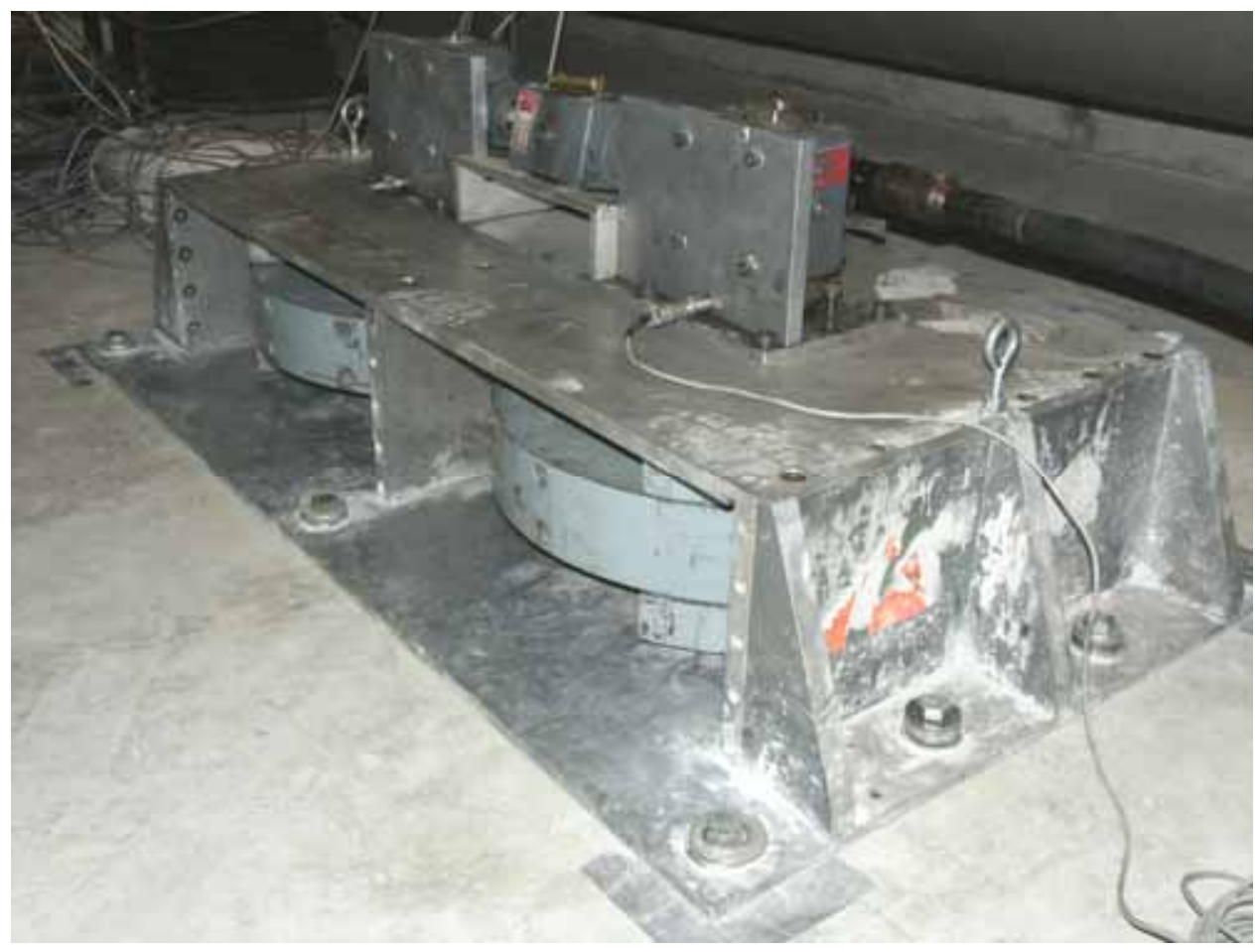

Figure 9. Eccentric mass vibrator installed at Folsom Dam

The shaker is shown installed inside the pipeline gallery in Monolith No. 14 at Folsom Dam. The large set of masses is installed for this particular test, and the shaft seen in the upper right corner connects the gearbox to the induction motor (not shown in the picture). For the tests at Folsom Dam, the force levels indicated in Figure 10 were achieved over the frequency ranges 2 to $10 \mathrm{~Hz}$ and 2 to $20 \mathrm{~Hz}$. While the shaker was on the crest at Monolith 11, large weights were used from 2 to $10 \mathrm{~Hz}$, and small weights were used from 10 to $20 \mathrm{~Hz}$. When the shaker was located at Monolith 21, only the small weights were used, since they provided sufficient force from 2 to $20 \mathrm{~Hz}$. The large weights were required to produce sufficient force while the shaker was in the pipeline gallery at 


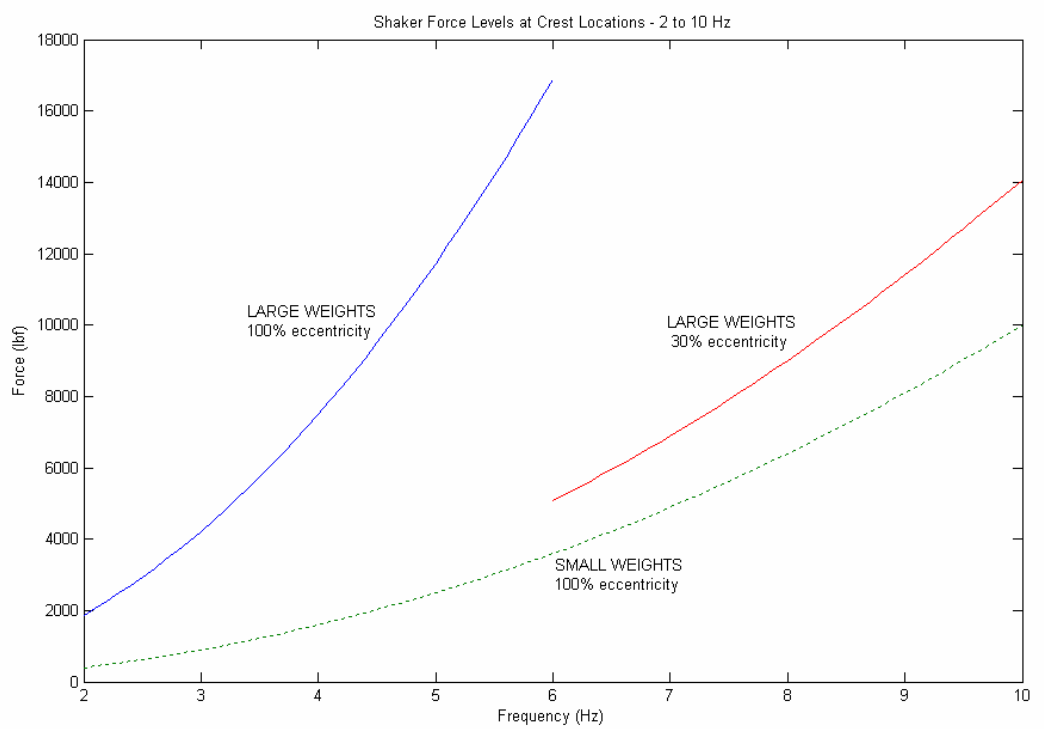

a. Shaker force levels, $2-10 \mathrm{~Hz}$

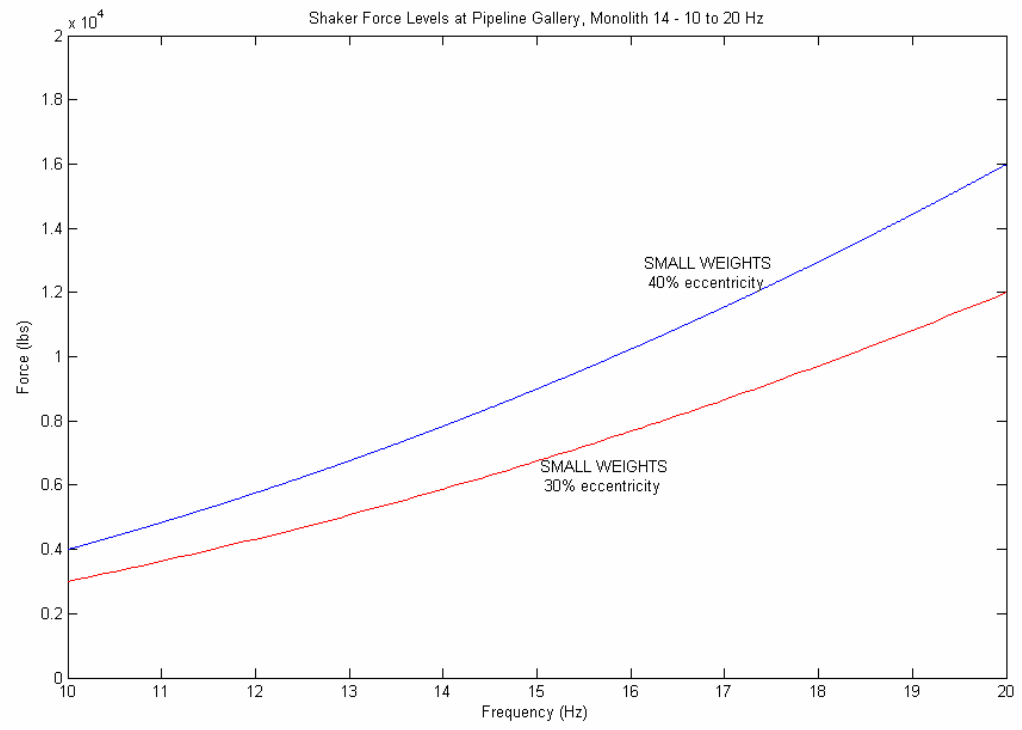

b. Shaker force levels, $10-20 \mathrm{~Hz}$

Figure 10. Shaker force levels achieved at Folsom Dam

Monolith 14. Since the shaker was not designed to operate using the large weights above $10 \mathrm{~Hz}$, the frequency range was limited to between 2 and $10 \mathrm{~Hz}$ inside the gallery.

The shaker has the ability to track the orientation of the applied force vector at the shaker location by sensing the leading edge of a single tooth disc that rotates along with one of the vertical shafts. The leading tooth edge is aligned to 
coincide with the desired orientation of the force vector as it passes under a reed switch that produces a $0-$ to $5-\mathrm{V}$ pulse during each revolution when the leading edge is detected. The pulse is used to trigger data acquisition and to determine the phase lag of measured responses relative to the excitation force. Although the orientation of the force vector can be aligned in any desired direction, for the tests at Folsom Dam, the force vector remained oriented in the radial (upstreamdownstream) direction. As can be seen in Figure 9, the shaker is attached to the dam using twelve 3/4-in.-diam wedge or stud anchors that attach the shaker base plate to the concrete surface, and the relatively short profile of the shaker housing ensures proper load transfer from the shaker to the dam through the base plate.

\section{Automated shaker operation - iSHAKE}

The shaker can be operated manually by dialing a potentiometer to the desired excitation frequency and allowing the controller to stabilize operation prior to acquiring response measurements. For tests in which responses are required over the shaker's operating frequency range and for which $0.1-\mathrm{Hz}$ resolution is desired, manual operation of the shaker often results in extended shaker operation because of the large number of discrete excitation frequencies required. For example, testing over a $20-\mathrm{Hz}$ range at $0.1-\mathrm{Hz}$ resolution produces 200 discrete frequency settings that can take up to $4 \mathrm{hr}$ to complete. To mitigate extended shaker operation and in anticipation of the need for finer excitation frequency resolution for the tests at Folsom Dam, automated shaker control was employed.

Automated shaker control was achieved using iSHAKE (front panel shown in Figure 11) and a National Instruments card that provided a 0 to $9 \mathrm{~V}$ DC analog output signal to the controller. While the Hp controller effectively steadies the frequency of the shaker to the above-mentioned $\pm 0.01 \mathrm{~Hz}$, its response to voltage or manual dial input is not perfectly linear. Feedback control was considered to achieve specific desired frequencies, but it was not employed because of the low feedback sampling rate of one force pulse per revolution. Instead, a linear fit was used to approximate the shaker's voltage to frequency response.

The $\boldsymbol{i S H A K E}$ is used to perform the following sequence of functions:

a. Determine the relationship between DC voltage and shaker frequency for the particular frequency range of interest and output the proper voltage.

b. Allow for a 5-sec warm-up for the controller to adjust and stabilize shaker operation and for transients to decay prior to acquisition.

c. Acquire and store force pulse and sensor signals to data files.

d. Repeat the entire process after incrementing excitation frequency by user-selected increment until the desired frequency range has been swept. 


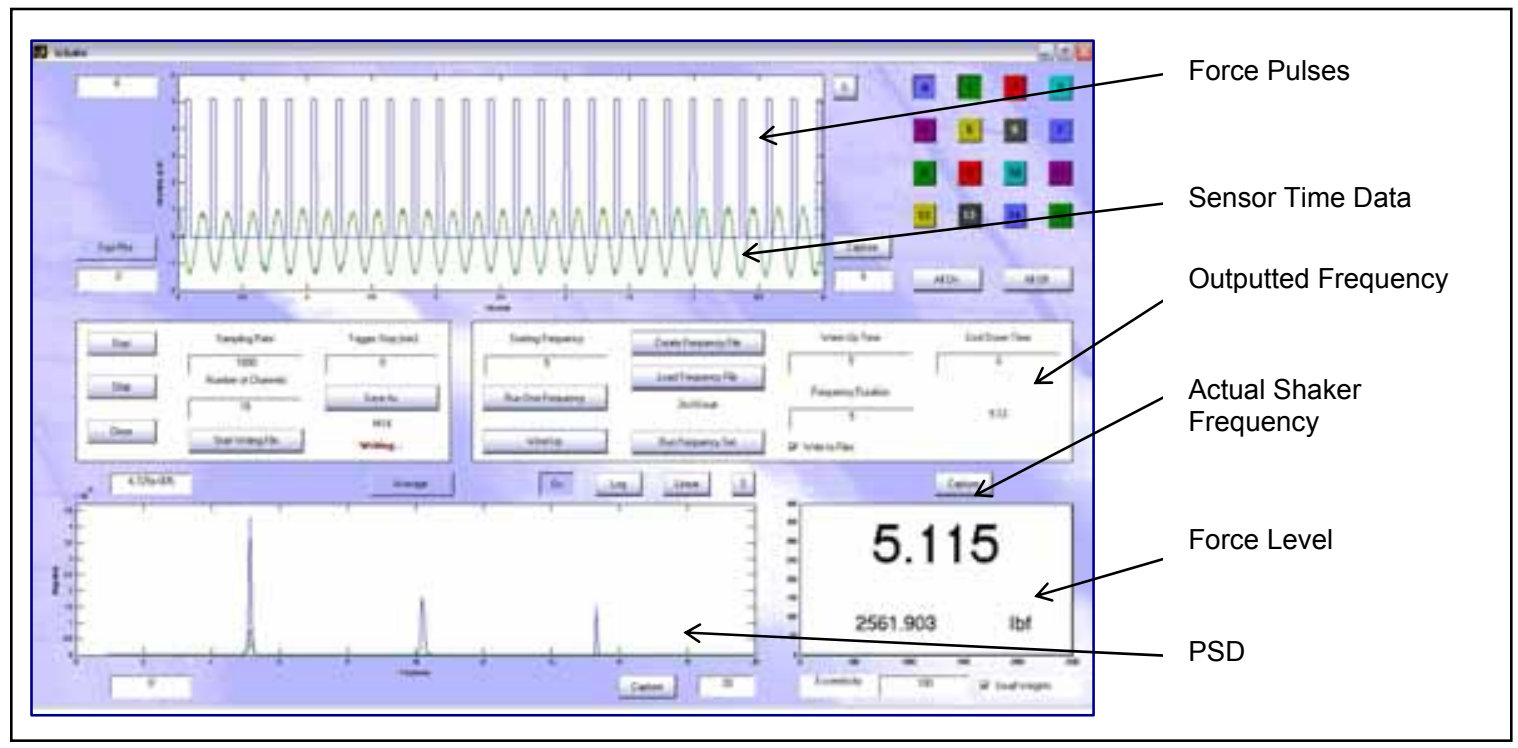

Figure 11. The iSHAKE panel

\section{Forced vibration test procedure}

The conduct of forced vibration tests on large structures typically employs the use of an excitation source attached directly to the structure to excite measurable steady-state responses. Since variations exist when forced responses are induced by different means (i.e., impact devices and controlled explosive devices), the tests conducted at Folsom Dam all used a single shaker to induce forced response in the dam, foundation, and reservoir. The testing procedures generally followed accepted practice, and details can be found in Duron and Hall (1988).

As mentioned above, at each excitation frequency, iSHAKE allows the shaker to stabilize over a 5-sec period and then acquires steady-state responses over a 5-sec period. Responses, along with the shaker force pulse signal, are then stored to file prior to the next excitation frequency. Recording of the shaker force pulse signal allows for precise determination of excitation frequencies and phase in the postanalysis. By employing automated control during the tests at Folsom Dam, test times that typically reach $4 \mathrm{hr}$ for sweeps over a $20 \mathrm{-Hz}$ range with $0.1-\mathrm{Hz}$ increments would require less than $1 \mathrm{hr}$ to complete. Because of the enhanced shaker control and automated test procedures, finer resolution between excitation frequencies was possible with reduced shaker operating times.

\section{Frequency response resolution}

A main consideration in any forced vibration test in which a shaker is operated at discrete frequencies is the frequency response resolution that results. Since the resolution in measured response functions is defined by the shaker frequency increment used during testing, a suitable increment must be selected that ensures no resonances are missed and that peaks are adequately defined both in terms of magnitude and bandwidth. On the other hand, if too fine a resolution 
is required, extended test times may result in the shaker approaching or even exceeding its operating limits.

A suitable increment for the tests at Folsom Dam was judged to be less than $0.1 \mathrm{~Hz}$ based on the ambient response information previously acquired. Ambient derived spectral response functions were reported with $0.122-\mathrm{Hz}$ resolutions; however, resonant frequencies were selected using the maximum entropy method based power spectra that provided $0.05-\mathrm{Hz}$ spectral resolution. To achieve a $0.05-\mathrm{Hz}$ resolution from a forced vibration test over a $20-\mathrm{Hz}$ frequency range, as many as 400 data files would result, and extended test times would be required under normal conditions in which shaker excitation frequencies are manually controlled.

Taking advantage of the automated control provided by iSHAKE, however, allowed frequency increments of $0.02 \mathrm{~Hz}$ to be used and resulted in significant timesavings to complete testing over the $20-\mathrm{Hz}$ band. For example, a complete frequency sweep in which near maximum force levels were achieved over the entire range required $2 \mathrm{hr}$ to complete with $0.02-\mathrm{Hz}$ resolution. The frequency resolution in response functions helped to reduce the likelihood of missed resonances.

\section{Example steady-state responses and curve fits}

A sample steady-state acceleration response acquired during the forced vibration tests at Folsom Dam is shown in Figure 12. The type and quality indicated is typical of the measurements used to develop associated frequency response functions at Folsom Dam. The dominant period of the signal corresponds to the shaker excitation frequency, and the magnitude of the response provides the magnitude portion of the frequency response measured in the dam, while the phase of the signal provides the phase portion of the frequency response function. The corresponding curve fit to the measured response is also shown in Figure 12, and details associated with the curve-fitting procedures and resulting parameters can be found in Duron and Hall (1988).

As shown in Figure 12, good agreement can be achieved for relatively large amplitude responses; however, less than satisfactory agreement between measured response and curve fit parameters can result for signals in which forced magnitudes do not rise above ambient levels.

Frequency response curves are obtained by plotting magnitude and phase against excitation frequency, and these curves are then used to obtain response shape information in the dam, along monolith heights, and in the reservoir. Sample response curves (in units of $\mathrm{g} / \mathrm{lbf}$ and $\mathrm{psi} / \mathrm{lbf}$ for acceleration and pressure magnitude response, respectively; and in degrees for phase response) are presented for the most relevant monoliths in the following sections, along with a discussion of the corresponding observed characteristics. 


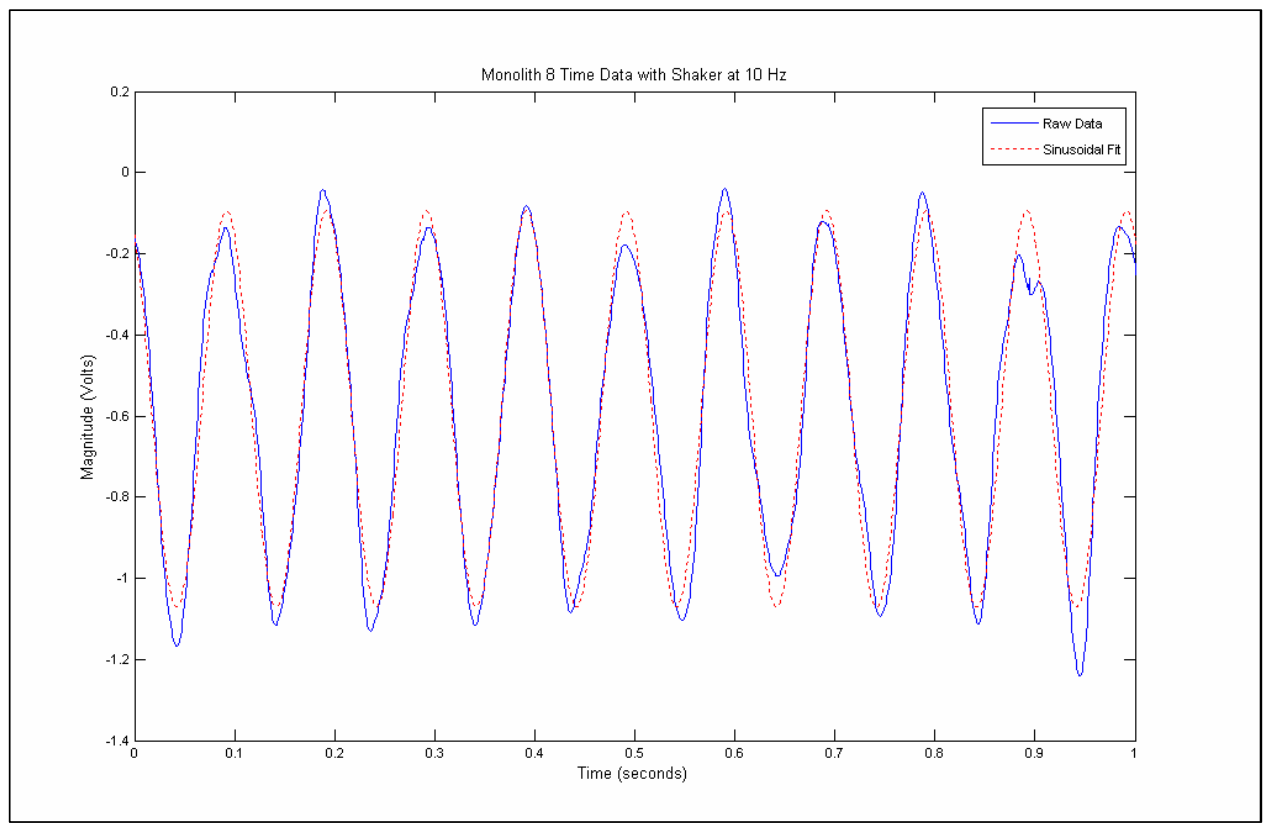

Figure 12. Response measurement and curve fit comparison 


\section{Description of Dam Response Characteristics}

The dynamic response characteristics of Folsom Dam as observed during the June 2004 forced vibration tests are discussed in the following sections. Characteristics are described in terms of measured frequency response functions acquired in the dam, along the dam-foundation interface, in the left embankment, and in the reservoir behind Monoliths 14 and 21. The influence of the elevator tower in Monolith 11 on dam response is investigated. Monolith response behavior is described in terms of response shape information, amplification response behavior, and relative joint motion characteristics. Evidence of foundation flexibility effects is presented in terms of responses acquired at the heel and toe of Monolith 14. Finally, an attempt to characterize the fundamental resonant behavior of the reservoir is presented.

\section{Measured Acceleration Frequency Response Characteristics}

The following sections provide samples of acceleration magnitude and phase frequency responses acquired at Folsom Dam during the forced vibration tests. Sample responses shown were acquired with the shaker at its three mounting locations: on the crest at Monolith 11, on the crest at Monolith 21, and in the pipeline gallery in Monolith 14. A complete set of magnitude and phase frequency response curves obtained along the crest and along Monoliths 13, 14, 15, and 21 are included in Appendix A. Individual monolith response curves are presented in Appendix B.

\section{Shaker mounted on crest at Monolith 11}

Responses shown in Figures 13-15 were acquired on the crest at Monoliths 8, 14, and 21 and are typical of the crest response behavior observed during the forced vibration tests. The small peak between 4 and $5 \mathrm{~Hz}$ corresponds to the fundamental symmetric resonance of the coupled dam-foundation-reservoir system at $4.65 \mathrm{~Hz}$ and is consistent with the behavior identified during the previous ambient survey. The large response peak below $6 \mathrm{~Hz}$ corresponds to the 


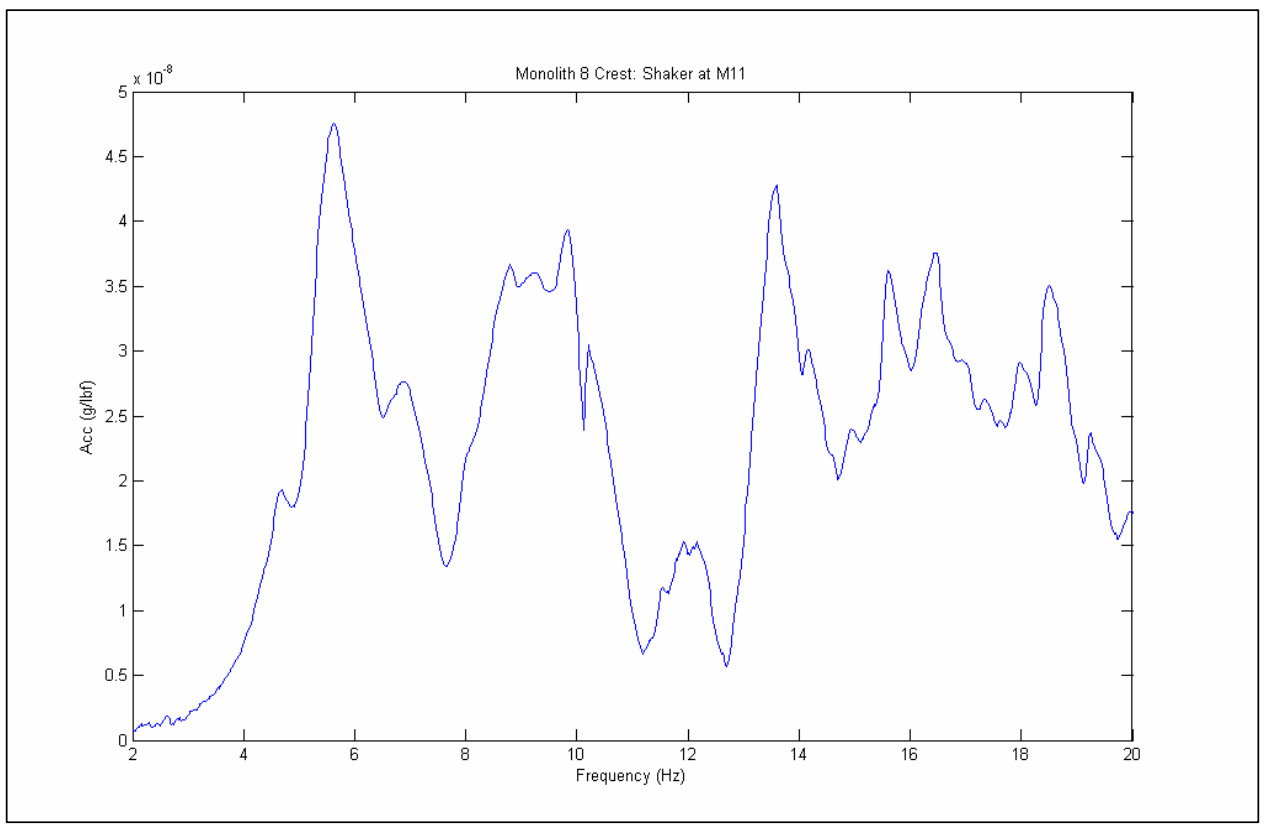

Figure 13. Crest response at Monolith 8 with shaker at Monolith 11

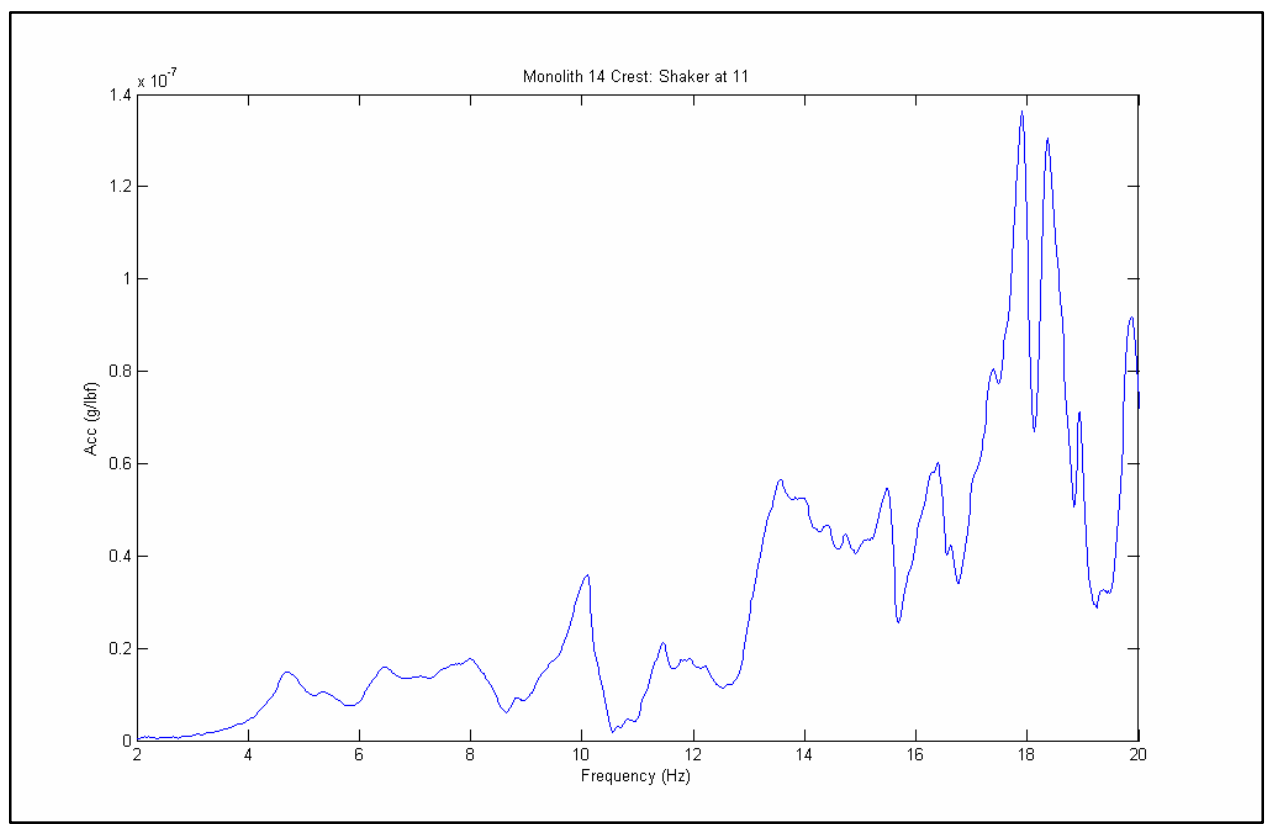

Figure 14. Crest response at Monolith 14 with shaker at Monolith 11

second fundamental resonance in the dam at $5.46 \mathrm{~Hz}$ and is also consistent with the behavior identified during the ambient survey. Frequency response behavior between 6 and $11 \mathrm{~Hz}$ is characterized by broad response peaks. A number of response peaks are observed above $11 \mathrm{~Hz}$ in the measured frequency responses acquired on the crest. Response shapes computed at the various peak frequencies seen in the response must be reviewed to assess the type of behavior that may be 


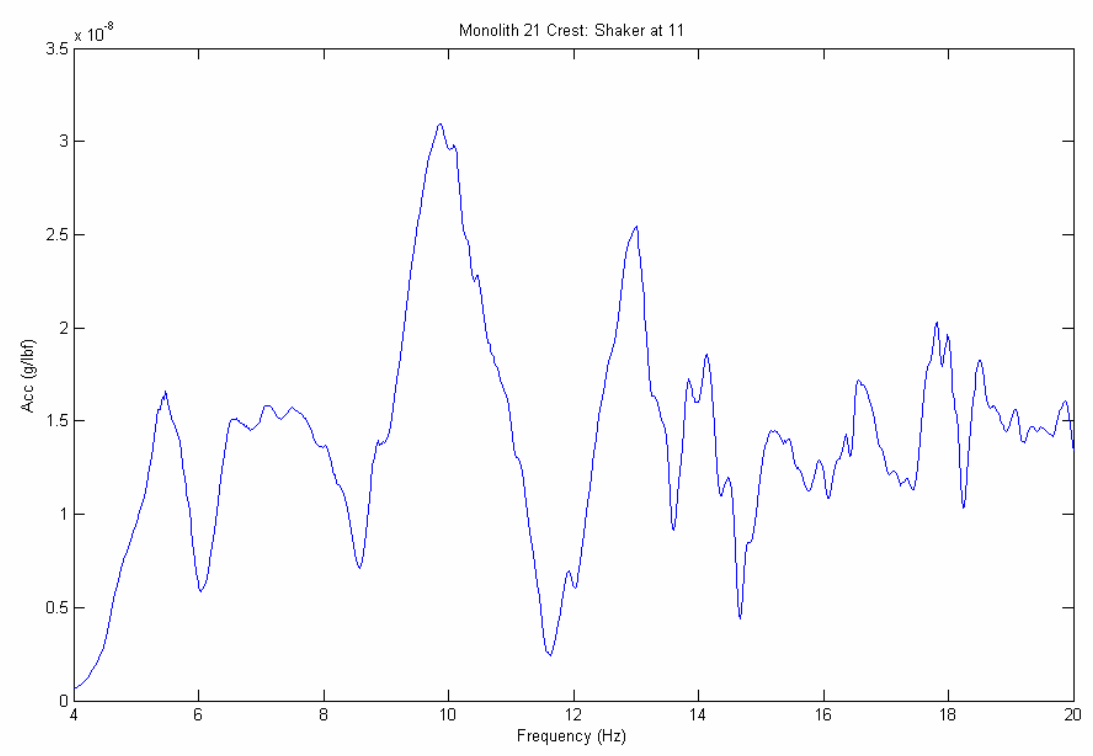

Figure 15. Crest response at Monolith 21 with shaker at Monolith 11

present in the dam. Still, the quality of response measurements taken during the crest tests is judged to be quite high, and the $0.02-\mathrm{Hz}$ resolution made possible by the automated control of the shaker by $\boldsymbol{i S H A K E}$ lends confidence to the peak density seen in these measurements.

The absence of significant response below $4 \mathrm{~Hz}$ in the crest measurements suggests that no system resonances were present in the dam over this range, a finding consistent with the results reported from the previous ambient survey at Folsom Dam.

\section{Shaker mounted on crest at Monolith 21}

Responses shown in Figure 16 were acquired on the crest and at an elevation below the crest on the downstream face of Monolith 21. The responses observed at Monolith 21, taken with the shaker on the crest of the monolith, can be compared with the response on Monolith 21 on the crest with the shaker installed at Monolith 11. While the overall character of the response on the crest at Monolith 21 with the shaker at Monolith 11 seems to be present in the response on the crest at Monolith 21 with the shaker at Monolith 21, some differences are notable. For example, the response levels on the crest of Monolith 21 are smaller when excited by the shaker at Monolith 11 compared with the levels on the crest of Monolith 21 and the shaker at Monolith 21. In addition, there is a noticeable shift in resonant frequencies present in the response with the shaker at Monolith 21, compared with the same response with the shaker at Monolith 11 (higher with the shaker at Monolith 21). 


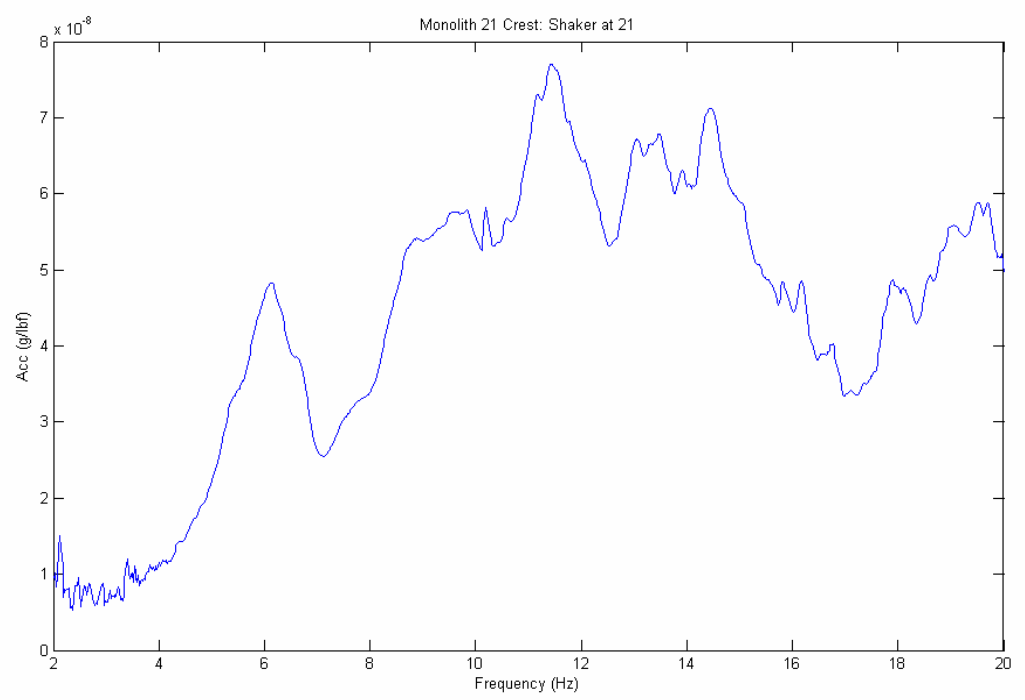

a. Crest response

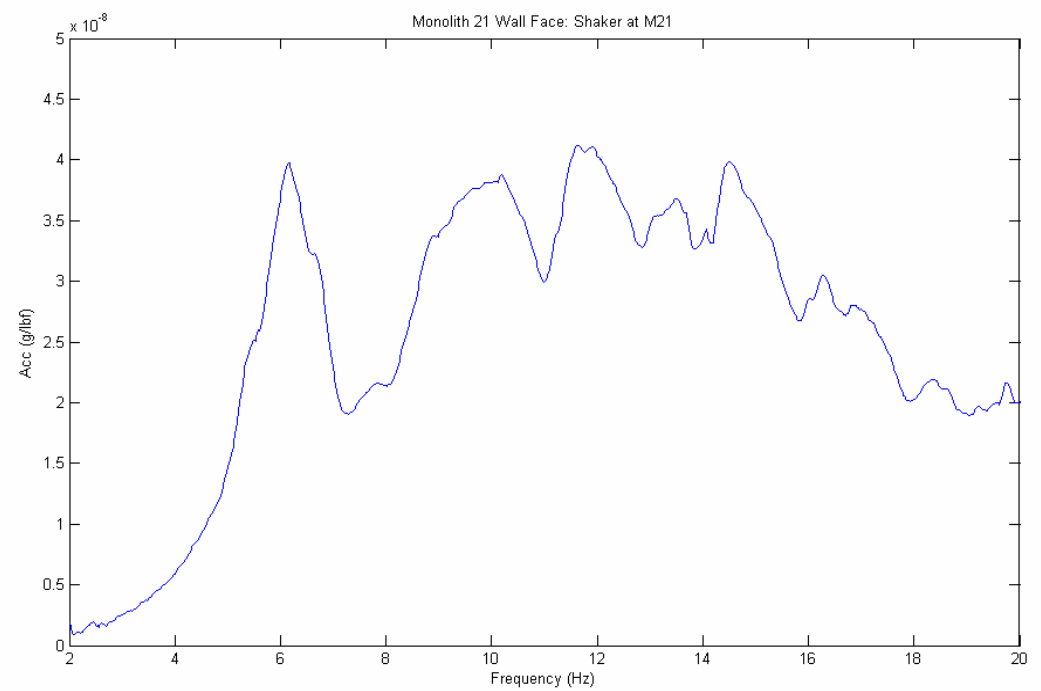

b. Downstream face response

Figure 16. Measurements at Monolith 21

These differences may occur because, with the shaker at Monolith 11, a reduction in excitation force likely occurs across the spillway monoliths prior to reaching Monolith 21. With the shaker at Monolith 11 then, the response at Monolith 21 may reflect it being "dragged" along by adjacent monolith response coupled across the joints, while the response observed with the shaker over Monolith 21 may be more representative of the individual (cantilever) behavior at Monolith 21. 
A sample response in the dam acquired on the downstream face at elevation $421 \mathrm{ft}$ (see measurement layout Figure 7) with the shaker located over Monolith 21 is shown in Figure 16. The magnitude response indicates a large peak just above $6 \mathrm{~Hz}$, but does not indicate significant activity near the fundamental resonance at $4.65 \mathrm{~Hz}$. Still, close inspection of the response shows "cliffs" present on each side of the resonance at $5.46 \mathrm{~Hz}$ that suggest coupling with close or nearby resonant behavior. As before, no significant response is observed below $4 \mathrm{~Hz}$.

\section{Shaker mounted in the pipeline gallery at Monolith 14}

Responses shown in Figure 17 were acquired at crest and in the grouting gallery of Monolith 14 with the shaker mounted in the pipeline gallery of Monolith 14. Since the series of tests were intended to characterize cantilever behavior in Monoliths 13, 14, and 15, relative joint motion between adjacent monoliths, and monolith base rocking behavior, testing was limited to $10 \mathrm{~Hz}$ with the large weights. In this manner, the largest force levels were available to excite the desired responses.

The crest response exhibits expected behavior; however, the influence of the nearby resonances associated with spillway pier action (see next section) is evident. The quality in the grouting gallery response is seen to be quite high, and the presence of four resonant peaks below $10 \mathrm{~Hz}$ indicated that the shaker was able to excite multiple resonances even when installed inside the dam. Both measurements at the crest and in the grouting gallery clearly reflect a fundamental resonance at $4.65 \mathrm{~Hz}$. Again, no significant behavior was observed below $4 \mathrm{~Hz}$.

\section{Identification of Dam Resonance Characteristics}

A comprehensive review of the measured frequency responses acquired during the forced vibration tests at Folsom Dam was conducted to identify fundamental resonant frequencies and associated response shape behavior. Ideally, a resonance of the dam-foundation-reservoir system would result in acceleration peak response observed everywhere in the dam at the same frequency. Resonant peaks observed to be shifting in frequency across the dam, or peaks that "disappear" at locations in the dam, would not normally be identified as full system resonances. The monolithic construction of Folsom Dam and the large number of frequency responses acquired required a careful review to ensure fundamental behavior could be accurately identified.

\section{Trends in resonant frequencies}

For most structures, the mere presence of resonant peaks can be sufficient to identify these peaks with resonant behavior in the structure. At Folsom Dam, however, the possibility that individual monoliths could be excited into resonance apart from full system monolithic behavior in the dam required that candidate resonances be examined in terms of both resonant peak and response shape 


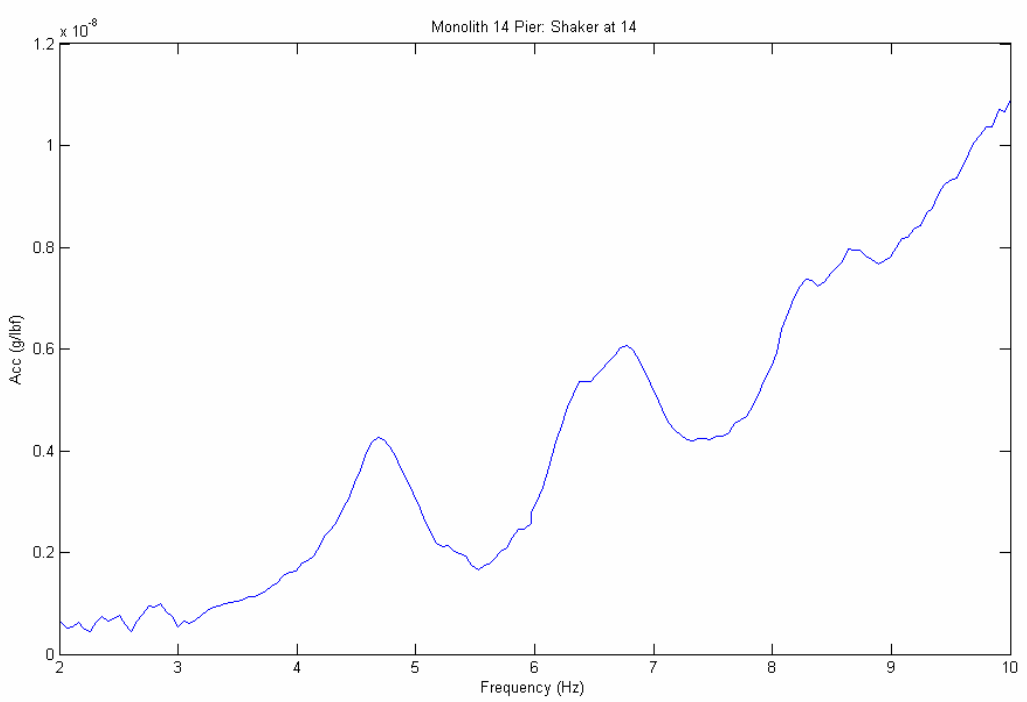

a. Pier response

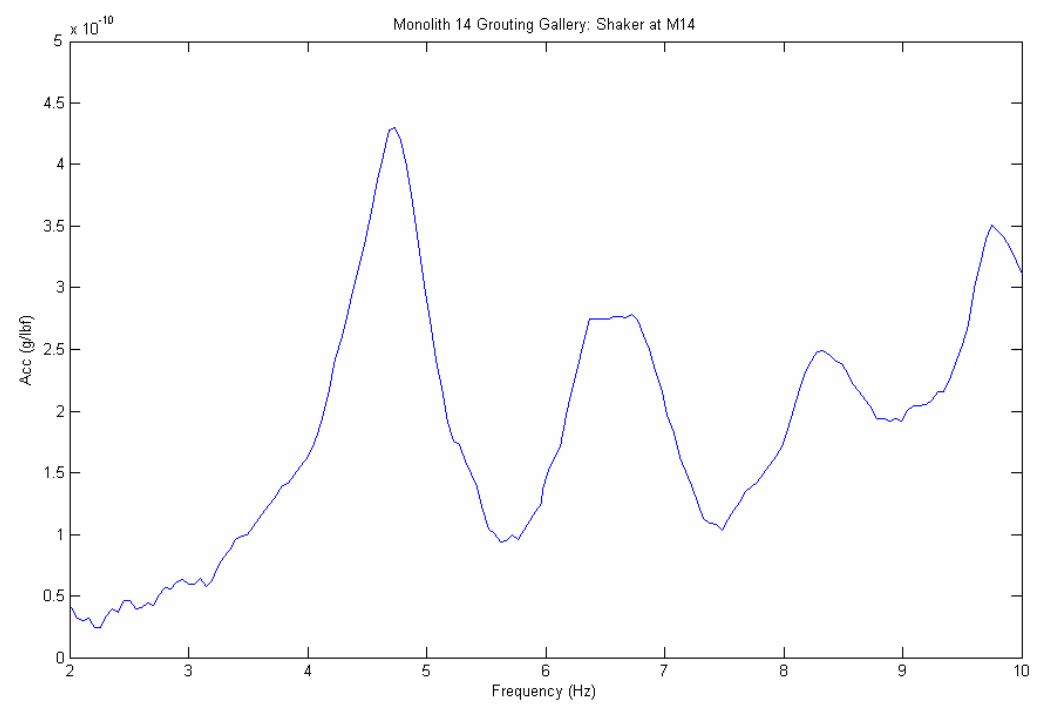

b. Responses at dam-foundation interface

Figure 17. Responses at Monolith 14

characteristics. In the strictest sense, response shape characteristics include behavior associated with all contributing modal characteristics and, as a result, the measured responses at Folsom Dam may be more accurately described as operating deflection shapes (but will be referred to as response shapes in this report).

The first step in identifying candidate resonances for Folsom Dam involved examination of all measured crest response functions acquired with the shaker 
mounted on the crest at Monolith 11. Rather than overlaying all of the measured responses, a scatter plot of the type indicated in Figure 18 presents an overview of the presence and value of candidate resonances. Each bar represents a peak in crest acceleration response (identified along the vertical axis, and excited with the shaker at Monolith 11) associated with each Monolith (identified along the horizontal axis) in the dam. The plot is divided into three sections that correspond to the right gravity portion (Monoliths 1 through 11), the spillway portion (Monoliths 12 through 20) and the left gravity portion (Monoliths 21

through 28). Candidate resonances and the suggested behavior characteristics in each portion of the dam are discussed below.

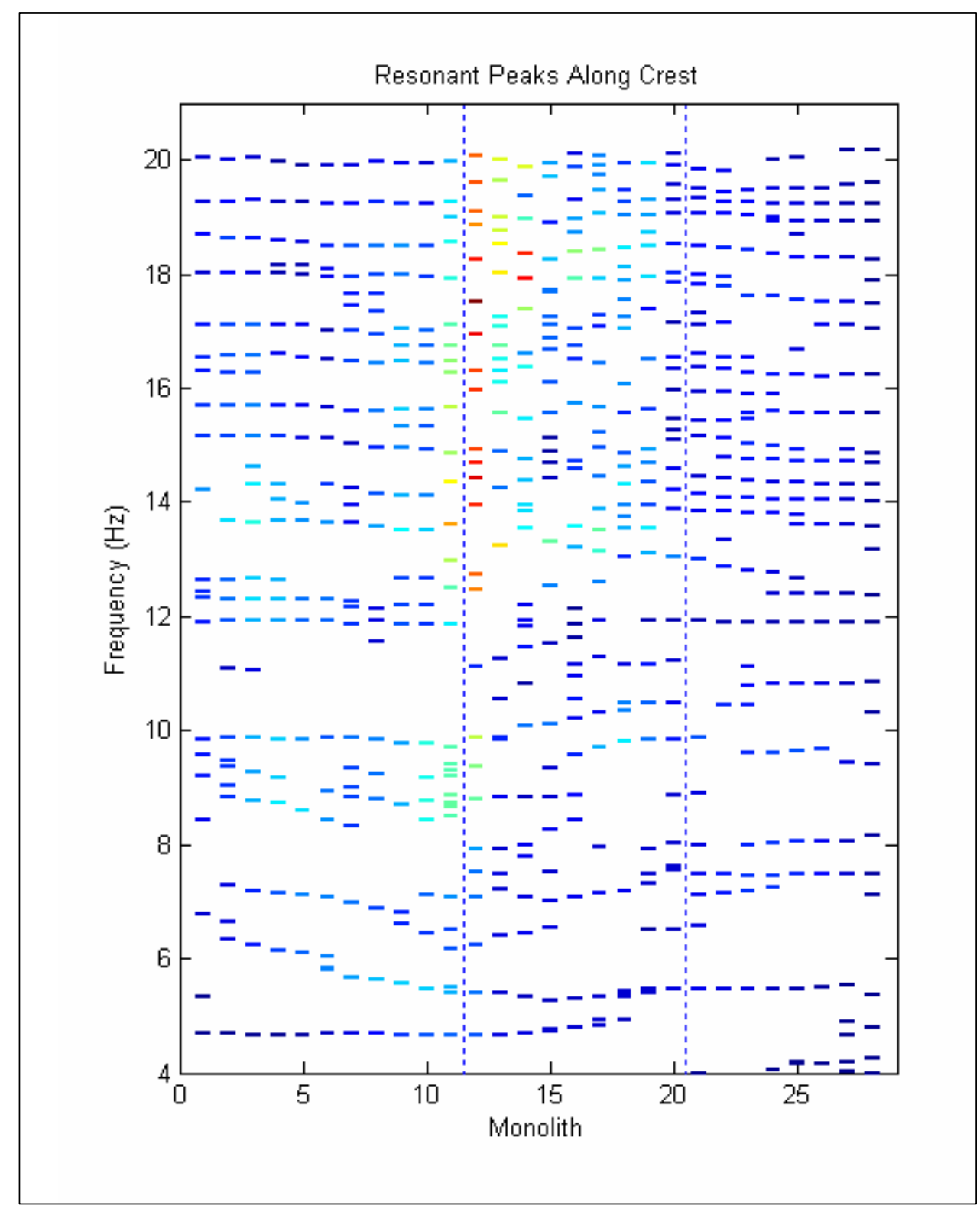

Figure 18. Resonant frequency distributions at Folsom Dam (resonant information was obtained with the shaker mounted on the crest at Monolith 11) 


\section{Right gravity response behavior - Monoliths 1-11}

The resonant behavior in the right gravity section of Folsom Dam indicates monolithic behavior characterized by consistent and in-phase motion across all monoliths as well as probable individual monolith behavior. As seen in Figure 18, a steady resonance appears in this section of the dam at $4.65 \mathrm{~Hz}$ that corresponds (shown later) with the fundamental resonance of the coupled damfoundation-reservoir system. The scatter of resonances in Figure 18 between 5 and $7 \mathrm{~Hz}$ suggests a sliding resonant behavior consistent with a softening or increasing flexibility characteristic between Monoliths 1 and 11. This decreasing trend is further illustrated in Figure 19.

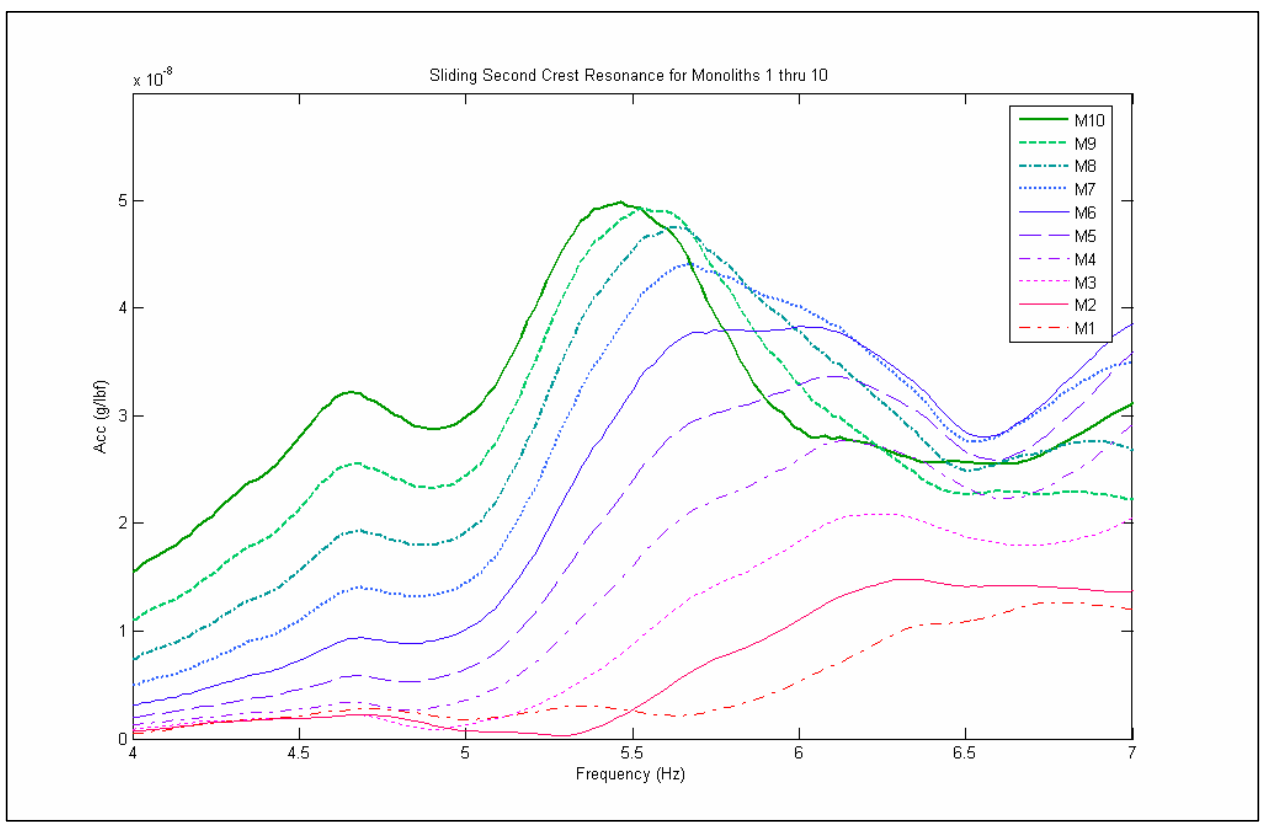

Figure 19. Sliding resonant behavior in Monoliths 1-10

The responses in Figure 19 were acquired on the crest in Monoliths 1 through 10 with the shaker located on the crest at Monolith 11 and clearly show the stationary resonance at $4.65 \mathrm{~Hz}$ and the changing character of the second system resonance beginning at $5.46 \mathrm{~Hz}$. The response at Monolith 11 is not included in the figure since local effects commonly associated with drive point measurements influence the response. Above $5 \mathrm{~Hz}$, the largest and narrowest peak with the lowest frequency corresponds to the response measured at Monolith 10, and subsequent resonances characterized by wider, lower amplitude peaks were found, moving away from Monolith 10, at Monoliths 9 through 1.

The resonance at $4.65 \mathrm{~Hz}$ is likely driven by reservoir resonant behavior, in a manner similar to that observed during a previous study described in Duron and Hall (1988). In that study, the dynamic response of a concrete arch dam revealed a coupling between fundamental resonances in the reservoir and in the damfoundation subsystems that produced a low-amplitude fundamental resonance of the coupled dam-foundation-reservoir system. At Folsom Dam, estimates of the fundamental resonance of the dam-foundation subsystem (obtained from both 
2-D and 3-D numerical models) range between 5 and $6 \mathrm{~Hz}$, while the fundamental resonance of the reservoir was observed to be $5.23 \mathrm{~Hz}$ (as described later in this report). The coupling of the reservoir and dam-foundation subsystems is believed to produce the low-amplitude, steady resonance at $4.65 \mathrm{~Hz}$ shown in Figure 19, and is identified as the fundamental resonance in the dam system.

Identification of the second and third fundamental resonances from these measurements is difficult based solely on a visual association with peaks in the frequency response curves. The character of the measurements suggests that interference between adjacent resonances is present, and a quantitative approach to identifying true system resonances is required. Identification of the resonances present was achieved using a curve-fitting algorithm that fits a complex frequency response function to the measured responses, and that was also used to obtain damping estimates in the dam.

Attempts to curve-fit a complex frequency response function to the measured responses in Figure 19 resulted in the identification of two dominant system poles, near 5.5 and $6.25 \mathrm{~Hz}$. A system pole can be thought of as an eigenvalue and therefore can be interpreted to be associated with true resonant behavior. In this case, since only two dominant poles resulted from the curve fit, behavior other than that associated with each individual monolith may be present. Instead, the response behavior may be associated with groups or clusters of monoliths acting together in this section of the dam to produce two dominant resonances. However interpreted, the observed characteristics in the dam between Monoliths 1 and 11 suggest groups or even individual monoliths may be excited at Folsom Dam in this frequency range. Although this behavior was not readily observed during the March 2004 ambient survey, it is possible that ambient excitation levels were not sufficient to overcome the friction between monoliths, thereby masking the trends observed during the forced vibration tests.

In the frequency range 10 to $13 \mathrm{~Hz}$, the resonant behavior is influenced by the presence of the tower (described later) and the spillway monoliths. Above $14 \mathrm{~Hz}$, steady resonances are associated with higher order response behavior.

\section{Spillway response behavior - Monoliths 12-20}

Interpreting the scatter of resonances in this section of the dam is complicated by the varying monolith geometries present. The spillway section contains two transition monoliths (12 and 17), four similarly sized overflow monoliths $(13,14,15$, and 16), and three shorter nonoverflow monoliths $(18,19$, and 20$)$. It is believed that the somewhat inconsistent peak responses, especially above $12 \mathrm{~Hz}$, resulted from individual pier responses that may or may not contribute to monolithic resonances.

\section{Left gravity response behavior - Monoliths 21-28}

The scatter of resonances shown in this portion of the dam is similar to that observed in the right gravity section. Steady resonant peaks are seen in this section of dam above $5 \mathrm{~Hz}$ and again above $13 \mathrm{~Hz}$; however, the presence of the 
fundamental resonance at $4.65 \mathrm{~Hz}$ is vague at best. The absence of the fundamental resonance likely results from the shaker's inability to provide sufficient excitation to the left gravity section when mounted on the crest at Monolith 11. As such, any peak in the response at $4.65 \mathrm{~Hz}$ is masked by the magnitude of the more dominant second resonance at $5.46 \mathrm{~Hz}$. Force levels are probably dissipated across monolith joints, particularly in the spillway section. Nonetheless, sufficiently consistent response shape information was obtained to identify the fundamental resonance at $4.65 \mathrm{~Hz}$. The sliding resonant behavior between adjacent monoliths observed in the right gravity section is not apparent here; however, the location of the shaker in the right gravity section and the probable reduction in excitation levels across monoliths may be contributing factors.

\section{Dominant dam response}

Although the scatter plot provides an overview of the value and distribution of resonant peak frequencies in the dam, it does not provide indications of the dominant response sections in the dam. A surface plot of acceleration response functions measured in the dam with the shaker mounted on the crest at Monolith 11 is shown in Figure 20. The dominant response in the dam at the fundamental resonance is present in Monoliths 9 through 12. The fundamental resonance is not readily observed elsewhere in the surface plot since the levels are much lower than the levels in Monoliths 9 through 12.

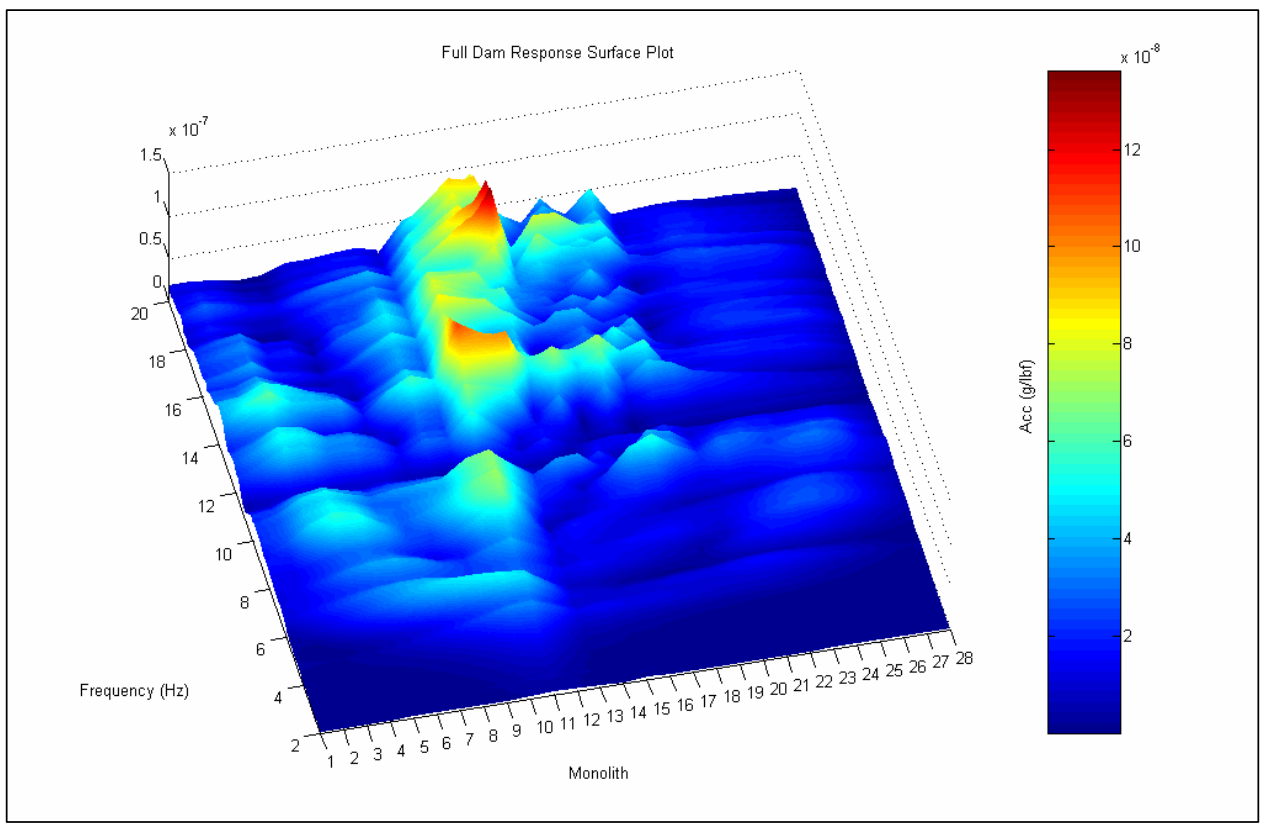

Figure 20. Surface plot of crest acceleration responses with the shaker at Monolith 11

The lack of response behavior between 10 and $12 \mathrm{~Hz}$, clearly demonstrated in the surface plot, results from the tower's influence on dam response (discussed below). Below $10 \mathrm{~Hz}$, the behavior around the second resonance dominates and 
has the greatest magnitude in Monoliths 4 through 13 . Above $12 \mathrm{~Hz}$, the measured response in the dam is dominated by spillway behavior.

\section{Influence of elevator tower on dam response}

The influence of the elevator tower at Monolith 11 on overall dam response (with the shaker mounted on the crest at Monolith 11) is captured in the response curves shown in Figure 21. The tower exhibits a fundamental resonance near $11 \mathrm{~Hz}$ (indicated by the response at Level 9, $22 \mathrm{ft}$ above crest elevation) that coincides with an antiresonance in the dam as illustrated by the acceleration response (indicated by the response at Level 5, $46 \mathrm{ft}$ below crest elevation) acquired in Monolith 11.

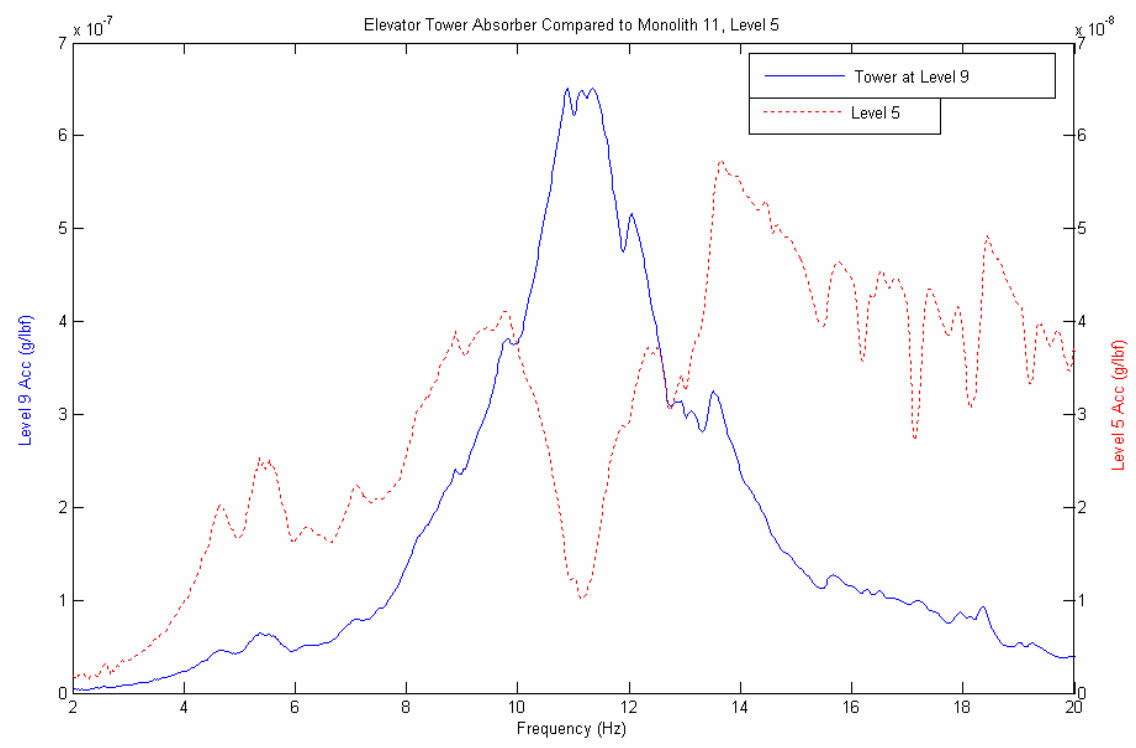

Figure 21. Measured tower response behavior

The observed behavior in the frequency range of 8 to $13 \mathrm{~Hz}$ and the influence of the tower on dam response can be explained by using a simplified model of the dam-tower system. The model consists of a spring-mass-damper oscillator that represents the dam and a subsystem that represents that portion of the tower attached to the dam that acts as a tuned vibration absorber (TVA). The behavior of this two-degree of freedom (2DOF) system is well known, and its main characteristics are described in Appendix C.

A typical response acquired on the dam crest at Monolith 21 (with the shaker on the crest at Monolith 11) is shown in Figure 22. An attempt to reproduce the general character of this response within the frequency range of 8.5 to $13.5 \mathrm{~Hz}$ was made using the simplified model described above. 


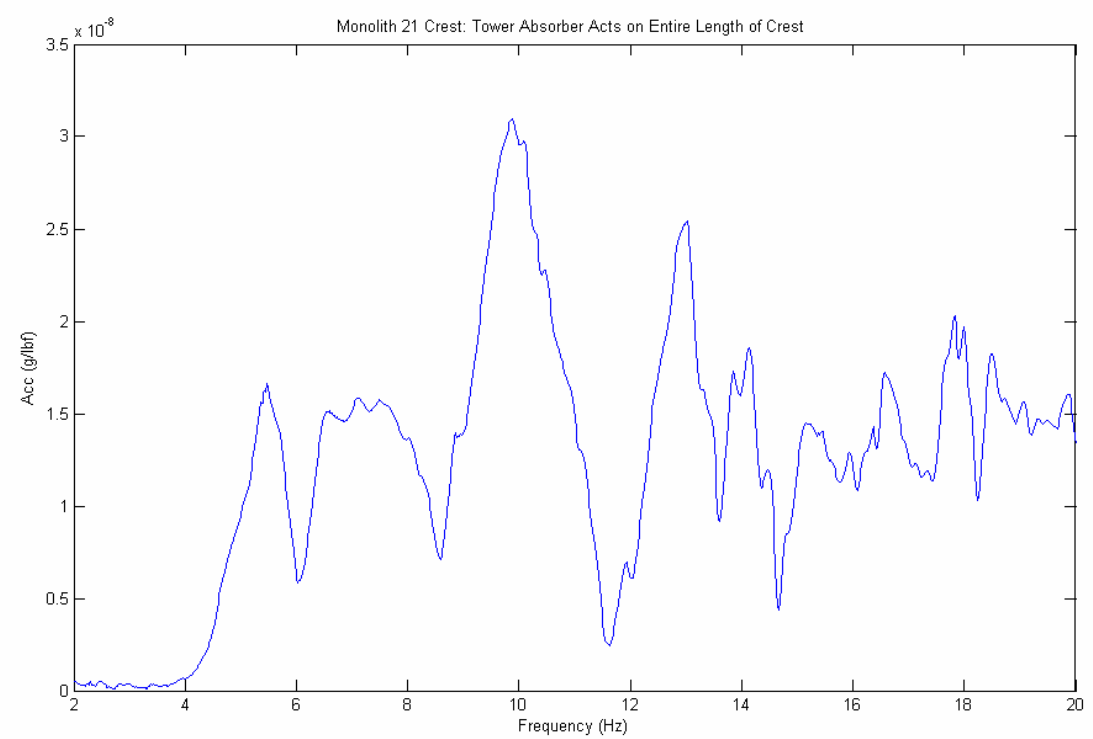

Figure 22. Response behavior on crest at Monolith 21

A comparison of the observed acceleration response (solid curve) and that predicted using the TVA model (dotted curve) is shown in Figure 23. The curves in Figure 23a compare the measured dam response to that predicted by the TVA model, and the curves in Figure $23 \mathrm{~b}$ compare the measured tower response to that predicted by the same model. The comparison was obtained by tuning the absorber to $11.6 \mathrm{~Hz}$ based on the observed resonance in the tower. The mass ratio of 0.06 , used to obtain the result shown, indicates that the absorber mass is approximately 6 percent of the participating modal mass in the dam near $11 \mathrm{~Hz}$. The damping associated with the tower was estimated at 1 percent of critical, and the damping in the dam was estimated at 8 percent critical. The parameters used in this comparison were selected based on achieving a "best overall" comparison with the observed behavior. Although no quantitative criteria were used to determine these parameters, the comparison shown in Figure 23a captures the antiresonance and the "split" resonant behavior and confirms the suspected influence of the tower on dam response.

The TVA model used in this comparison contains only two degrees of freedom and cannot be expected to reproduce the details observed in the measured response. For example, a number of smaller resonant peaks are present in the measured response in Figure 23a; however, the 2DOF model is unable to capture these characteristics. It is recognized that a higher order model would do better in reproducing the observed behavior.

A second comparison of the tower's response and that predicted by the 2DOF model is shown in Figure 23b and highlights the inability of the model to capture the tower response. Although the measured tower response exhibits a dominant response in the vicinity of $11.6 \mathrm{~Hz}$, it is clear that multiple resonances are contributing to the response. While the 2DOF model does a reasonable job of 


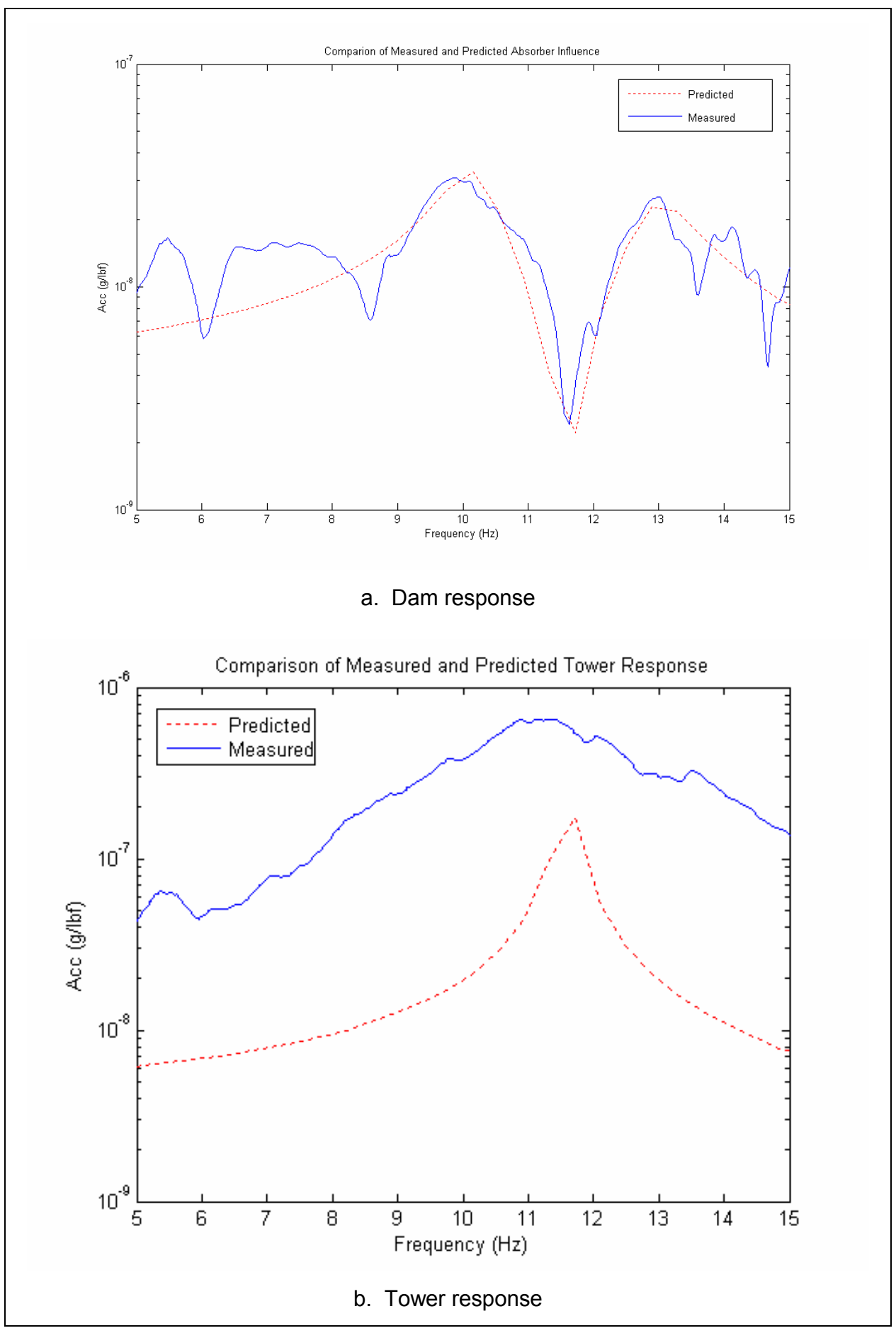

Figure 23. Evidence of absorption characteristics at Folsom Dam

illustrating the dominant resonant behavior, further discretization of the absorber model allowing modal contributions other than the single response at $11.6 \mathrm{~Hz}$ would produce a closer match with measured behavior. 
The limitations of the model as reported herein notwithstanding, the above comparisons demonstrate the important role of the tower on dam response and the need to include these effects in a numerical model of the dam.

\section{Damping estimates for Folsom Dam}

Damping estimates were obtained for Folsom Dam using measured forced vibration responses in the dam. Ranges of damping values for Folsom Dam were obtained using the following techniques:

a. Half-power method using acceleration frequency response functions.

b. Curve-fitting technique using acceleration frequency response function.

c. Matching observed vibration absorption characteristics using tower and crest acceleration frequency response functions.

The half-power method for estimating damping is well known and assumes that the measured resonant peaks in the response functions are not influenced by closely spaced resonances. As such, the half-power damping estimate of the fundamental resonance suffers from coupling associated with the nearby second resonance. Careful examination of the measured resonances associated with the second resonant frequency in the dam revealed that sufficient peak separation was present and produced damping estimates of 7.0 percent of critical with a standard deviation of 1.4 percent.

Damping was also estimated using a curve-fitting technique that attempts to fit a complex frequency response function to the measured responses in the dam. Details of the curve fit and samples of the results are provided in Appendix D. Plots are produced that show how the poles vary with fit order, and a true system pole is easily identified when its value remains unchanged or "locks in" for a particular fit order and for all subsequent orders. The algorithm produces scatter plots of resonant frequency versus fit order, damping versus fit order, and resonant frequency versus damping for all fit orders. This approach is able to handle well separated as well as closely spaced resonances. Estimates were obtained using this technique for the fundamental and second resonance. The estimates were 5.25 percent of critical with a standard deviation of 1.2 percent for the fundamental resonance at $4.65 \mathrm{~Hz}$, and 5.9 percent of critical with a standard deviation of 1.1 percent for the second resonance at $5.46 \mathrm{~Hz}$.

As a final check on damping, comparisons between the observed tuned vibration absorber characteristics of the tower against those predicted using the analytical model described in Appendix $\mathrm{C}$ were made. To produce comparisons of the kind illustrated in Figure 23, appropriate absorber mass and damping estimates are required in addition to damping estimates suitable for observed dam response behavior. The use of the absorber model to obtain damping estimates for the dam is based on the expectation that a true fit to the observed tower influence on dam response should produce consistent damping estimates across the entire dam. As a result, measured crest acceleration responses along the dam at Monolith 11, 14, and 21 were examined. Resulting damping estimates were 
7 percent of critical with a standard deviation of 1 percent. It is important to note that these damping estimates are not necessarily associated with the fundamental or even second resonant frequency in the dam. Rather, the damping estimates are obtained by fitting observed behavior in the 8 - to $13-\mathrm{Hz}$ frequency range. As such, the estimates derived from this approach can be used to gain some confidence in the appropriate damping for higher order resonances in the dam. Table 2 contains a listing of the damping estimates obtained from the three techniques applied to the measured responses at Folsom Dam.

\begin{tabular}{|l|l|l|l||}
\hline \multicolumn{2}{|l||}{$\begin{array}{l}\text { Table } 2 \\
\text { Resonant Frequencies and Damping Estimates Identified } \\
\text { at Folsom Dam }\end{array}$} \\
\hline \hline \multirow{3}{*}{ Resonant Frequency, Hz } & Half-Power Method & $\begin{array}{l}\text { Curve-Fitting } \\
\text { Approach }\end{array}$ & TVA Model \\
\cline { 2 - 5 } & --- & $4.0-6.5$ & --- \\
\hline \hline 4.65 & --5 & --- \\
\hline 5.46 & $5.6-8.4$ & $4.8-7.0$ & -- \\
\hline 6.24 & --- & $4.0-8.0$ & -- \\
\hline 7.16 & $6.3-8.0$ & $4.0-7.8$ & $6.0-8.0$ \\
\hline 8.00 & --- & --- & $6.0-8.0$ \\
\hline 8.87 & --- & --- & \\
\hline
\end{tabular}

\section{Response shape behavior - crest}

Final identification of resonances in the dam requires examination of corresponding response shapes defined by the magnitude and phase responses along the crest. A partial listing of resonant frequencies and associated damping estimates is presented in Table 2, and corresponding response shapes are shown in Figures 24 and 25.

Damping estimates were not obtained for the 5th and 6th resonances using the half-power and curve-fitting techniques; however, the estimates obtained from the TVA model comparisons are assumed to be indicative of damping present in the dam for resonant behavior between 8 and $13 \mathrm{~Hz}$. The response shapes shown in Figure 25 illustrate the influence of the elevator tower on the dam response at $11.59 \mathrm{~Hz}$ (left) and highlight the influence of the spillway section at $13.55 \mathrm{~Hz}$ (right).

Table 3 provides a comparison of the resonant frequencies below $10 \mathrm{~Hz}$ that were identified from the ambient and forced vibration surveys at Folsom Dam. 


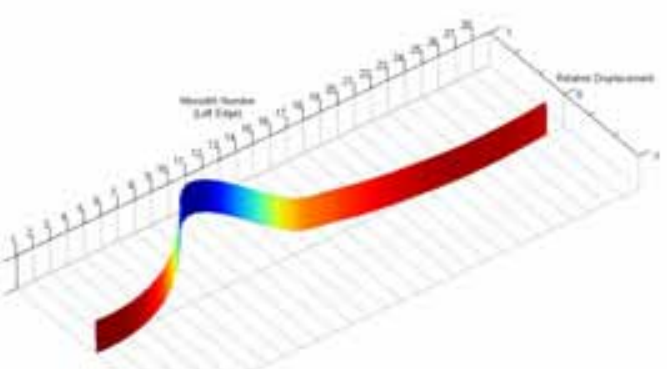

a. $4.65 \mathrm{~Hz}$

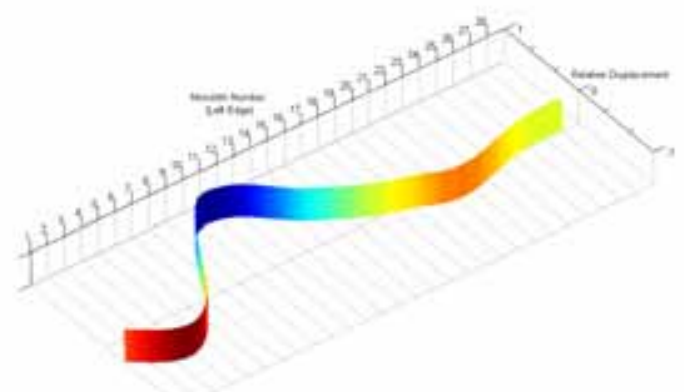

c. $6.24 \mathrm{~Hz}$

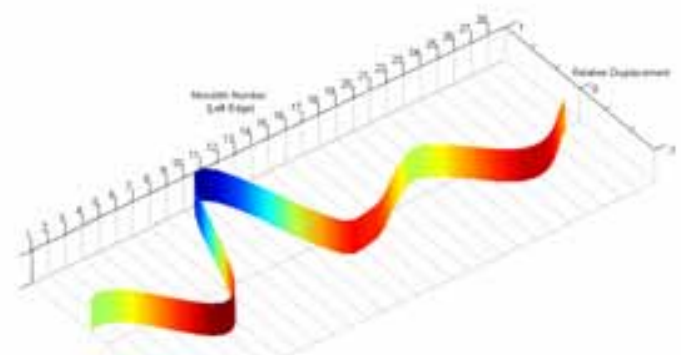

e. $8.00 \mathrm{~Hz}$

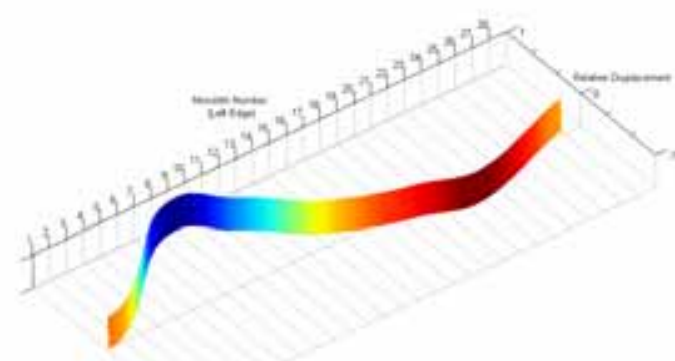

b. $5.46 \mathrm{~Hz}$

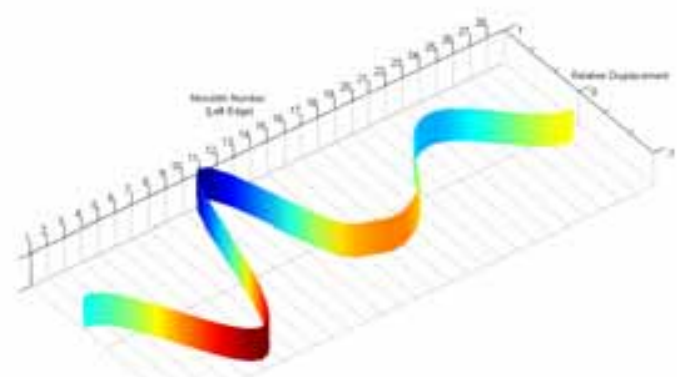

d. $7.16 \mathrm{~Hz}$

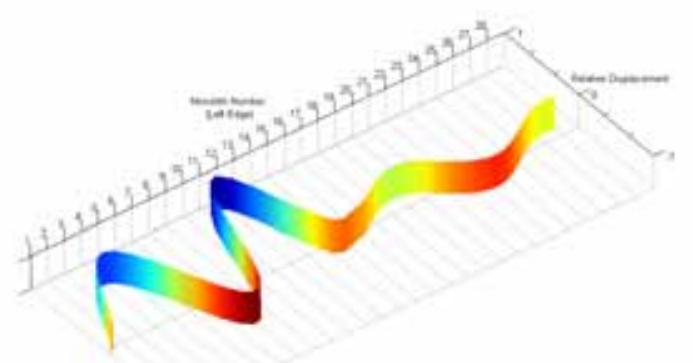

f. $8.87 \mathrm{~Hz}$

Figure 24. Response shapes corresponding to resonances below $10 \mathrm{~Hz}$ 


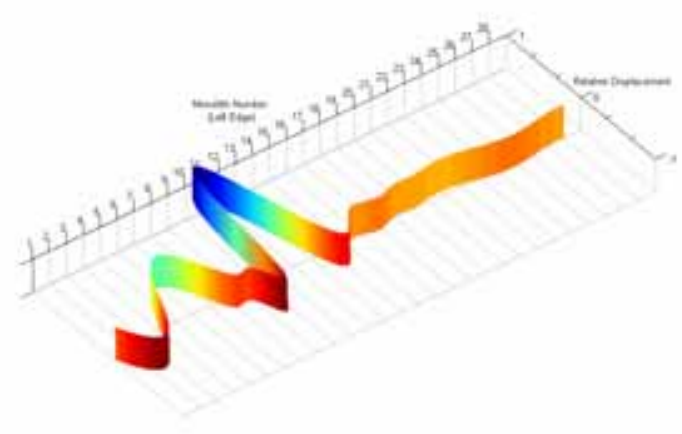

a. $11.59 \mathrm{~Hz}$

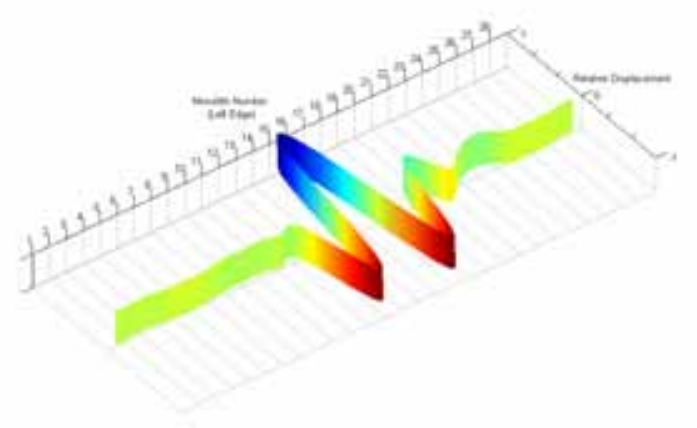

b. $13.55 \mathrm{~Hz}$

Figure 25. Response shapes indicating influence of tower and spillway characteristics on dam response

\section{Table 3 \\ Comparison of Measured Ambient and Forced Resonances at Folsom Dam}

\begin{tabular}{||l|l||}
\hline \hline \multicolumn{2}{|c|}{ Resonant Frequency, Hz } \\
\hline Ambient Vibration Survey & Forced Vibration Tests \\
\hline \hline 4.64 & 4.65 \\
\hline 5.49 & 5.46 \\
\hline 6.47 & 6.24 \\
\hline 7.32 & 7.16 \\
\hline 8.18 & 8.00 \\
\hline 8.91 & 8.87 \\
\hline
\end{tabular}

A comparison of the corresponding response shapes indicates reasonably good agreement near and around $8 \mathrm{~Hz}$. Above $8 \mathrm{~Hz}$, response shape comparisons indicate some differences, as evidenced by the ambient response shape at $8.91 \mathrm{~Hz}$ (large motion in spillway section, see Figure 2) and the forced response shape at $8.87 \mathrm{~Hz}$ (large motion in the right gravity section). The differences may point to a dependency on forcing or excitation levels that may or may not engage joint behavior between monoliths or sections in the dam.

\section{Monolith Response Behavior Characteristics}

Monolith response behavior was examined in Monoliths 13, 14, 15, and 21. In each monolith, acceleration responses were acquired on the crest, in the grouting gallery, and at intermediate elevations as indicated in Figures 4-8. Relative joint motion measurements were also made between adjacent monoliths. Response characteristics are described in terms of measured monolith (cantilever) response shapes and amplification behavior in the monoliths defined by the ratio of crest to grouting gallery responses. 


\section{Monolith response shape behavior}

Monolith response shape behavior was examined using measured acceleration responses acquired along the height of select monoliths with the shaker mounted inside the pipeline gallery in Monolith 14. Response behavior was obtained for Monoliths 13, 14, 15, and 21, and typical response shapes are shown in Figure 26 for Monolith 14 (fundamental response shape, top) and Monolith 21

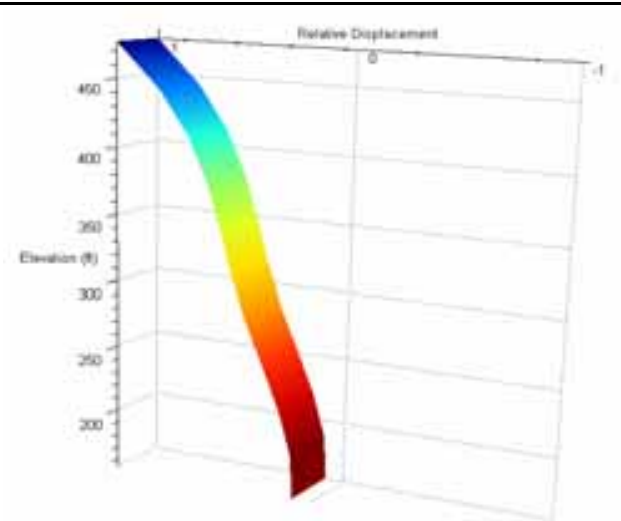

a. Monolith 14 - Fundamental cantilever resonance $(4.65 \mathrm{~Hz})$

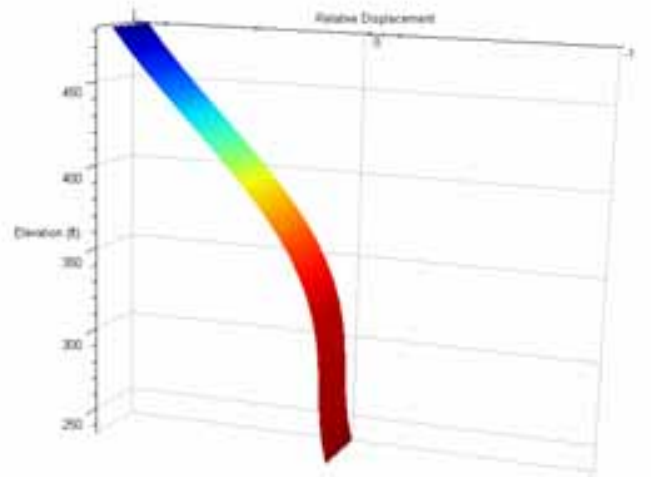

b. Monolith 21 - Fundamental cantilever resonance $(4.65 \mathrm{~Hz})$

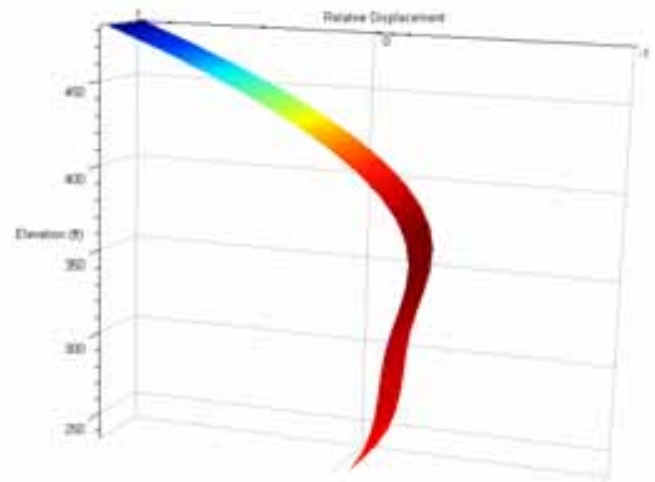

c. Monolith 21 - Second cantilever resonance $(10.94 \mathrm{~Hz})$

Figure 26. Resonant response behavior observed at Monoliths 14 and 21 
(fundamental and secondary response shapes, middle and bottom plots, respectively).

The measured response shapes appear consistent with the cantilever response behavior expected for the two monoliths considered. The fundamental response shapes for both monoliths correspond to the frequency $4.65 \mathrm{~Hz}$. The second response shape for Monolith 21 is identified at a frequency of $10.94 \mathrm{~Hz}$. It is recognized, however, that the shaker force levels may not have been sufficiently large enough to excite independent motion in each monolith. That is to say, the interactions between monoliths may obscure behavior that may otherwise have been present had each monolith been excited individually. Notwithstanding, the response shape information along with the amplification behavior (described below) provides a basis for evaluating numerical model response behavior under sinusoidal loading.

\section{Amplification response behavior}

Amplification frequency response was computed as the ratio between crest elevation and grouting gallery elevation response measurements in Monoliths 13, 14, and 15, as shown in Figure 27. Responses were obtained with the shaker mounted inside the dam at the pipeline gallery of Monolith 14.

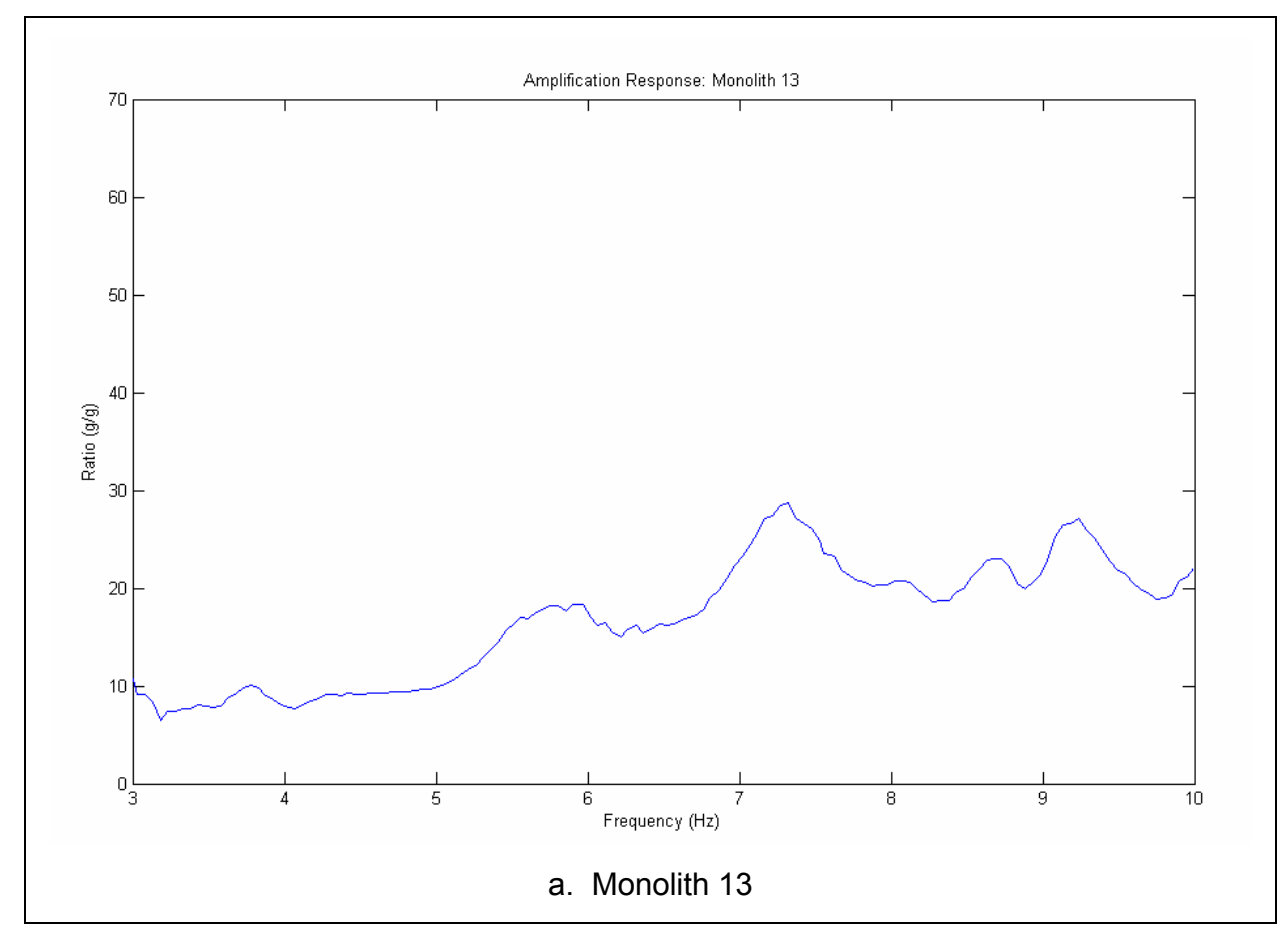

Figure 27. Observed amplification response behavior (Continued) 


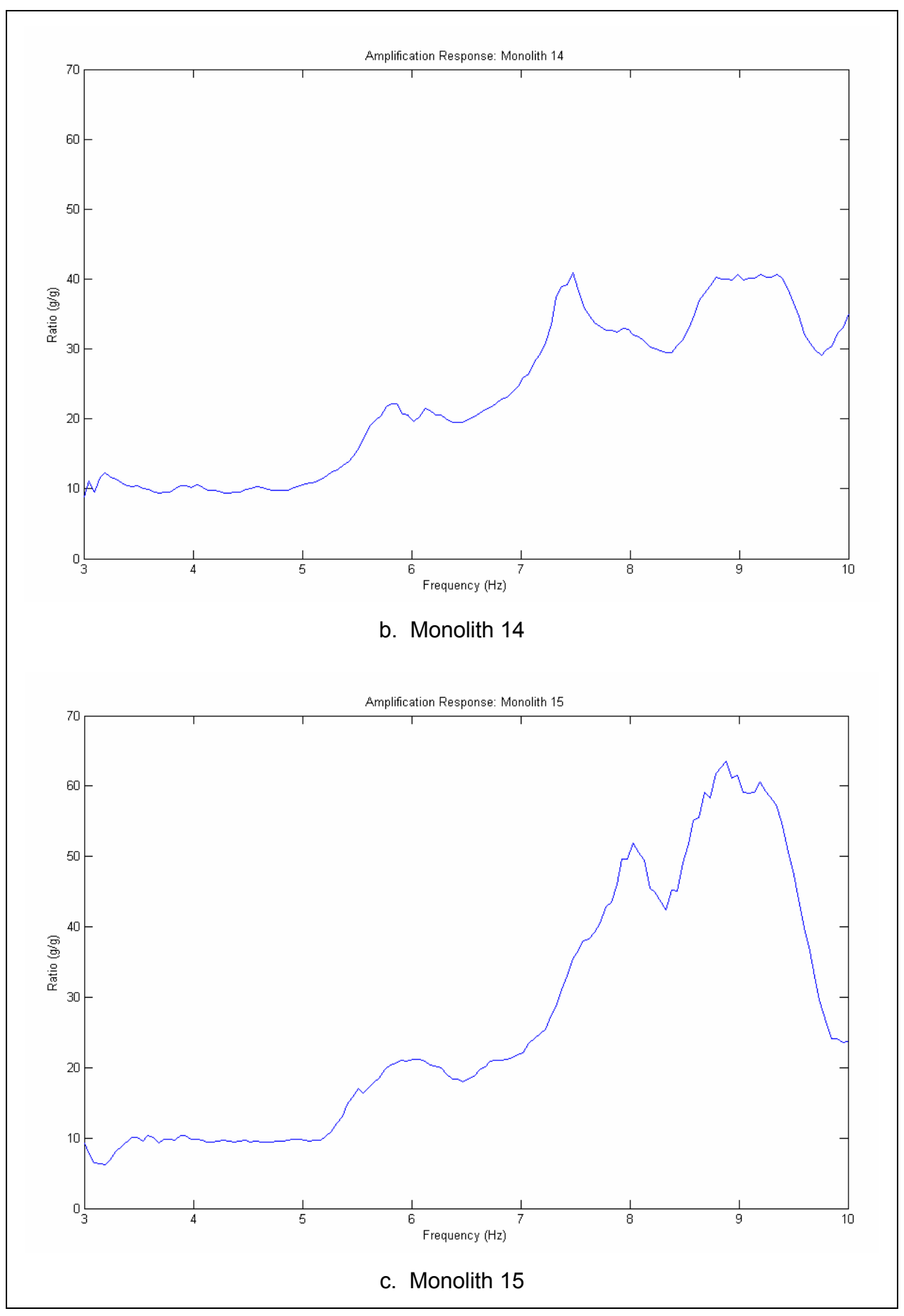

Figure 27. (Concluded)

The responses indicate that amplification levels below $5 \mathrm{~Hz}$ are on the order of 10, but appear to increase dramatically beyond $5 \mathrm{~Hz}$ (particularly in Monolith 15). The increased amplification above $5 \mathrm{~Hz}$ is perhaps better understood after examination of the responses at the crest and grouting gallery in Monolith 15, as shown in Figure 28. 


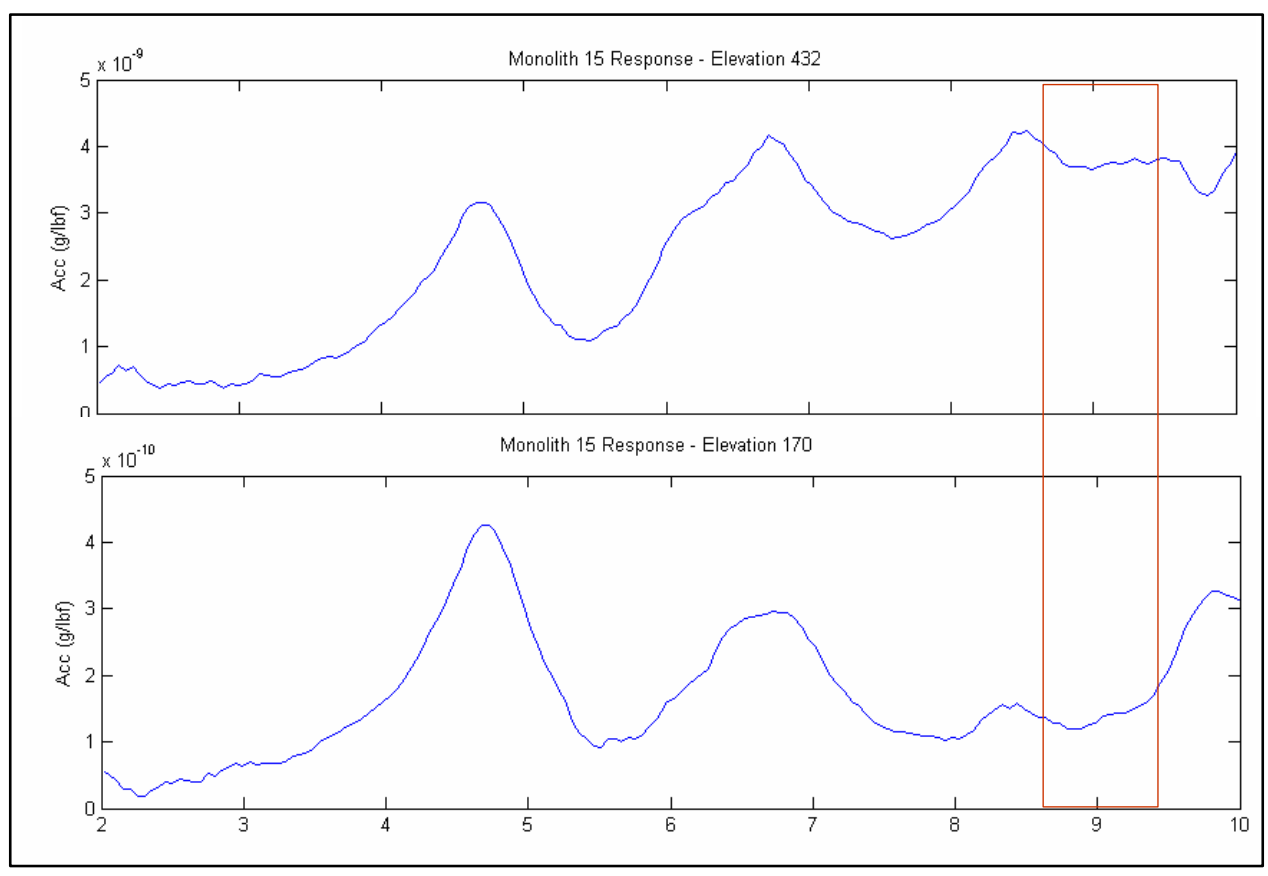

Figure 28. Measured crest (top) and grouting gallery (bottom) acceleration responses used to determine amplification behavior in Monolith 15

The responses indicated in Figure 28 are typical of the quality obtained during the forced vibration tests at Folsom Dam, characterized by measurable peak response levels as well as levels otherwise associated with "noise floor" or the absence of resonant activity. In the frequency range below $5.5 \mathrm{~Hz}$, the ratio of the two responses indicates an order of magnitude difference between the crest and grouting gallery measurements. Amplification is observed to increase above $6 \mathrm{~Hz}$ by approximately a factor of 2 . However, above $7 \mathrm{~Hz}$, amplification levels increase rapidly toward $9 \mathrm{~Hz}$ as evidenced by the large amplification peak value in excess of 60 shown in Figure 27(c). This amplification peak corresponds to the ratio of the measured responses in Figure 28 highlighted by the boxed region. In this frequency range, the response on the crest does not exhibit significantly larger response levels as compared with the levels outside this frequency range. However, in the same frequency range, the grouting gallery response levels are lower compared with levels outside the boxed area.

The significant amplification levels suggested above $5 \mathrm{~Hz}$ in Figure 27 could occur, in part, because of the reduced response in the grouting gallery, and they do not necessarily reflect a dynamic characteristic of the system. The trends indicated in the amplification curves, however, suggest that amplification levels greater than 10 could be expected in each monolith for excitation frequencies above $5 \mathrm{~Hz}$. 


\section{Observed relative joint motion behavior}

Relative joint motion between adjacent monoliths was measured by placing accelerometers on either side of a joint, and a typical installation between Monoliths 10 and 11 is shown in Figure 29. Joint motion measurements were acquired on the crest (with the shaker on the crest) and inside the pipeline gallery (with the shaker inside the dam).

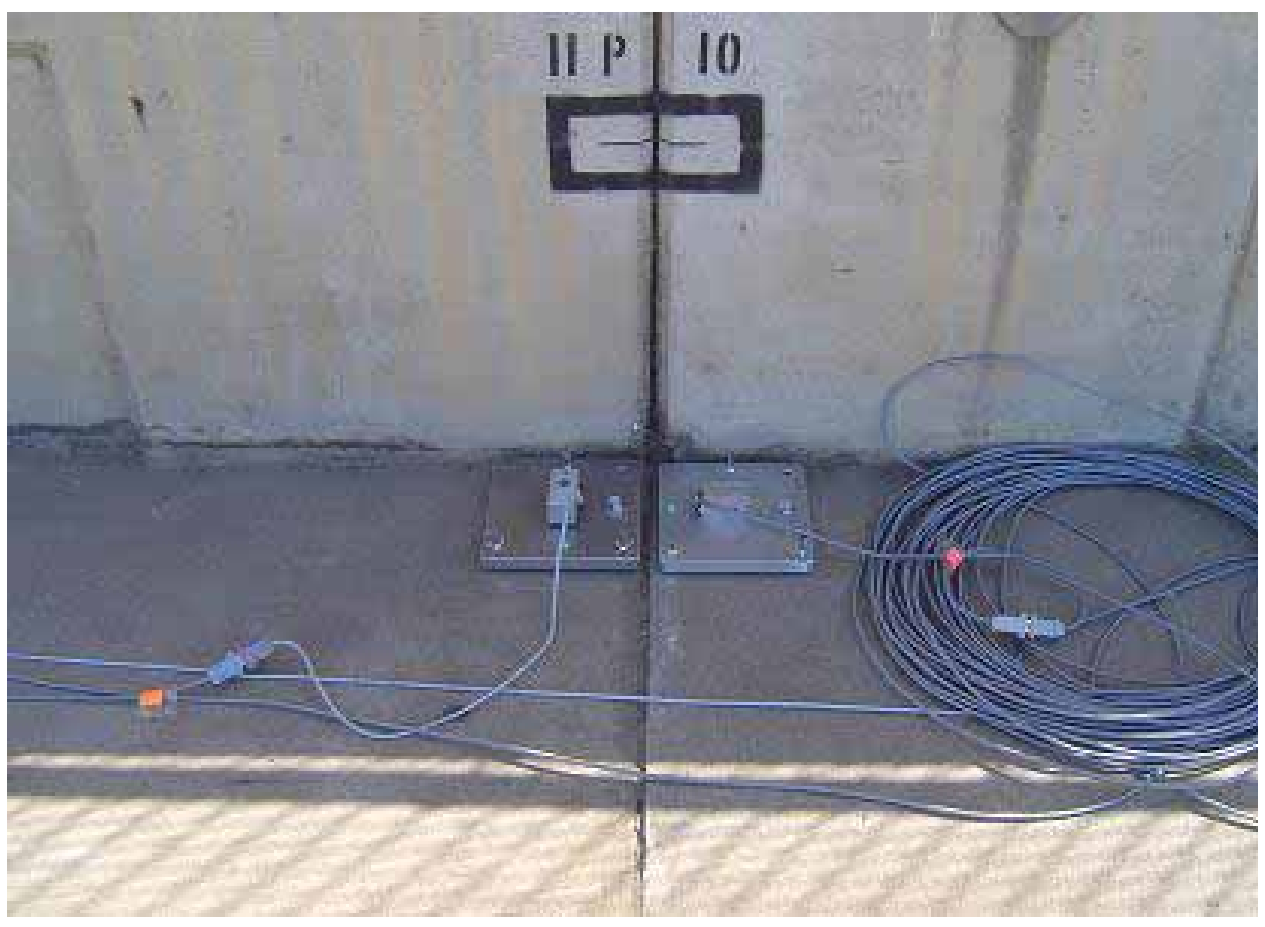

Figure 29. Relative joint motion measurement layout

Relative joint motion, defined by the ratio between adjacent measurements, can be obtained only after calibrating measured responses using appropriate accelerometer sensitivities and careful removal of imposed signal-conditioning characteristics. A unity response magnitude and zero relative phase are indicative of no relative motion across the joint, where relative motion (slippage or sliding) results in a non-unity response magnitude and varying phase. The responses shown in Figure 30 illustrate measured relative joint motion behavior on the crest and inside the dam in the pipeline gallery.

The joint measurement between Monoliths 10 and 11, shown in Figure 30a, was acquired with the shaker mounted on the crest at Monolith 11. The large mass set was used to excite between 2 and $13 \mathrm{~Hz}$, and the small mass set was used to excite between 13 and $20 \mathrm{~Hz}$. The intent was to achieve near-maximum force levels in an effort to induce measurable relative joint motion. The nearunity response magnitude indicates that negligible relative motion exists below $10 \mathrm{~Hz}$; however, some relative motion is present above $10 \mathrm{~Hz}$ and seems to increase in magnitude above $15 \mathrm{~Hz}$. It is possible that the shaker force levels between 2 and $10 \mathrm{~Hz}$ were insufficient to overcome joint friction between Monoliths 10 and 11, but levels were sufficient to induce some relative motion 


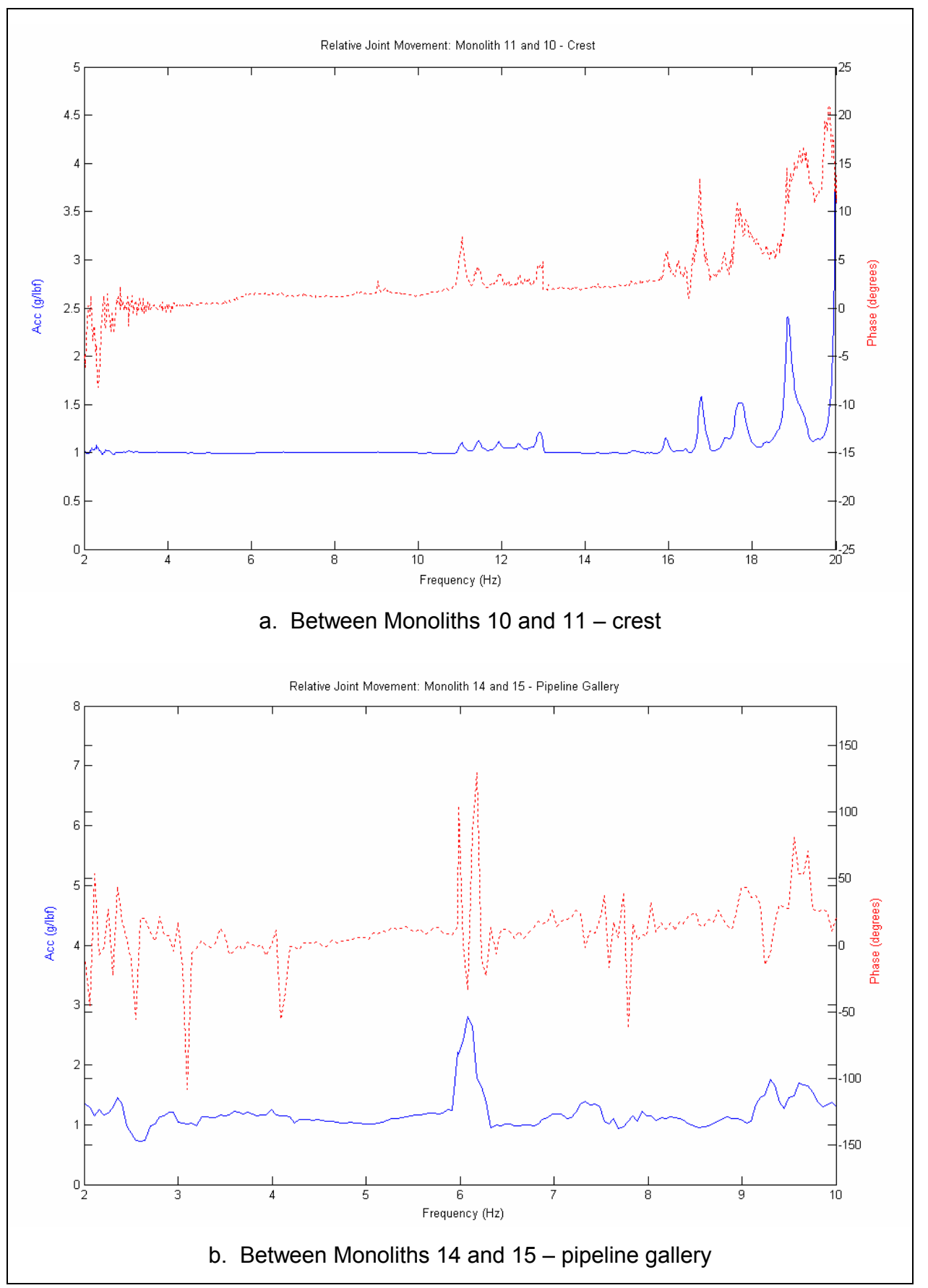

Figure 30. Relative joint movement

above $10 \mathrm{~Hz}$ (see shaker force levels in Figure 10). The phase response behavior at the joint indicates relatively in-phase motion below $16 \mathrm{~Hz}$, but does show an increasing trend toward $20 \mathrm{deg}$ at $20 \mathrm{~Hz}$.

The joint measurement between Monoliths 14 and 15, shown in Figure 30b, was acquired with the shaker mounted in the pipeline gallery of Monolith 14 . While the relative joint motion levels remain near unity (except near $6 \mathrm{~Hz}$ ), an 
increasing trend in phase response is observed, which may suggest that some relative motion is present.

Interpreting the relative joint motion measurements at Folsom Dam is aided to some extent by relative joint motion measurements acquired on Seven Mile Dam and reported by Duron (1994). Seven Mile Dam is comparable in size and construction to Folsom Dam, and all of the joints in the dam were monitored at an elevation just below the crest during a series of ambient tests conducted in February (winter) and August (summer) of the same year. Joint measurements taken in the winter clearly demonstrated relative motion when compared with the same measurements taken during the summer. The relevance to the joint measurements at Folsom Dam is in regard to the effectiveness of the test procedure employed. As such, the indications of relative motion present in the measurements at Folsom Dam should be given consideration in subsequent numerical studies, even if characteristics such as the relative response near $6 \mathrm{~Hz}$ between Monoliths 14 and 15 are not readily explained.

\section{Influence of Foundation Flexibility on Monolith Response}

An attempt was made to assess the effect of foundation flexibility on monolith response behavior by monitoring vertical acceleration response at the heel and toe in Monolith 14 with the shaker installed in the pipeline gallery of Monolith 14. These responses were used to compute frequency response functions to evaluate foundation flexibility in the context of relative vertical motion along the monolith-foundation interface. The measurements were also used to estimate the percentage of radial crest motion at Monolith 14 that may be attributed to foundation flexibility effects.

Figure 31 shows the heel and toe responses at the base of Monolith 14 acquired during the forced vibration tests. The relative phase difference in the response at these locations is shown in Figure 32. The near 180-deg difference in phase at $4.65 \mathrm{~Hz}$ signifies a rotational-like behavior due to foundation flexibility at the base of the monolith.

The influence of foundation flexibility on overall monolith response can be quantified by calculating the expected radial acceleration response at the crest due to rotation and comparing it with the radial measurement at the crest during the same test. Figure 33 gives an exaggerated representation of the anticipated response at $4.65 \mathrm{~Hz}$ of Monolith 14 due to rotation alone and identifies the vertical accelerations and the corresponding radial contribution at the crest. The estimated contribution to the measured or total crest response that can be attributed to rotation is 19 percent. This calculation was repeated using ambient measurements acquired in Monolith 12 during the previous ambient survey at Folsom Dam and produced a contribution of 14 percent. Contributions to crest motion from foundation flexibility effects on the order of 14 to 19 percent suggest that foundation flexibility should be included in the model of Folsom Dam. 


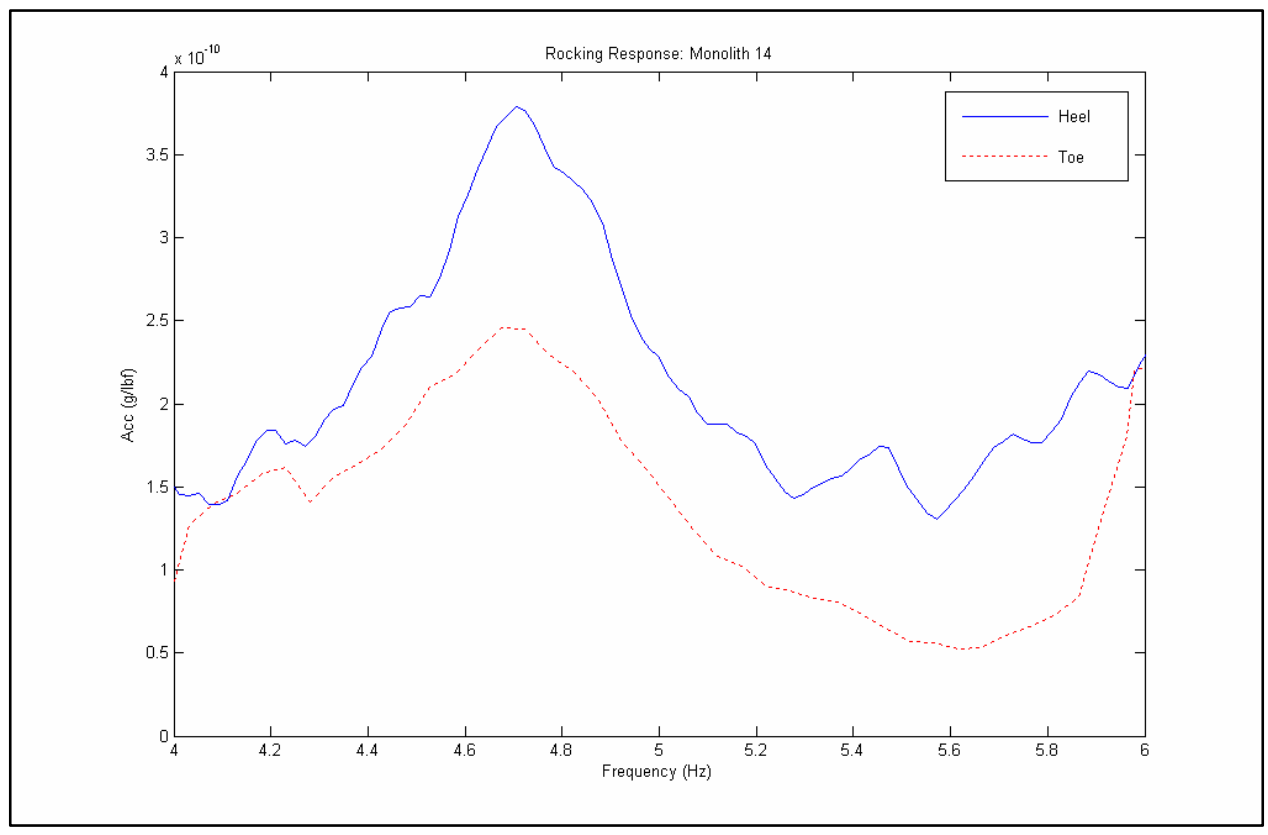

Figure 31. Vertical motion at base of Monolith 14

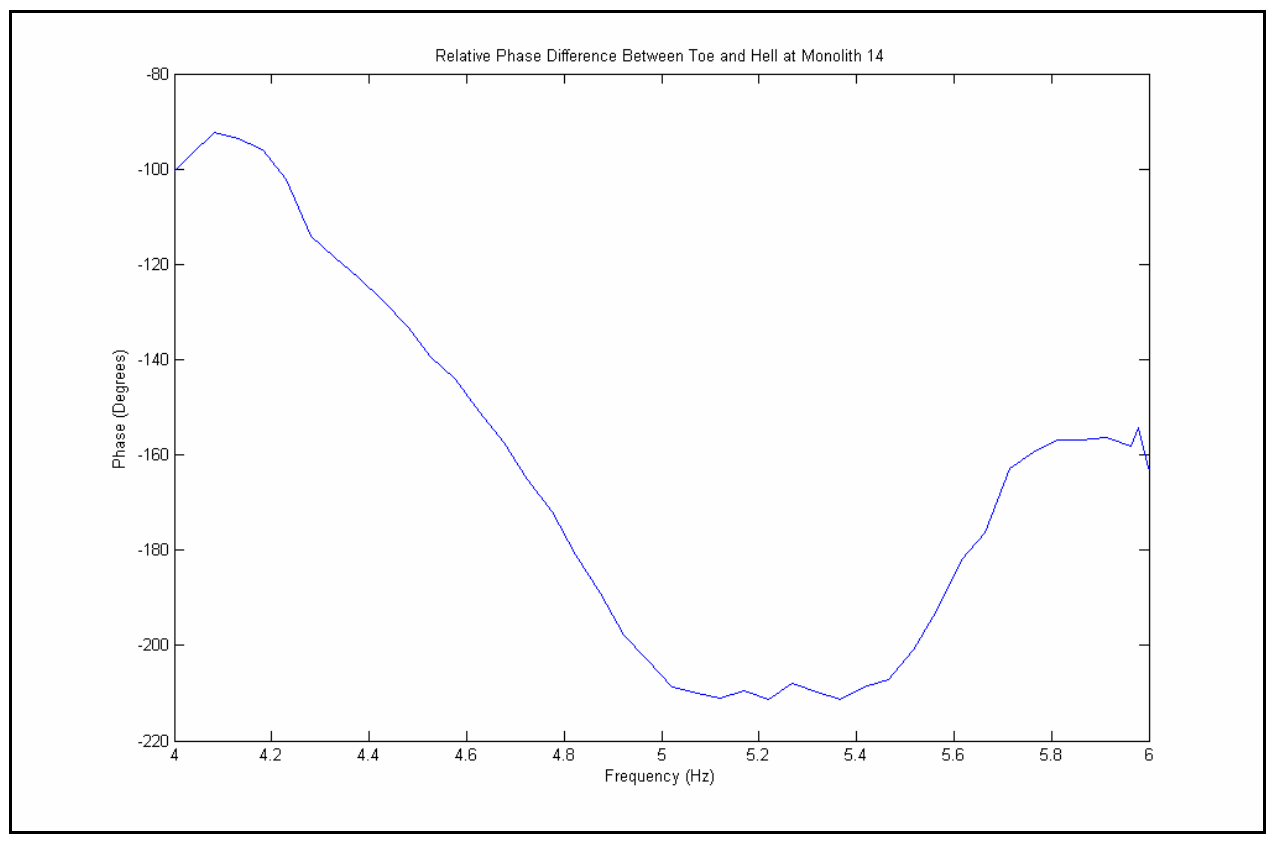

Figure 32. Relative phase of vertical motion in Monolith 14 


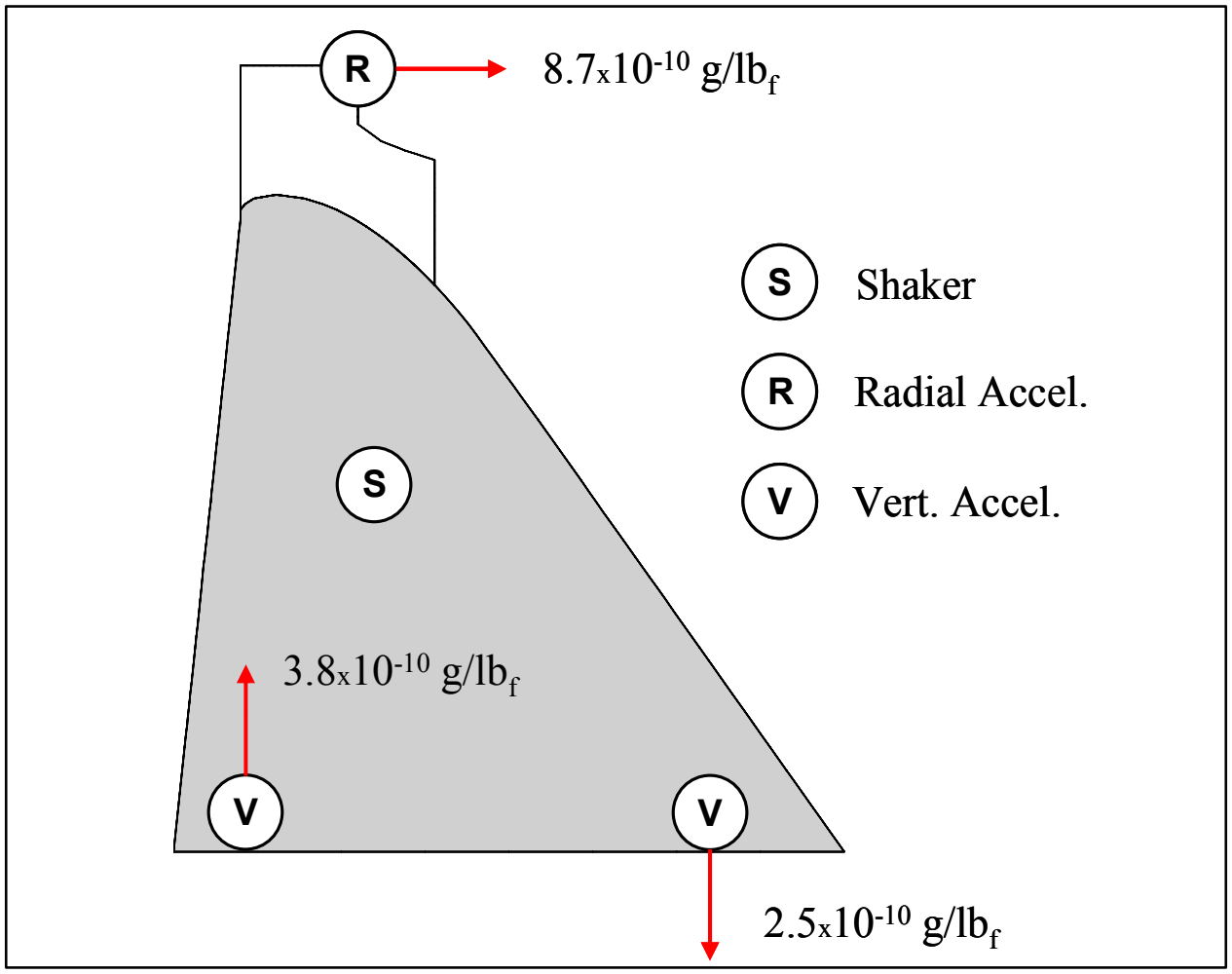

Figure 33. Contribution to measured radial crest response at Monolith 14 due to foundation flexibility effects

\section{Embankment Response Behavior}

Acceleration responses were acquired on the left embankment at crest elevation and near the stilling basin to assess embankment response behavior. Measurement layout is shown in Figure 34.

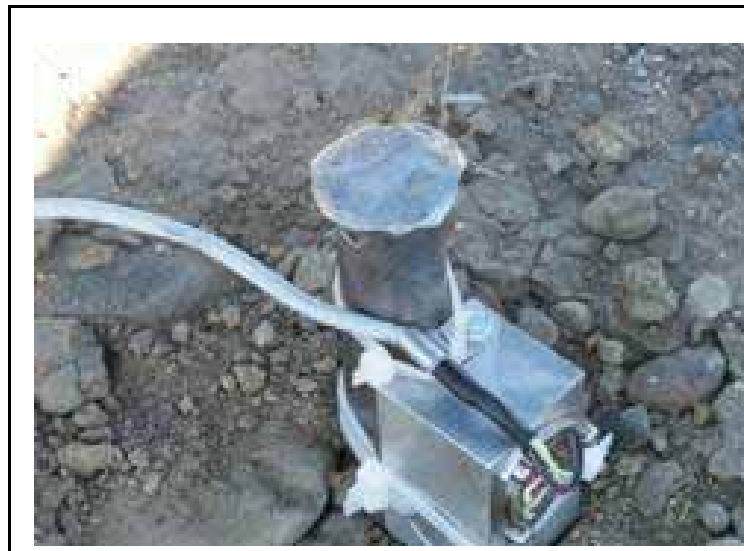

a. Measurement setup

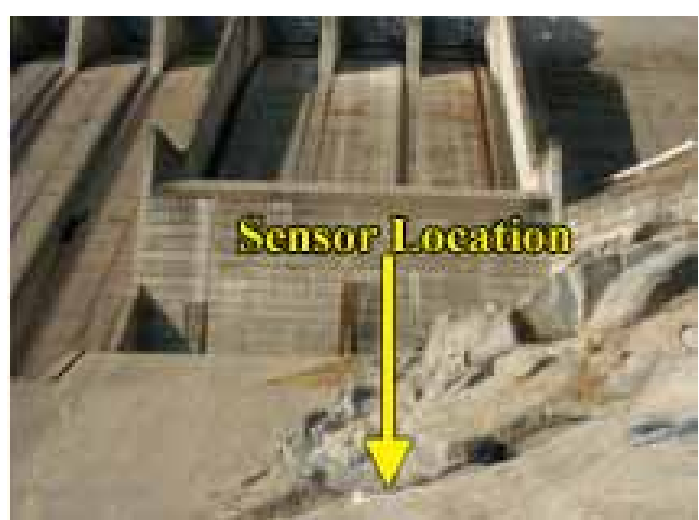

b. Sensor location

Figure 34. Embankment response measurement layout 
The response on the top of the embankment was taken at $20.5 \mathrm{ft}$ from the edge of Monolith 28 by driving a 1-in.-diam steel rod $3 \mathrm{ft}$ into the embankment and attaching an accelerometer to the rod just above the surface. The response on the stilling basin is indicated in the figure and was located approximately $200 \mathrm{ft}$ from the visible base of Monolith 19. Acceleration responses acquired, and the resulting amplification between the measurements, are shown in Figure 35.

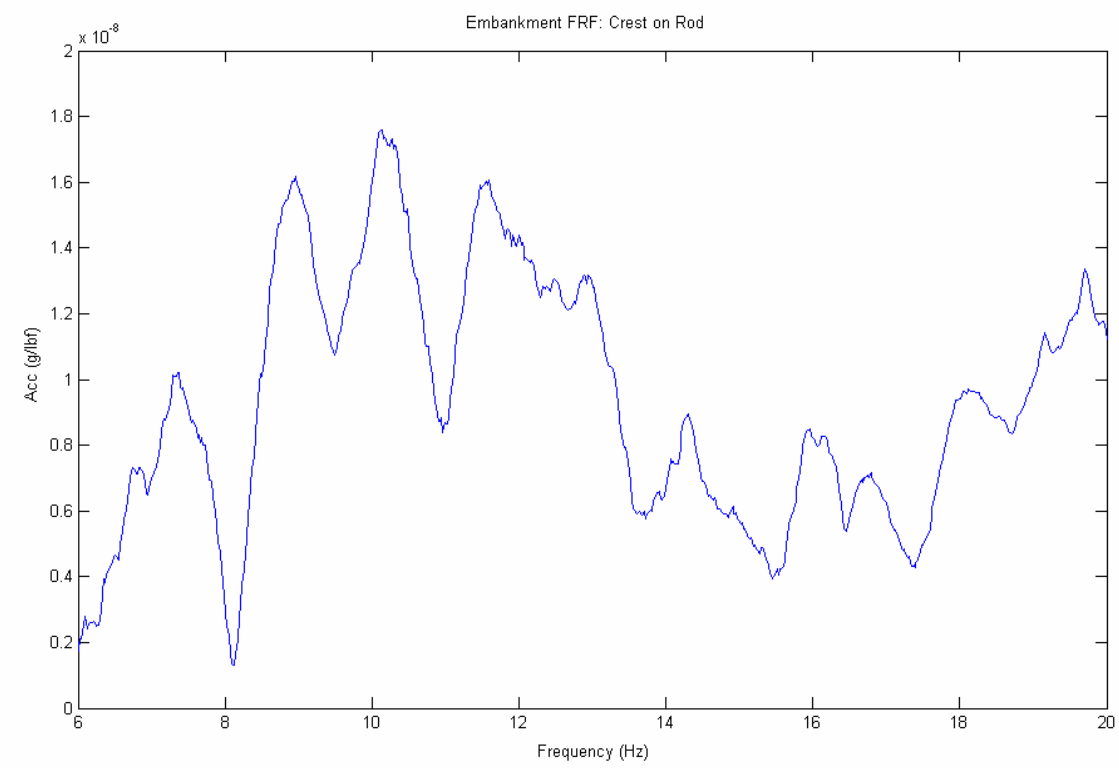

a. Acceleration response at crest elevation

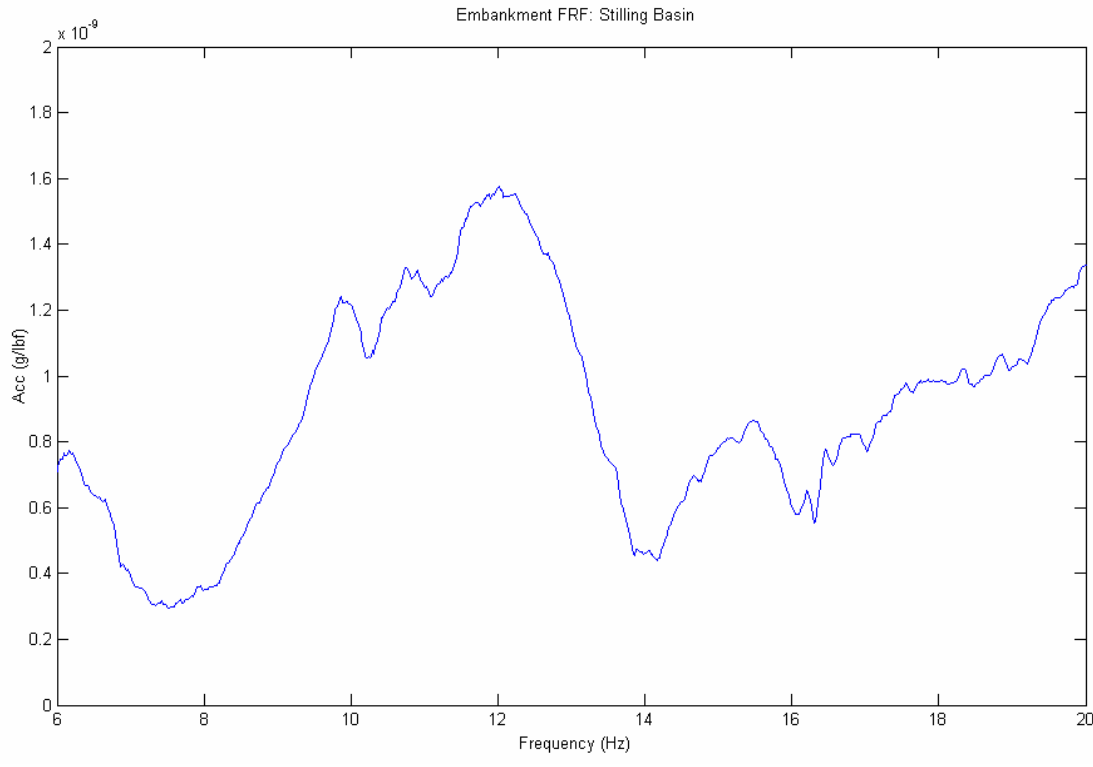

b. Acceleration response near stilling basin

Figure 35. Left embankment responses (Continued) 


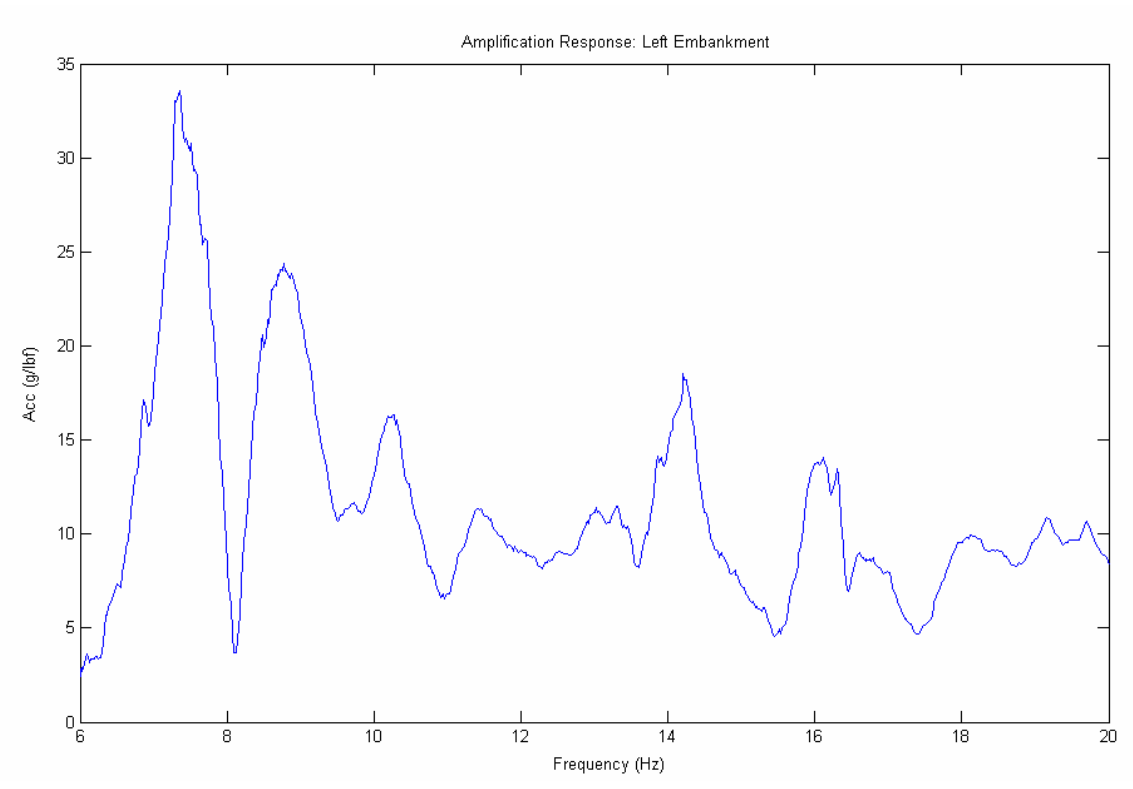

c. Amplification response function

Figure 35. (Concluded)

\section{Dam-Reservoir Interaction Effects}

Hydrodynamic pressure and companion acceleration responses obtained at Folsom Dam during the forced vibration tests can be analyzed in an attempt to extract fundamental reservoir characteristics. Specifically, reservoir characteristics in the form of extracted frequency response functions that indicate reservoir resonant behavior may be obtained. These characteristics can be used to evaluate dam-reservoir interaction effects and the possible influence of water compressibility on dam response. Further, the reservoir response curves can provide a means for determining suitable reservoir boundary absorption parameters that may be necessary for the seismic evaluation of Folsom Dam. The measurement layouts shown in Figures 4-8 were used to obtain responses in the reservoir and in the dam behind Monoliths 14 and 21, which were analyzed as described below.

\section{Determination of reservoir frequency response characteristics}

Reservoir frequency response characteristics are estimated using measurements of hydrodynamic pressure in the reservoir along the upstream dam face and acceleration in the dam. The measurement layout in Figure 4 shows the placement of the hydrophone array behind Monolith 14, and acceleration responses corresponding to or near each hydrophone elevation were used to obtain estimates of reservoir characteristics. A sample of measured hydrodynamic pressure behind Monolith 14 at a depth of $244 \mathrm{ft}$ below the water surface, believed to be at or near the reservoir bottom, is shown in Figure 36. 


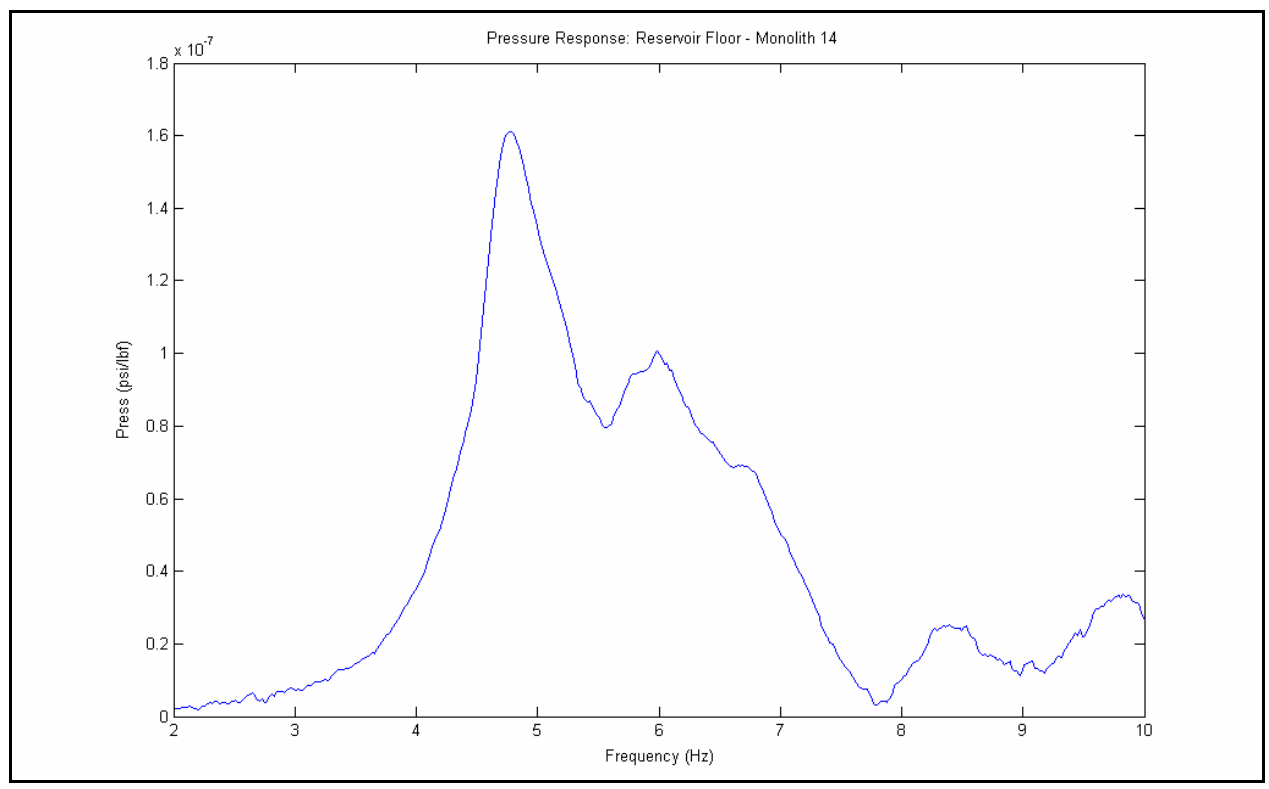

Figure 36. Measured hydrodynamic pressure behind Monolith 14 at $244 \mathrm{ft}$ below the water surface

The response indicates peak behavior at or near the resonant peak identified in the dam response measurements. Although not shown here, hydrodynamic pressure phase response was also obtained. The first and second pressure profiles were identified as shown in Figure 37. The pressure profiles associated with the fundamental resonant peak near $4.65 \mathrm{~Hz}$ and a second resonant peak identified near $6 \mathrm{~Hz}$ are consistent with pressure response information obtained for similarly sized dam-reservoir geometries.

A theoretically valid procedure to isolate the response of a resonating water mode is to extract the modal amplitude from the water pressure response and to normalize it by the amplitude of the component of the dam acceleration that delivers a pure excitation to the water mode. To do this, knowledge of the shape of the water mode and the distribution of pressure and acceleration everywhere on the dam face is required. While these criteria are not fully met at Folsom Dam, experience has shown that, for most dam-reservoir geometries, the distribution of pressure and acceleration behind tall monoliths can be representative of the distribution over the entire dam face. by

The frequency response function describing the reservoir behavior is defined

$$
R(j \omega)=\frac{\int_{0}^{H_{w}} P(y, \omega) \Phi(y) d y}{\int_{0}^{H_{w}} A(j \omega) \Phi(y) d y}
$$




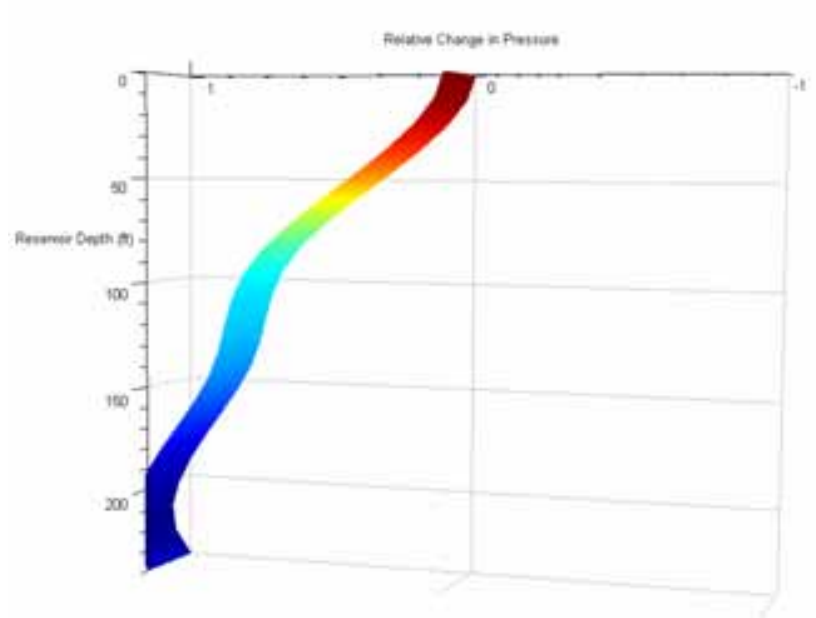

a. Fundamental hydrodynamic pressure resonance $(4.65 \mathrm{~Hz})$

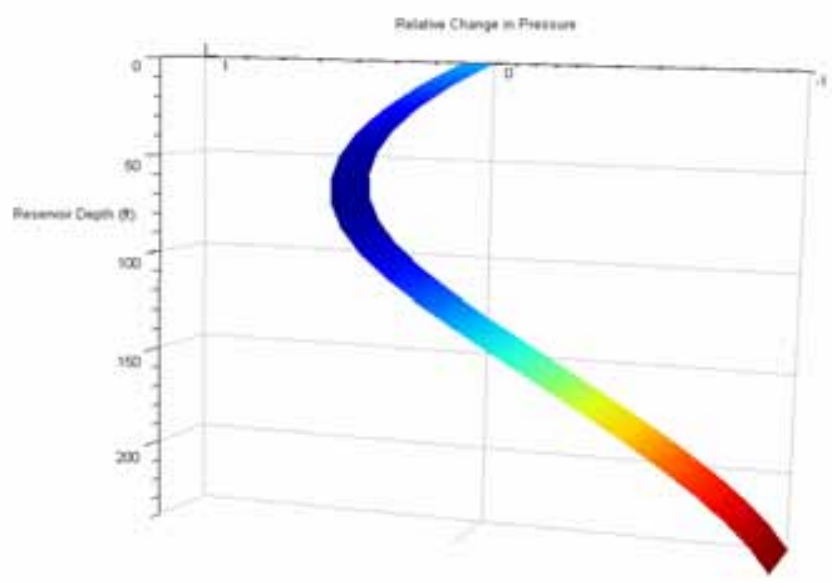

b. Second hydrodynamic pressure resonance $(6.00 \mathrm{~Hz})$

Figure 37. Hydrodynamic pressure profiles behind Monolith 14

where $P(j \omega)$ and $A(j \omega)$ denote the hydrodynamic pressure and acceleration (component normal to the upstream face) distribution along the height of a particular monolith, respectively, and $\Phi(y)$ is the shape function that corresponds to the fundamental pressure profile. For most applications, a suitable form for the assumed fundamental pressure profile is given as

$$
\Phi(y)=\cos \left(\frac{\pi y}{2 H_{w}}\right)
$$

where $y$ is the vertical distance from the reservoir bottom to the measurement location, and $H_{w}$ is the water depth. The assumed profile is not unreasonable considering the observed shape shown in Figure 37. 
The reservoir frequency response function shown in Figure 38 was obtained using the formulation described above and the measurements obtained along Monolith 14 with the shaker mounted inside the dam in the pipeline gallery in Monolith 14. The reservoir response shows a dominant resonance at $5.23 \mathrm{~Hz}$. This fundamental reservoir resonance interacts with the fundamental resonance of the dam-foundation subsystem, producing the observed coupled damfoundation-reservoir system resonance at $4.65 \mathrm{~Hz}$.

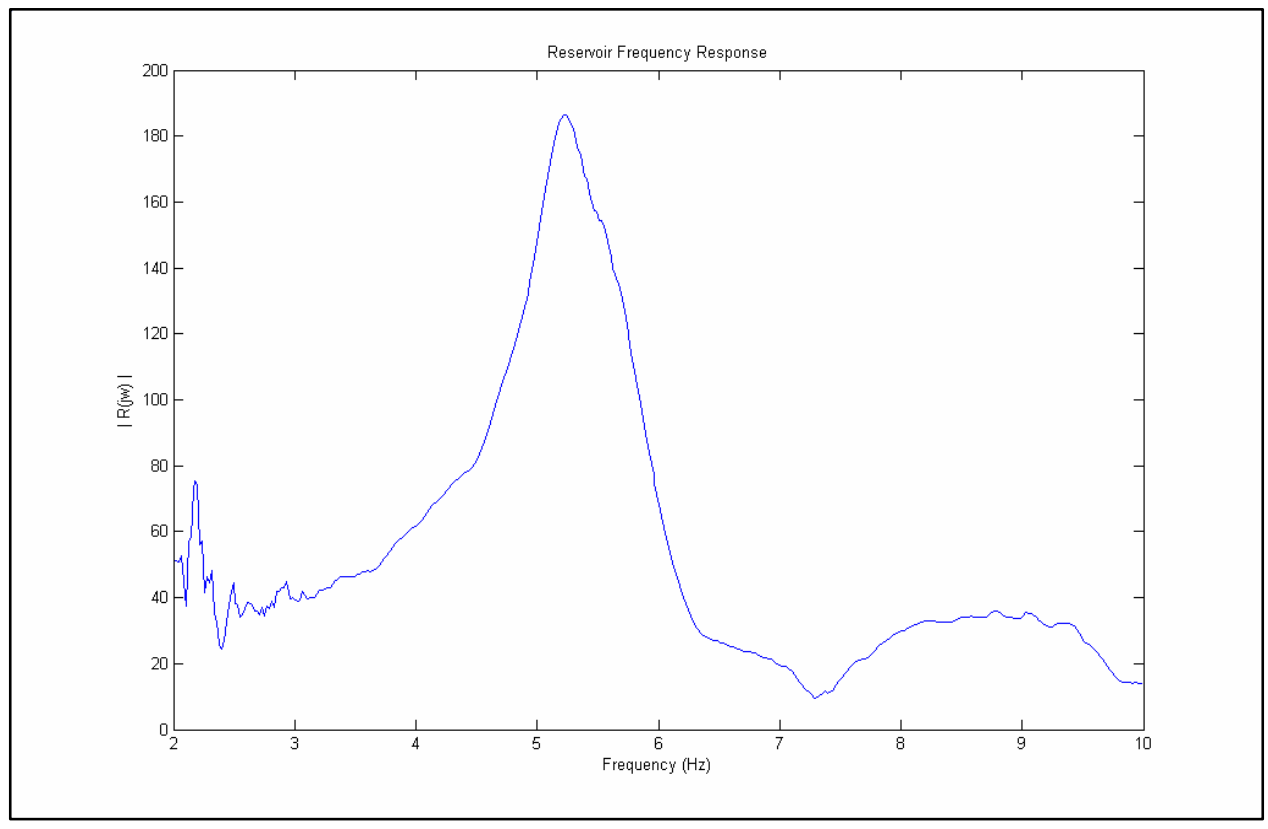

Figure 38. Reservoir frequency response at Folsom Dam

A criterion exists that can be used to estimate the influence or importance of water compressibility effects on overall dam response. The criterion compares the fundamental resonance of the reservoir to the fundamental resonance of the dam-foundation subsystem and states that if the ratio between the fundamental frequency of the reservoir, $f_{\text {reservoir }}$, and the fundamental frequency of the dam under empty reservoir conditions, $f_{\text {dam }}$, is less than 1.1 , it is likely that the dynamic response will be influenced by water compressibility effects. At Folsom Dam, the reservoir response function indicates a fundamental resonance at $5.23 \mathrm{~Hz}$, and the fundamental resonance of the dam-foundation subsystem can be estimated to be in the range 5.4 to $6.0 \mathrm{~Hz}$ (based on preliminary results from numerical models). According to the stated criterion, the value of the ratio $f_{\text {reservoir }} / f_{\text {dam }}$ may be within 0.87 and 0.95 for this case, thus suggesting that the system response is influenced by compressibility effects.

\section{Effective water depth}

The shape of the response curve (when examined in terms of real and imaginary components not shown here) can be used to indicate reservoir geometry 
adjacent to the dam. The type of reservoir geometry shown in Figure 39 is associated with the type of reservoir response function measured at Folsom Dam.

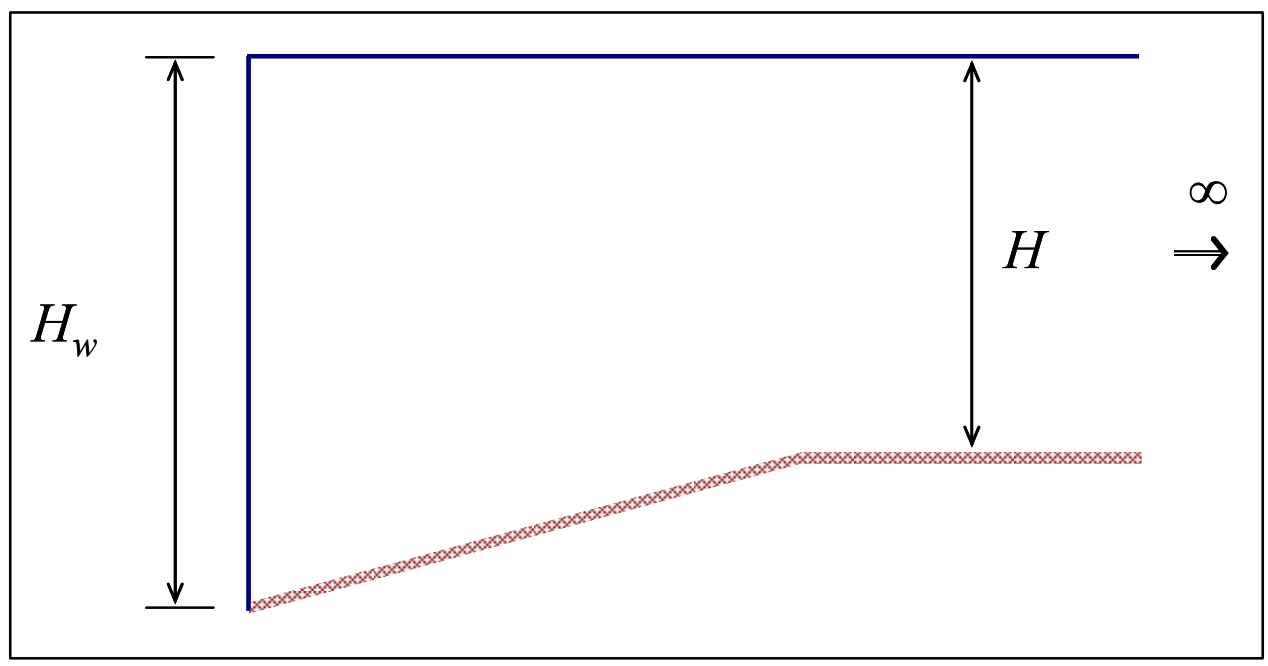

Figure 39. Simplified reservoir geometry

The reservoir geometry has a sloped floor near the dam upstream face, and the water height at the dam, $H_{w}$, is greater than the actual water depth away from the dam. An "effective" value of water depth $H_{w}$ can be derived from the exact expression for the fundamental natural frequency for a reservoir of constant depth as follows:

$$
H_{\text {eff }}=\frac{C_{w}}{4 f_{\text {reservoir }}}
$$

where $C_{w}$ is the speed of sound wave propagation in water $(4,720 \mathrm{ft} / \mathrm{sec})$. For the reservoir fundamental frequency estimated at $f_{\text {reservoir }}=5.23 \mathrm{~Hz}$, an effective water depth $H_{\text {eff }}=226 \mathrm{ft}$ is obtained. While this figure compares favorably (less than $20 \mathrm{ft}$ shallower) with the elevations shown in Figures 4-8, reservoir bottom profiling conducted onsite may provide a more accurate depth for comparison and modeling purposes. 


\section{Numerical Correlation Studies}

\section{Analysis Considerations}

Considering the combined ambient and forced vibration results reported in the previous sections of this report, a series of numerical models are developed to explore their advantages and limitations as suitable tools for predicting the dynamic performance of Folsom Dam. The development of reliable numerical models must follow a carefully planned progression, starting with linear models that provide a convenient baseline for analysis. The data provided by the ambient and forced vibration tests reported in previous sections should be considered representative of the dynamic response of the dam-foundation-reservoir system subjected to small vibration levels. Therefore, the results from appropriate linear models could be directly compared with the observed data. It is important to note, however, that these excitation levels may not have been sufficient to reveal some significant dynamic effects and interaction phenomena that can be induced only by severe earthquake motions.

\section{Modeling issues}

Accurate evaluation of the seismic performance of concrete dams requires the development of numerical procedures that account effectively for the most critical factors controlling the response. The seismic response characteristics of the system constituted by the dam, the reservoir, and the foundation may be affected by various factors, such as geometry, spatial variability, intensity and frequency content of the seismic input, constitutive behavior of concrete and foundation materials, behavior of lift and contraction joints, and dynamic interaction phenomena between the different subdomains.

Severe earthquake motions could lead to nonlinear behavior in the damfoundation-reservoir system. For example, dynamic stresses caused by strong earthquakes may create areas of localized damage, mostly associated with the low tensile strength of mass concrete and lift joints. Other nonlinear effects could be associated with the behavior of contraction joints between monoliths, which may move relative to each other during the seismic event, thus inducing the cyclic opening, closing, and sliding motion of the joint. Therefore, the characteristics of the system when exposed to strong ground motions are such that the actual response could differ from that obtained under the assumption of linear 
behavior. Under these conditions, the actual postcracking behavior and the ultimate capacity of the dam could be determined only by performing nonlinear dynamic analyses. Some efficient numerical procedures have been successfully developed to model nonlinear material response and other phenomena such as frictional interaction along sliding surfaces. However, most of the nonlinear numerical models currently available are associated with difficulties related to the reliable determination of their input parameters, and they should be used with extreme engineering judgment (Hall and Matheu 1999).

The development of numerical models should be performed in phases in order of increasing complexity, and data provided by the ambient and forced vibration tests at Folsom Dam provide a suitable basis for model development. The modeling efforts described herein are based on assuming linear (low-level) response behavior. Linear models provide the analyst with valuable insight and information, and they should be considered a necessary step in the analysis progression as recommended in Engineer Regulation 1110-2-1806 (HQUSACE 1995a). In spite of being limited to those cases in which the behavior of the material is essentially linear, linear dynamic analyses represent a very useful tool that can provide significant information regarding the main response characteristics of the system (Yamaguchi et al. 2004).

The development of any dam-foundation-reservoir numerical model representative of the actual conditions at Folsom Dam should initially focus on reproducing the main dynamic characteristics observed in the field tests. Measured monolith amplification response and monolith rocking behavior can be used to calibrate the elastic properties to appropriately represent dam-foundation interaction effects induced by foundation flexibility. Appropriate models and analyses should also be considered to include the observed dam-tower interaction effects. Construction of the corresponding reservoir model may require several approaches and some sensitivity analyses to isolate the influence of water compressibility effects on the numerical predictions. The measured reservoir frequency response can provide guidance in terms of model construction and evaluation of appropriate model dam-reservoir interactions.

Any comprehensive numerical model capable of rigorously predicting the seismic performance of Folsom Dam under severe ground motions must make provisions for postcracking behavior, relative joint motion, and soil-structure interaction effects associated with the wing dams. Of course, such models should also include appropriate consideration of the additional energy-dissipating mechanisms that are engaged under severe excitations. Actual calibration of a model like this, for response levels that significantly exceed those investigated by the field tests conducted at Folsom Dam, is beyond the scope of this report.

\section{Reservoir elevation}

Determination of reservoir elevation at the time of testing is necessary to develop numerical models representative of the actual conditions. Figure 40 shows monthly average reservoir elevation data during the period January and through October 2004. 


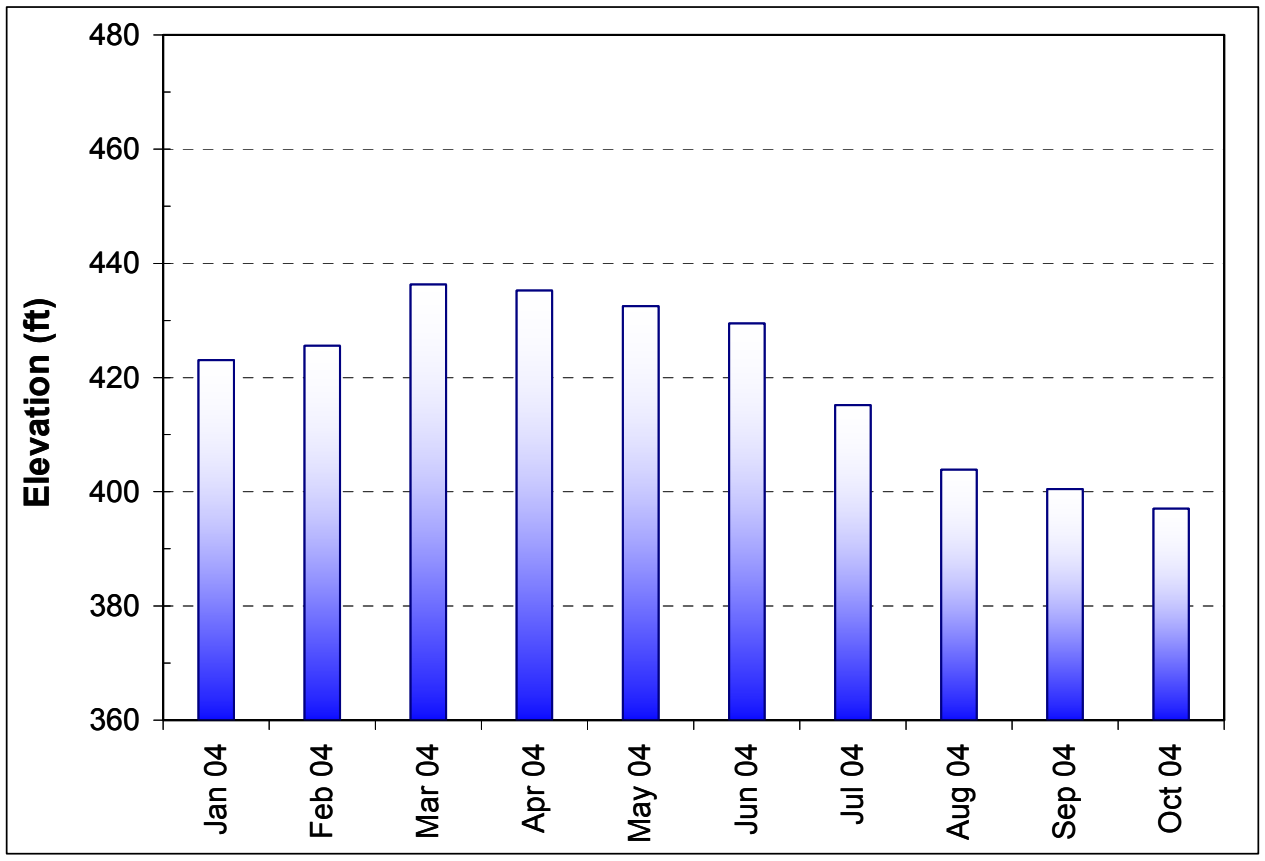

Figure 40. Average reservoir elevation

The ambient survey was conducted between March 29 and April 2, 2004, and the average reservoir elevation over that period was close to $440 \mathrm{ft}$. The forced vibration tests were conducted June 14-30, 2004, and the corresponding average reservoir elevation was about $430 \mathrm{ft}$.

\section{Two-Dimensional Modeling}

As an initial step, a series of analyses were performed to assess the predictive value of 2-D models in assessing the dynamic characteristics of relevant dam sections. These models also offered a convenient platform to evaluate the influence of foundation flexibility on monolith vibration characteristics.

\section{Model description}

The analyses in this section focus on the determination of the in-plane dynamic response characteristics of Monolith 14, which corresponds to the spillway section, and of Monolith 21, which is the tallest monolith in the left gravity section. Geometry and relevant dimensions of the monoliths are presented in Figures 41 and 42 . 


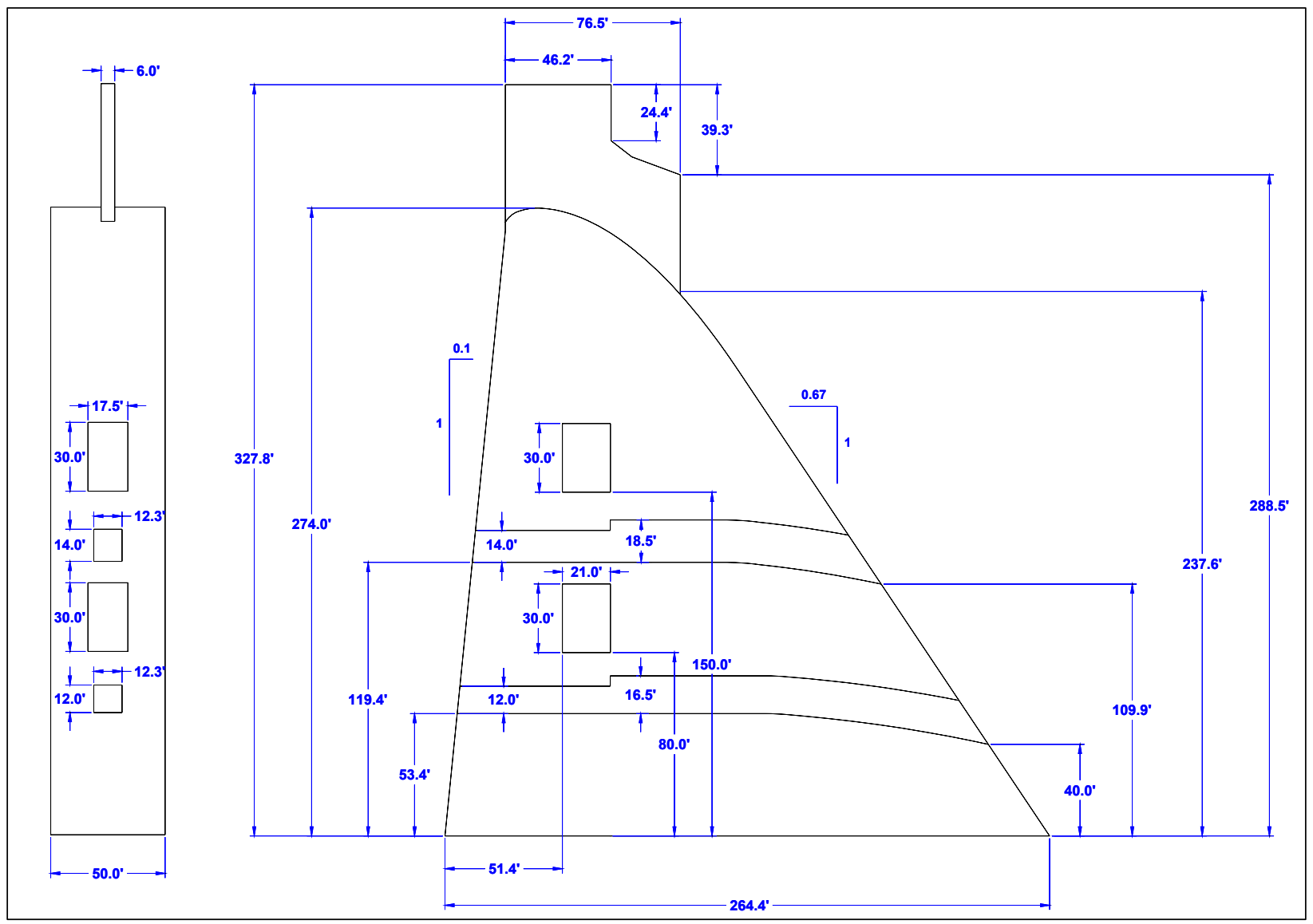

Figure 41. Geometry of overflow Monolith 14

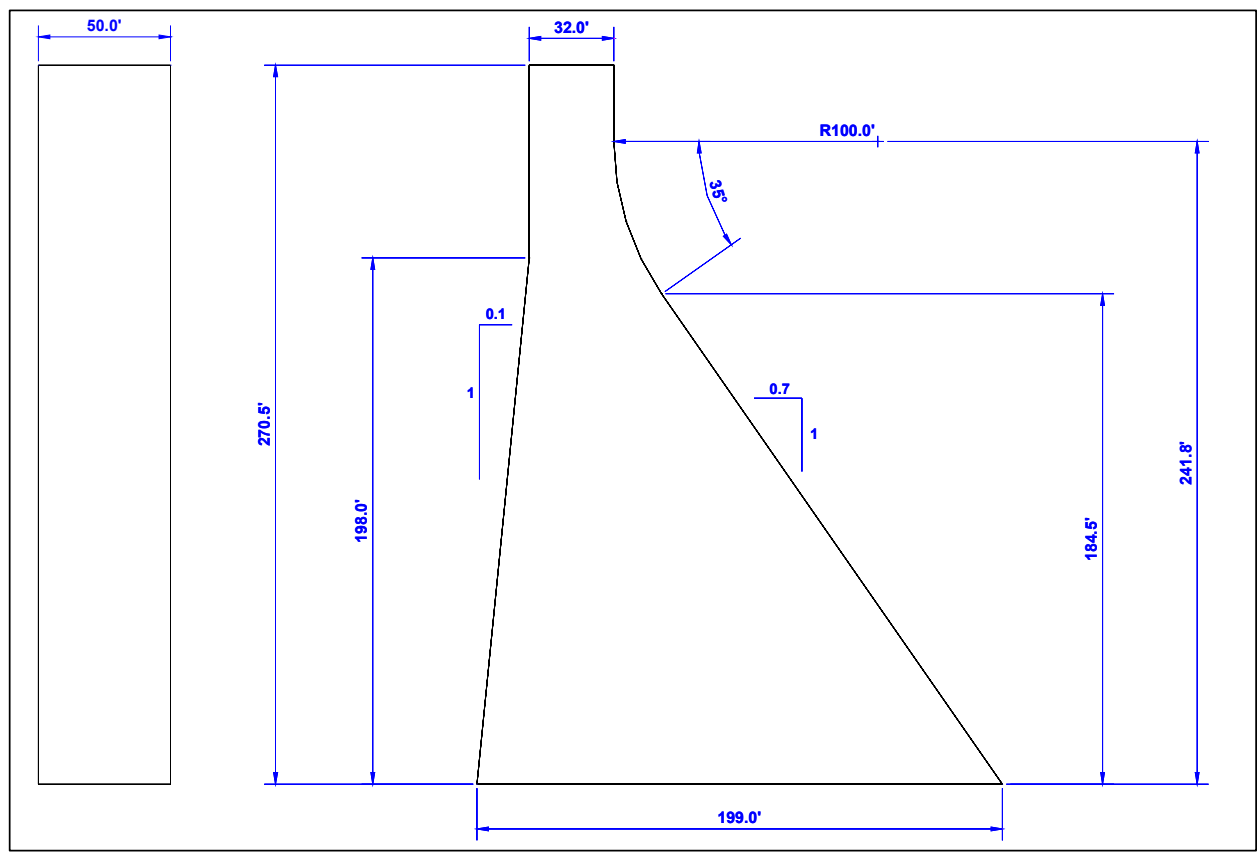

Figure 42. Geometry of nonoverflow Monolith 21 
The analyses were conducted using the program SAP2000, a commercially available finite-element computer program. The middle cross sections of these monoliths were idealized by 2-D finite-element models consisting of four-node quadrilateral elements. The mass concrete was assumed uniform, and Monolith 21 was modeled with only one material assigned to the whole section. In the case of Monolith 14, because of the spillway pier and the upper and lower chambers and conduits, it was necessary to account for the local variations in thickness of the section by appropriately modifying the corresponding material properties. Table 4 summarizes the material properties used in the concrete sections for the finite-element models of Monoliths 14 and 21.

\begin{tabular}{||l|l|l|l|l||}
\hline \multicolumn{5}{|l|}{$\begin{array}{l}\text { Table } 4 \\
\text { Material Parameters Used in Finite-Element Models }\end{array}$} \\
\hline \hline Material Property & $\begin{array}{l}\text { Mass } \\
\text { Concrete }\end{array}$ & Pier & Chambers & Conduits \\
\hline \hline Unit weight $\gamma_{c}[\mathrm{pcf}]$ & 158 & 25.3 & 102.7 & 119.1 \\
\hline Dynamic modulus of elasticity $E_{c}[\mathrm{psi}]$ & $5.910^{6}$ & $0.9410^{6}$ & $3.8410^{6}$ & $4.4510^{6}$ \\
\hline Poisson's ratio $v_{c}$ & 0.19 & 0.19 & 0.19 & 0.19 \\
\hline \hline
\end{tabular}

Figures 43 and 44 show the finite-element models for Monoliths 14 and 21, respectively. A massless foundation region was included as part of the model to capture the influence of foundation flexibility on the resulting response characteristics. Different values were considered to characterize the elastic modulus of the foundation rock, $E_{f}$, whereas a value of 0.30 was adopted for the Poisson's ratio. The reservoir water surface was assumed at an elevation of $430 \mathrm{ft}$. Hydrodynamic effects were approximated using added masses distributed along the upstream face of the monoliths. The added mass values were computed according to Westergaard's approach as recommended in Engineer Manual (EM) 1110-22200 (HQUSACE, 1995b) and EM 1110-2-6051 (HQUSACE, 2003).

\section{Dynamic characteristics}

Table 5 shows the first six natural frequencies computed for Monolith 21 corresponding to a value of $E_{f}=7.9 \times 10^{6}$ psi, i.e., $E_{c} / E_{f}=0.75$. This value for the dynamic modulus of elasticity of the foundation rock has been used in previous seismic evaluation studies performed by the Sacramento District. The table also shows the modal participating mass ratios corresponding to the horizontal and vertical directions.

The first two natural frequencies are associated with mode shapes representing the lateral bending response. The third natural frequency is associated with a mode shape that reflects significant participation of the vertical response. The first two mode shapes are shown in Figure 45. 


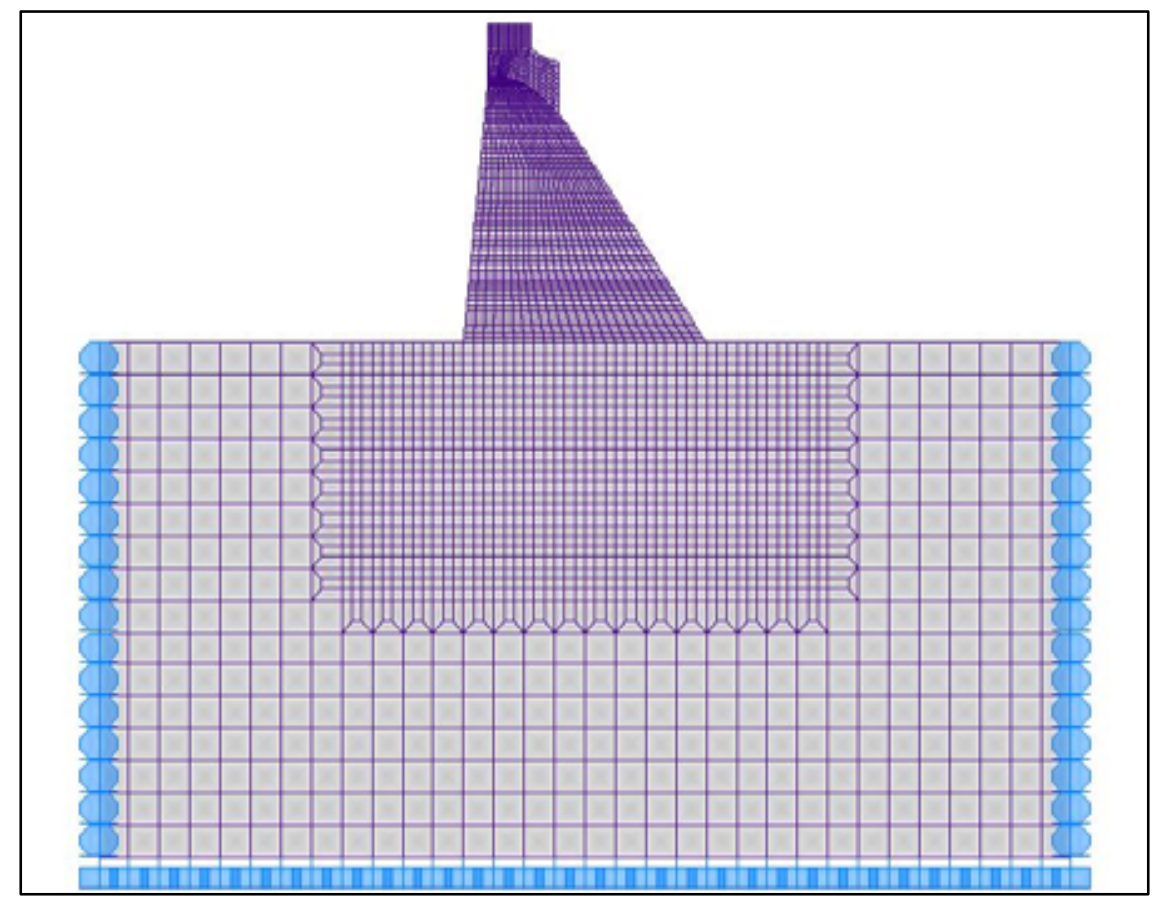

Figure 43. Finite-element model of Monolith 14

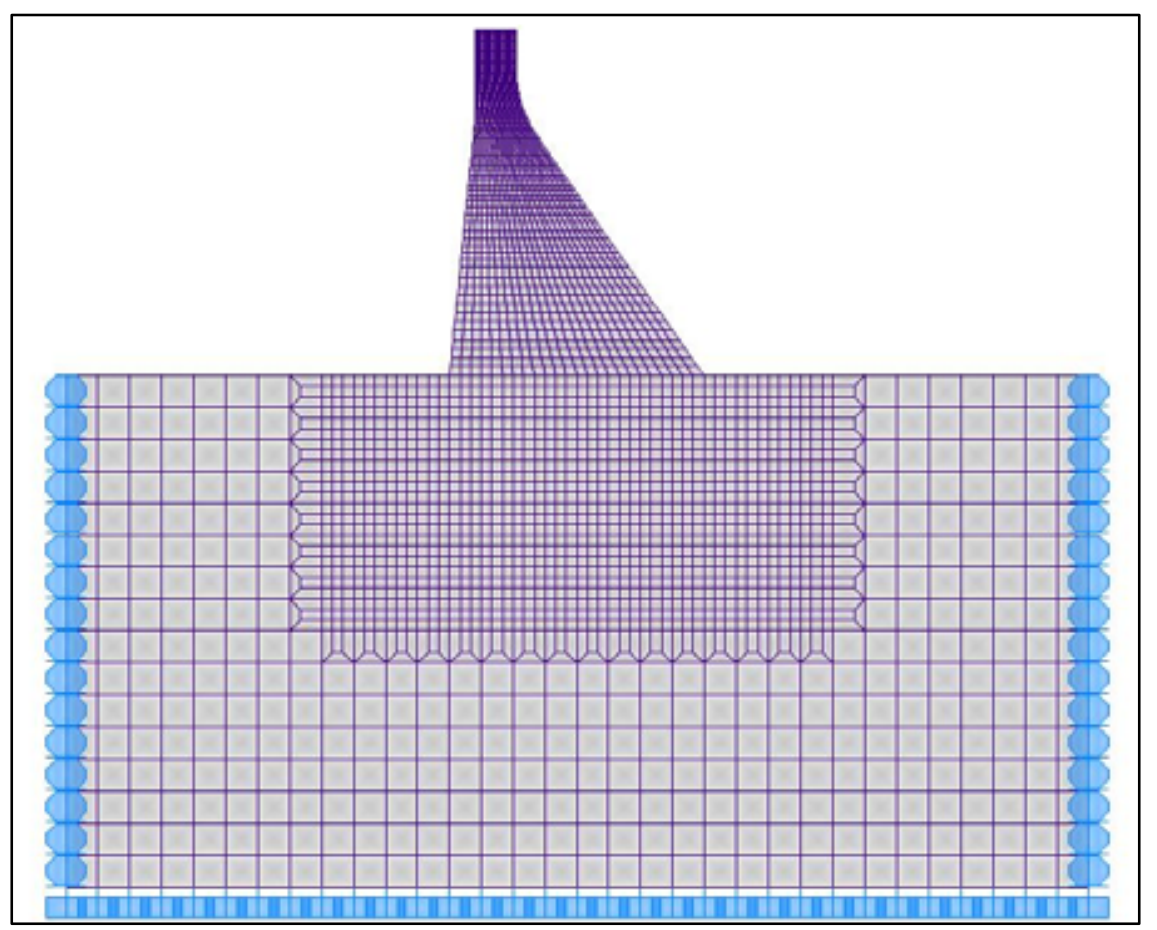

Figure 44. Finite-element model of Monolith 21 


\begin{tabular}{|c|c|c|c|c|}
\hline \multicolumn{5}{|c|}{$\begin{array}{l}\text { Table } 5 \\
\text { Dynamic Characteristics of Monolith } 21\left(E_{c} / E_{f}=0.75 \text {, }\right. \\
\text { Reservoir el } 430 \mathrm{ft})\end{array}$} \\
\hline \multirow[b]{2}{*}{ Mode } & \multirow{2}{*}{$\begin{array}{l}\text { Period } \\
\text { sec }\end{array}$} & \multirow{2}{*}{$\begin{array}{l}\text { Frequency } \\
\mathrm{Hz}\end{array}$} & \multicolumn{2}{|c|}{ 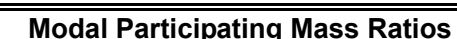 } \\
\hline & & & $\mathrm{Ux}$ & $\mathrm{Uz}$ \\
\hline 1 & 0.242 & 4.13 & 0.5764 & 0.0100 \\
\hline 2 & 0.120 & 8.37 & 0.3002 & 0.0008 \\
\hline 3 & 0.088 & 11.32 & 0.0165 & 0.8898 \\
\hline 4 & 0.067 & 14.85 & 0.0811 & 0.0397 \\
\hline 5 & 0.041 & 24.02 & 0.0166 & 0.0001 \\
\hline 6 & 0.037 & 27.17 & 0.0002 & 0.0473 \\
\hline
\end{tabular}

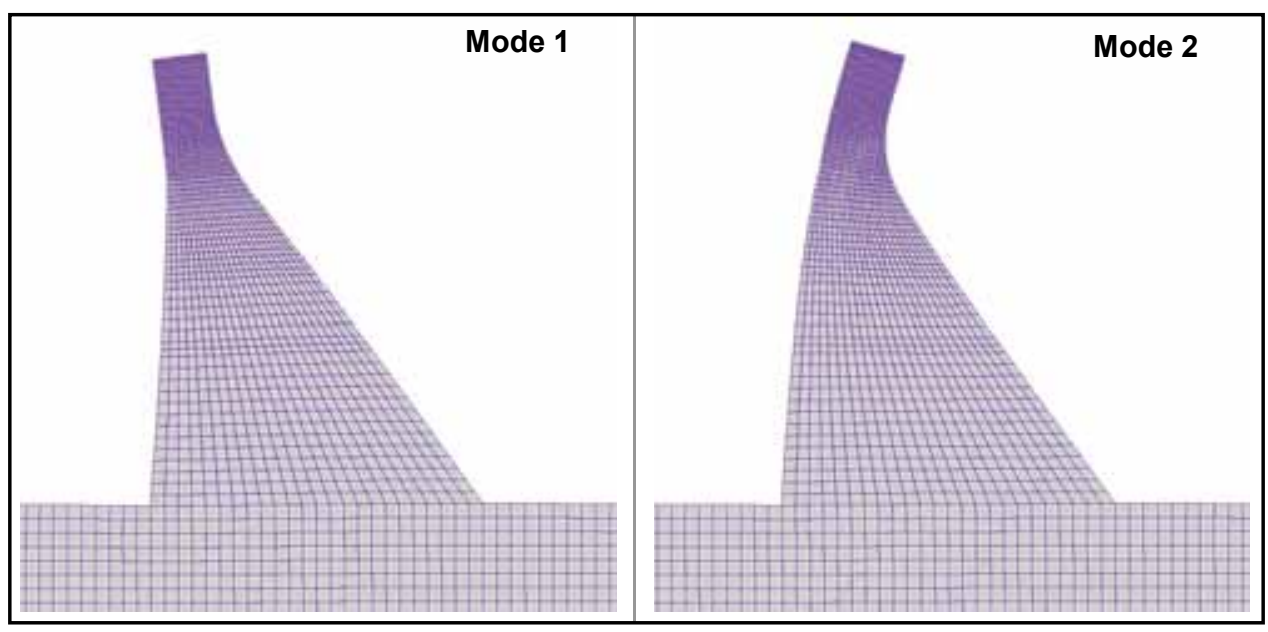

Figure 45. First and second mode shapes computed for Monolith 21

Table 6 shows the first six natural frequencies computed for Monolith 14 corresponding to the same value of $E_{f}=7.9 \times 10^{6} \mathrm{psi}$. As in the previous case, this table also shows the modal participating mass ratios corresponding to the horizontal and vertical directions.

\section{Table 6}

Vibration Characteristics of Monolith $14\left(E_{c} / E_{f}=0.75\right.$,

Reservoir el $\mathbf{4 3 0} \mathrm{ft}$ )

\begin{tabular}{||l|l|l|l|l||}
\hline \hline \multirow{2}{*}{ Mode } & Period & Frequency & \multicolumn{2}{|c||}{ Modal Participating Mass Ratios } \\
\cline { 4 - 5 } & sec & Hz & Ux & Uz \\
\hline \hline 1 & 0.254 & 3.93 & 0.7253 & 0.0083 \\
\hline 2 & 0.112 & 8.95 & 0.2021 & 0.2791 \\
\hline 3 & 0.101 & 9.86 & 0.0340 & 0.6582 \\
\hline 4 & 0.060 & 16.73 & 0.0263 & 0.0023 \\
\hline 5 & 0.044 & 22.98 & 0.0056 & 0.0143 \\
\hline 6 & 0.042 & 23.82 & 0.0005 & 0.0158 \\
\hline
\end{tabular}


The first two natural frequencies are associated with mode shapes representing the lateral bending response, but in this case the vertical response participation in the second mode is more important. As in the previous case, the third frequency is associated with a mode shape with significant vertical response participation. The first two mode shapes are shown in Figure 46.

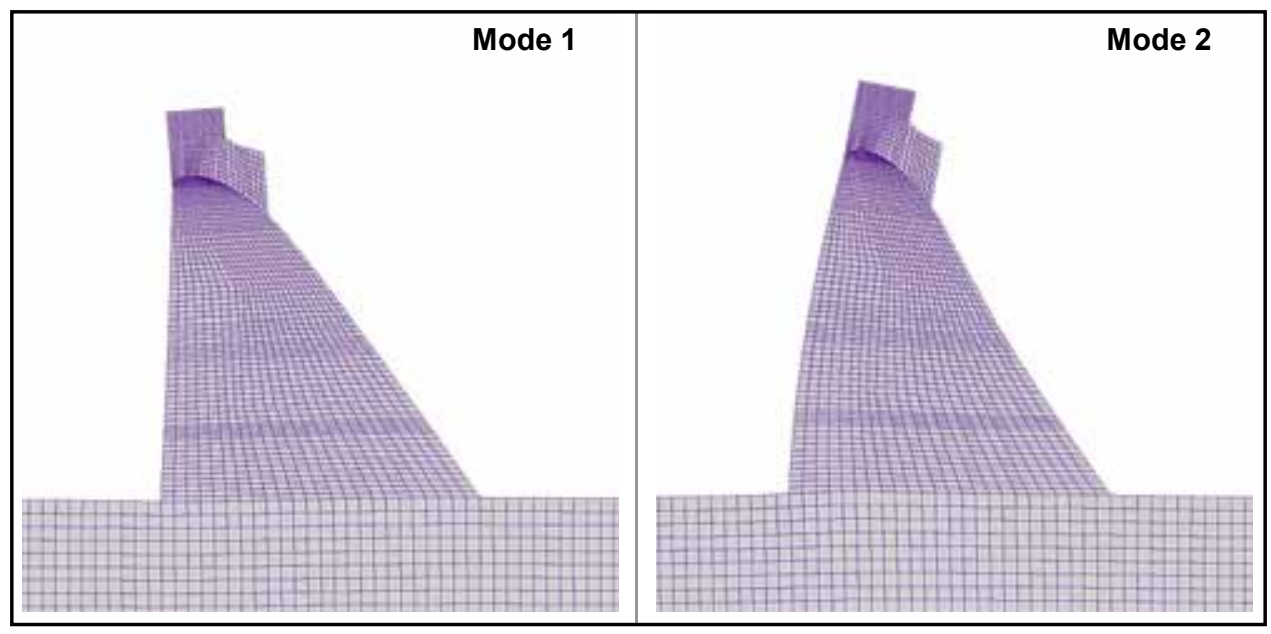

Figure 46. First and second mode shapes computed for Monolith 14

Table 7 shows the first natural frequencies for Monoliths 14 and 21 corresponding to two extreme values of the foundation's dynamic modulus of elasticity. The first case corresponds to a dam on rigid foundation $\left(E_{f}=\infty\right)$, and the second case corresponds to a value of $E_{f}$ for which both fundamental frequencies for Monolith 14 and 21 approach those determined by the field tests $(4.65 \mathrm{~Hz})$ for the same reservoir conditions.

\begin{tabular}{|c|c|c|c|c|}
\hline \multicolumn{5}{|c|}{$\begin{array}{l}\text { Table } 7 \\
\text { Foundation Flexibility Effects on the Vibration Characteristics of } \\
\text { Monoliths } 14 \text { and } 21 \text { (Reservoir el } 430 \mathrm{ft} \text { ) } \\
\end{array}$} \\
\hline \multirow[b]{3}{*}{ Mode } & \multicolumn{4}{|c|}{ Frequency, $\mathrm{Hz}$} \\
\hline & \multicolumn{2}{|c|}{ Monolith 14} & \multicolumn{2}{|c|}{ Monolith 21} \\
\hline & $E_{c} / E_{f}=0$ & $E_{c} / E_{f}=0.25$ & $E_{c} / E_{f}=0$ & $E_{c} / E_{f}=0.25$ \\
\hline 1 & 5.23 & 4.68 & 5.00 & 4.67 \\
\hline 2 & 12.31 & 10.80 & 10.50 & 9.52 \\
\hline 3 & 14.63 & 12.43 & 16.80 & 14.37 \\
\hline 4 & 19.96 & 18.31 & 18.98 & 16.95 \\
\hline 5 & 25.73 & 24.40 & 28.53 & 26.09 \\
\hline 6 & 29.14 & 25.99 & 35.14 & 30.62 \\
\hline
\end{tabular}

This value for $E_{f}$ (about $23.610^{6} \mathrm{psi}$ ) is significantly beyond the range estimated by geophysical investigations. However, this artificially stiff foundation condition is required by the 2-D models to reproduce the observed fundamental frequency, perhaps as a way to "compensate" for the fact that these models 
assume unconstrained planar motion. That is, the intrinsic assumption in the 2-D models is that each monolith vibrates independently. Under the low-intensity excitation levels associated with the field test conditions, it is likely that 3-D effects were significant and each individual monolith was not completely free to move without restraint with respect to each other.

\section{Three-Dimensional Modeling}

A series of analyses were performed using a detailed 3-D numerical model of the dam-foundation-reservoir system. Eigenvalue analyses of the model were performed to evaluate the model's dynamic response characteristics. Then, steady-state analyses aimed at reproducing observed behavior during the forced vibration tests at Folsom Dam were conducted. Finally, the influence of the tower on overall dam response was evaluated by computing the steady-state response in the dam using a numerical model whose tower had been removed.

\section{Model description}

A 3-D numerical model of the dam-foundation-reservoir system at Folsom Dam was developed using SAP2000 (Figure 47). The model of the dam consists of 8,355 solid brick elements and includes the tower, the roadway, and the varying geometries of the spillway monoliths. A massless foundation model, constructed with 12,774 solid brick elements, contributes stiffness only to the overall system. The nodes along the base and sides of the foundation model were fixed for all analyses. The presence of the reservoir is accounted for by attaching incompressible added masses to the nodes along the upstream face of the dam. A Westergaard approach was used to compute the added mass values. The modulus of elasticity adopted for the mass concrete was $E_{c}=5.910^{6} \mathrm{psi}$. The model does not account for the presence of the earth wing dams.

A special feature of this model was the ability to alter the stiffness at the vertical joints between adjacent monoliths in the dam. This was achieved by including a vertical line of brick elements at the interface between adjacent monoliths whose elastic properties could be varied from that in the dam $\left(E_{c}\right.$, modeling a closed joint) to a softer value that would allow some relative joint motion between monoliths. In this manner, the influence of relative joint motion on dam response could be investigated at a later stage. This feature was not intended to model behavior that involved opening and closing of the joints between monoliths. After some preliminary test runs, a value of $E_{f}$

$=11.010^{6}$ psi, i.e., $E_{c} / E_{f}=0.54$ was finally adopted for the dynamic modulus of elasticity of the foundation rock. 


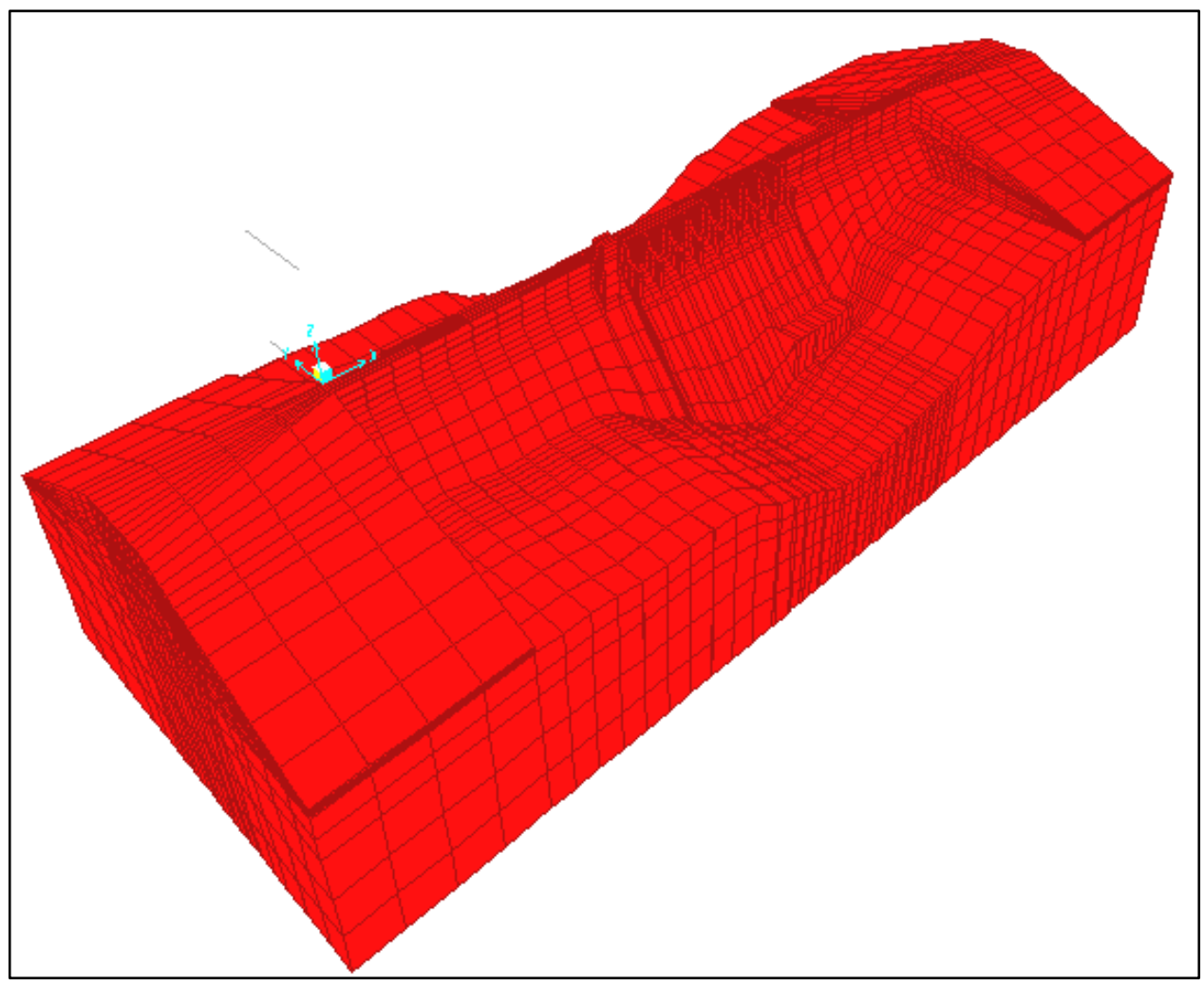

Figure 47. Three-dimensional finite-element model of Folsom Dam

\section{Model results}

Sample results from the numerical model analyses performed are described in the context of the model's ability to reproduce, or capture, response behavior observed during the forced vibration survey at Folsom Dam. Of particular interest is the model's ability to reproduce resonant frequencies, frequency response behavior, the "sliding" resonant behavior observed in Monoliths 1 through 10 , the influence of the elevator tower on dam response, and foundation flexibility effects.

Frequency response comparisons. Comparisons between measured resonant frequencies and the numerical model's modal frequencies, or eigenvalues, as shown in Table 8, provide limited information pertaining to a model's ability to capture observed behavior. Notwithstanding, the correlation in resonant and model modal frequencies below $10 \mathrm{~Hz}$ does provide some confidence in the modeling approach. Still, a better evaluation of model performance must include comparisons of frequency response functions, because the measured responses obtained at Folsom Dam consist of a combination of the dam-foundationreservoir mode shapes, or eigenvectors. So, while comparing a model's eigenvalues to a system's measured resonant behavior may provide some insight, it is far better to compare a measured response with its counterpart as predicted from a steady-state analysis. 


\begin{tabular}{|c|c|c|}
\hline \multicolumn{3}{|c|}{$\begin{array}{l}\text { Table } 8 \\
\text { Comparison of Measured Resonant and Modal Frequencies } \\
\text { (Reservoir el } 430 \mathrm{ft} \text { ) }\end{array}$} \\
\hline \multicolumn{2}{|c|}{ Resonant Frequency, Hz } & \multirow{2}{*}{$\begin{array}{l}\text { Natural Frequency, Hz } \\
\text { SAP3000 3-D Model }\end{array}$} \\
\hline Ambient Vibration Survey & Forced Vibration Tests & \\
\hline $\begin{array}{l}4.64 \\
\end{array}$ & 4.65 & 24.67 \\
\hline 5.49 & 5.46 & 5.35 \\
\hline Not observed & Not observed & 5.91 \\
\hline 6.47 & 6.24 & 6.56 \\
\hline 7.32 & 7.16 & 7.47 \\
\hline 8.18 & 8.00 & 8.40 \\
\hline 8.91 & 8.87 & 8.82 \\
\hline
\end{tabular}

Measured acceleration frequency responses on the crest at Monoliths 8, 14, and 21 are shown in blue, and responses at the same locations predicted from the numerical model are shown in red in Figure 48. The numerical model results were obtained from a steady-state analysis in which a steady-state excitation (i.e., a shaker loading) was applied at a node in the model that coincided with the actual shaker placement on the crest at Monolith 11. No adjustments were made to the model's material property parameters, and no efforts were made to obtain a "best" match in dam response anywhere below $20 \mathrm{~Hz}$.

The comparisons in Figure 48 suggest that the model's ability to capture measured response behavior varies across the frequency range. Below $6 \mathrm{~Hz}$, for example, adjustments can be easily made to both dam and foundation properties in the model to achieve a near match in both fundamental resonance and in response amplitude and damping. In the frequency range 6 to $12 \mathrm{~Hz}$, where the influence of the tower is clearly indicated, the frequency spacing between adjacent resonances in the model responses is inconsistent with the spacing present in the measured response. It is possible that, in this frequency range, water compressibility may have some influence on dam response, and a model that represents the reservoir water as incompressible added masses may not accurately capture dam-reservoir interactions effects. In the frequency range above $12 \mathrm{~Hz}$, the model responses generally exhibit much higher levels of damping and do not reflect the apparent modal density of the measured responses. The elevated damping levels in this frequency range can easily be reduced in subsequent analyses to reflect a more reasonable distribution with frequency. It is also possible that, in this range, the earth wing dams contribute added mass and constraint along the dam-foundation interface, which influences the higher resonances in the dam-foundation-reservoir system.

The sliding resonant behavior observed in Monoliths 1 through 10 was also investigated using the numerical model. The crest acceleration responses obtained from the numerical steady-state analysis are shown in Figure 49, and they must be compared with the observed behavior, previously shown in Figure 19. The model results provide consistent trends in response frequencies and amplitudes below $6 \mathrm{~Hz}$, and the presence of the resonant behavior near $6.5 \mathrm{~Hz}$ may be the result of improper frequency spacing. 

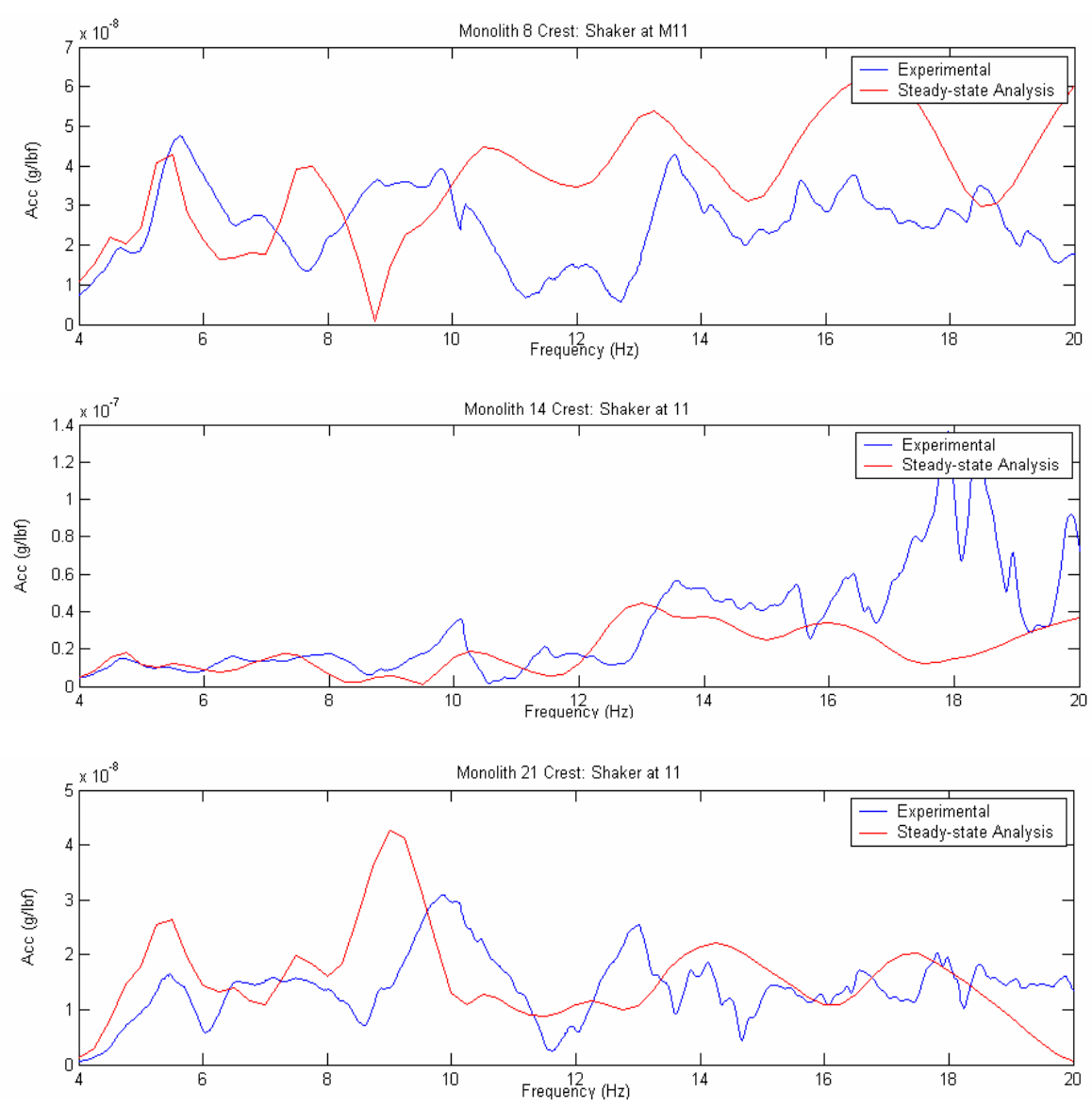

Figure 48. Comparisons of measured and predicted frequency responses for Monoliths 8, 14, and 21

Tower influence on dam response. The presence of the elevator tower and its influence on overall dam response behavior has been characterized in terms of vibration absorption in the frequency range of 8 to $13 \mathrm{~Hz}$. Evidence of the tower's influence on dam response and of the model's ability to reproduce the behavior is provided in Figures 50 and 51.

The measured responses in the tower are the same as those in Figure 21at Level 5 (46 ft below crest elevation) and Level 9 ( $22 \mathrm{ft}$ above crest elevation) in Monolith 11. As discussed above, the model can be adjusted to provide a satisfactory match in measured behavior below $6 \mathrm{~Hz}$. However, above $6 \mathrm{~Hz}$, water compressibility and excessive damping in the model probably affect the comparison shown. The response in the tower at Level 9, however, is more accurately represented by the numerical model compared with the results from the TVA model previously shown in Figure 23. This occurs because the 3-D model is able to include all modal characteristics within the analysis frequency range to compute the response of the tower. 


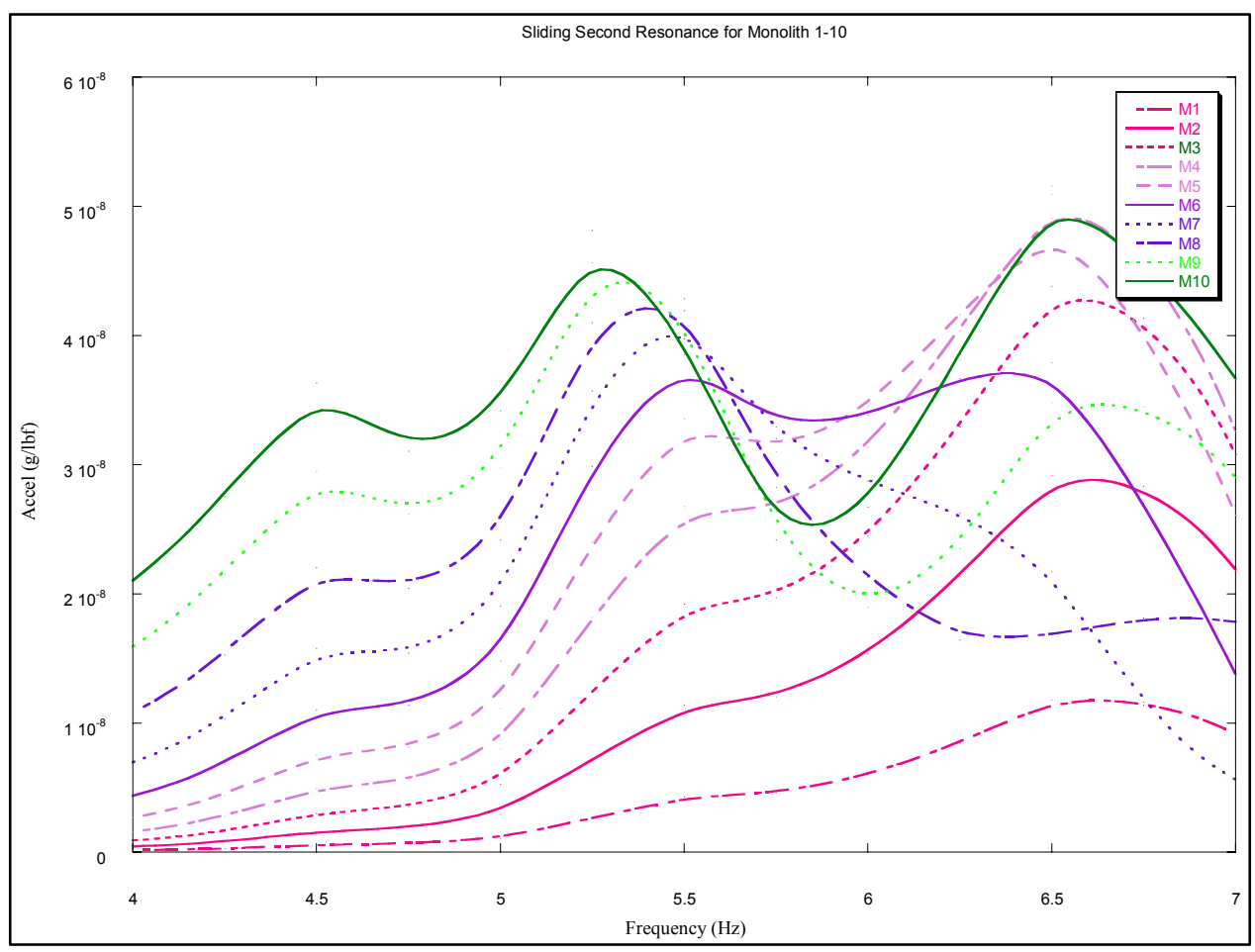

Figure 49. Resonant behavior for Monoliths 1-10 computed by 3-D numerical model

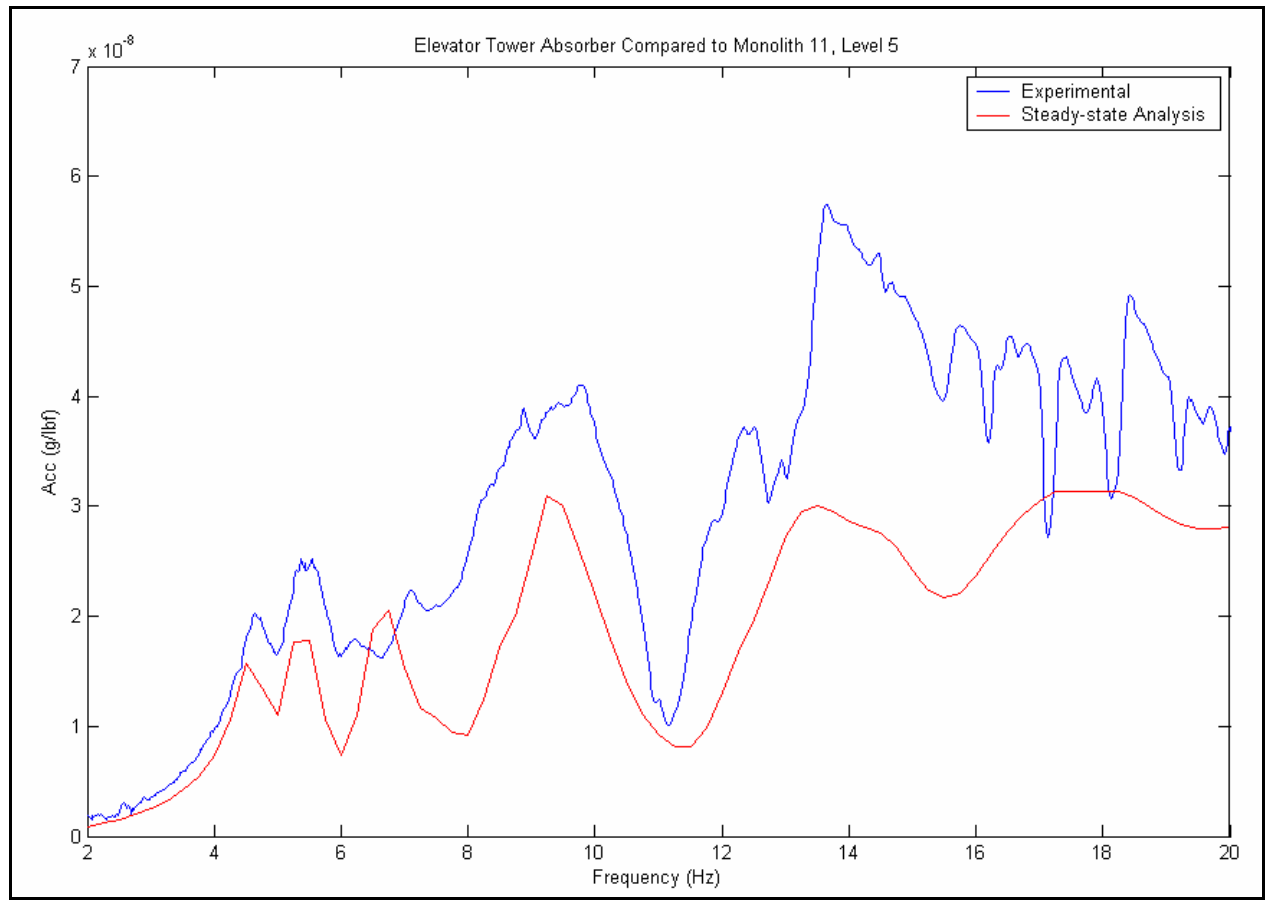

Figure 50. Comparison of measured and predicted tower response behavior Level 5 


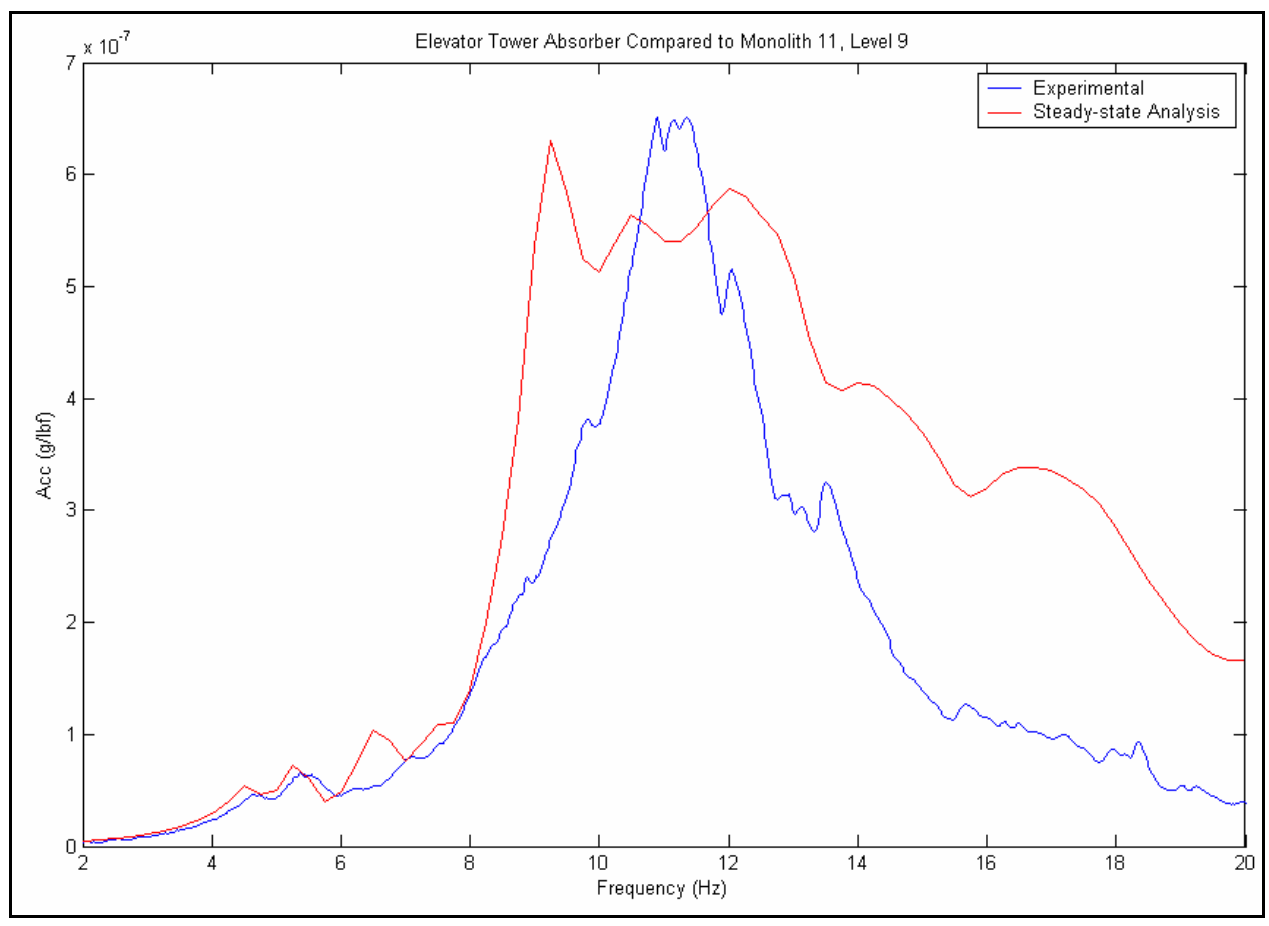

Figure 51. Comparison of measured and predicted tower response behavior Level 9

Surface plots of measured acceleration responses on the crest obtained from the 3-D numerical model analyses are shown in Figure 52. The top plot represents the results from the numerical model that includes the tower, whereas the bottom plot represents a case in which the tower was removed from the model. The model is able to reproduce the attenuated response "corridor" across all monoliths in the vicinity of $11 \mathrm{~Hz}$, and when the tower is removed from the model, the response levels in the frequency range 8 to $13 \mathrm{~Hz}$ are clearly amplified.

Foundation flexibility effects. An analysis was performed to investigate the model's ability to capture observed foundation flexibility effects on the dynamic response. The analysis consisted of applying a steady-state excitation at a node in the model in Monolith 14 coincident with the shaker location in the pipeline gallery during the forced vibration tests. Vertical responses at the heel and toe at the base of Monolith 14 were examined, and a figure similar to that shown in Figure 33 was produced (Figure 53).

The ratio of heel to toe response predicted by the numerical model is $2.44 / 2.52=1.60$, which compares quite well with the $3.80 / 2.50=1.52$ value observed during the forced vibration tests. While these results provide some consistency with the observed behavior, the results are considered only preliminary, and additional model refinements will be required to produce a more accurate representation of actual dam-foundation interface conditions. 


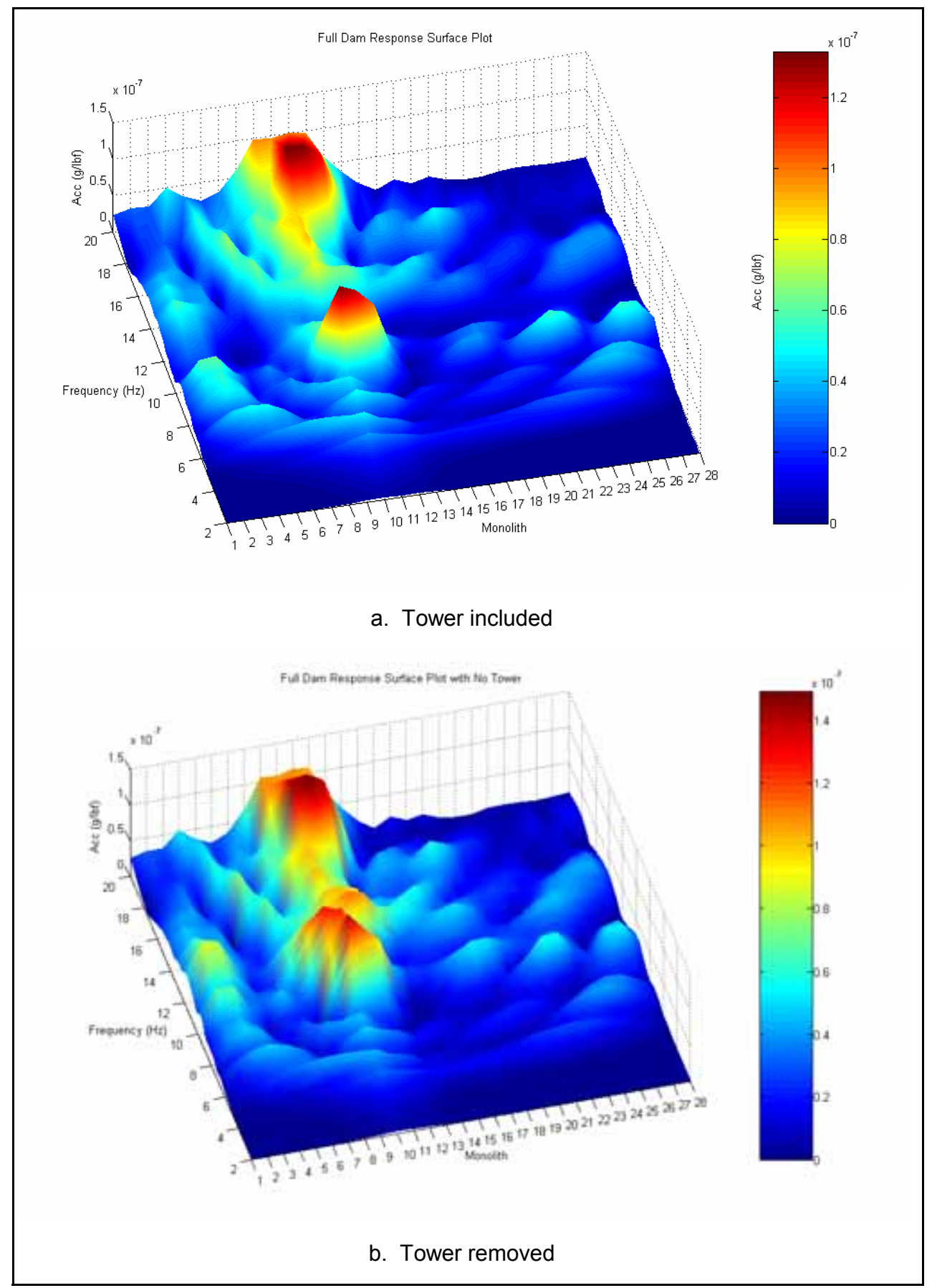

Figure 52. Surface plot comparison of crest acceleration responses 


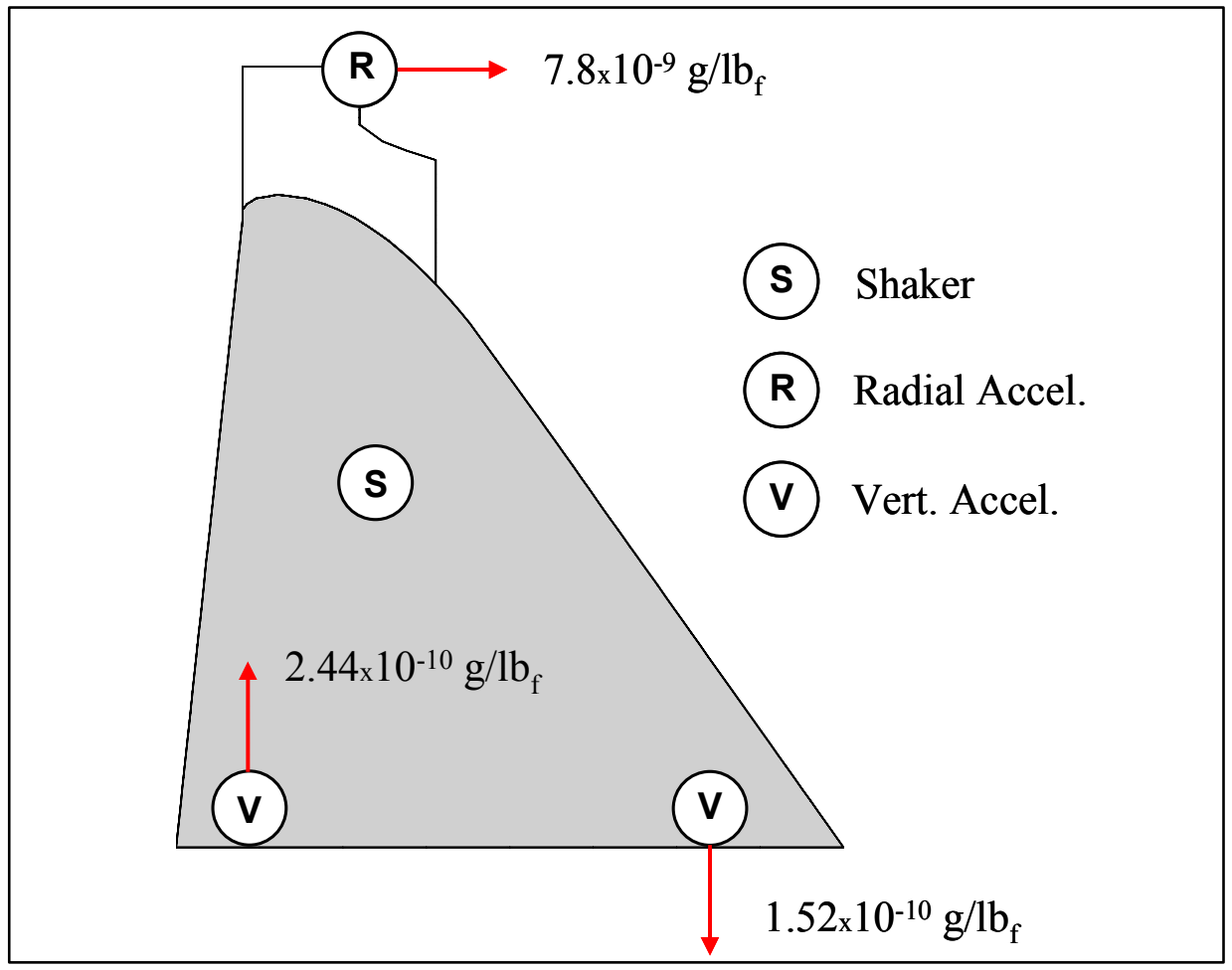

Figure 53. Predicted contribution to crest response due to foundation flexibility effects 


\section{Summary and Conclusions}

A series of forced vibration tests have been completed at Folsom Dam in an attempt to gain detailed understanding of dynamic response behavior in the dam, and of possible dam-foundation and dam-reservoir interaction effects. In addition, response information was obtained that will provide assistance in the validation of numerical model development for subsequent seismic and stability studies that may be planned.

Dam response behavior observed along the crest indicated that monolithic dam response exists below $10 \mathrm{~Hz}$, although evidence of individual monolith behavior was also observed. Specifically, monoliths present in the right gravity section of the dam exhibited sliding resonant behavior above the fundamental resonance at $4.65 \mathrm{~Hz}$. Interference from adjacent monolith resonant behavior produced lower amplitude response and wider response peaks as the monolith heights decreased in this section.

Spillway monolith behavior appeared to dominate dam response above $10 \mathrm{~Hz}$ and did not exhibit the monolithic behavior observed in the right gravity section. Monoliths in the left gravity section exhibited a more uniform distribution of resonant frequencies, although it is possible that significant excitation was absorbed by relative joint motion, reducing the likelihood that individual monolith behavior would be excited. The elevator tower acts as a vibration absorber tuned near $11 \mathrm{~Hz}$ and affects dam response across all monoliths. The tower interacts with the dam to produce an antiresonance near $11 \mathrm{~Hz}$ and results in split resonances near $10 \mathrm{~Hz}$ and $13 \mathrm{~Hz}$.

Some evidence of relative joint motion was observed at Folsom Dam. Relative motion on the crest and inside the dam between adjacent monoliths was observed for shaker force levels that approached 12,000 lbf. Dam-foundation interaction effects were observed in the form of monolith amplification response and grouting gallery response measurements in Monoliths 13, 14, and 15. Evidence of foundation flexibility was also observed at the base of Monolith 14 .

Dam-reservoir interaction was characterized in terms of reservoir frequency response behavior computed using measured hydrodynamic pressure and monolith acceleration responses. A fundamental reservoir resonance is indicated at $5.23 \mathrm{~Hz}$ and, when compared with the fundamental dam resonance at $4.65 \mathrm{~Hz}$, may suggest that water compressibility should be considered in the construction of a numerical model of the dam-foundation-reservoir system. 
A detailed model of the dam-foundation-reservoir system at Folsom Dam was developed for preliminary numerical correlation studies. The model's ability to reproduce observed behavior was investigated, and results from these comparisons can be used to identify required model refinements for subsequent analyses. Comparison of measured and predicted frequency responses in the dam suggests that the model is capable of capturing certain, but not all, of the major response characteristics at Folsom Dam. For example, the fundamental resonant behavior below $6 \mathrm{~Hz}$ is easily reproduced using a model that includes incompressible added masses to account for reservoir water. However, above $6 \mathrm{~Hz}$, a variety of influencing factors will require further investigation, including water compressibility effects and appropriate damping values for resonances above $6 \mathrm{~Hz}$. Additional numerical modeling efforts are required to rigorously examine the importance of interaction phenomena linked to water compressibility effects. Future studies should examine the influence of foundation rock material properties that may exhibit spatial variation, as well as the effects on the dynamic response associated with the earth wing dams. Additional studies using nonlinear joint elements may be required to fully determine the importance of relative joint motion effects. 


\section{References}

Duron, Z. H. (1994, Oct). "Full-scale dynamic testing at Seven Mile Dam." Report prepared for BC Hydro and Power, Vancouver, British Columbia.

Duron, Z. H., and Hall, J. F. (1988). "Experimental and finite element studies of the forced vibration response of Morrow Point Dam," Earthquake Engineering and Structural Dynamics 16, 1021-39.

Duron, Z. H., Flynn, E., von Gersdorff, N., Cho, A., and Chiarito, V. P. (2004). "Ambient vibration survey of Folsom Dam." Report prepared for U.S. Army Engineer Research and Development Center, Geotechnical and Structures Laboratory, by Engineering Department, Harvey Mudd College, Claremont, CA.

Duron, Z. H., Matheu, E. E., and Hall, R. L. (2003). "The value added of field testing on concrete dams." Paper, 35th Joint Meeting, UJNR Panel on Wind and Seismic Effects, 12-17 May, Tsukuba, Japan.

Hall, J. F. (1988). "The dynamic and earthquake behavior of concrete dams: Review of experimental behavior and observational evidence," Soil Dynamics and Earthquake Engineering 7(2), 58-121.

Hall, R. L., and Matheu, E. E. (1999). "Present and future roles of nonlinear numerical procedures in the seismic analysis of concrete dams." Paper, 31st Joint Meeting, UJNR Panel on Wind and Seismic Effects, 11-14 May, Tokyo, Japan.

Hall, R. L., Woodson, S. C., and Nau, J. M. (1989). "Seismic stability evaluation of Folsom Dam and Reservoir Project; Report 3, Concrete gravity dam," Technical Report GL-87-14, U.S. Army Engineer Waterways Experiment Station, Vicksburg, MS.

Headquarters, U.S. Army Corps of Engineers. (1995a). "Earthquake design and evaluation for civil works projects," Engineer Regulation 1110-2-1806, Washington, DC. . (1995b). "Gravity dam design," Engineer Manual 1110-2-2200, Washington, DC. 
Headquarters, U.S. Army Corps of Engineers. (2003). "Time-history dynamic analysis of concrete hydraulic structures," Engineer Manual 1110-2-6051, Washington, DC.

National Research Council. (1990). "Earthquake engineering for concrete dams: Design, performance, and research needs," National Academy Press, Washington, DC.

Wong, C., Poeppelman, R. L., and Graff, S. (2002). "Preliminary earthquake response analysis of Folsom Dam spillway monoliths," Proceedings, $3 \mathrm{rd}$ U.S.-Japan Workshop on Advanced Research on Earthquake Engineering for Dams, June 22-23, San Diego, CA.

Yamaguchi, Y., Hall, R. L., Sasaki, T., Matheu, E. E., Kanenawa, K., Chudgar, A., and Yule, D. E. (2004). "Seismic performance evaluation of concrete gravity dams," Paper No. 1068, 13th World Conference on Earthquake Engineering, August 1-6, Vancouver, Canada. 


\section{Appendix A Crest Response Curves}




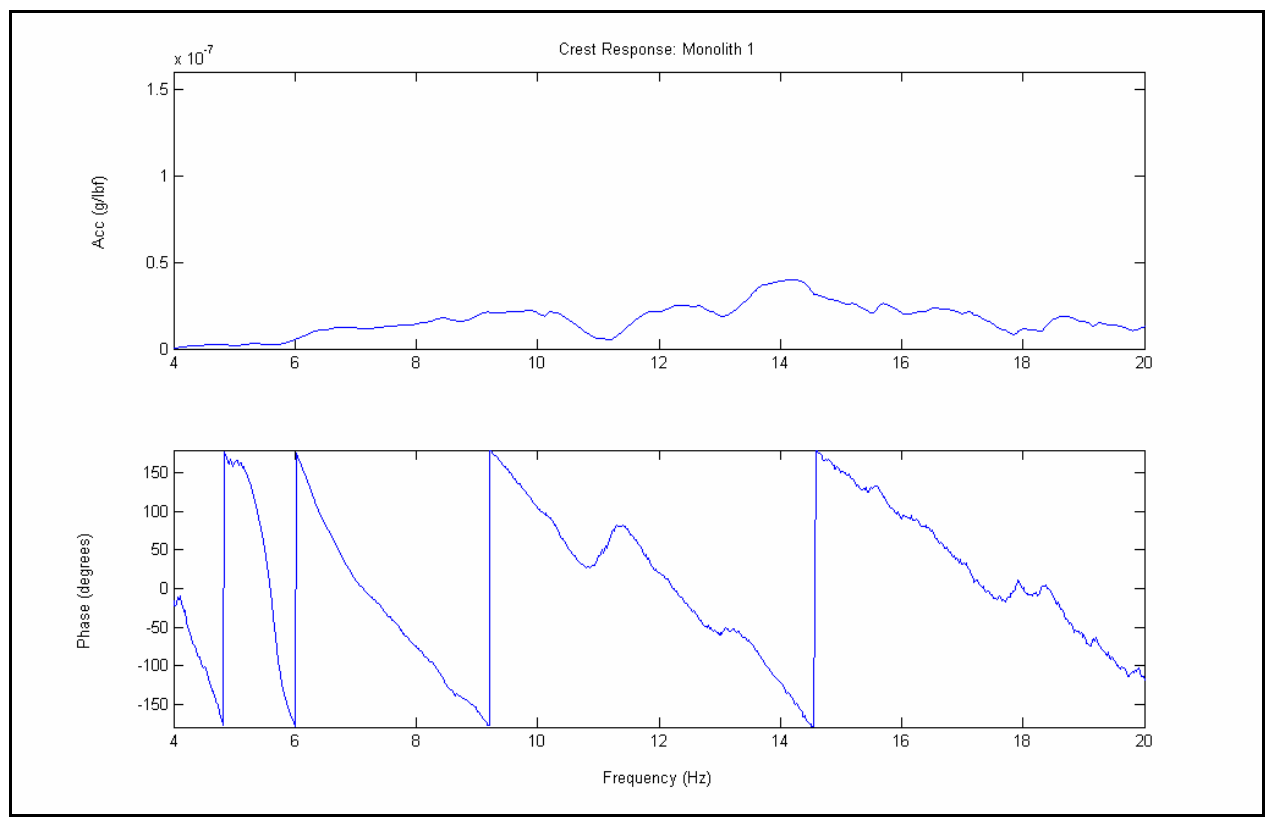

Figure A1. Crest response - Monolith 1

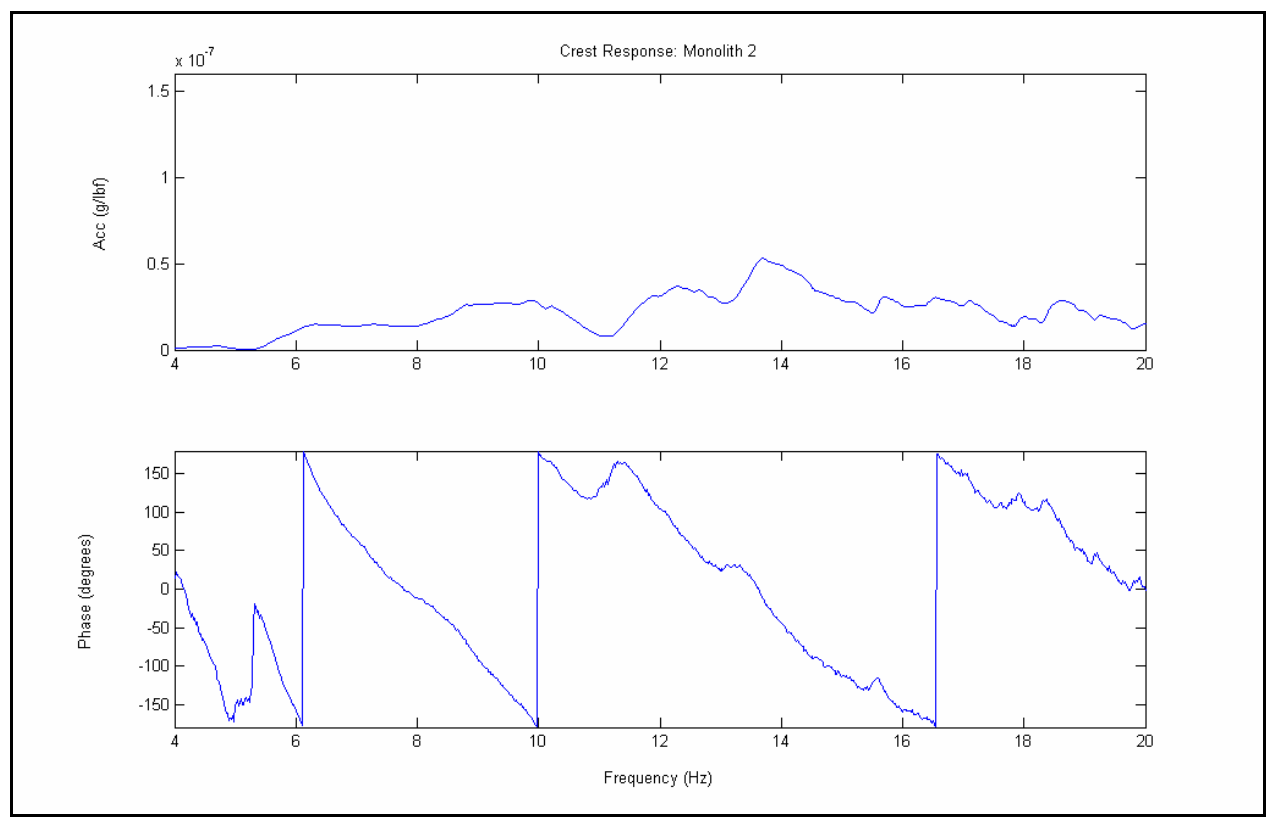

Figure A2. Crest response - Monolith 2 


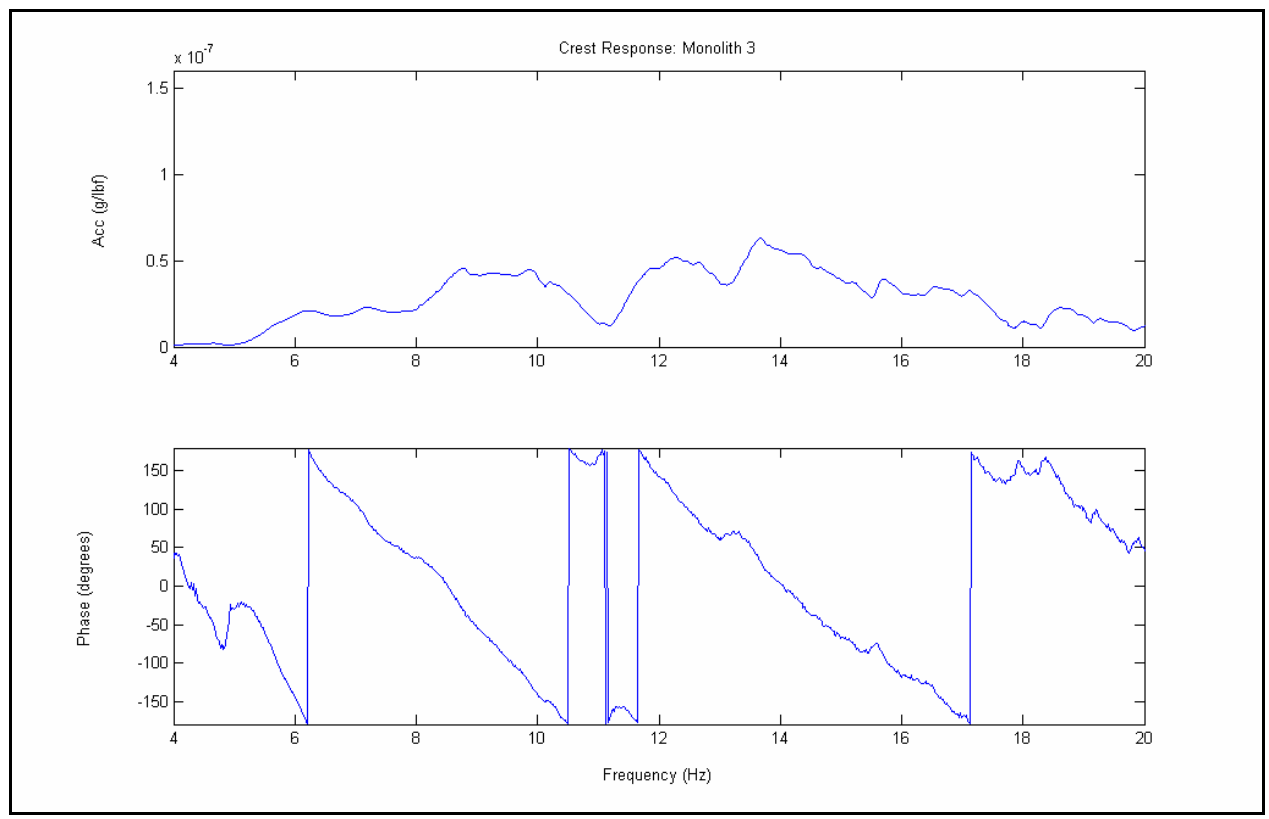

Figure A3. Crest response - Monolith 3

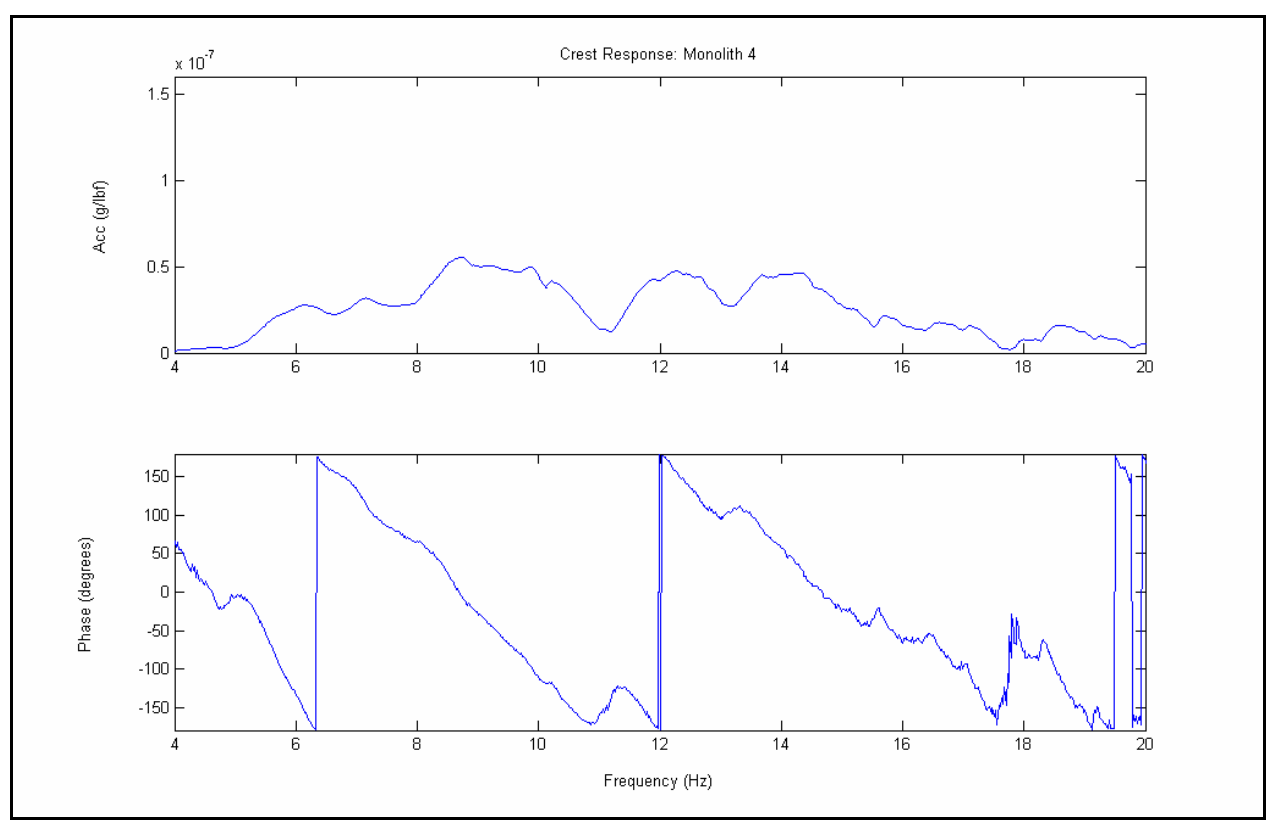

Figure A4. Crest response - Monolith 4 


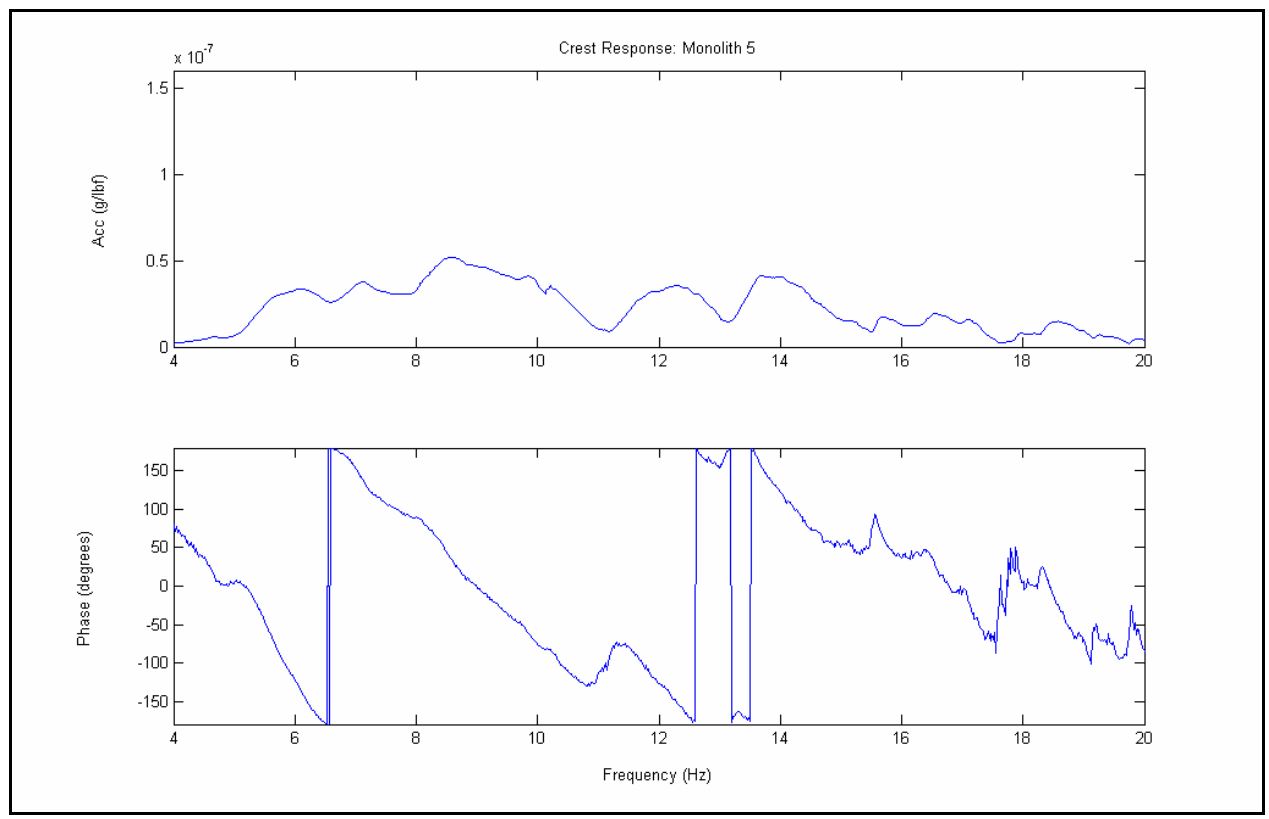

Figure A5. Crest response - Monolith 5

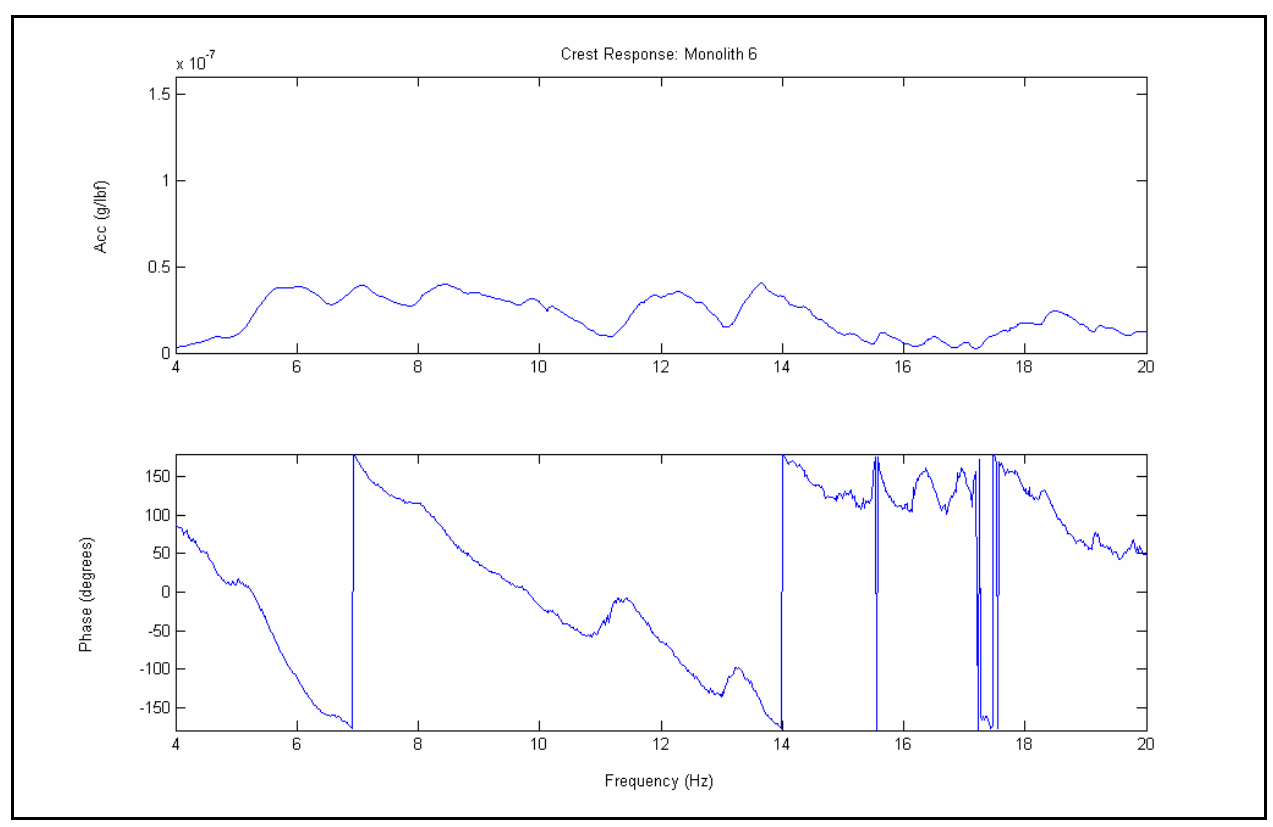

Figure A6. Crest response - Monolith 6 


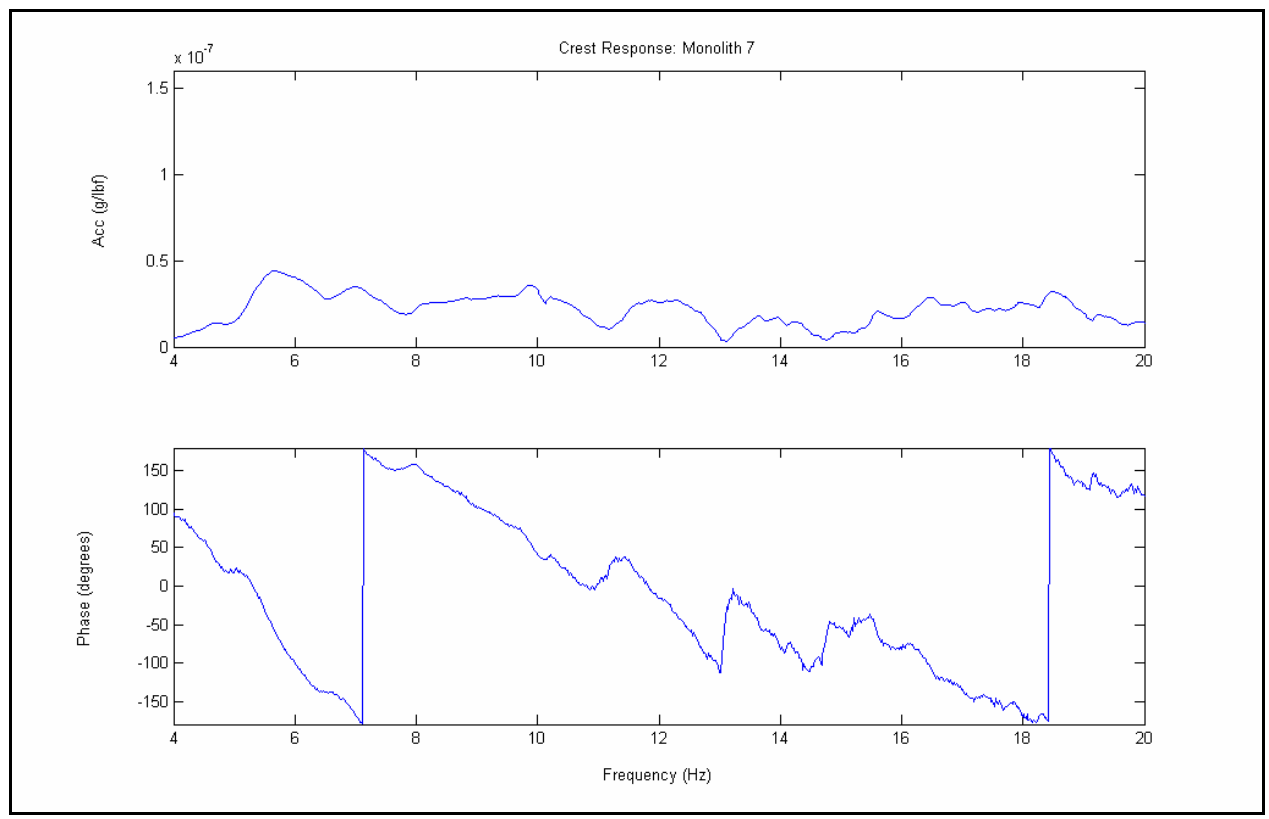

Figure A7. Crest response - Monolith 7

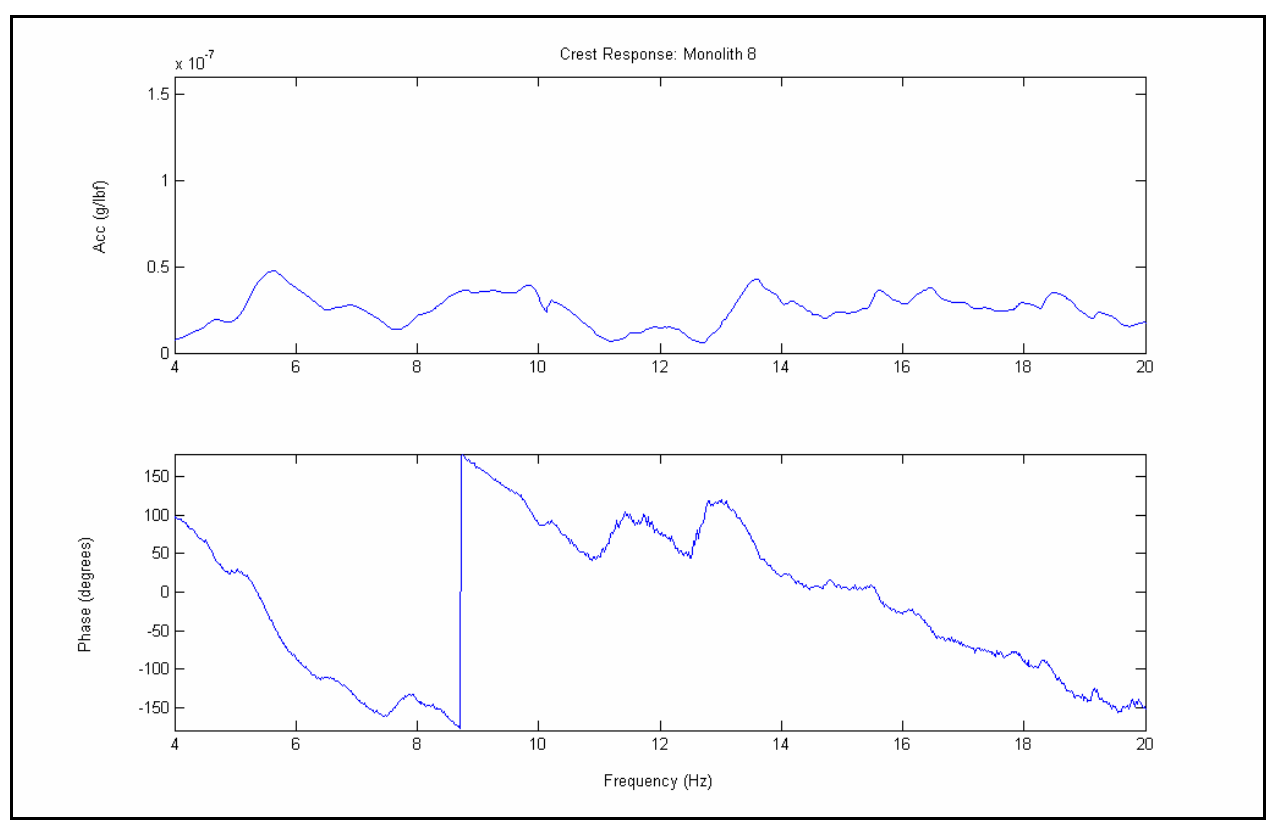

Figure A8. Crest response - Monolith 8 


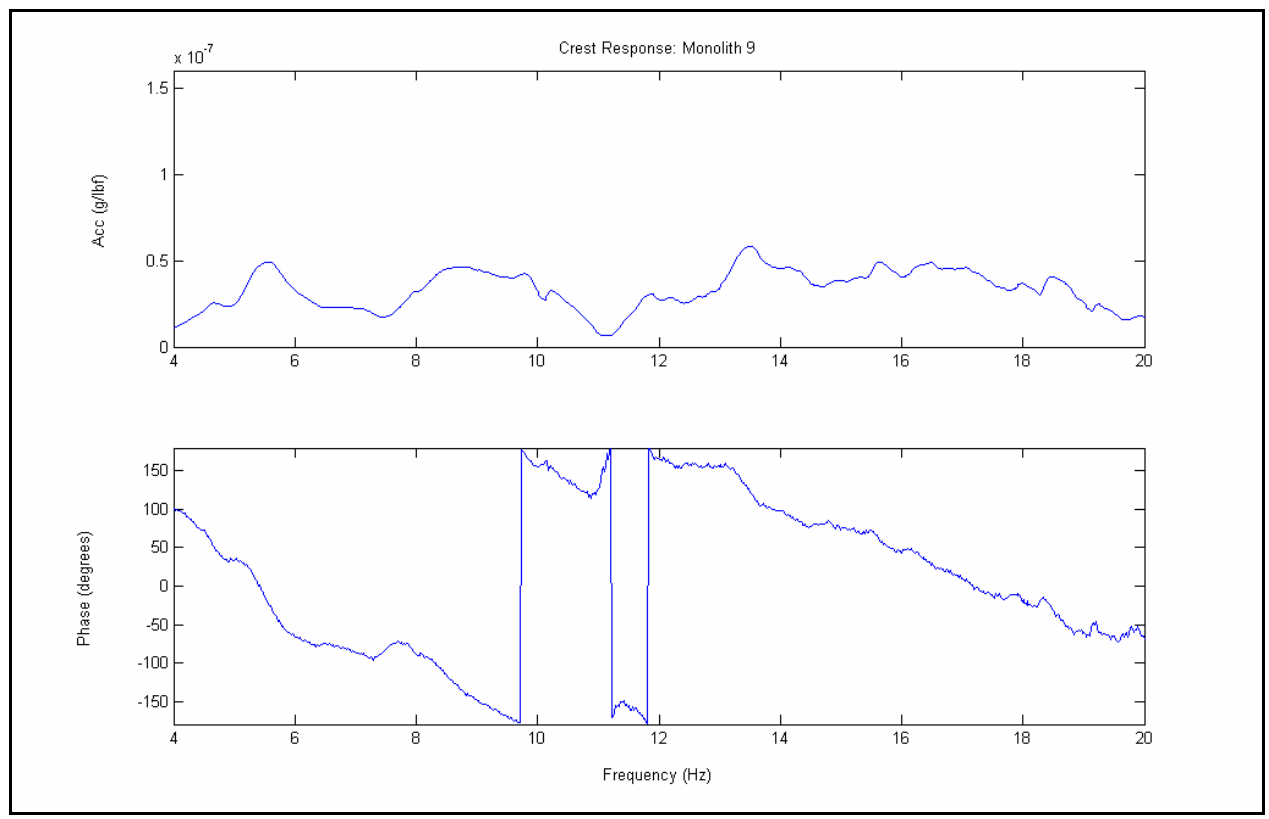

Figure A9. Crest response - Monolith 9

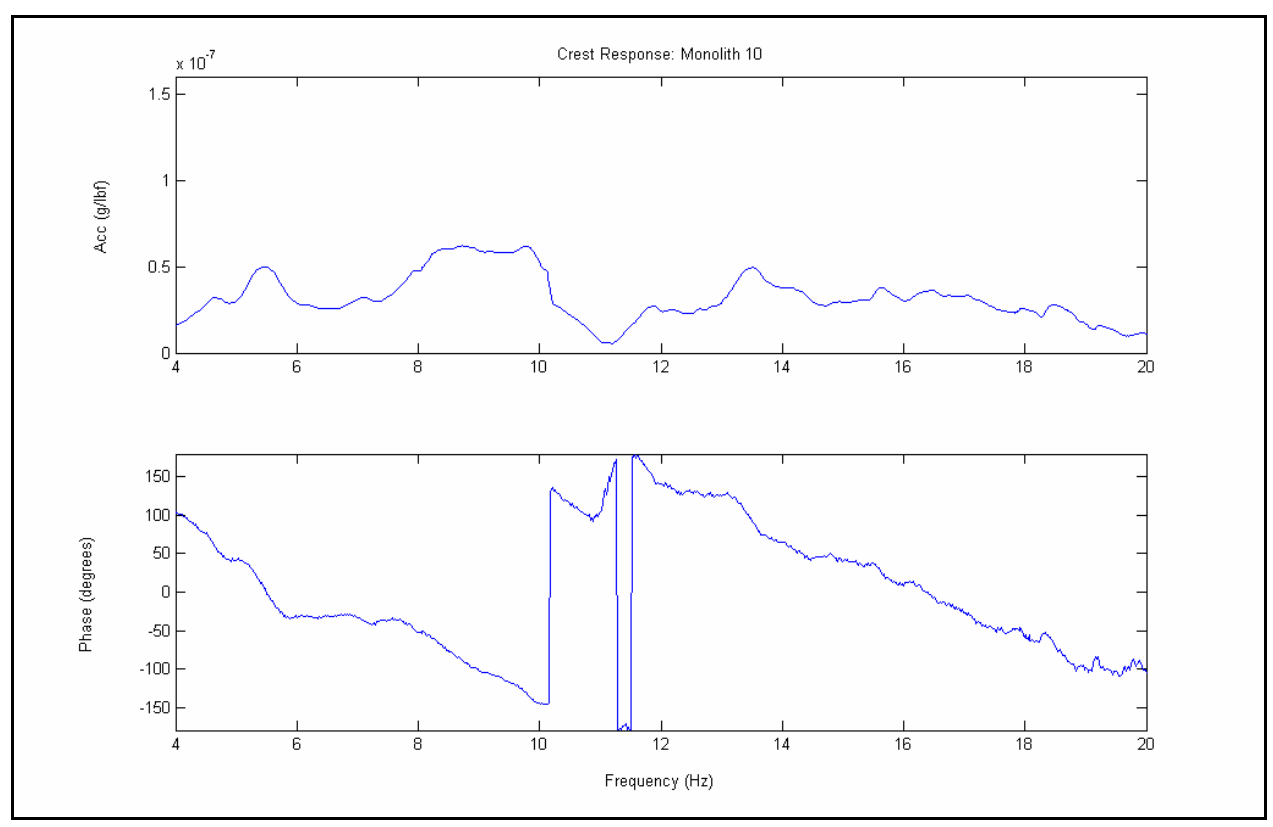

Figure A10. Crest response - Monolith 10 


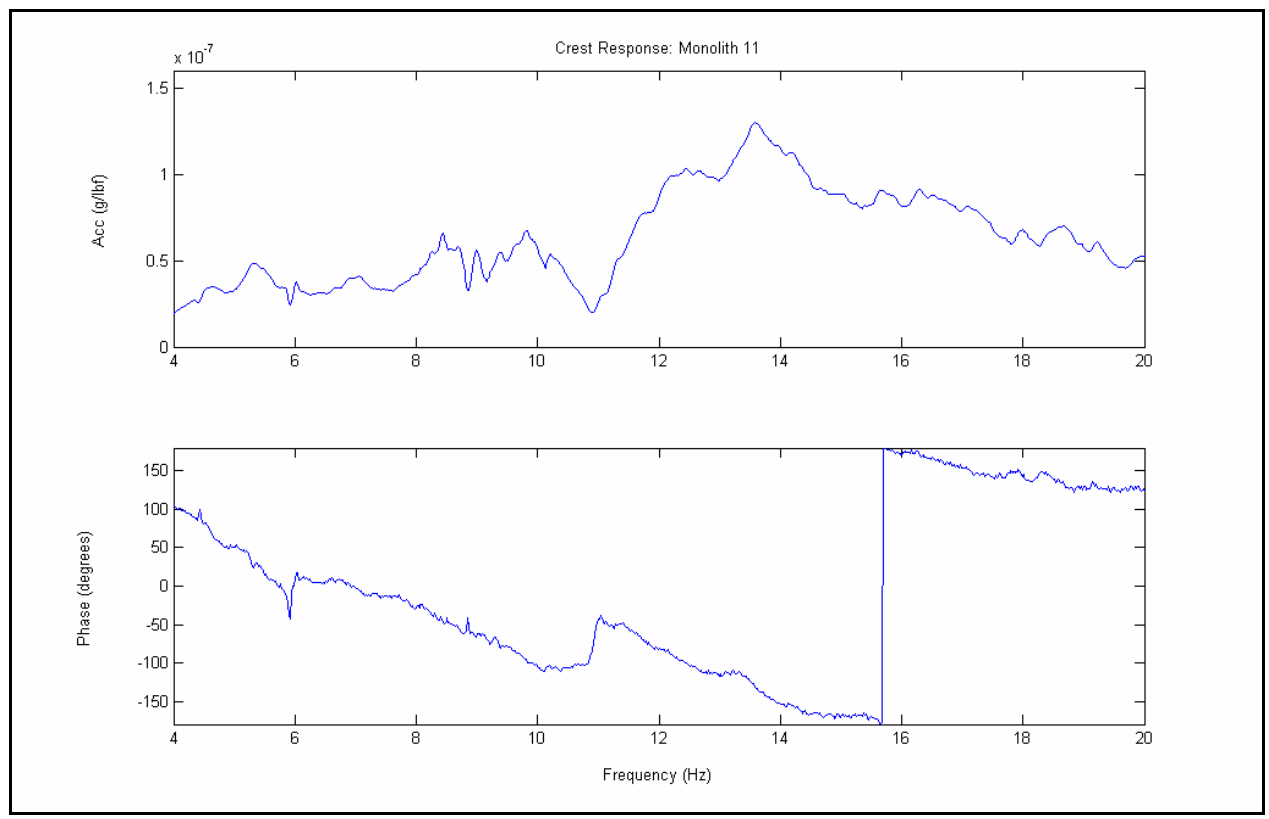

Figure A11. Crest response - Monolith 11

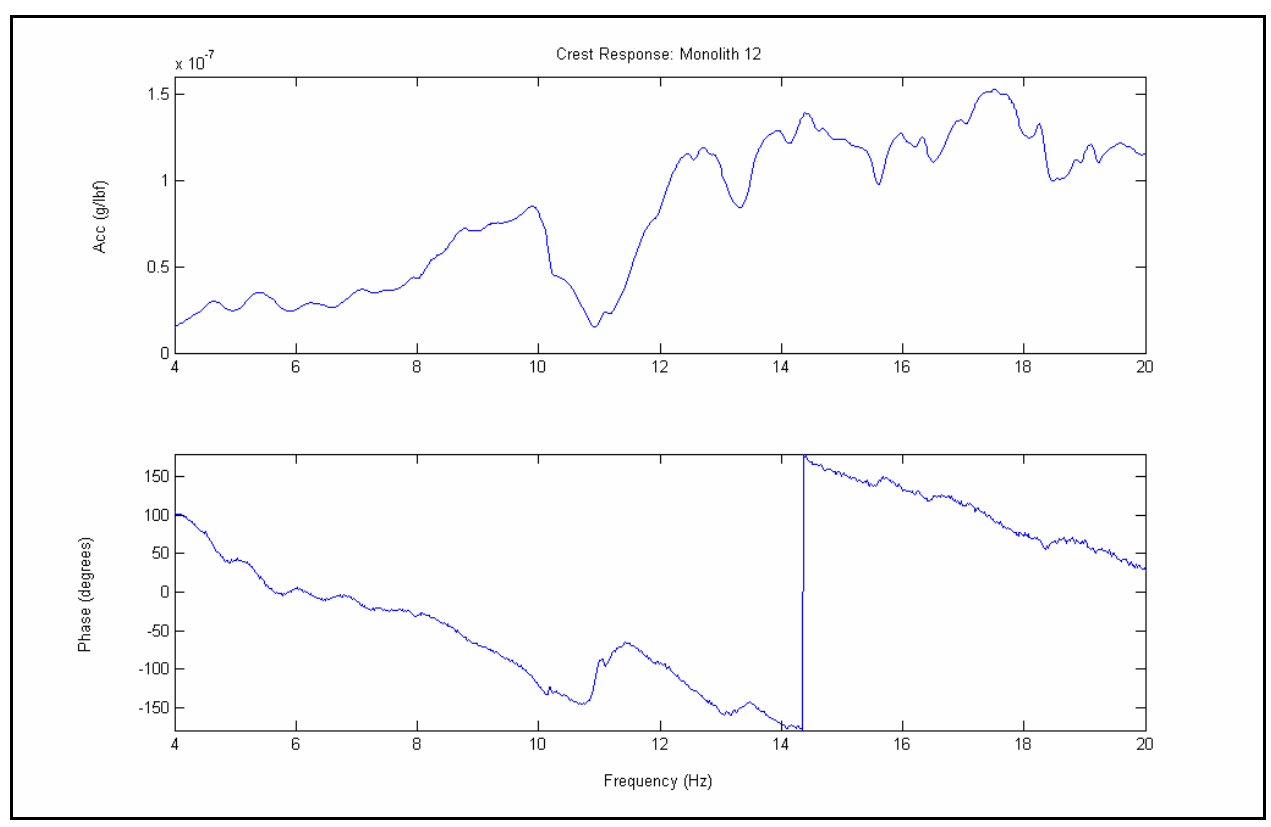

Figure A12. Crest response - Monolith 12 


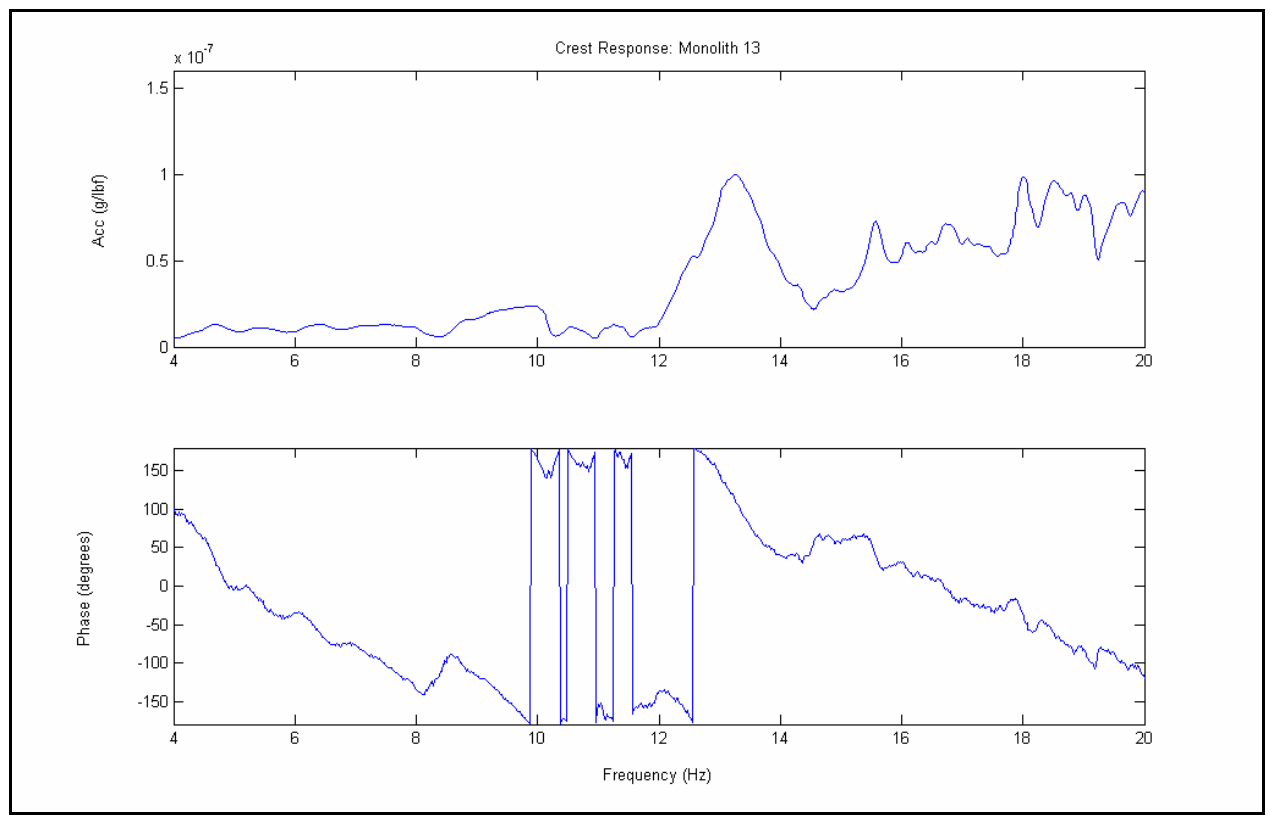

Figure A13. Crest response - Monolith 13

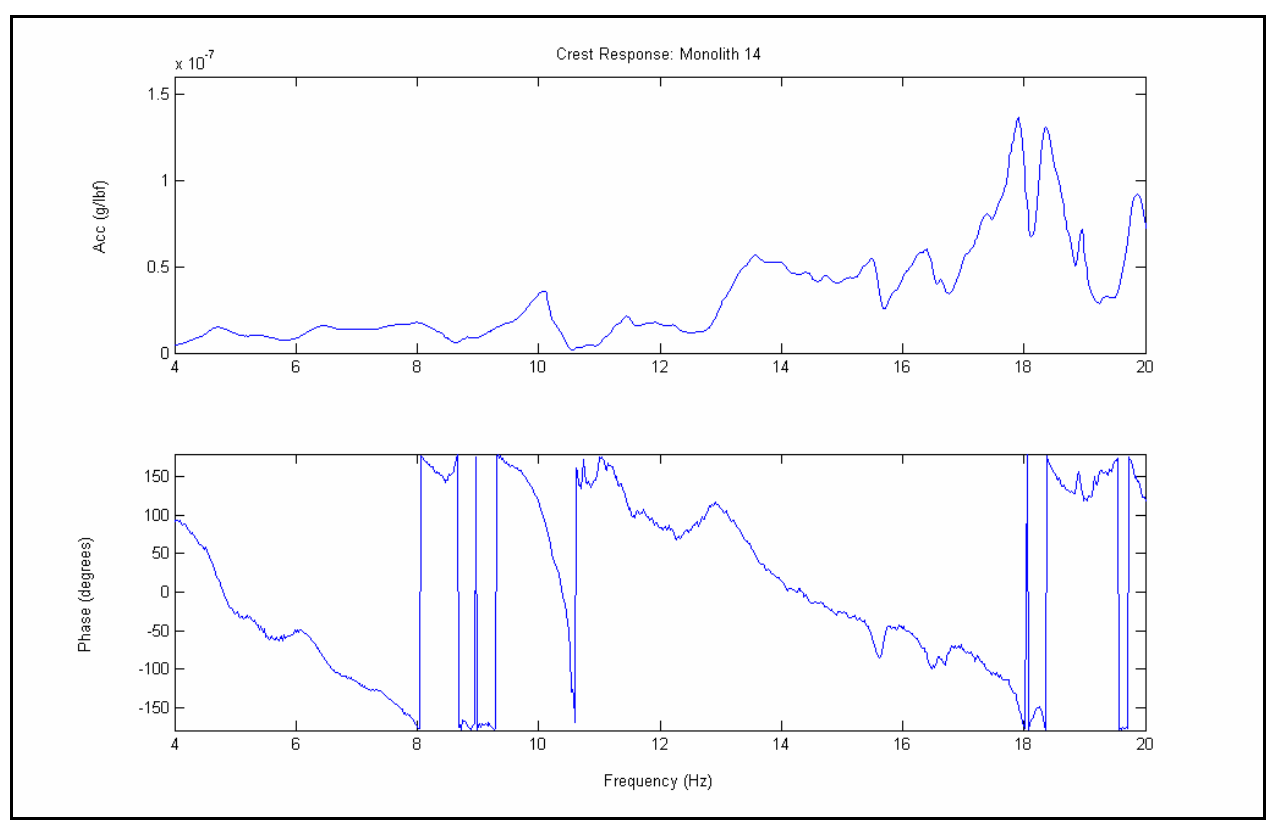

Figure A14. Crest response - Monolith 14 


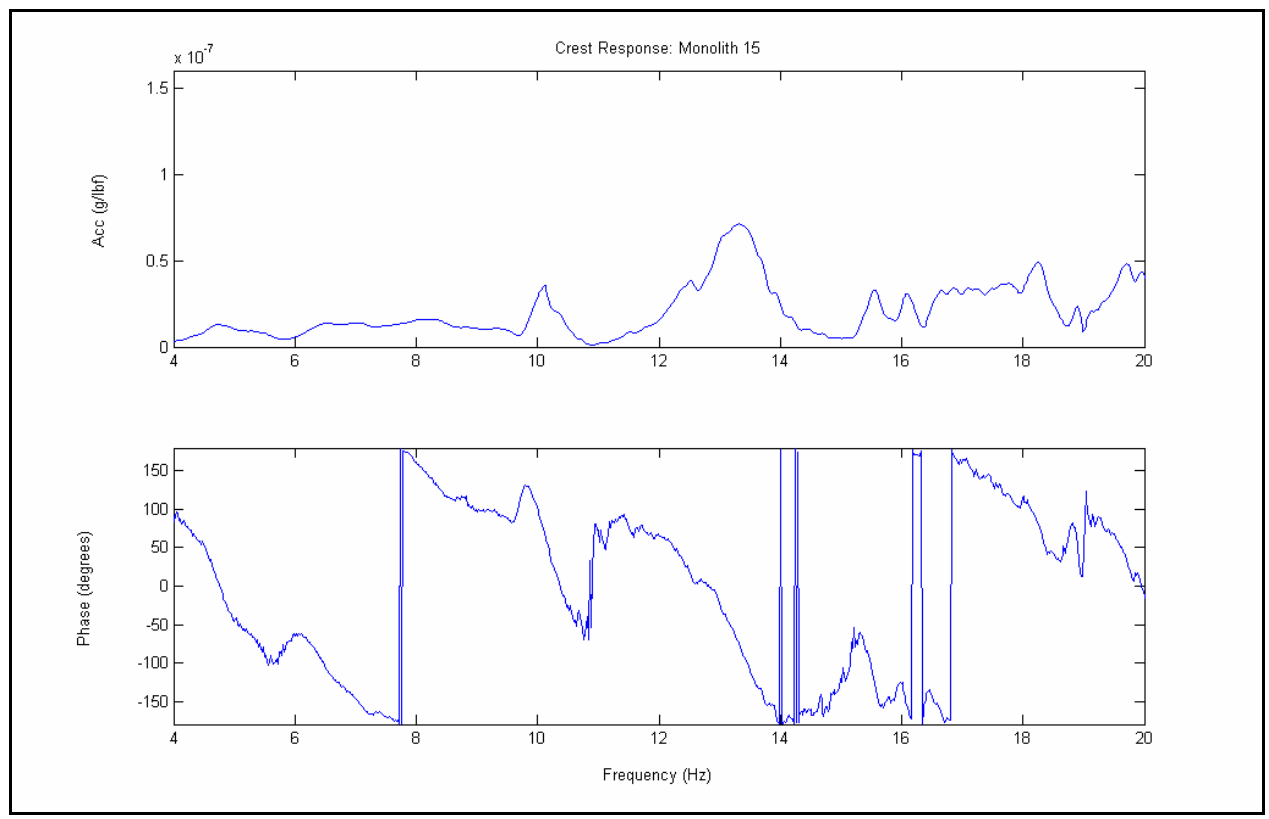

Figure A15. Crest response - Monolith 15

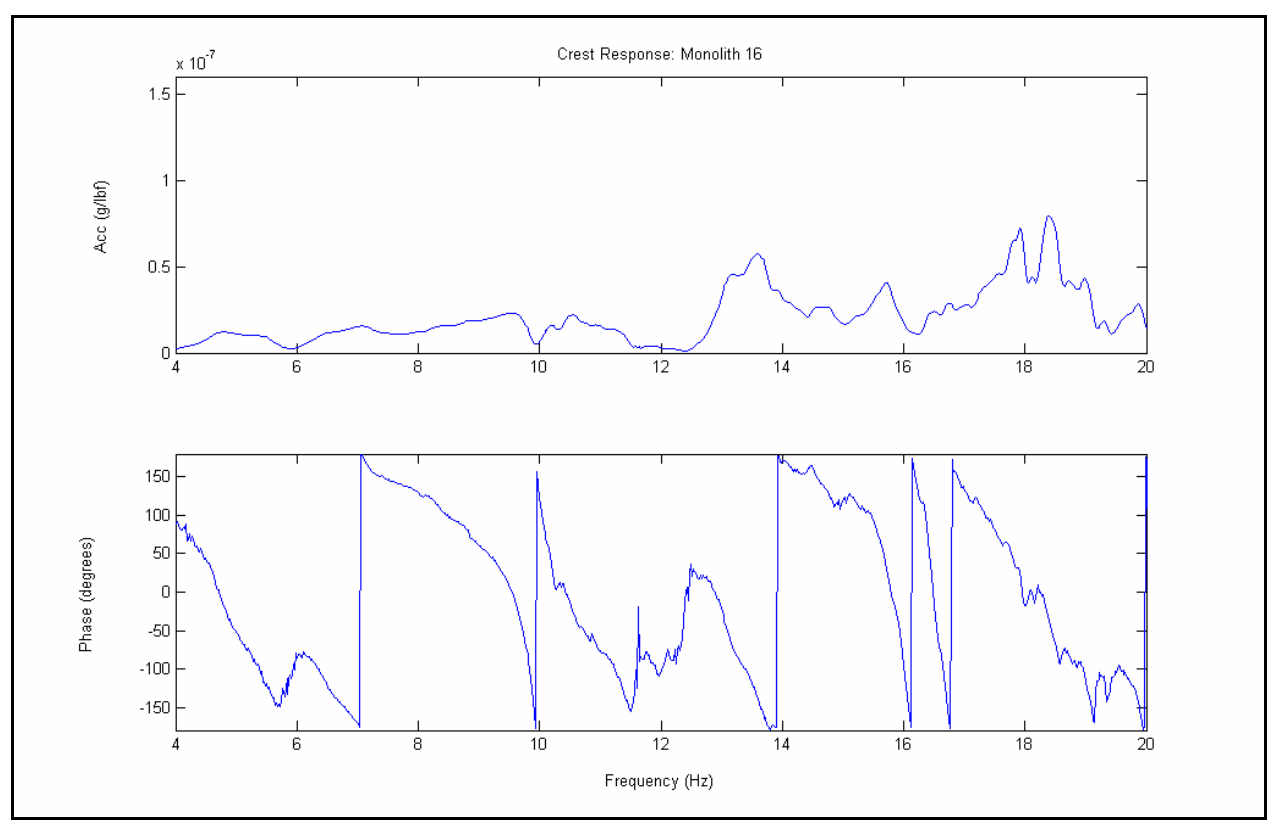

Figure A16. Crest response - Monolith 16 


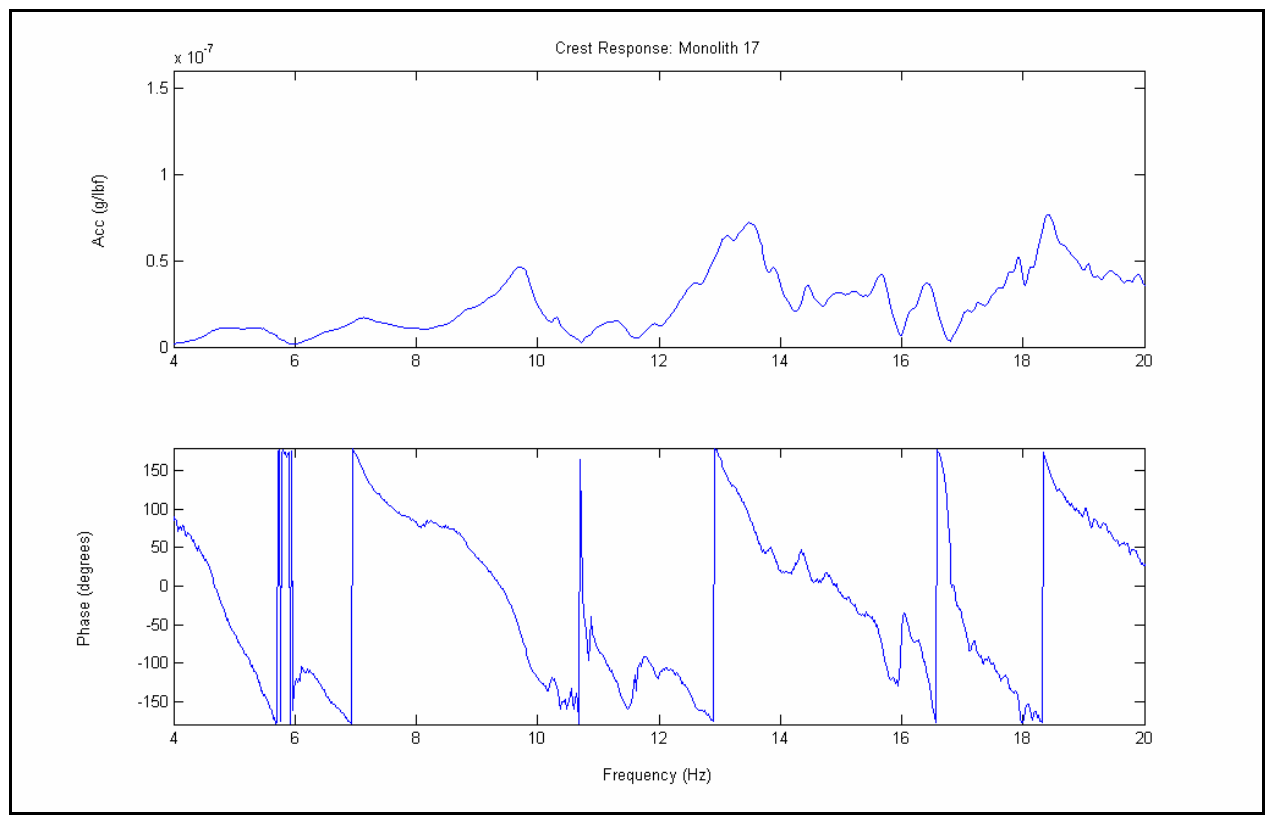

Figure A17. Crest response - Monolith 17

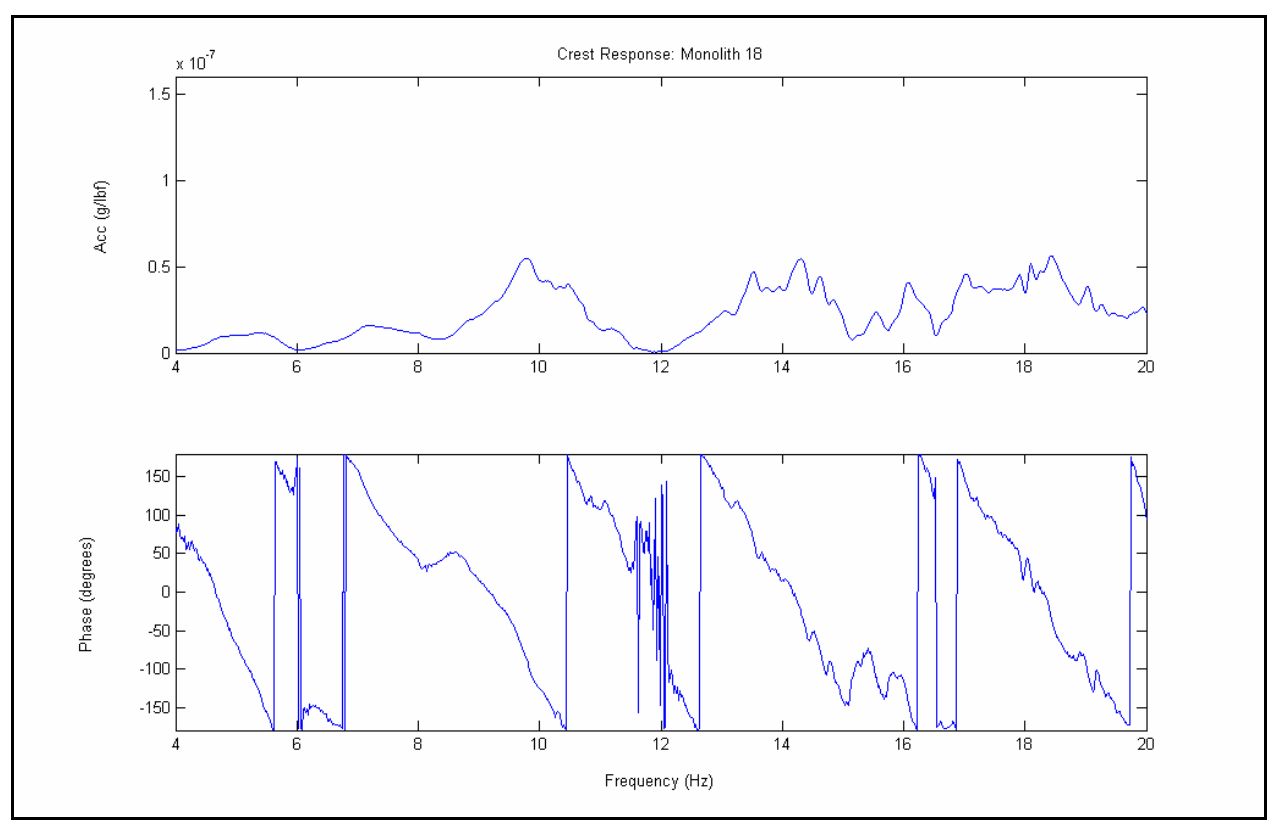

Figure A18. Crest response - Monolith 18 


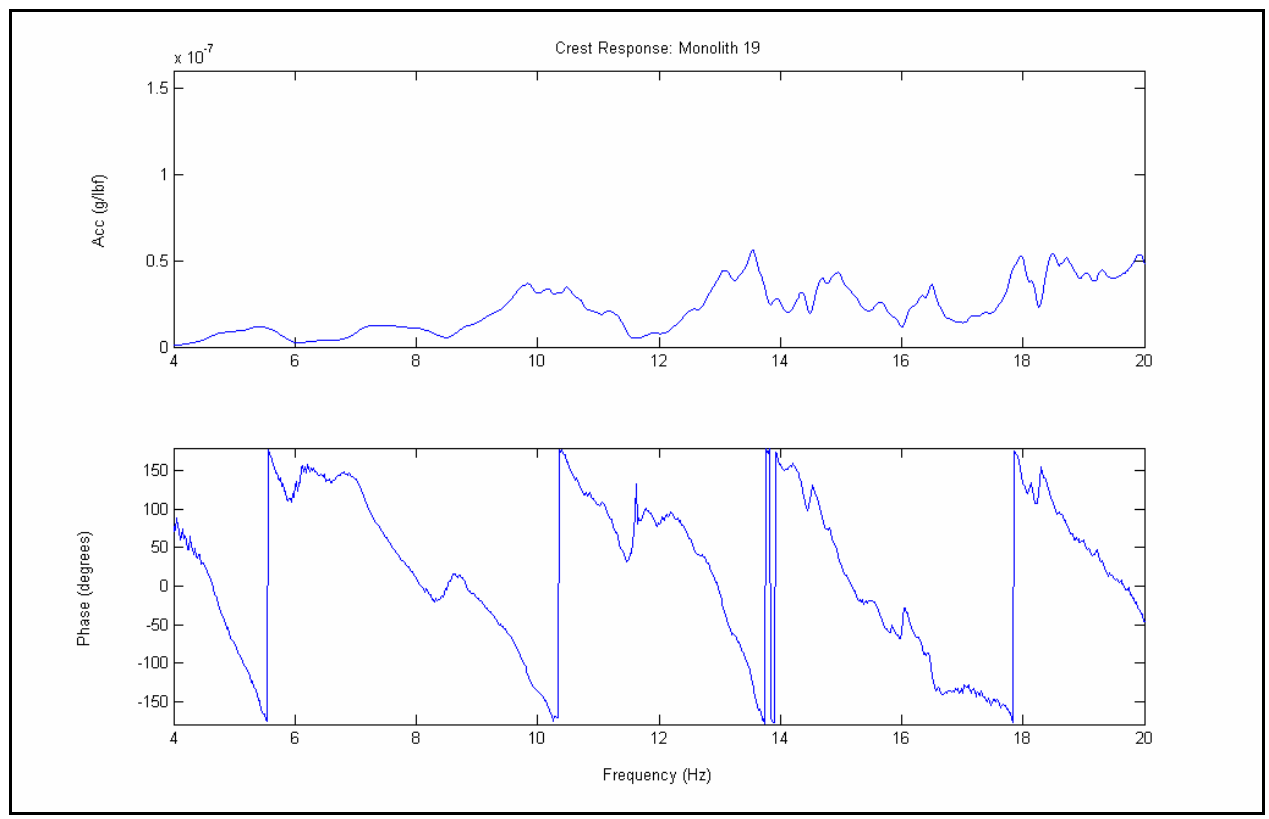

Figure A19. Crest response - Monolith 19

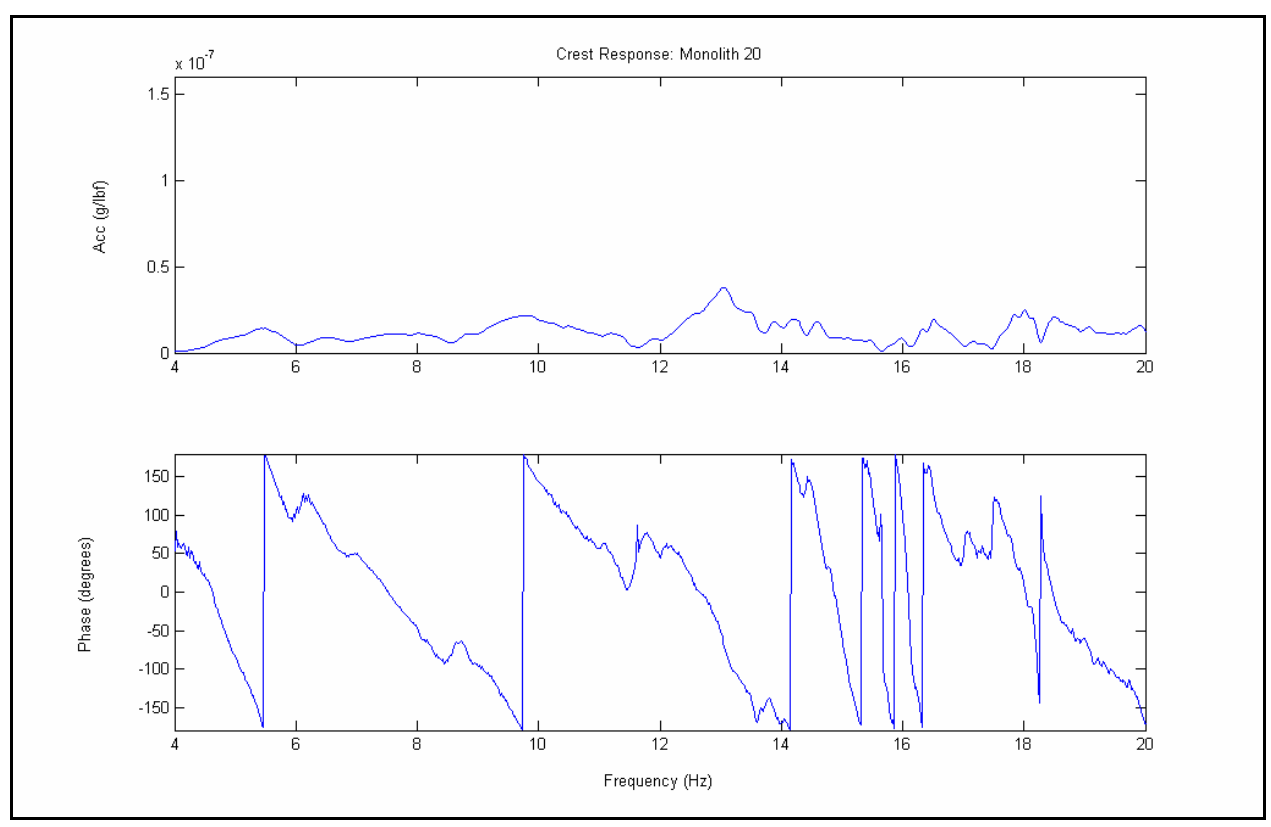

Figure A20. Crest response - Monolith 20 


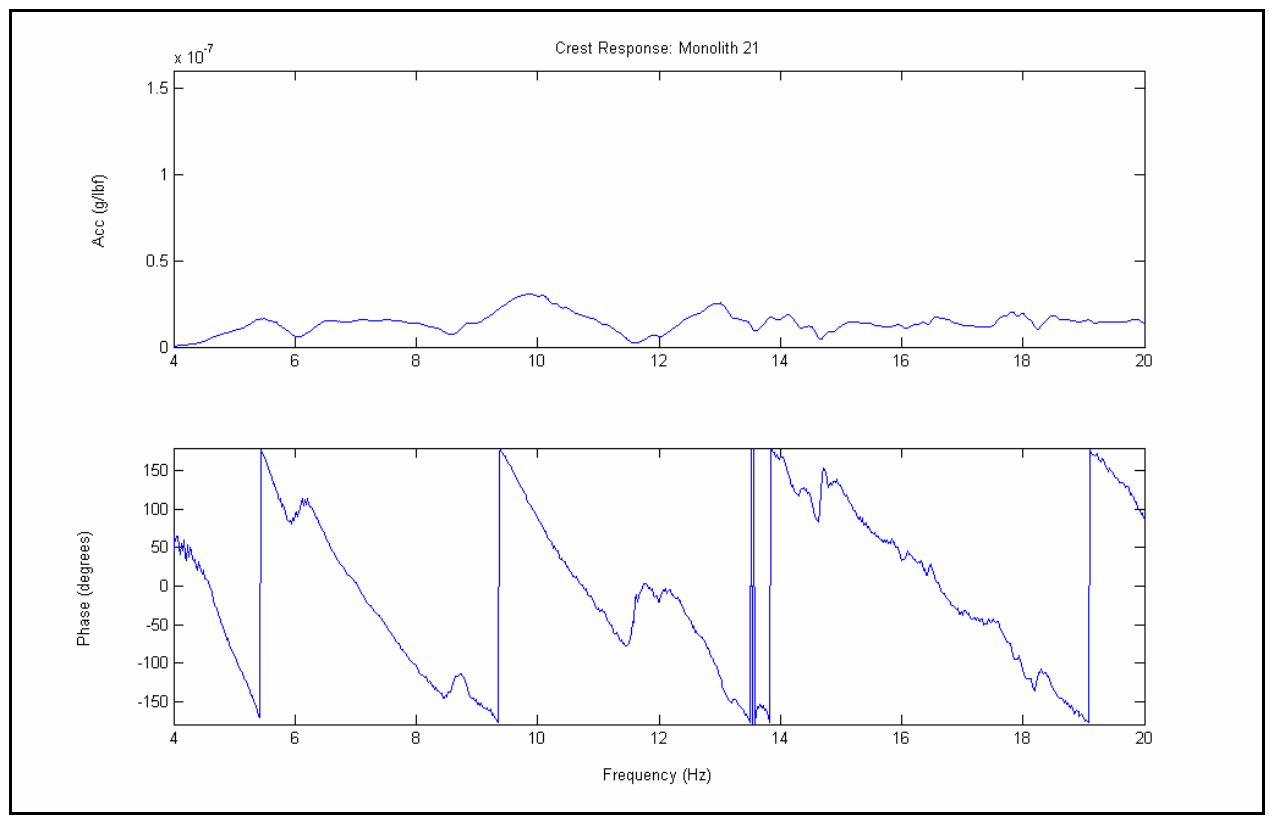

Figure A21. Crest response - Monolith 21

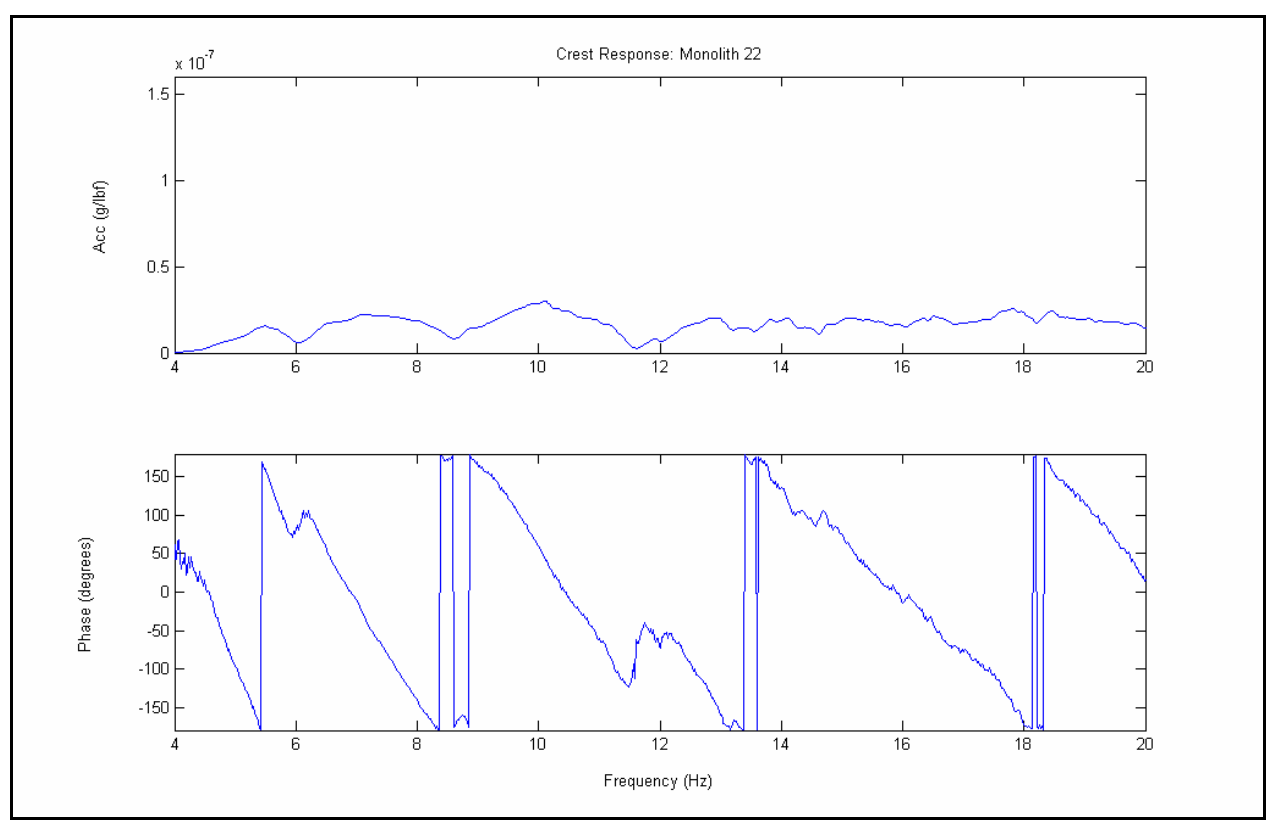

Figure A22. Crest response - Monolith 22 


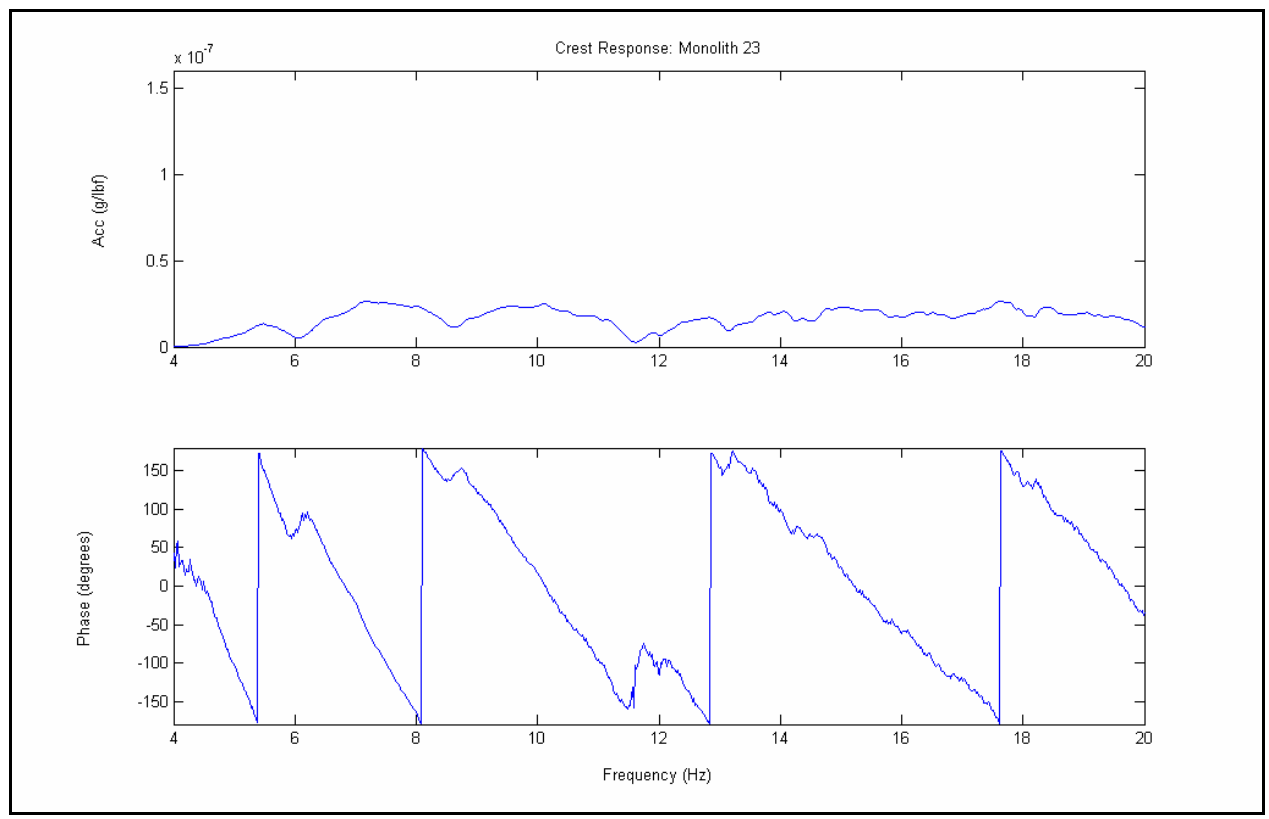

Figure A23. Crest response - Monolith 23

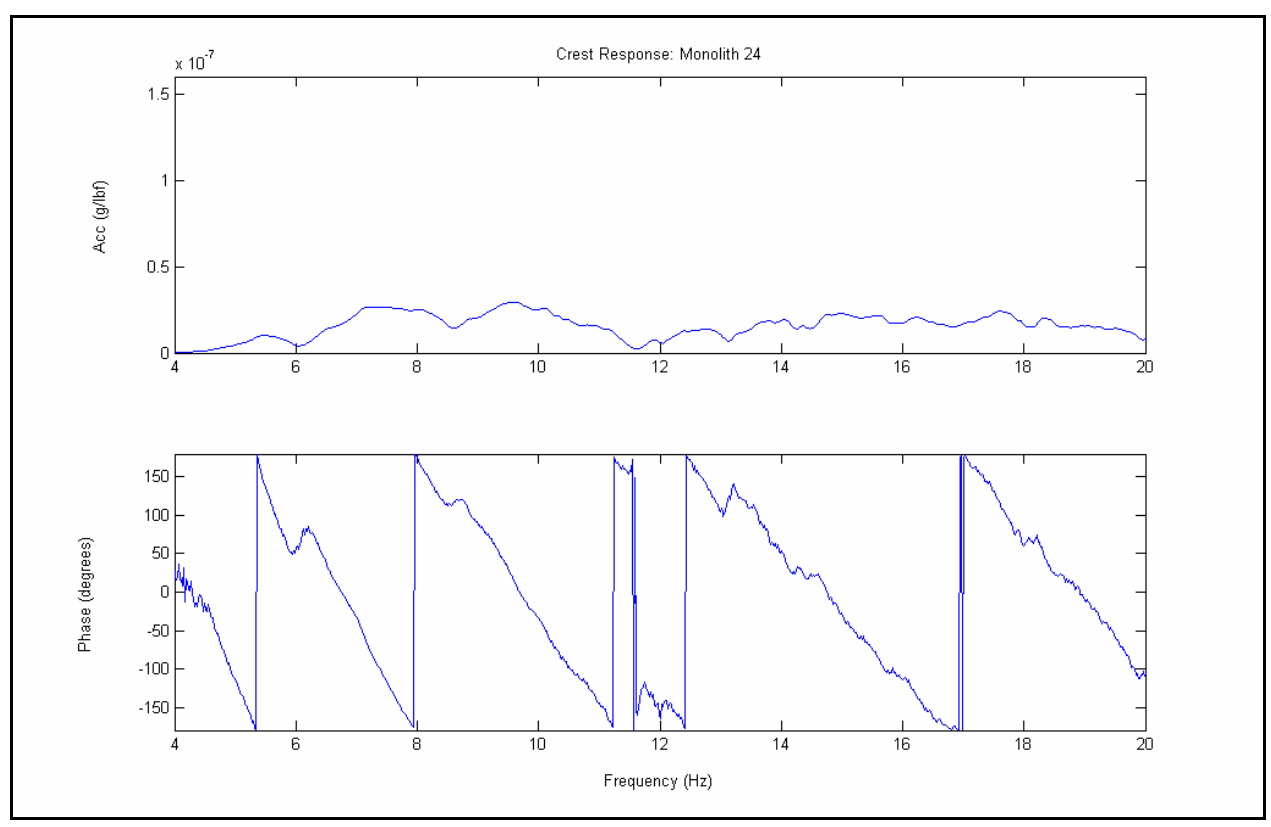

Figure A24. Crest response - Monolith 24 


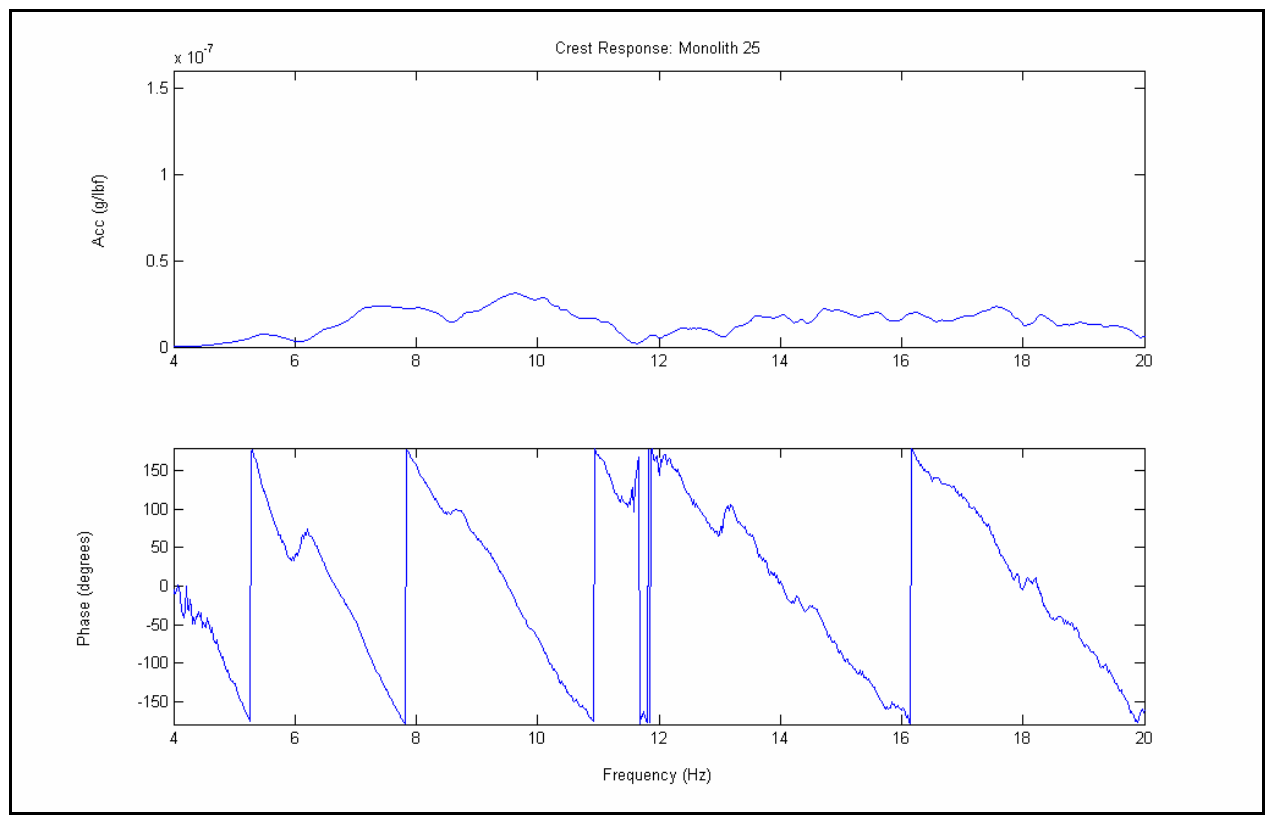

Figure A25. Crest response - Monolith 25

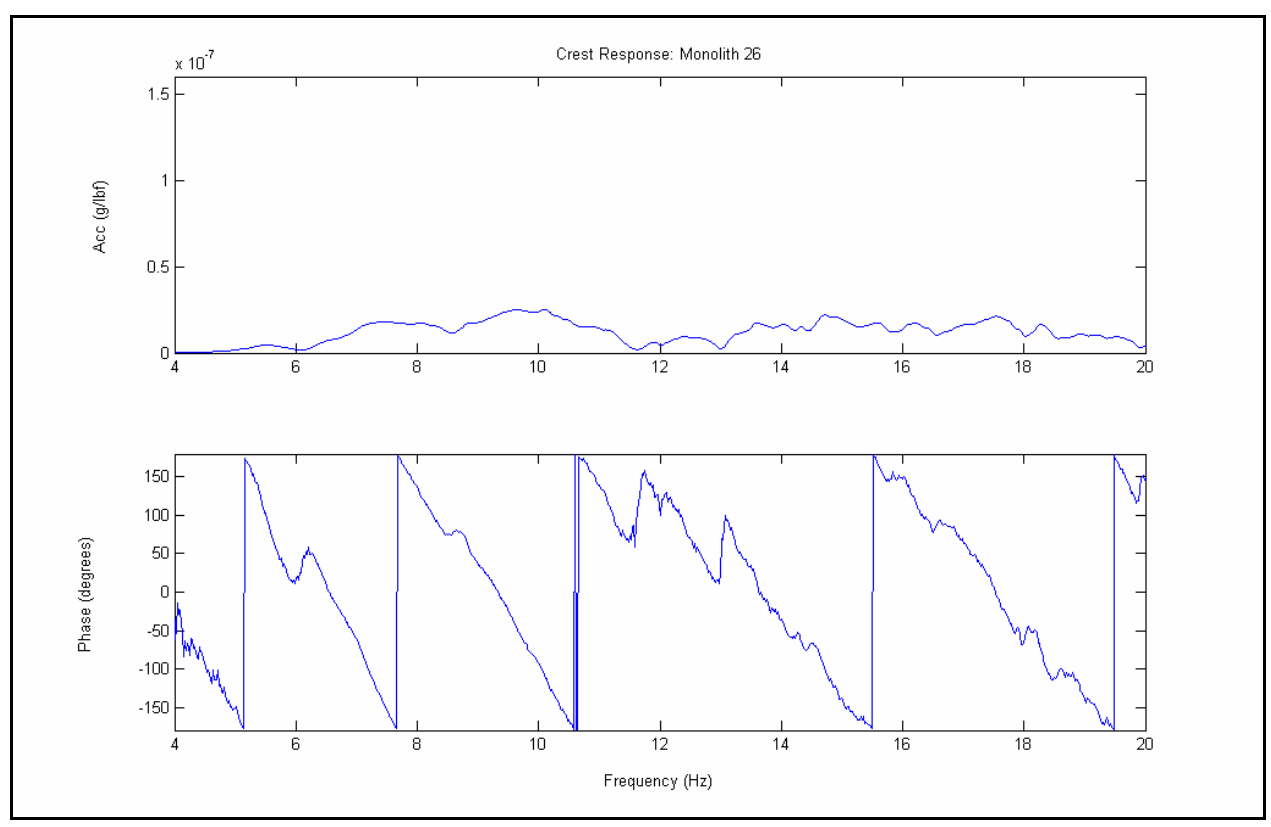

Figure A26. Crest response - Monolith 26 


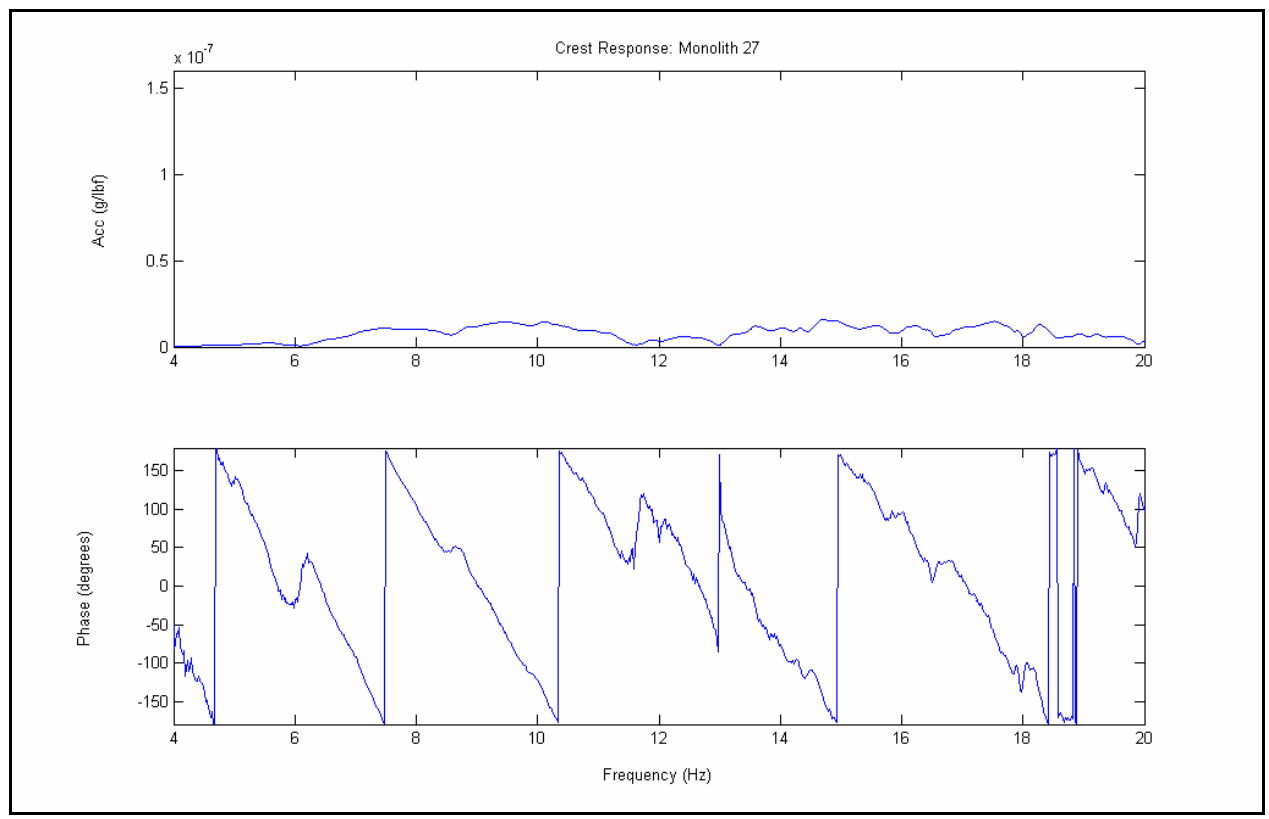

Figure A27. Crest response - Monolith 27

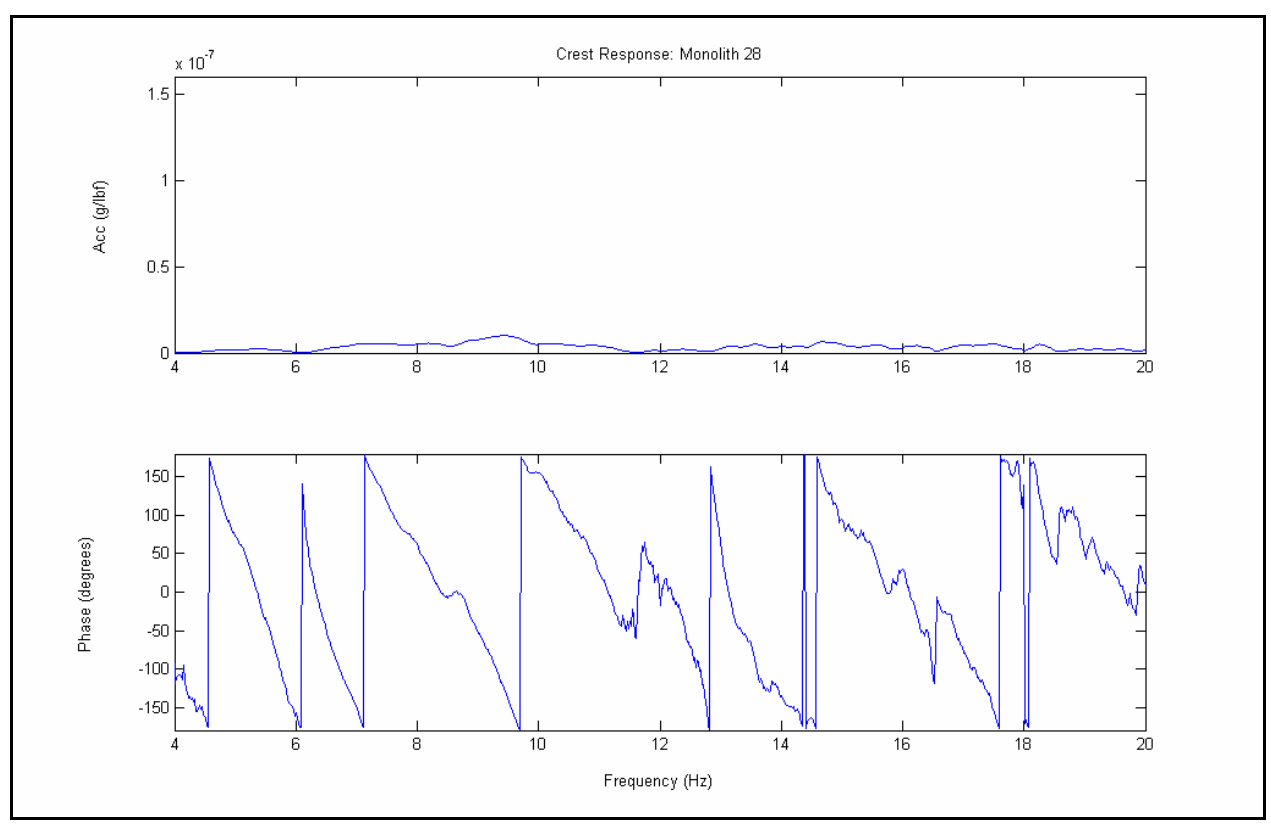

Figure A28. Crest response - Monolith 28 


\section{Appendix B Individual Monolith Response Curves}



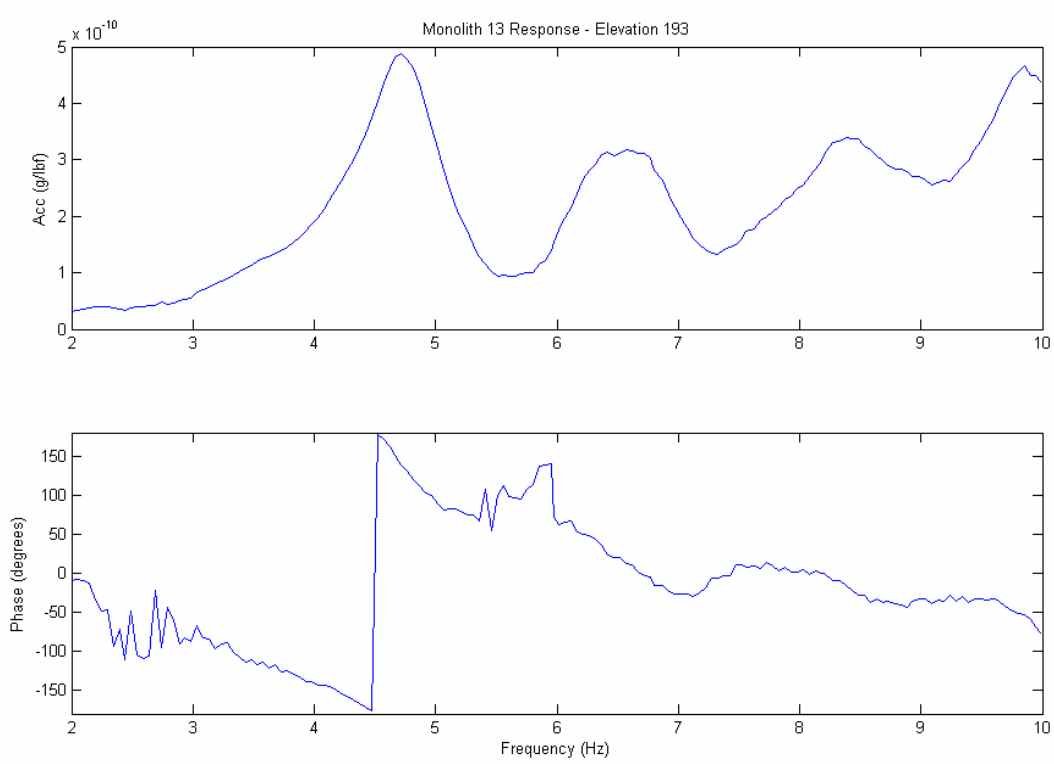

Figure B1. Monolith 13 response - Elevation $193 \mathrm{ft}$
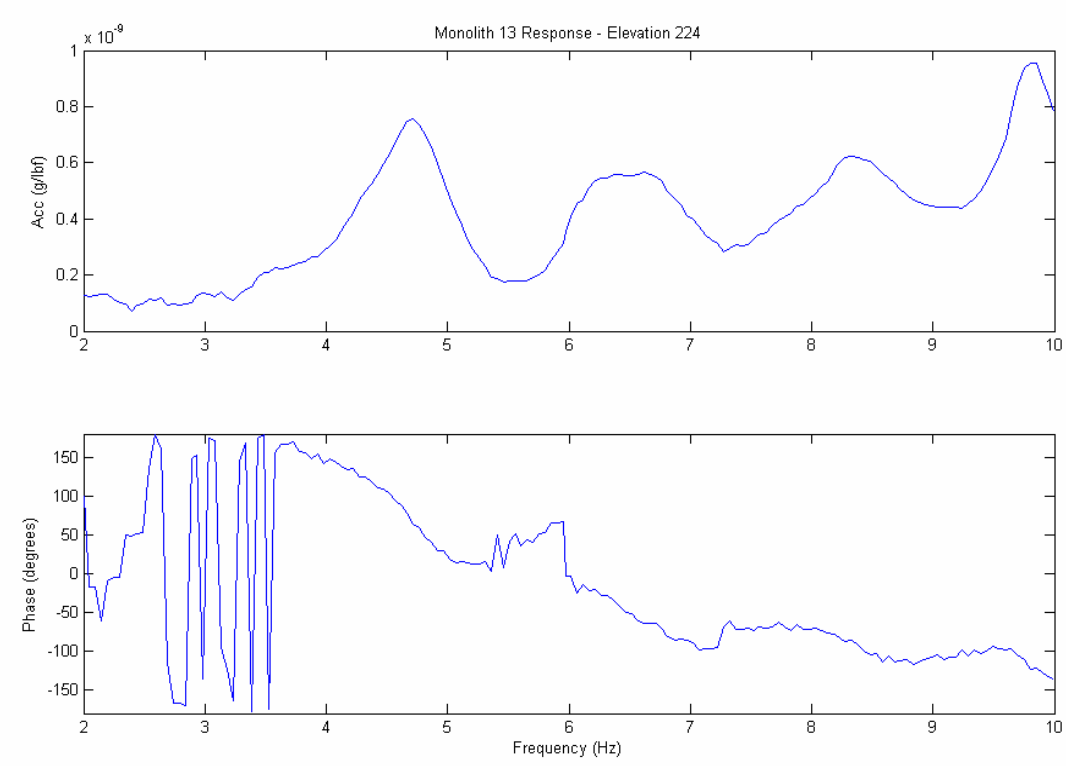

Figure B2. Monolith 13 response - Elevation $224 \mathrm{ft}$ 

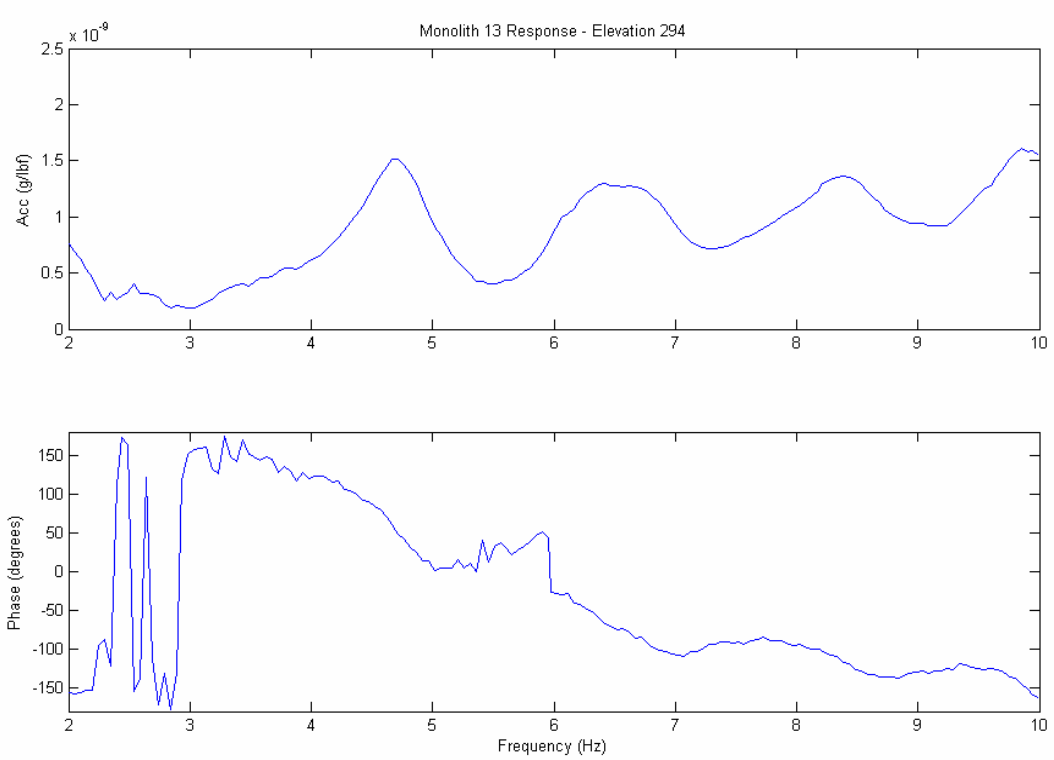

Figure B3. Monolith 13 response - Elevation $294 \mathrm{ft}$

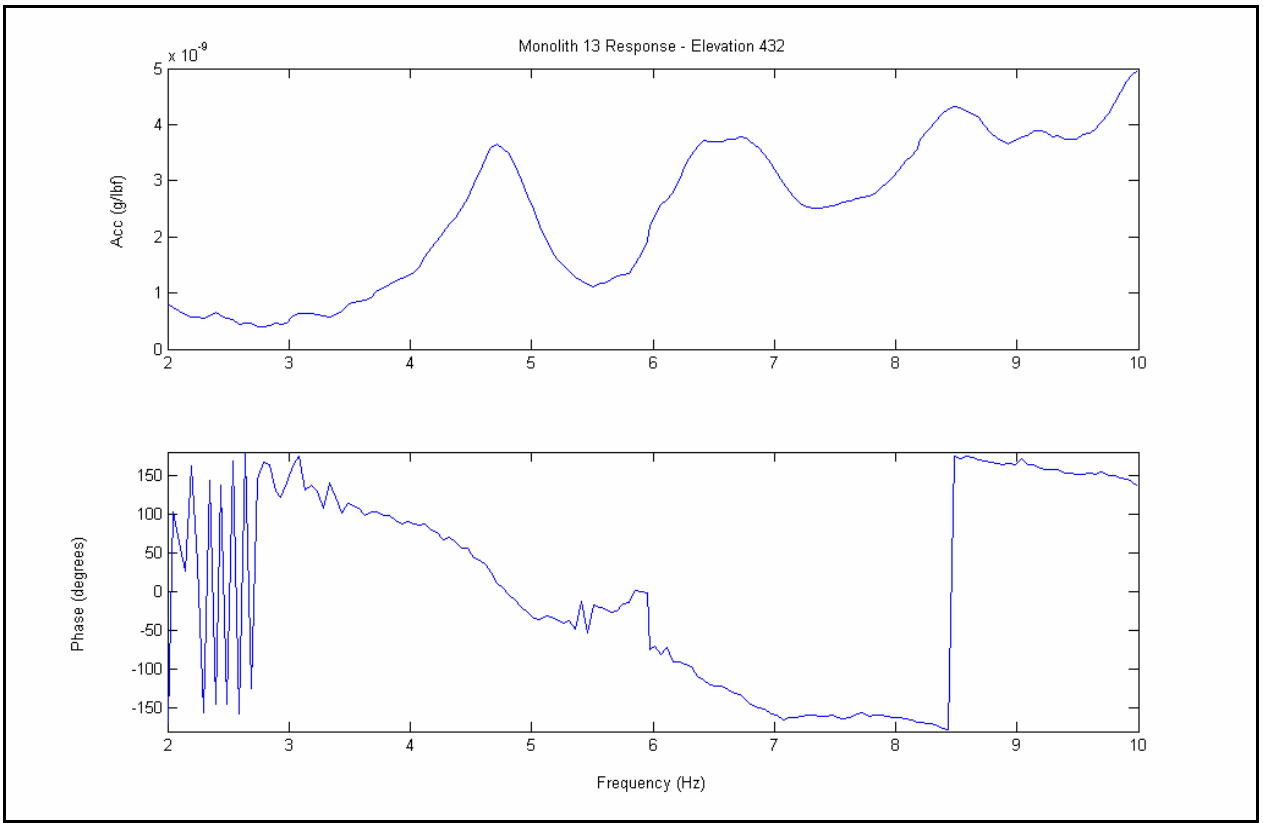

Figure B4. Monolith 13 response - Elevation $432 \mathrm{ft}$ 


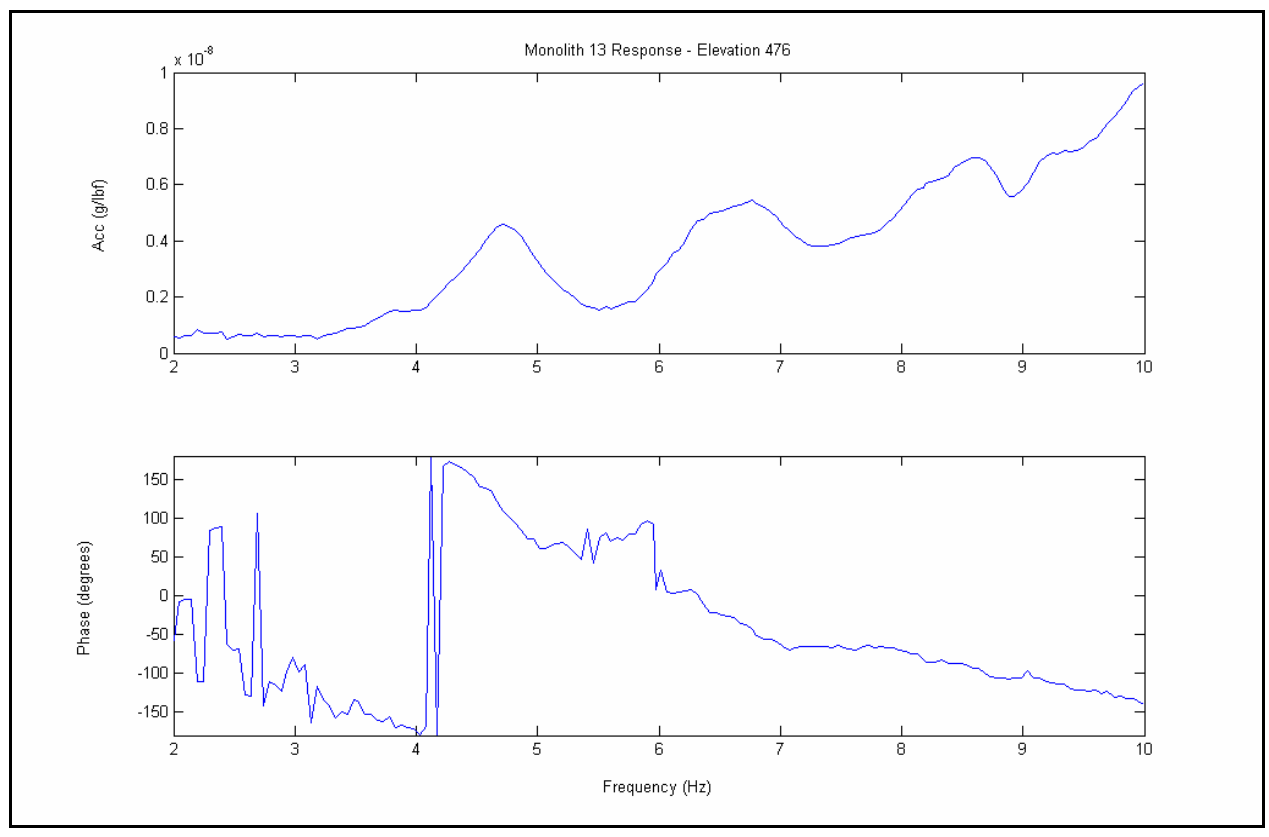

Figure B5. Monolith 13 response - Elevation $476 \mathrm{ft}$

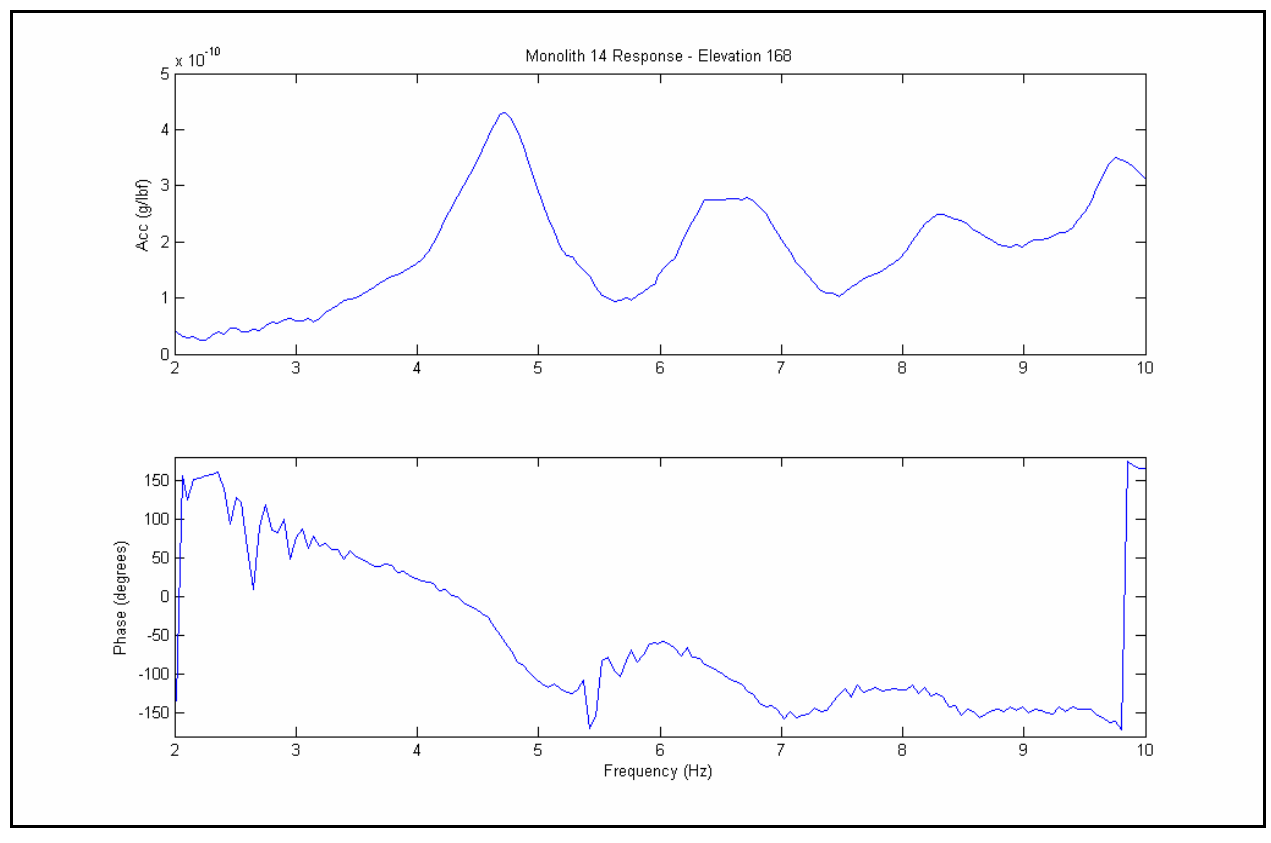

Figure B6. Monolith 14 response - Elevation $168 \mathrm{ft}$ 

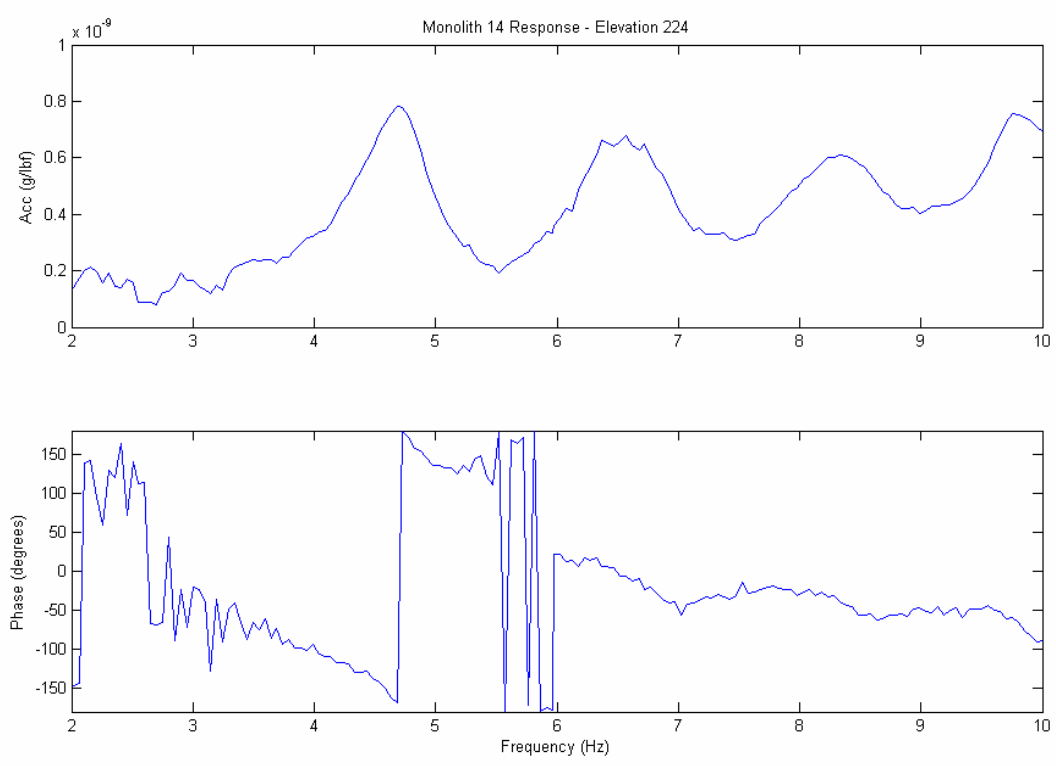

Figure B7. Monolith 14 response - Elevation $224 \mathrm{ft}$
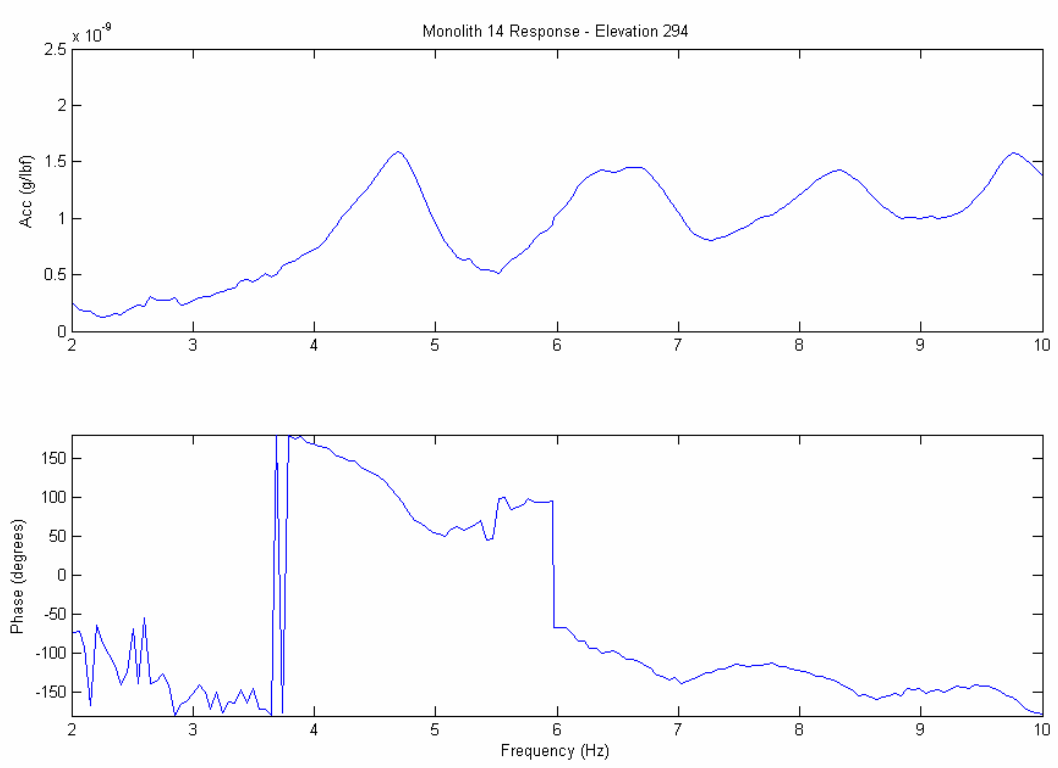

Figure B8. Monolith 14 response - Elevation $294 \mathrm{ft}$ 


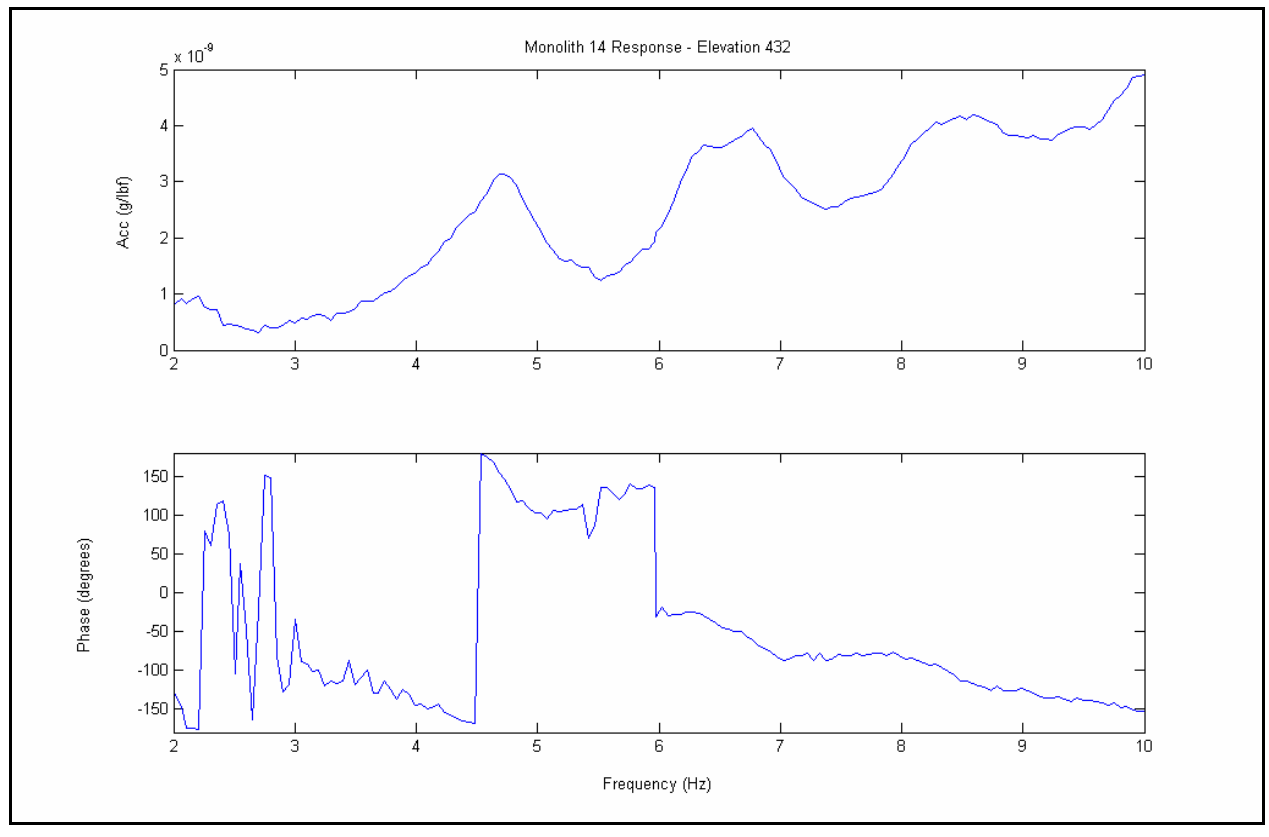

Figure B9. Monolith 14 response - Elevation $432 \mathrm{ft}$

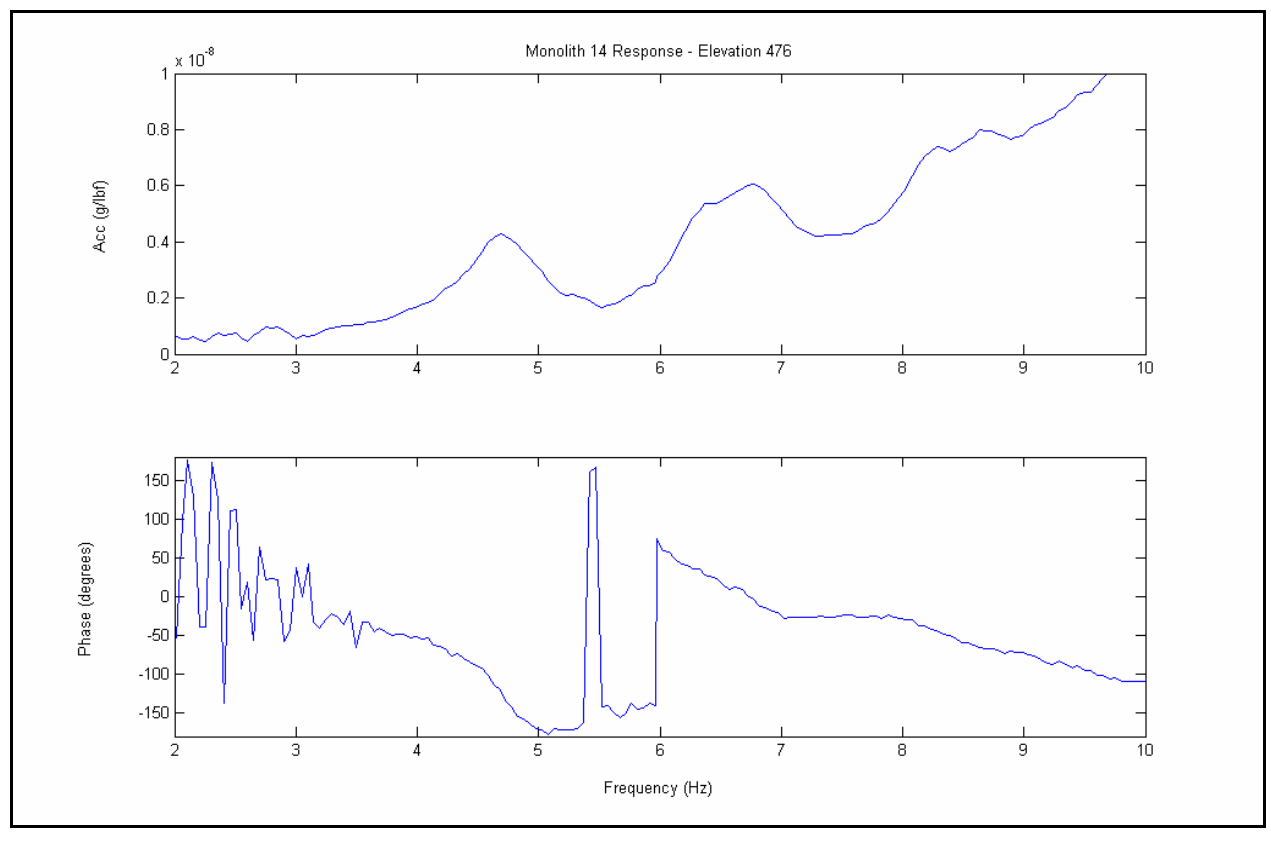

Figure B10. Monolith 14 response - Elevation $476 \mathrm{ft}$ 


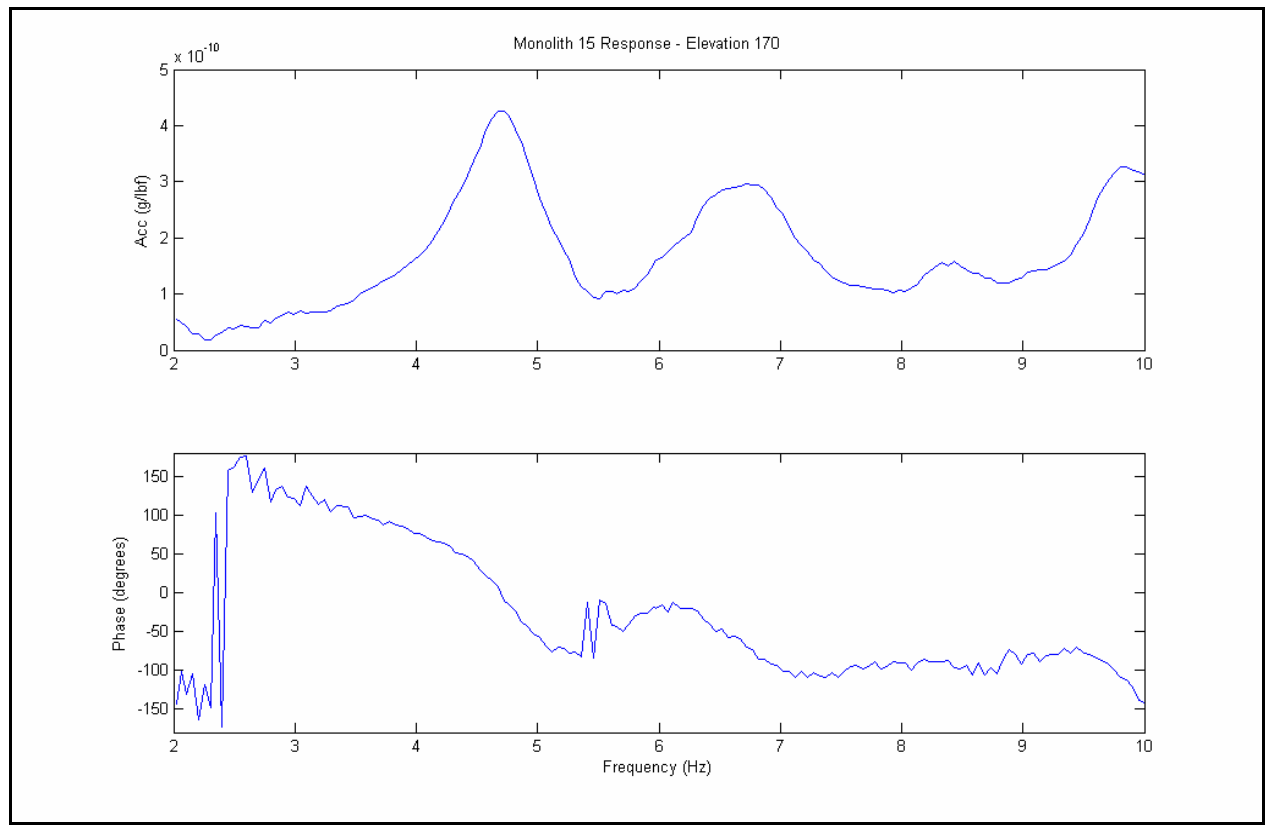

Figure B11. Monolith 15 response - Elevation $170 \mathrm{ft}$
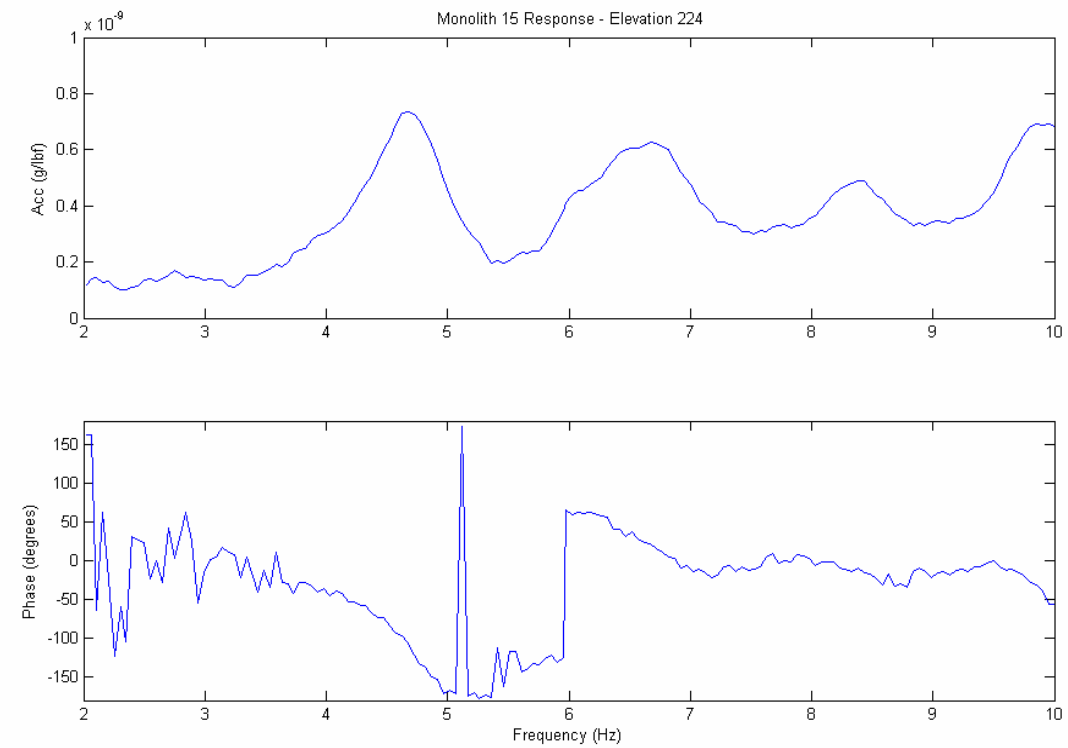

Figure B12. Monolith 15 response - Elevation $224 \mathrm{ft}$ 


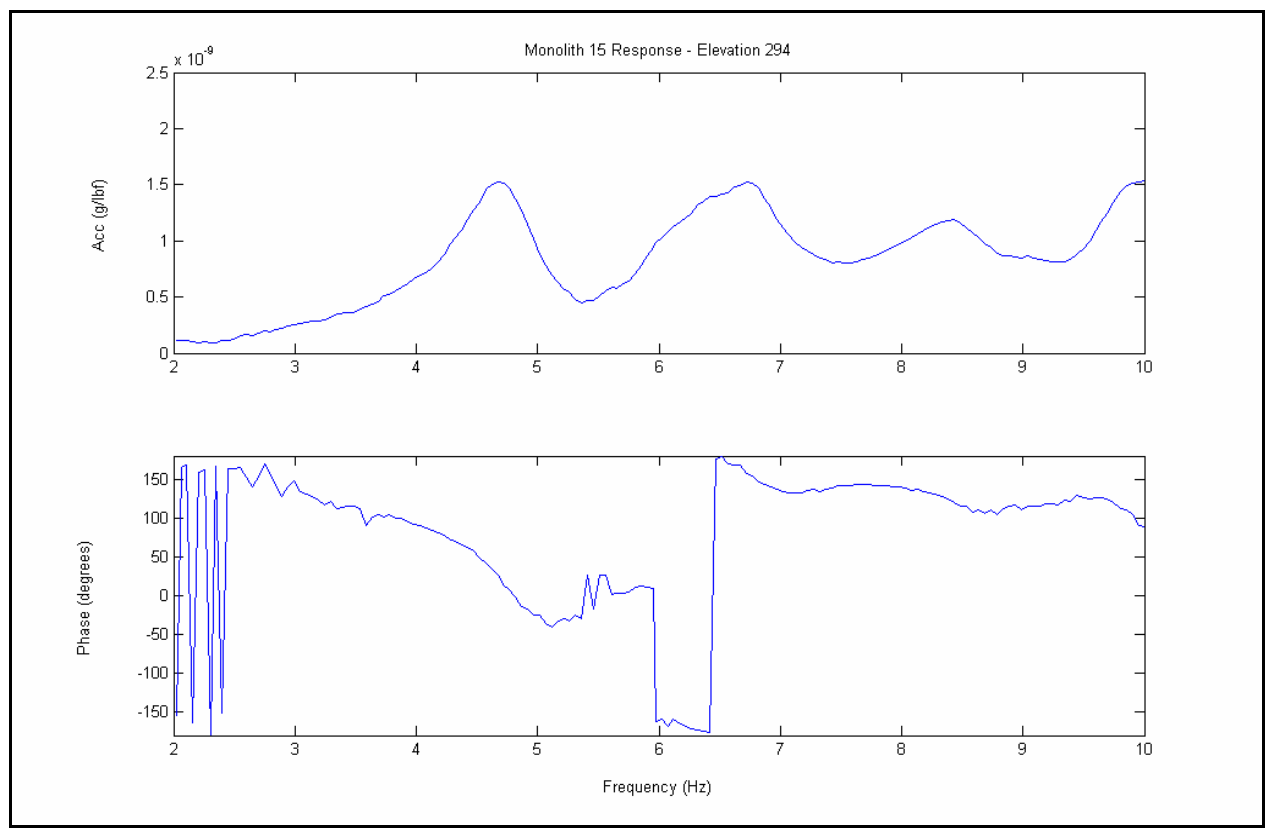

Figure B13. Monolith 15 response - Elevation $294 \mathrm{ft}$

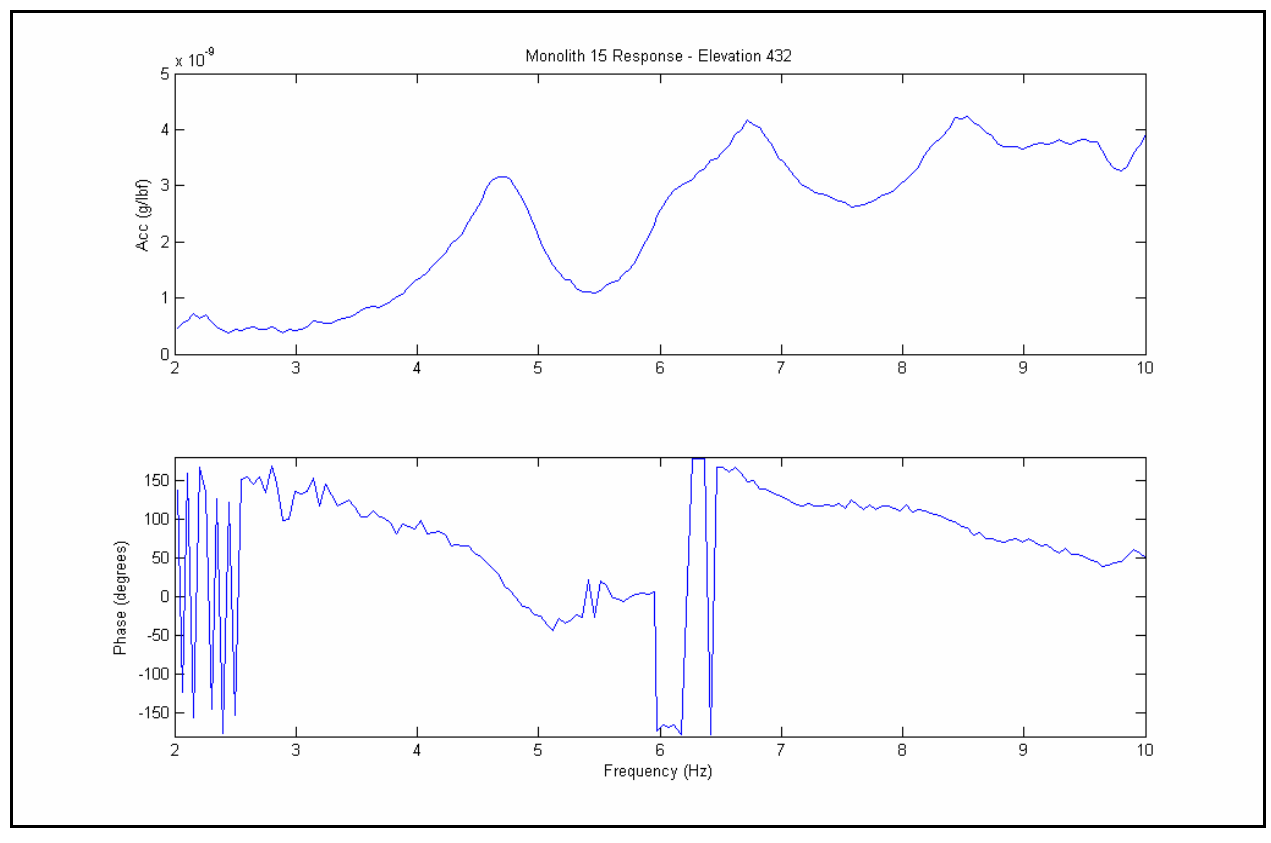

Figure B14. Monolith 15 response - Elevation $432 \mathrm{ft}$ 


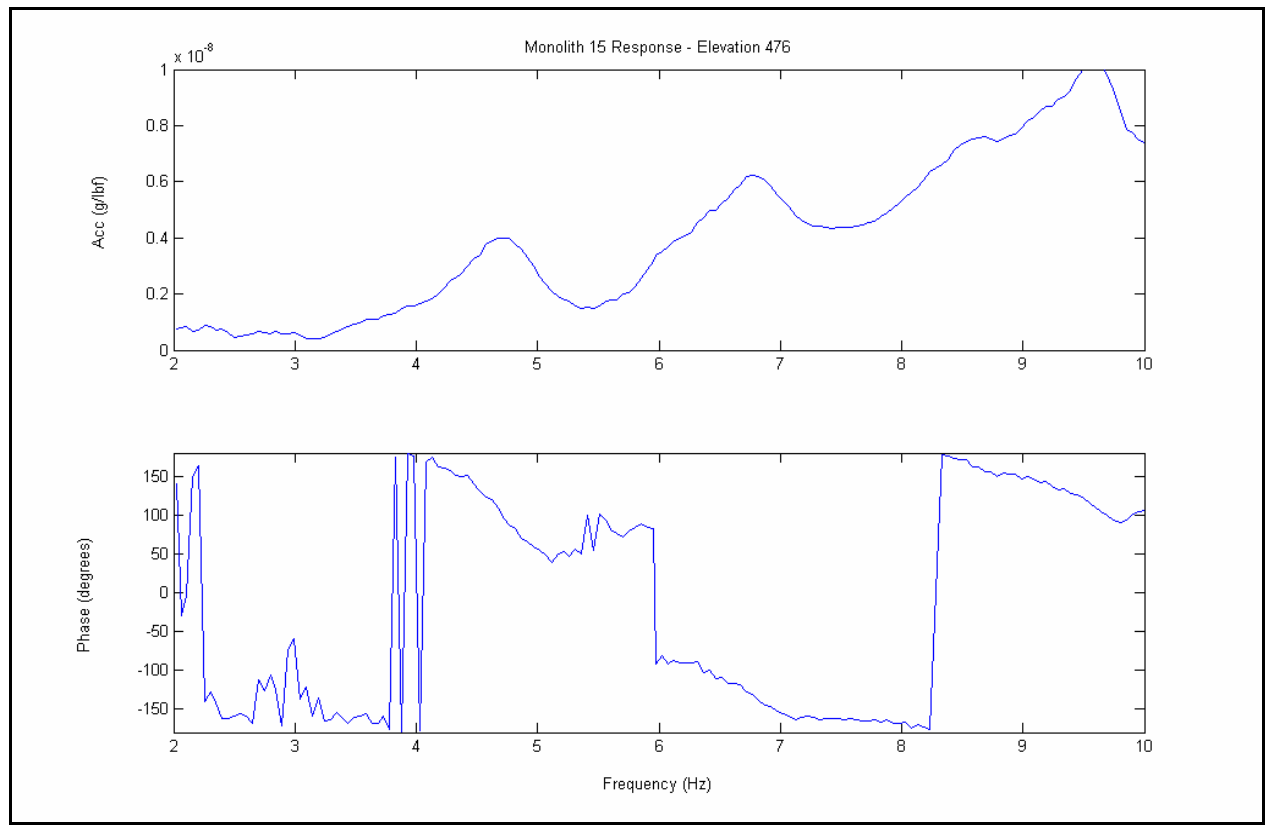

Figure B15. Monolith 15 response - Elevation $476 \mathrm{ft}$

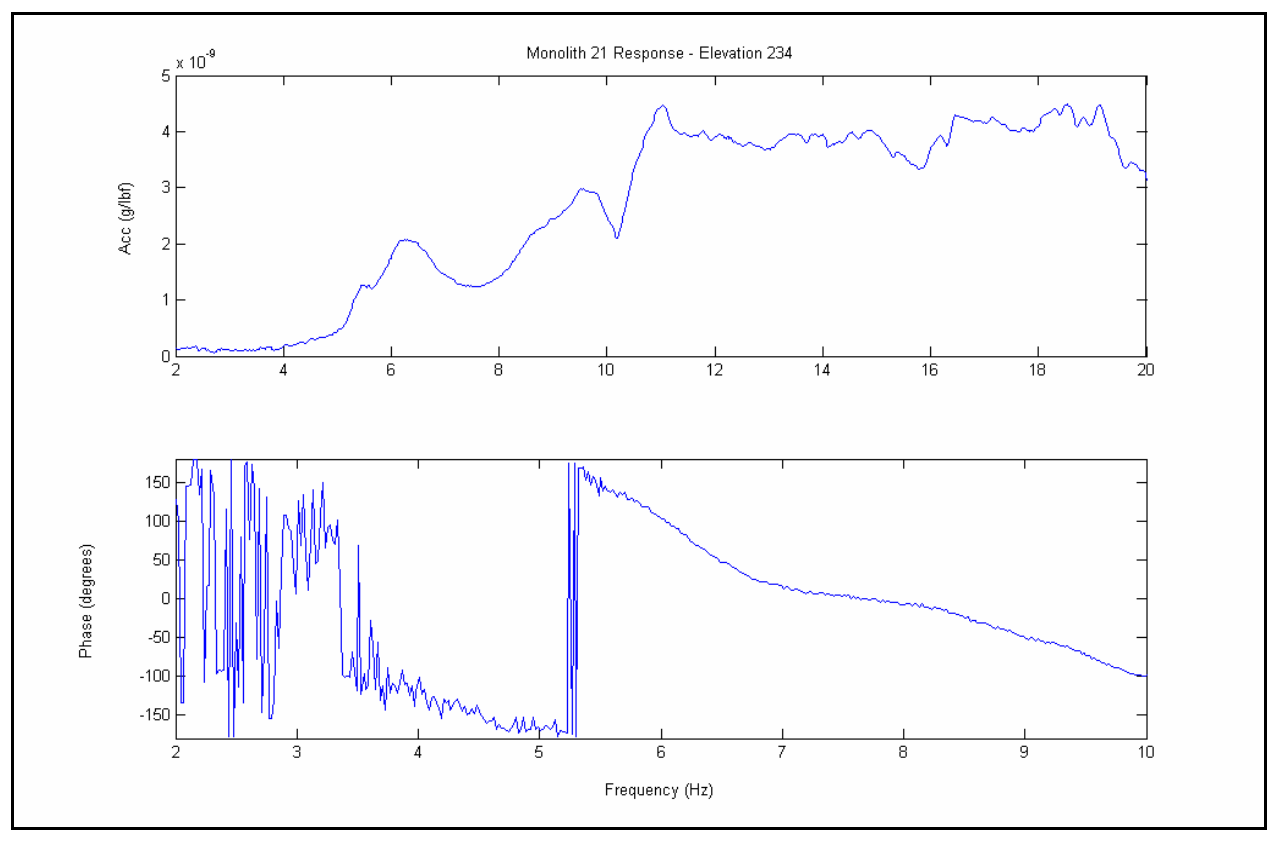

Figure B16. Monolith 21 response - Elevation $243 \mathrm{ft}$ 

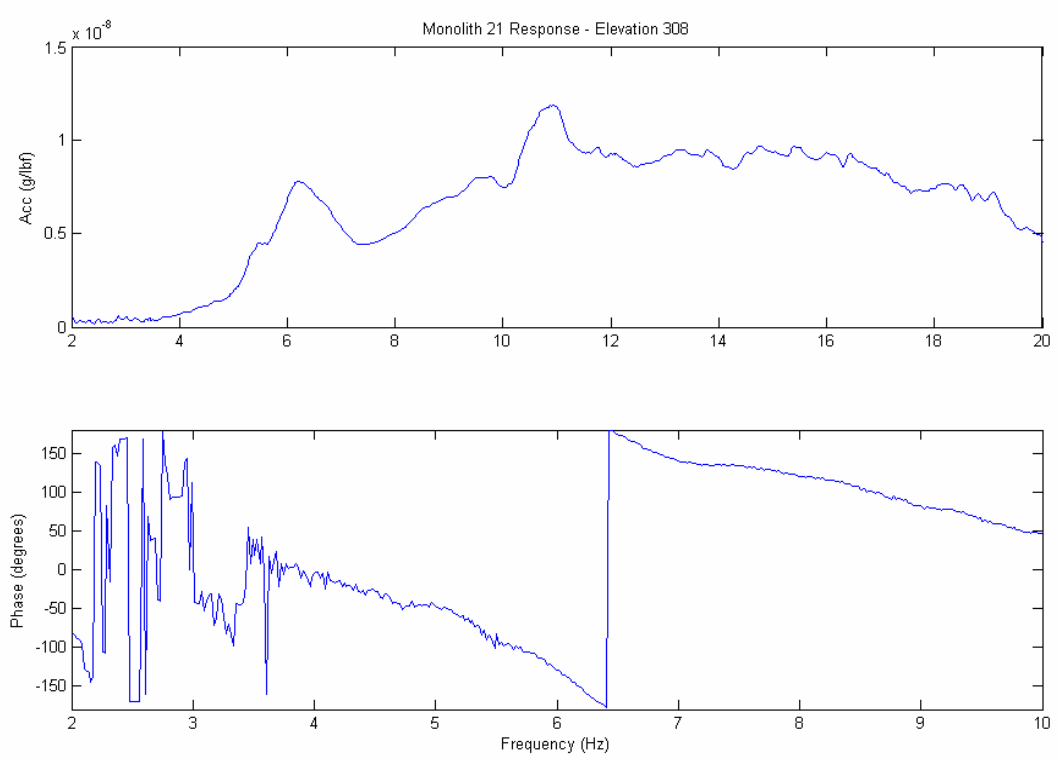

Figure B17. Monolith 21 response - Elevation $308 \mathrm{ft}$
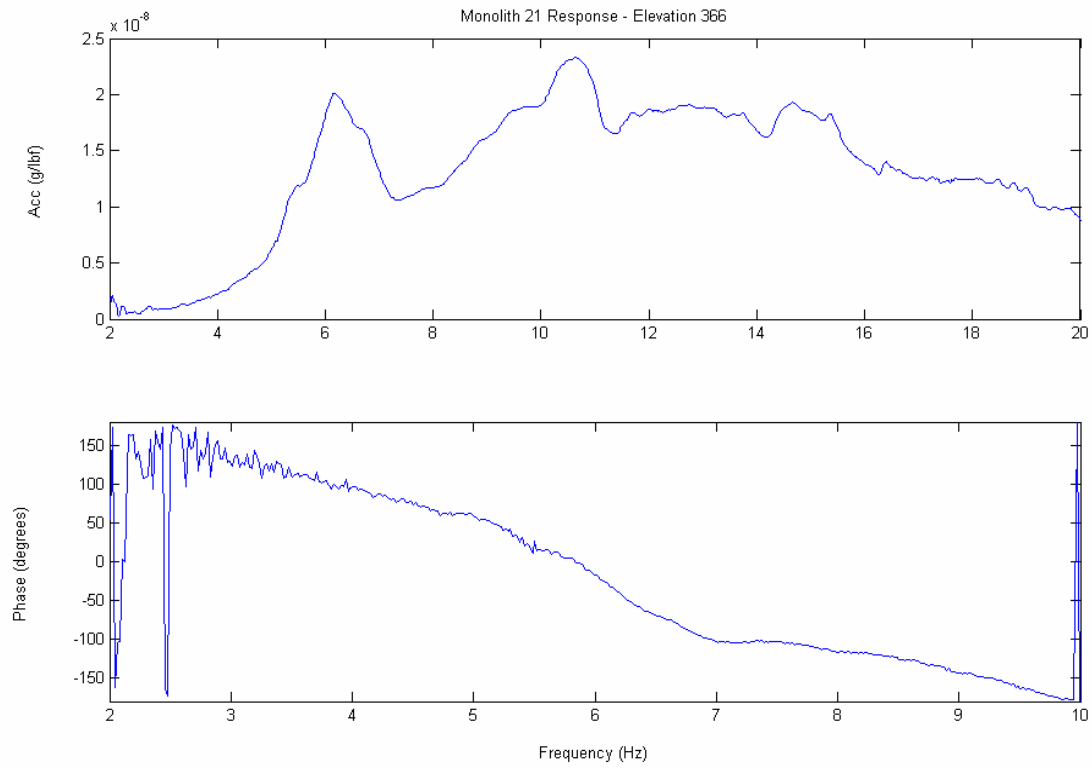

Figure B18. Monolith 21 response - Elevation $366 \mathrm{ft}$ 


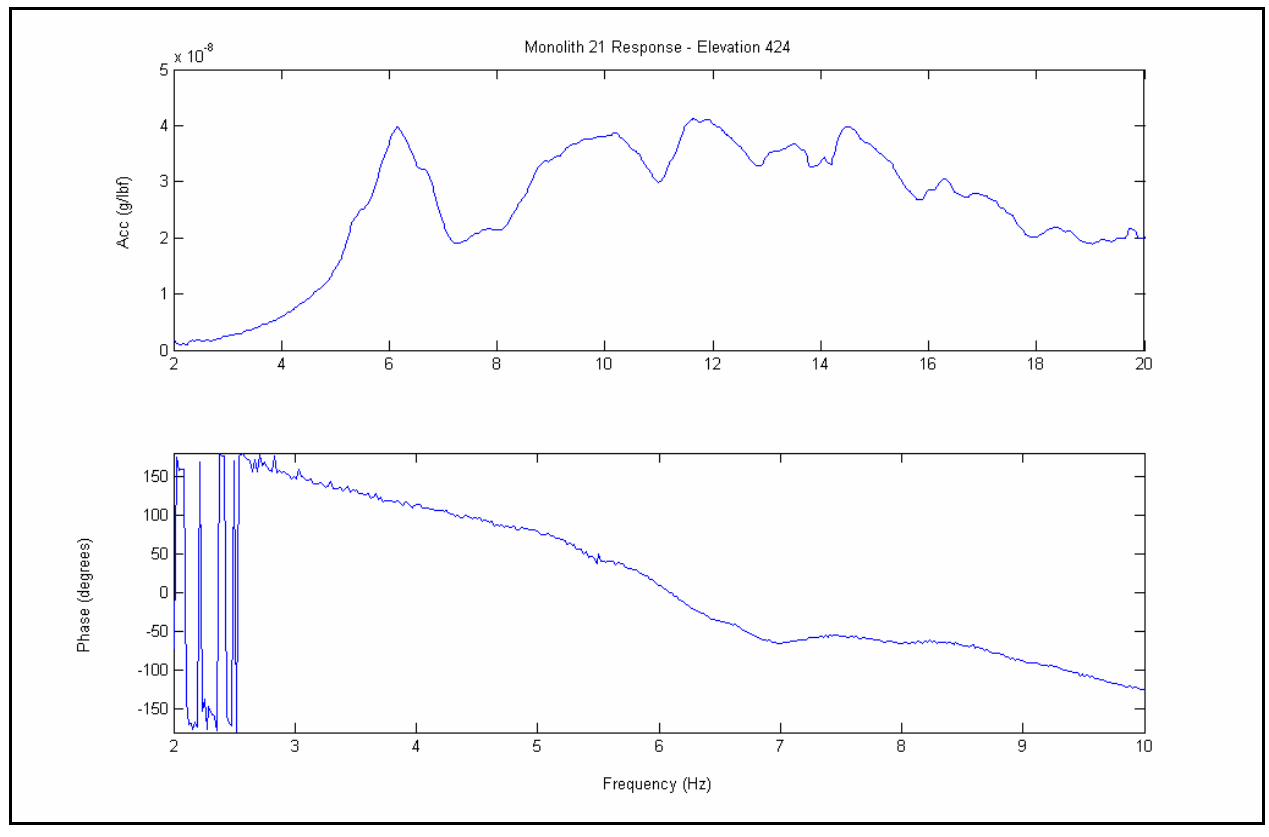

Figure B19. Monolith 21 response - Elevation $424 \mathrm{ft}$

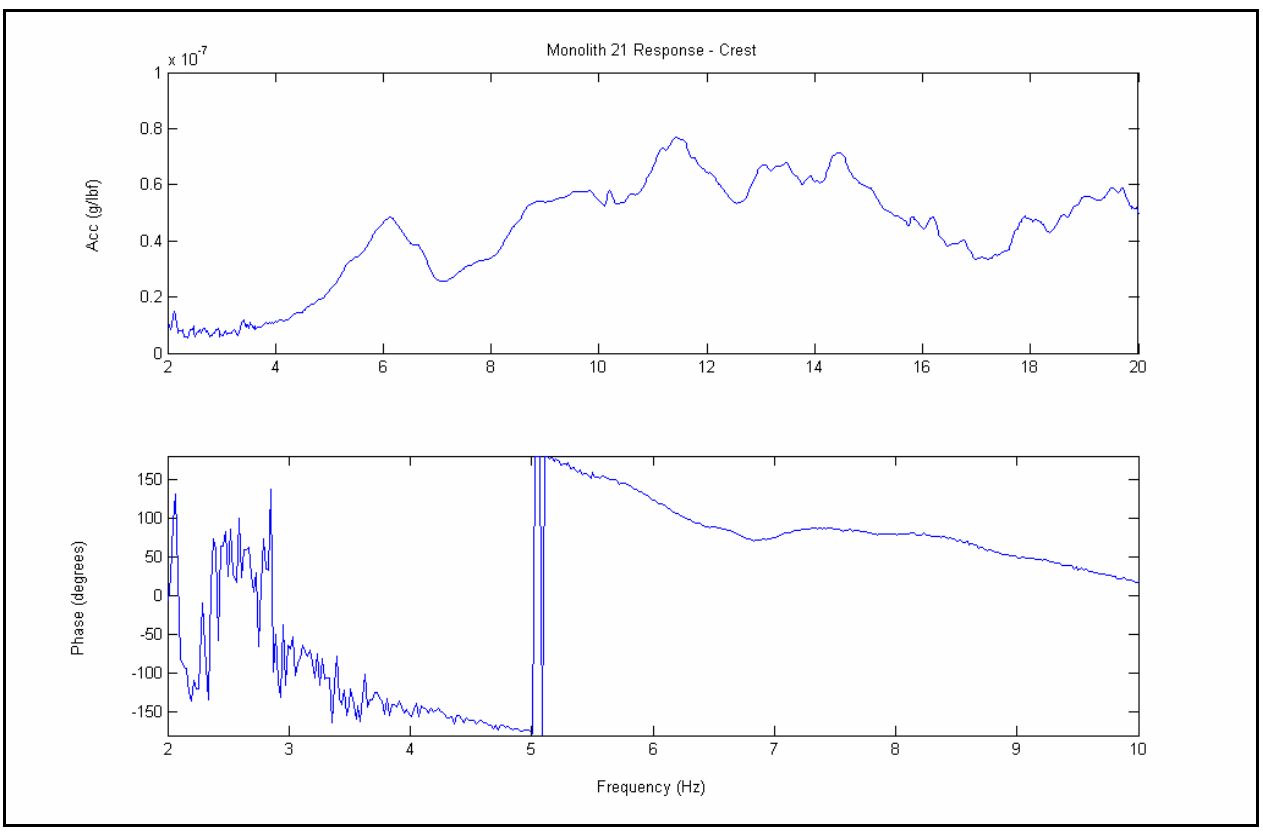

Figure B20. Monolith 21 response - Crest 


\section{Appendix C Tuned Vibration Absorber}

A tuned vibration absorber (or tuned mass damper) consists basically of a moving auxiliary mass attached to a primary structure with the objective of reducing its dynamic response. The external input energy is transformed into kinetic energy of the moving mass, which is properly designed to induce dynamic forces opposing the motion of the primary system. The advantage of this behavior is clearly seen from the frequency response function of the resulting coupled system. An antiresonance effect is generated at the frequency at which the vibration absorber is tuned, and two new smaller resonance peaks appear surrounding this frequency. Vibration absorbers have found wide application in mechanical engineering for systems subject to narrow-band excitations, and extensive research has been done to determine the frequency tuning and damping characteristics providing optimum performance. In civil engineering applications, tuned mass dampers are usually tuned to the first natural period of the structural system; therefore, they are most effective in those situations where the first mode contribution to the response is dominant.

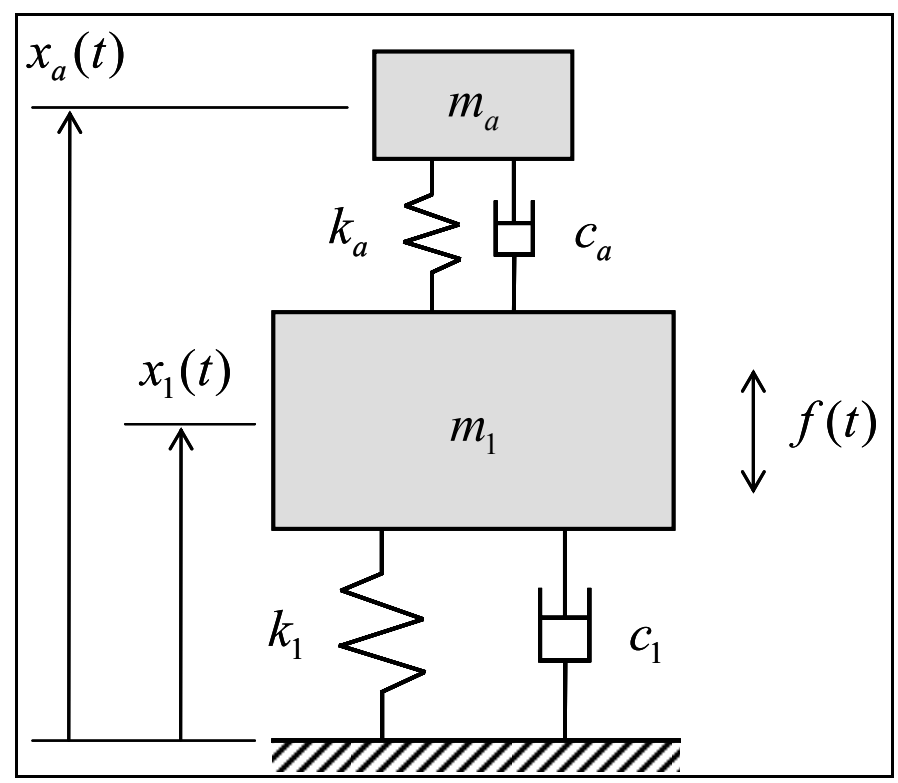

Figure C1. Tuned vibration absorber model 
The secondary system can be modeled in the form of a simple spring-massdamper configuration. Assuming that the primary system can also be represented by a single degree-of-freedom oscillator, the equations of motion for the system shown in Figure $\mathrm{C} 1$ are given by

$$
\mathbf{M} \ddot{\mathbf{x}}(t)+\mathbf{C} \dot{\mathbf{x}}(t)+\mathbf{K x}(t)=\mathbf{f}(t)
$$

where the displacement and excitation vectors are given by

$$
\mathbf{x}(t)=\left\{\begin{array}{l}
x_{1}(t) \\
x_{a}(t)
\end{array}\right\}, \quad \mathbf{f}(t)=\left\{\begin{array}{c}
f(t) \\
0
\end{array}\right\}
$$

and the system matrices are

$$
\mathbf{M}=\left[\begin{array}{cc}
m_{1} & 0 \\
0 & m_{a}
\end{array}\right], \quad \mathbf{C}=\left[\begin{array}{cc}
c_{1}+c_{a} & -c_{a} \\
-c_{a} & c_{a}
\end{array}\right], \quad \mathbf{K}=\left[\begin{array}{cc}
k_{1}+k_{a} & -k_{a} \\
-k_{a} & k_{a}
\end{array}\right]
$$

If the loading is of the form $f(t)=F_{o} e^{i \omega t}$, then solutions $x_{1}(t)=X_{1}(i \omega) e^{i \omega t}$ and $x_{a}(t)=X_{a}(i \omega) e^{i \omega t}$ can be obtained, where

$$
\begin{aligned}
\frac{X_{1}(i \omega)}{F_{o}} & =\frac{k_{a}-\omega^{2} m_{a}+i \omega c_{a}}{\operatorname{det}\left(\mathbf{K}-\omega^{2} \mathbf{M}+i \omega \mathbf{C}\right)} \\
\frac{X_{a}(i \omega)}{F_{o}} & =\frac{k_{a}+i \omega c_{a}}{\operatorname{det}\left(\mathbf{K}-\omega^{2} \mathbf{M}+i \omega \mathbf{C}\right)}
\end{aligned}
$$

Note that the relative response of the vibration absorber with respect to the response of the primary system is given by

$$
\frac{X_{a}(i \omega)}{X_{1}(i \omega)}=\frac{k_{a}+i \omega c_{a}}{k_{a}-\omega^{2} m_{a}+i \omega c_{a}}
$$

The main parameters of the problem are given by

$$
\omega_{1}=\sqrt{\frac{k_{1}}{m_{1}}}, \quad \xi_{1}=\frac{c_{1}}{2 m_{1} \omega_{1}}
$$

where $\omega_{1}$ and $\xi_{1}$ denote the natural frequency and damping ratio of the main system, respectively, and 


$$
\omega_{a}=\sqrt{\frac{k_{a}}{m_{a}}}, \quad \xi_{a}=\frac{c_{a}}{2 m_{a} \omega_{a}}
$$

where $\omega_{a}$ and $\xi_{a}$ denote the natural frequency and damping ratio of the vibration absorber, respectively. The mass ratio $m_{r}$ and tuning ratio $\beta$ are defined as follows:

$$
m_{r}=\frac{m_{a}}{m_{1}}, \quad \beta=\frac{\omega_{a}}{\omega_{1}}
$$

Figure $\mathrm{C} 2$ shows the normalized frequency response function corresponding to the acceleration of the main system $m_{1} \ddot{X}_{1}(i \omega) / F_{o}$ in terms of the normalized frequency $\omega / \omega_{1}$ for the case $m_{r}=0.02, \beta=1, \xi_{a}=3 \%$, and $\xi_{1}=5 \%$. These parameters are used for illustration purposes only, and they are not based on measured behavior at Folsom Dam. The blue line represents the response of the main mass without the vibration absorber. The red line represents the response of the main system including the presence of the absorber. In this case, the response indicates the two "split" resonances that straddle the original fundamental frequency. The height of the response peaks and the separation between main system peaks are controlled by both damping and mass ratio model parameters.

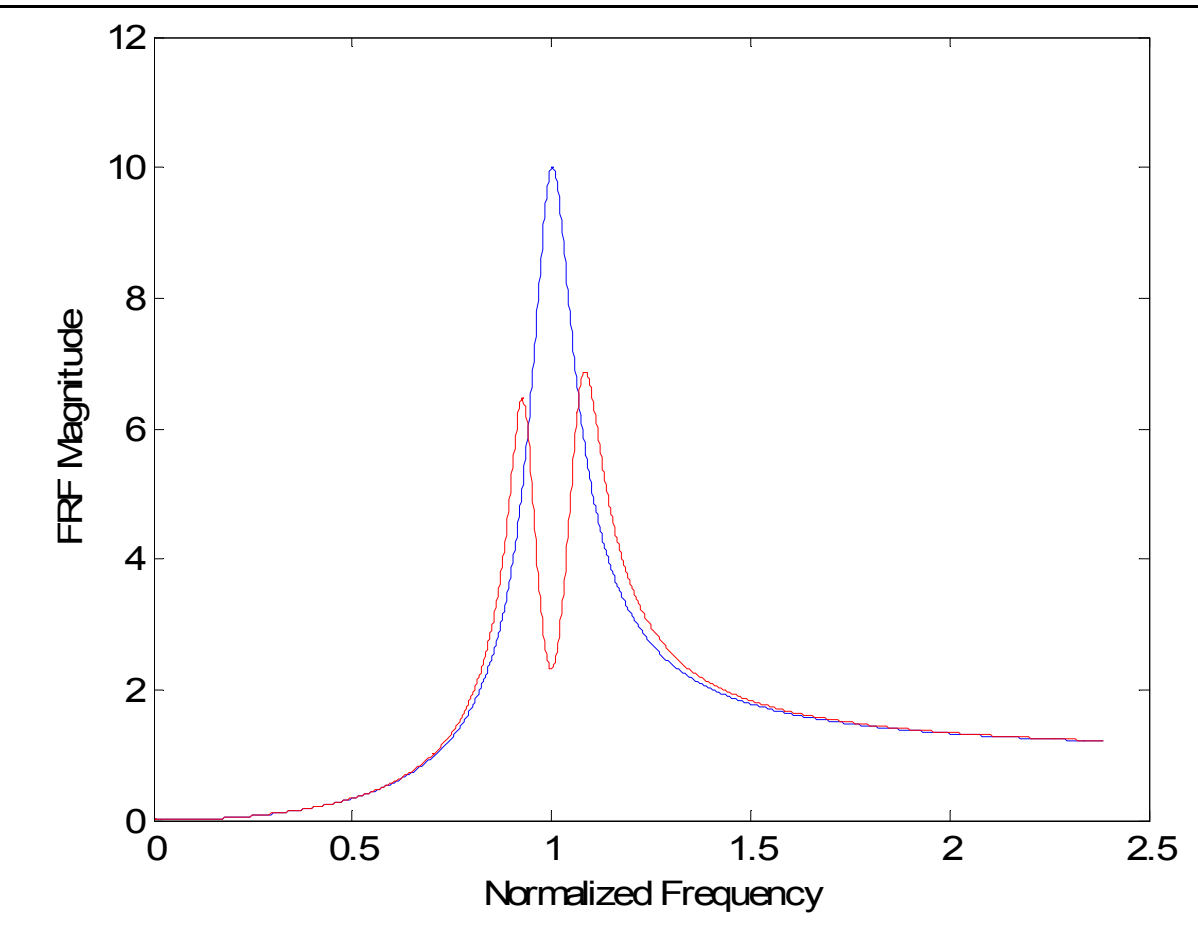

Figure C2. Main system frequency response functions 
Figure $\mathrm{C} 3$ shows the normalized frequency response function corresponding to the acceleration of the vibration with respect to the acceleration of the main system, $\ddot{X}_{a}(i \omega) / \ddot{X}_{1}(i \omega)$, in terms of the normalized frequency, $\omega / \omega_{1}$, for the same case. It can be seen that when the absorber frequency response is computed as the response of the absorber with respect to the main system response, it produces a single resonant peak as shown in Figure C3.

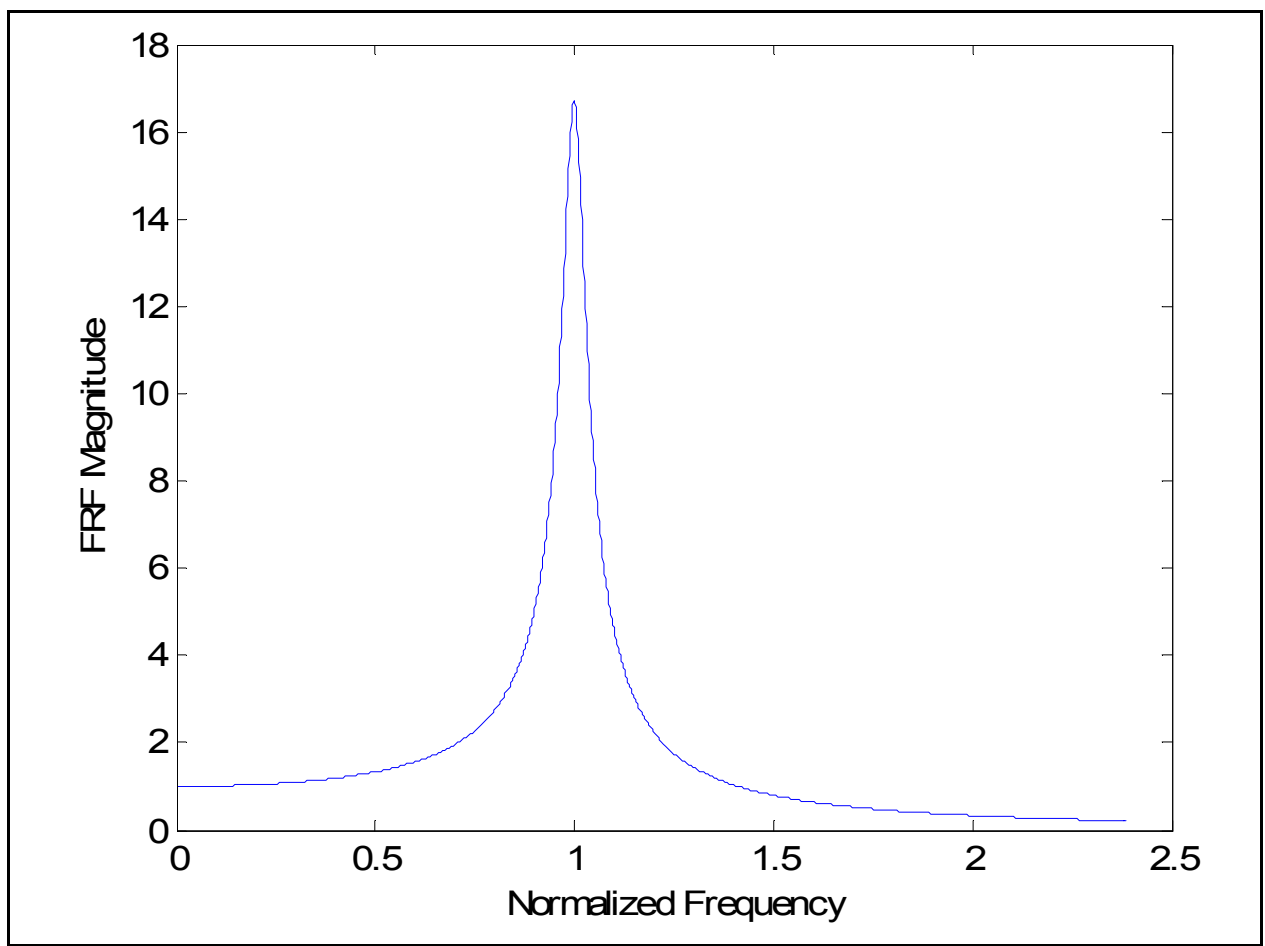

Figure C3. Vibration absorber frequency response function 


\section{Appendix D Curve-Fitting Approach to Measured Responses}

A curve-fitting algorithm was developed for the measured responses obtained at Folsom Dam. Of particular interest was the behavior observed along the crest between Monoliths 1 and 11 in the 5- to 7-Hz frequency range. The algorithm fits a complex frequency function, referred to as a transfer function, to measured responses in the form

$$
H(s)=\frac{b(1) s^{n}+b(2) s^{n-1}+b(n+1)}{a(1) s^{m}+a(2) s^{m-1}+a(m+1)}
$$

where $n, m$ are the orders of the numerator and denominator polynomials, and $s$ is a complex variable defined below. The roots of the numerator and denominator polynomials are commonly referred to as zeros and poles, respectively. For each measurement, the algorithm attempts an initial fit with a zero-order numerator and a first-order denominator, and then sets the orders to be the same for all subsequent fits. For each fit order, the algorithm finds the zeros, poles, and gain of the transfer function. Although any fit order can be applied, curve fits based on orders greater than eight were not judged to be reasonable for the type of measured behavior at the dam within the $5-\mathrm{Hz}$ range. Information pertaining to resonant frequency and damping can be extracted from the pole estimates.

The poles obtained are of the form

$$
s_{i}=-\zeta \omega_{n} \pm \omega_{n} \sqrt{1-\zeta^{2}}
$$

and are used to obtain estimates of natural frequency $\omega_{n}$ and damping $\zeta$. The algorithm produces scatter plots of fit order versus frequency, fit order versus damping, and frequency versus damping. The frequency versus damping scatter plots lead to the damping estimates discussed in Chapter 3 and reported in Table 2 of the main text. Sample results from the algorithm applied to the responses at Monoliths 6, 14, and 21 are shown in Figures D1 through D3. The second set of plots for each monolith location superimposes the measured response with its eighth-order curve fit. 

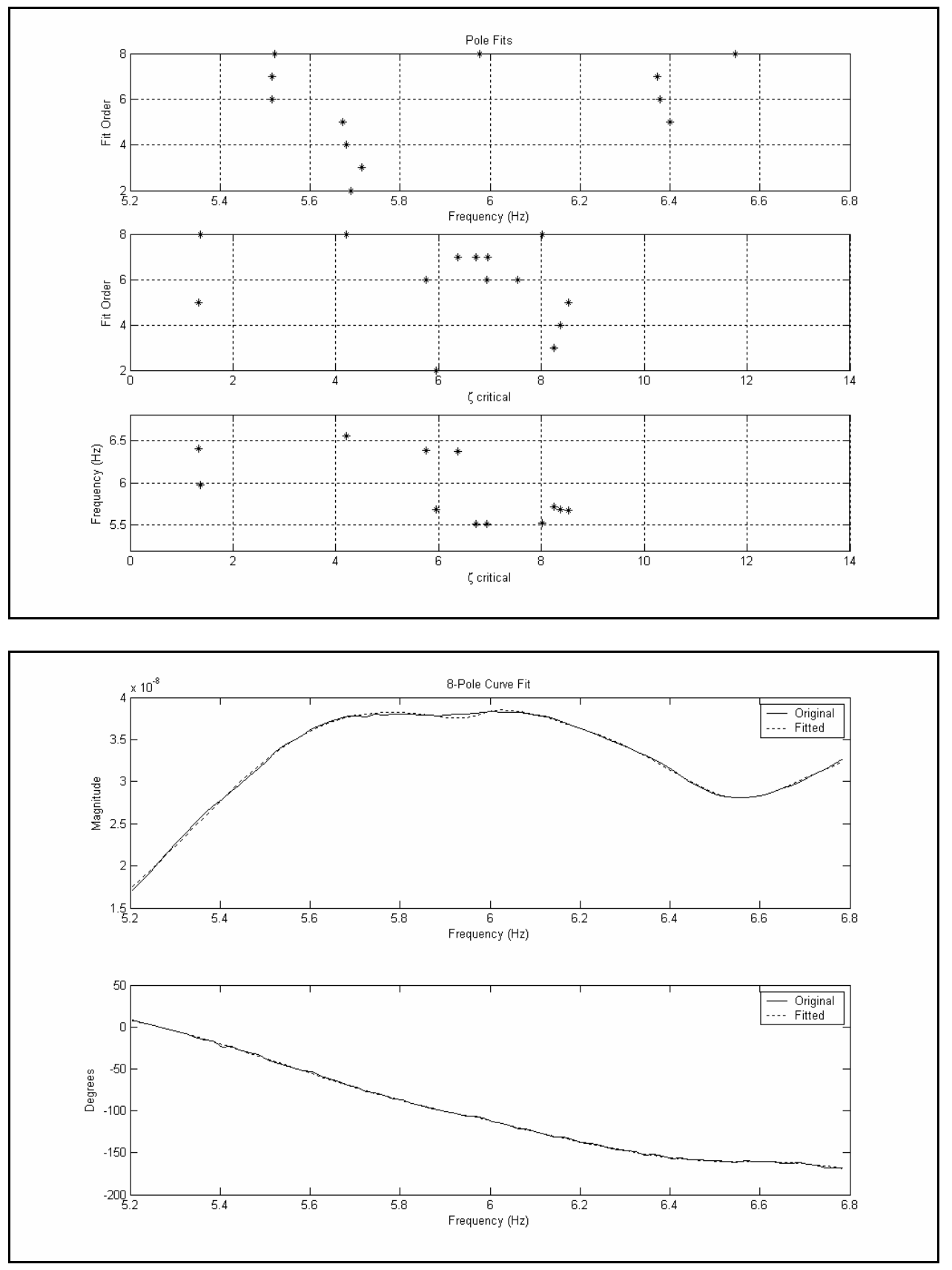

Figure D1. Curve fit results for Monolith 6 

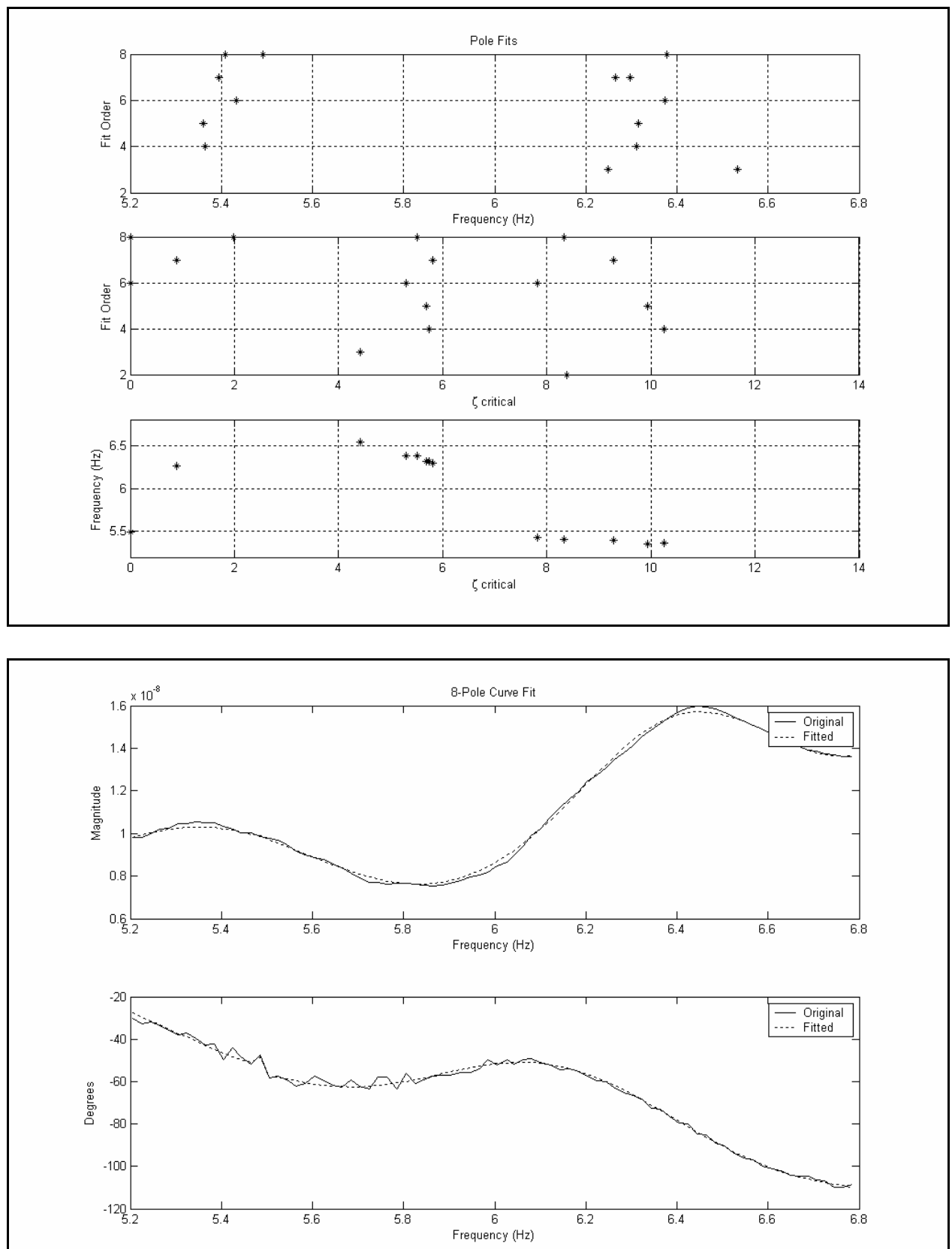

Figure D2. Curve fit results for Monolith 14 

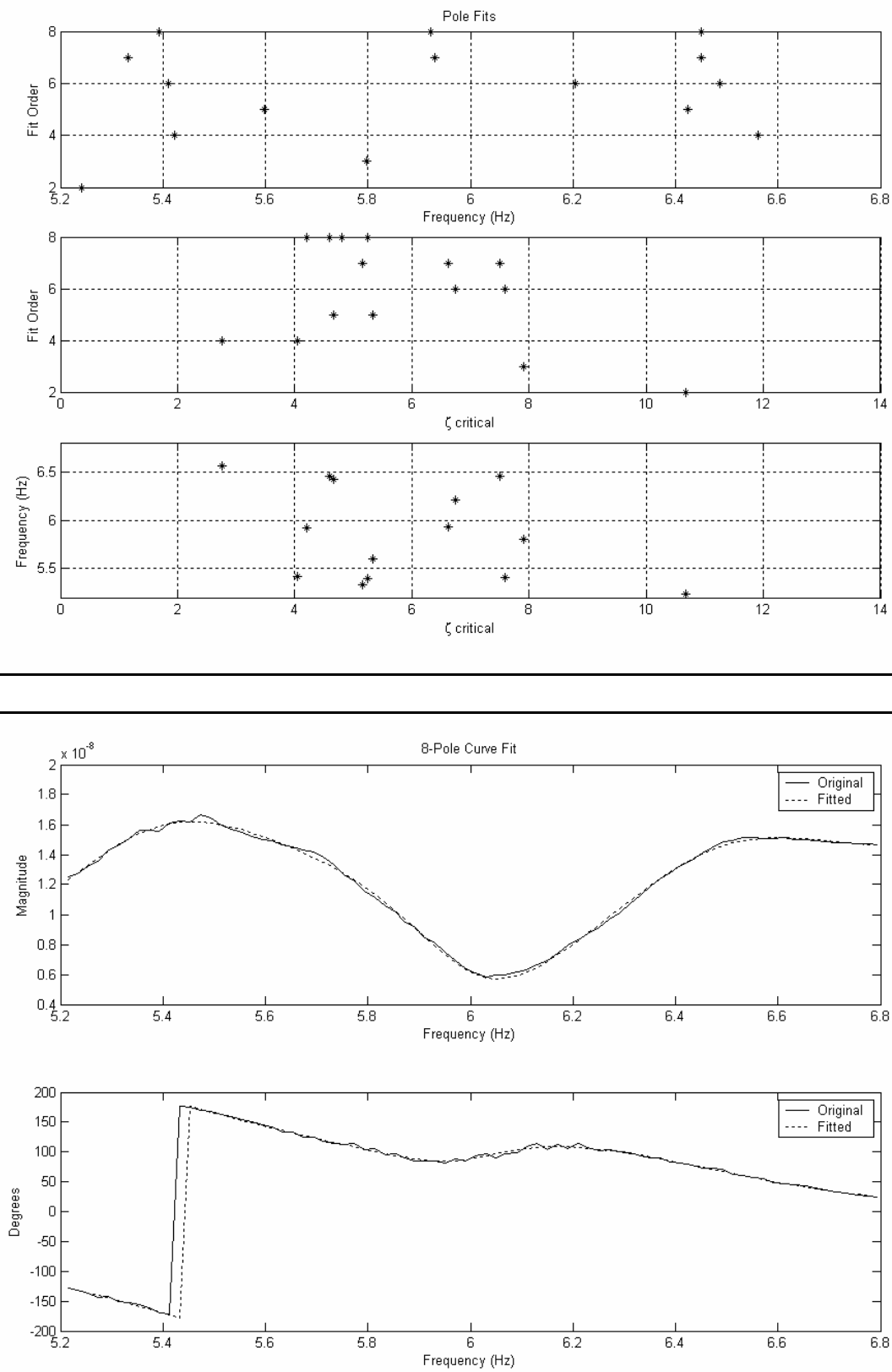

Figure D3. Curve fit results for Monolith 21

These scatter plots are typical of the type of distribution obtained for the curve fits of the measured monolith responses at Folsom Dam. A number of possible contributing factors can be identified that may account for the pole distribution and, hence, for the "sliding" resonant behavior seen in the dam between Monoliths 1 and 11. These include modal interference from neighboring modes, effects of nonclassical modes associated with dam-reservoir, damfoundation interactions, relative motion across vertical joints between monoliths, or a traveling wave effect involving the dam on a flexible foundation. Additional analyses using physically based numerical models is likely required to gain a 
fuller understanding of these and perhaps other likely factors. Although the pole locations (i.e., values of their real and imaginary components) cannot be characterized as stationary, trends were present that did allow candidate resonances to be identified. After a review of all of the curve fit results, 5.5 and $6.25 \mathrm{~Hz}$ were selected as the dominant resonances in the 5- to $7-\mathrm{Hz}$ range. 


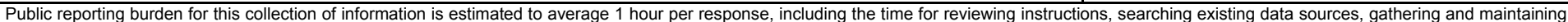

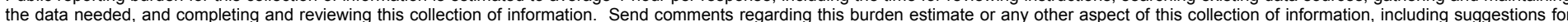

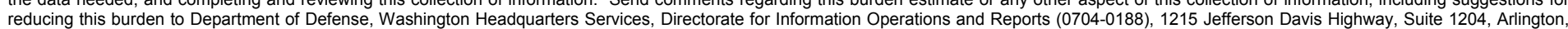

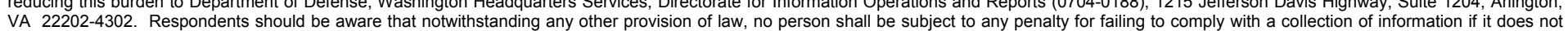
VA 22202-4302. Respondents should be aware that notwithstanding any other provision of law, no person shall be sube
display a currently valid OMB control number. PLEASE DO NOT RETURN YOUR FORM TO THE ABOVE ADDRESS.

\begin{tabular}{l|c}
$\begin{array}{l}\text { 1. REPORT DATE }(D D-M M-Y Y Y Y) \\
\text { September } 2005\end{array}$ & $\begin{array}{c}\text { 2. REPORT TYPE } \\
\text { Final report }\end{array}$ \\
\hline
\end{tabular}

4. TITLE AND SUBTITLE

Dynamic Testing and Numerical Correlation Studies for Folsom Dam

G. AUTHOR(S)

\section{AUTHOR(S)}

Ziyad Duron, Enrique E. Matheu, Vincent P. Chiarito, John F. Hall, Michael K. Sharp

5d. PROJECT NUMBER

3. DATES COVERED (From - To)

5a. CONTRACT NUMBER

5b. GRANT NUMBER

5c. PROGRAM ELEMENT NUMBER

5e. TASK NUMBER

5f. WORK UNIT NUMBER

7. PERFORMING ORGANIZATION NAME(S) AND ADDRESS(ES)

8. PERFORMING ORGANIZATION REPORT
NUMBER

See reverse.

ERDC/GSL TR-05-22

9. SPONSORING / MONITORING AGENCY NAME(S) AND ADDRESS(ES)

10. SPONSOR/MONITOR'S ACRONYM(S)

U.S. Army Engineer District, Sacramento

1325 J Street

Sacramento, CA 95814-2922

11. SPONSOR/MONITOR'S REPORT NUMBER(S)

\section{DISTRIBUTION / AVAILABILITY STATEMENT}

Approved for public release; distribution is unlimited.

\section{SUPPLEMENTARY NOTES}

\section{ABSTRACT}

It is widely recognized that full-scale dynamic testing produces a wealth of useful information in the context of seismic performance evaluation studies of concrete dams. These types of tests can be used to determine not only the main characteristics of the dynamic response of the structure, but can also provide information to assess the relative importance of interaction mechanisms involving the dam, the impounded reservoir, and the underlying foundation region. The information gathered by dynamic full-scale tests can also be used to assess the limitations of the different numerical models that could be employed to quantify the response of the system under severe seismic excitations. This report describes a research study conducted by the U.S. Army Engineer Research and Development Center consisting of a series of field tests and numerical analyses performed on Folsom Dam, California, at the request of the U.S. Army Engineer District, Sacramento. Ambient tests and forced vibration were conducted to determine the main dynamic characteristics of the dam-foundation-reservoir system. Numerical studies of the observed response behavior were performed using $2 \mathrm{D}$ and $3 \mathrm{D}$ models of the system. This report describes these experimental and modeling efforts and discusses the comparison between the critical response features derived from observed and computed results. The results from this study complement and validate the results from other previous and current technical studies conducted on Folsom Dam, and they will effectively contribute toward a more accurate assessment of the seismic performance of this critical structure.

\section{SUBJECT TERMS}

Ambient survey

Concrete dams

16. SECURITY CLASSIFICATION OF:

Dynamic testing

Finite-element models

\begin{tabular}{|l|l|l|}
\hline a. REPORT & b. ABSTRACT & c. THIS PAGE \\
UNCLASSIFIED & UNCLASSIFIED & UNCLASSIFIED \\
\hline
\end{tabular}

Forced-vibration testing

Numerical correlation

\begin{tabular}{|l|c|l|}
$\begin{array}{l}\text { 17. LIMITATION } \\
\text { OF ABSTRACT }\end{array}$ & $\begin{array}{l}\text { 18. NUMBER } \\
\text { OF PAGES }\end{array}$ & $\begin{array}{l}\text { 19a. NAME OF RESPONSIBLE } \\
\text { PERSON }\end{array}$ \\
\cline { 3 - 3 } & 116 & $\begin{array}{l}\text { 19b. TELEPHONE NUMBER (include } \\
\text { area code) } \\
601-634-2692\end{array}$ \\
\hline
\end{tabular}




\section{7. (Concluded)}

Harvey Mudd College

Engineering Department

301 E. 12th Street, Claremont, CA 91711;

U.S. Army Engineer Research and Development Center

Geotechnical and Structures Laboratory

3909 Halls Ferry Road, Vicksburg, MS 39180-6199;

California Institute of Technology

Department of Civil Engineering and Applied Mechanics

1200 East California Boulevard, Pasadena, CA 91125 